\title{
Crustal Structure of the Coastal and Marine San Francisco Bay Region, California
}

Professional Paper 1658

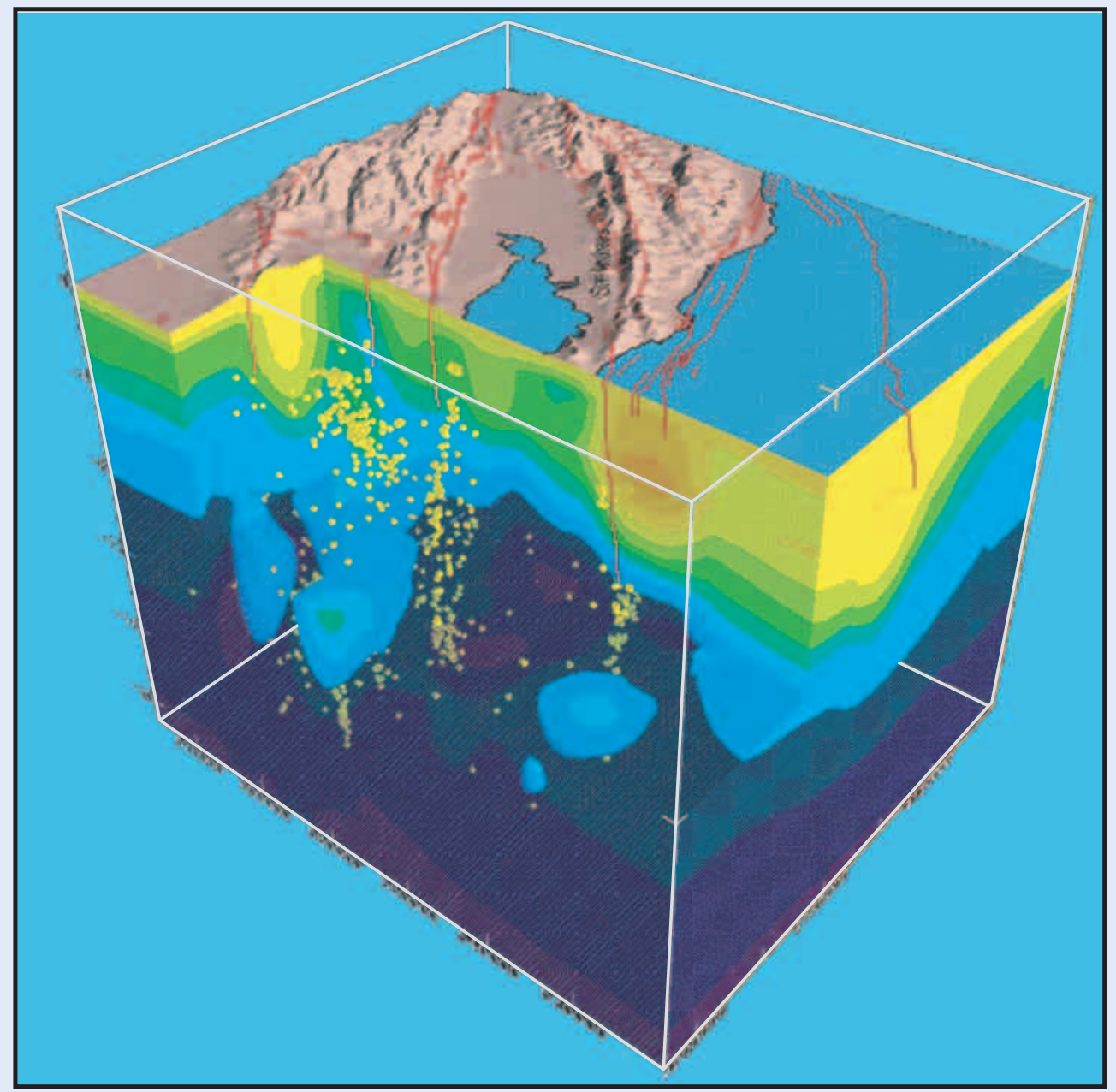

U.S. Department of the Interior

U.S. Geological Survey 


\section{Crustal Structure of the Coastal and Marine San Francisco Bay Region, California}

Tom Parsons, Editor

Professional Paper 1658 


\section{U.S. Department of the Interior \\ Gale A. Norton, Secretary}

\section{U.S. Geological Survey}

Charles G. Groat, Director

Any use of trade, product, or firm names in this publication is for descriptive purposes only and does not imply endorsement by the U.S. Government.

United States Government Printing Office: 2002

For additional copies please contact:

USGS Information Services

Box 25286

Denver, CO 80225

This report and any updates to it are available at http://geopubs.wr.usgs.gov/prof-paper/pp1658/

Additional USGS publications can be found at http://geology.usgs.gov/products.html

For more information about the USGS and its products:

Telephone: 1-888-ASK-USGS

World Wide Web: http://www.usgs.gov/

Text edited by George A. Havach

Layout and design by Stephen L. Scott

Manuscript approved for publication, October 30, 2001

Cataloging-in-Publication data is on file with the Library of Congress 


\section{CONTENTS}

[Numbers designate chapters]

1. Introduction

By Tom Parsons

2. High-Resolution Crosshole Radar Tomography:

Application to Liquefaction-Induced Changes

in Soil on Treasure Island-

By Robert E. Kayen, Walter A. Barnhardt, Scott Ashford, Kyle Rollins, Diane L. Minasian, and Bradley A. Carkin

3. Biostratigraphy Beneath Central San Francisco Bay

Along the San Francisco-Oakland Bay Bridge

Transect

By Mary L. McGann, Doris Sloan, and Elmira Wan

4. Examination of the Tsunami Generated by the 1906

San Francisco $M_{w}=7.8$ Earthquake, Using New

Interpretations of the Offshore San Andreas

Fault

By Eric L. Geist and Mary Lou Zoback

5. Concealed Strands of the San Andreas Fault System

in Central San Francisco Bay, as Inferred from

Aeromagnetic Anomalies

By Robert C. Jachens, Carl M. Wentworth, Mary Lou Zoback,

Terry R. Bruns, and Carter W. Roberts

6. Marine Seismic-Reflection Data Acquired in the

San Francisco Bay Region, 1991-97

By Patrick E. Hart, Jonathan R. Childs, Tom Parsons,

Ray W. Sliter, Dennis M. Mann, and Jill McCarthy

7. Structure of the Submerged San Andreas and San

Gregorio Fault Zones in the Gulf of the Farallones, as Inferred from High-Resolution Seismic-

Reflection Data-

By Terry R. Bruns, Alan K. Cooper, Paul R. Carlson, and

David S. McCulloch

8. A Review of Faults and Crustal Structure in the

San Francisco Bay Region as Revealed by

Seismic Studies, 1991-97-

By Tom Parsons, Jill McCarthy, Patrick E. Hart,

John A. Hole, Jonathan R. Childs, David H. Oppenheimer, and Mary Lou Zoback 


\section{Introduction}

\section{By Tom Parsons}

As of the time of this writing, the San Francisco Bay region is home to about 6.8 million people, ranking fifth among population centers in the United States. Most of these people live on the coastal lands along San Francisco Bay, the Sacramento River delta, and the Pacific coast. The region straddles the tectonic boundary between the Pacific and North American Plates and is crossed by several strands of the San Andreas Fault system. These faults, which are stressed by about $4 \mathrm{~cm}$ of relative plate motion each year, pose an obvious seismic hazard.

We have many ways to study earthquake faults. Where faults break the land surface, we may learn valuable information needed for hazard assessment, such as cumulative offset, slip rate, and earthquake history. However, many of the major faults in the region are partly submerged beneath San Francisco and Monterey Bays. Although this situation poses problems in gathering observational data for hazard assessment, bay-region waterways provide an opportunity to study faultzone structure by using marine subsurface-imaging techniques, which are easier and cheaper than equivalent studies on land.

In 1993, the U.S. Geological Survey (USGS) launched a 5-year project aimed at unearthing the basic science of the submerged San Andreas strike-slip fault system in the San Francisco Bay region with its many interacting strands. Primary project goals were structural, such as to discover how the San Andreas and Hayward Faults are connected or related at depth, to learn how the complex of faults in the San Andreas stepover zone on the Golden Gate platform functions, and to locate previously unknown faults. This volume thus contains mostly structural information about the San Francisco Bay region, much of it gathered through exploratory geophysical experiments.

The volume is organized "top down," from studies in the shallowest crust to the base of the crust. The first three chapters are linked through their use of novel geophysical techniques to study earthquake effects, coseismic slip, and shallow stratigraphy. Kayen and others examine crustal structure at very high resolution and demonstrate the use of ground-penetrating-radar tomography to measure the liquefaction potential of coastal sedimentary deposits. McGann and others use microfossils from drill cores along the San Francisco-Oakland Bay Bridge to determine a more detailed late Pleistocene stratigraphy of San Francisco Bay than was previously available. Geist and Zoback use the historical record of a small local tsunami generated by the great 1906 San Francisco earthquake to model the rupture process of that earthquake.

The last four chapters are dedicated to studies of faultrelated structure of the seismogenic crust in and around the San Andreas Fault system in the San Francisco Bay region. Jachens and others compile an aeromagnetic anomaly map from new high-resolution flights across the bay region. Some of these anomalies mark the positions of offshore faults, and others are offset by faults, providing constraints on cumulative slip. Hart and others concisely summarize the marine seismic data recorded in and around San Francisco Bay, map the coverage, and provide archival information for those interested in acquiring data.

The last two chapters present the results of the seismic data that have been analyzed. Bruns and others present their analysis of high-quality intermediate-resolution ( $\sim 5-\mathrm{km}$ penetration) seismic-reflection data gathered over the complex San Andreas-San Gregorio Fault junction. This junction, which is thought to be where the 1906 San Francisco earthquake originated (see Geist and Zoback, this volume), contains an apparent extensional right stepover in the San Andreas Fault. Finally, Parsons and others review and summarize the results of deep-crustal seismic-reflection experiments and local-earthquake tomographic studies, including previously unpublished data, and provide additional support and discussion for already-published studies.

In summary, these studies were carried out in an environment where background information on faults in the San Francisco Bay region was sought. Much of the structural information presented here comes from experiments of a style unlikely to be conducted by the USGS in the near future. Together, the chapters in this volume provide a structural framework for a major part of a complex strike-slip fault system.

\section{Papers Published as a Result of Project Research}

Bohannon, R.G., and Parsons, Tom, 1995, Tectonic implications of post-30 Ma Pacific and North American relative plate motions: Geological Society of America Bulletin, v. 107, no. 8, p. 937-959.

Brocher, T.M., McCarthy, Jill, Hart, P.E., Holbrook, W.S., Furlong, K.P., McEvilly, T.V., Hole, J.A., and Klemperer, S.L., 1994, Seismic evidence for a lower-crustal detachment beneath San Francisco Bay, California: Science, v. 265, no. 5177, p. 1436-1439.

Brocher, T.M., Brabb, E.E., Catchings, R.D., Fuis, G.S., Fumal, T.E., Jachens, R.C., Jayko, A.S., Kayen, R.E., McLaughlin, R.J., Parsons, Tom, Rymer, M.J., Stanley, R.G., and Wentworth, C.M., 1997, A crustal-scale 3-D seismic velocity model for the San Francisco Bay area, California [abs.]: Eos (American Geophysical Union Transactions), v. 78, no. 46, supp., p. 435-436.

Geist, E.L., and Zoback, M.L., 1999, Analysis of the tsunami generated by the $M_{w} 7.81906$ San Francisco earthquake: Geology, v. 27, no. 1, p. 15-18.

Hole, J.A., Klemperer, S.L., Brocher, T.M., Parsons, Tom, Benz, H.M., and Furlong, K.P., in press, Crustal structure of the San Francisco Bay area from local earthquake tomography: Journal of Geophysical Research.

Kayen, R.E., Barnhardt, W.A., Fumal, T.F., Carkin, B.A., and Minasian, D.L., 1999, Radar imagery of fault breaks in soil; San Andreas and Hayward Faults, central California [abs.]: Seismological Research Letters, v. 70, no. 2, p. 231.

Kayen, R.E., Edwards, B.D., and Lee, H.J., 1999, Nondestructive laboratory measurement of geotechnical and geoacoustical properties through intact core-liner, in Marr, W.A., and Fairhurst, 
C.E., eds., Nondestructive and automated testing for soil and rock properties: American Society for Testing and Materials Special Technical Publication 1350, p. 83-94.

Kayen, R.E., and Mitchell, J.K., 1995, Ground motion characteristics and their relation to soil liquefaction at the Wildlife Liquefaction Array, Imperial Valley, California, in O'Rourke, T.D., and Hamada, M., eds., Proceedings of the fifth U.S.-Japan workshop on earthquake resistant design of lifeline facilities and countermeasures against soil liquefaction: Buffalo, N.Y., National Center for Earthquake Engineering Research Technical Report 94-0026, p. 267-284.

1997a, Arias intensity assessment of liquefaction on the east side of San Francisco Bay during the Loma Prieta, California, earthquake of 17 0ctober 1989: Natural Hazards, v. 16, no. 2-3, p. 243-265.

1997b, Assessment of liquefaction potential during earthquakes by Arias intensity: Journal of Geotechnical and Geoenvironmental Engineering, v. 123, no. 12, p. 1162-1175.

-1998a, Arias intensity assessment of liquefaction test sites on the east side of San Francisco Bay affected by the Loma Prieta, California, earthquake of 17 October 1989, in El-Sabh, M.I., Venkatesh, S., Lomnitz, C., and Murty, T.S., eds., Earthquake and atmospheric hazards; preparedness studies: Dordrecht, Kluwer Academic Publishers, p. 243-265.

-1998b, Variation of the intensity of earthquake motion beneath the ground surface: U.S. National Conference on Earthquake Engineering, 6th, Seattle, 1998, Proceedings, $19 \mathrm{p}$.

1999, Closure on liquefaction potential during earthquakes by Arias intensity: Journal of Geotechnical and Geoenvironmental Engineering, v. 125, no. 7, p. 626-629.

Kayen, R.E., Mitchell, J.K., Seed, R.B., and Nishio, Shinya, 1998, Soil liquefaction in the east bay during the earthquake, in Holzer, T.L., ed., The Loma Prieta, California, earthquake of October 17, 1989-liquefaction: U.S. Geological Survey Professional Paper 1551-B, p. B61-B86.

Liu, H.-P., Warrick, R.E., Westerlund, R.E., and Kayen, R.E., 1994, Insitu measurement of seismic shear-wave absorption in San Francisco bay mud by the pulse-broadening method: Seismological Society of America Bulletin, v. 84, no. 1, p. 62-75.

Marlow, M.S., Hart, P.E., Carlson, P.R., Childs, J.R., Mann, D.M., Anima, R.J., and Kayen, R.E., 1996, Misinterpretation of lateral acoustic variations on high-resolution seismic reflection profiles as fault offsets of Holocene bay mud beneath the southern part of San Francisco Bay, California: Marine and Petroleum Geology, v. 13, no. 3, p. 341-348.

Marlow, M.S., Jachens, R.C., Hart, P.E., Carlson, P.R., Anima, R.J., and Childs, J.R., 1999, Development of San Leandro Synform and neotectonics of the San Francisco Bay Block, California:
Marine and Petroleum Geology, v. 13, no. 5, p. 431-442.

McCarthy, Jill, and Hart, P.E., 1993, Data report for the 1991 Bay Area Seismic Imaging eXperiment (BASIX): U.S. Geological Survey Open-File Report 93-301, 26 p.

Mitchell, J.K., Lodge, A.L., Coutinho, R.Q., Kayen, R.E., Seed, R.B., Nishio, Shinya, and Stokoe, K.H., II, 1994, Insitu test results from four Loma Prieta earthquake liquefaction sites; SPT, CPT, DMT and shear wave velocity: Berkeley, University of California, Earthquake Engineering Research Center Report UCB/EERC-94/04, $179 \mathrm{p}$.

Parsons, Tom, 1998, Seismic-reflection evidence that the Hayward fault extends into the lower crust of the San Francisco Bay area, California: Seismological Society of America Bulletin, v. 88 , no. 5, p. 1212-1223.

Parsons, Tom, and Hart, P.E., 1999, Dipping San Andreas and Hayward faults revealed beneath San Francisco Bay, California: Geology, v. 27, no. 9, p. 839-842.

Parsons, Tom, Stein, R.S., Simpson, R.W., and Reasenberg, P.A., 1999, Stress sensitivity of fault seismicity; a comparison between limited-offset oblique and major strike-slip faults: Journal of Geophysical Research, v. 104, no. B9, p. 20183-20202.

Parsons, Tom, and Zoback, M.L., 1997, Three-dimensional upper crustal velocity structure beneath San Francisco Peninsula, California, from earthquake and controlled source studies: Journal of Geophysical Research, v. 102, no. B3, p. 5473-5490.

Ross, S.L, Ryan, H.F., and Stevenson, A.J., 1999, A new map of the offshore San Gregorio Fault between Pillar Point and Pescadero, CA [abs.]: Eos (American Geophysical Union Transactions), v. 80 , supp., p. F1004.

Tinsley, J.C., III, Eagan, J.A., Kayen, R.E., Bennett, M.J., Kropp, Alan, and Holzer, T.L., 1998a, Appendix; maps and descriptions of liquefaction and associated effects, in The Loma Prieta, California, earthquake of October 17, 1989-liquefaction: U.S. Geological Survey Professional Paper 1551-B, p. B287-B314.

Wessells, S.M., Parsons, Tom, and Hart, P.E., 1999, Future quakes; unlocking the mysteries of Bay Area earthquake faults: U.S. Geological Survey Open-File Report 99-519, videotape.

Williams, P.L., Anima, R.J., Ingram, Lynn, McCarthy, Jill, McEvilly, T.V., Nakata, Takashi, Okamura, M., and Shimazaki, Kunihiko, in press, Geometry and Holocene activity of the Pinole and southernmost Rodgers Creek faults, San Pablo Bay, California: Geological Society of America Bulletin.

Youd, T.L., Kayen, R.E., and Mitchell, J.K., 1998, Liquefaction criteria based on energy content of seismograms, in Youd, T.L., and Izzat, M.I., eds., Proceedings of the NCEER workshop on evaluation of liquefaction resistance of soils: Buffalo, N.Y., National Center for Earthquake Engineering Research Technical Report NCEER-97-0022, p. 217-224. 


\title{
High-Resolution Crosshole Radar Tomography: Application to Liquefaction-Induced Changes in Soil on Treasure Island
}

\author{
By Robert E. Kayen, ${ }^{1}$ Walter A. Barnhardt, ${ }^{1}$ Scott Ashford, ${ }^{2}$ Kyle Rollins, ${ }^{3}$ Diane L. Minasian,, and \\ Bradley A. Carkin'
}

\section{CONTENTS}

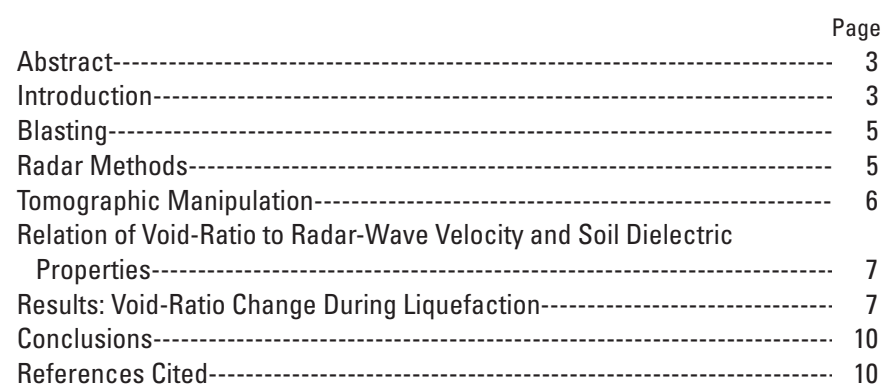

\section{Abstract}

In 1998-99, the U.S. Geological Survey conducted a crosshole radar tomographic experiment at the lateral-pileload testsite on Treasure Island to nondestructively image the soil column for changes in void ratio before and after a liquefaction event that was caused by controlled blasting. A geotechnical borehole radar technique was used to acquire high-resolution two-dimensional radar velocity data. This method of nondestructive site characterization uses transillumination surveys through the soil column and tomographic data-manipulation techniques to construct velocity tomograms, from which computed void ratios can be derived at 0.25 - to $0.5-\mathrm{m}$-pixel footprints. Tomograms of void ratio are constructed by using a relation between soil void ratio and corresponding dielectric properties. The two-dimensional imagery is used to model changes in void ratio and to quantify void-ratio reduction in response to soil contraction during liquefaction. Predicted settlements based on planar-radar estimates of void-ratio reduction compare well with the observed settlements surveyed.

\section{Introduction}

This chapter describes a new nondestructive geophysical technique using ground-penetrating radar (GPR) to determine

${ }^{1}$ U.S. Geological Survey.

${ }^{2}$ University of California, San Diego.

${ }^{3}$ Brigham Young University. changes in soil void ratio due to the effects of liquefaction events. The void-ratio state of soil is principally controlled by depositional history, sedimentary texture, postdepositional load history, ground-water influence, and diagenetic changes to the soil fabric (Mitchell, 1993). Even subtle variations in environmental state and intrinsic physical properties can significantly alter the soil void ratio. The inplace void ratio of sand is typically estimated indirectly through empirical correlations with standard-penetration-test (SPT) and conventional cone-penetration-test (CPT) results. If a large budget is available, the inplace void ratio can be determined from laboratory analysis of frozen samples, or from neutron or gamma-ray density logging. The void-ratio state and sedimentary texture have a first-order influence on the liquefaction susceptibility of soils, and other factors (for example, particle orientation) are known to have a secondary influence (Seed and Idriss, 1982). This application of field crosshole GPR methods to characterize a potentially liquefiable soil mass is new, although early work on the relation between soil porosity and radar-band velocity dates back to Topp and others' (1980) the laboratory study using time-domain reflectometry (TDR).

Treasure Island is a hydraulically filled manmade structure in central San Francisco Bay, north of Yerba Buena Island, that was constructed for the 1939 Golden Gate International Exposition (fig. 1). The island was built in 1936 and 1937 by hydraulically pumping estuarine soil behind a perimeter rip-rap dike (fig. 1). Treasure Island is a National Geotechnical Experimentation Site (NGES), for which a considerable data set of geotechnical information is available. The soil profile at the testsite consists of hydraulically placed fill to 7-m depth, underlain by Holocene bay mud and older Pleistocene estuarine and terrestrial deposits. The hydraulic fill is primarily loose silty fine sand and sandy silt (Bennett, 1994). The water table is 1.0 to $1.5 \mathrm{~m}$ below the ground surface and was found to be fresh when we occupied the testsite.

The GPR-based technique for measuring soil-void-ratio changes complements a series of 10 full-scale pile-group and cast-in-steel-shell pile-load tests performed between December 1998 and February 1999 by researchers from the University of California, San Diego, and Brigham Young University, supported by the California Department of Transportation (Caltrans) and the National Science Foundation (Kayen and others, 2000). Other field data obtained from the testsite 
included soil borehole logs, conventional CPT logs, and shear-wave-velocity profiles. All the testing at Treasure Island was conducted in cooperation with the U.S. Navy and the city of San Francisco (fig. 1).
The purpose of this study was to observe the effects of liquefaction on soil void ratio without the overprinting effect of mechanical lateral loading of the pile groups. To achieve this result, an array of three polyvinyl chloride (PVC)-cased
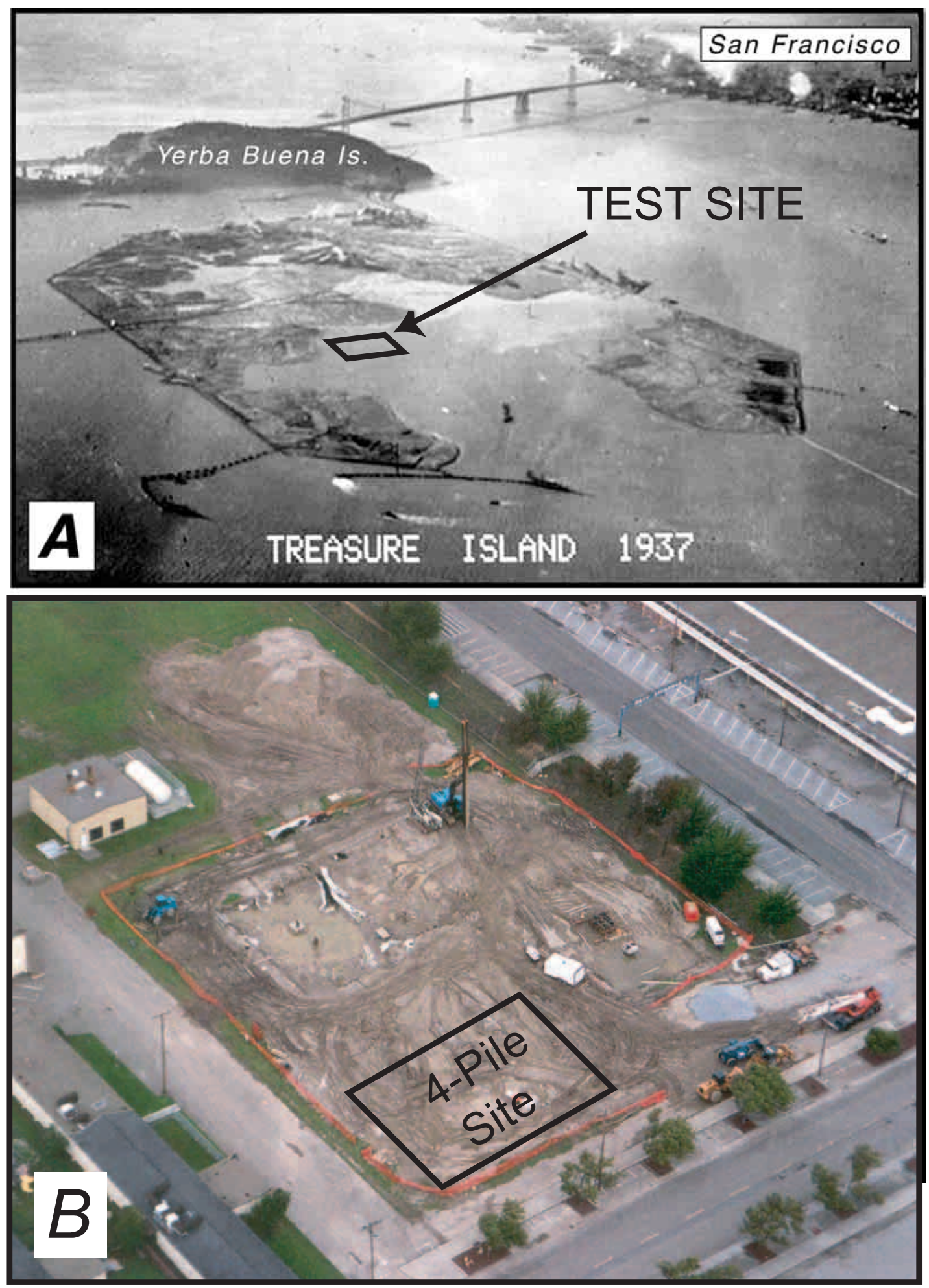

Figure 1.-Treasure Island in San Francisco Bay. A, Hydraulic filling in 1937. B, Radar and lateral-pile-load testsite (box) at intersection of Ninth and $\mathrm{H}$ streets near center of island. 
boreholes were placed approximately $8 \mathrm{~m}$ away from the pile groups on the opposite side, equidistant from the blast charges. As such, the radar testsite was subjected to the same blast intensity as the pile group but isolated from pile-group loading after the blast. A drill rig augered each of the boreholes to 9-m depth and laid out the three boreholes in a 3-4-5-m triangular pattern. The holes were then cased with PVC liner.

\section{Blasting}

Blasts consisted of multiple sets of eight $0.5-\mathrm{kg}$ explosive charges placed in circular patterns around the pile group. Each charge pattern had a diameter of approximately $5 \mathrm{~m}$ from the closest pile location and was approximately $5 \mathrm{~m}$ inside the radar borehole. The blasting was done in accord with the guidelines recommended by Studer and Kok (1980) and Narin van Court and Mitchell (1995). Paired charges were placed approximately $3.5 \mathrm{~m}$ below the excavated surface (approx $3 \mathrm{~m}$ below the ground-water table) and set off sequentially, with a short delay (250-1,000 ms) between charges to maximize the effect of the total blast on the soil mass. For each blast, porepressure time histories were collected, using horizontal and

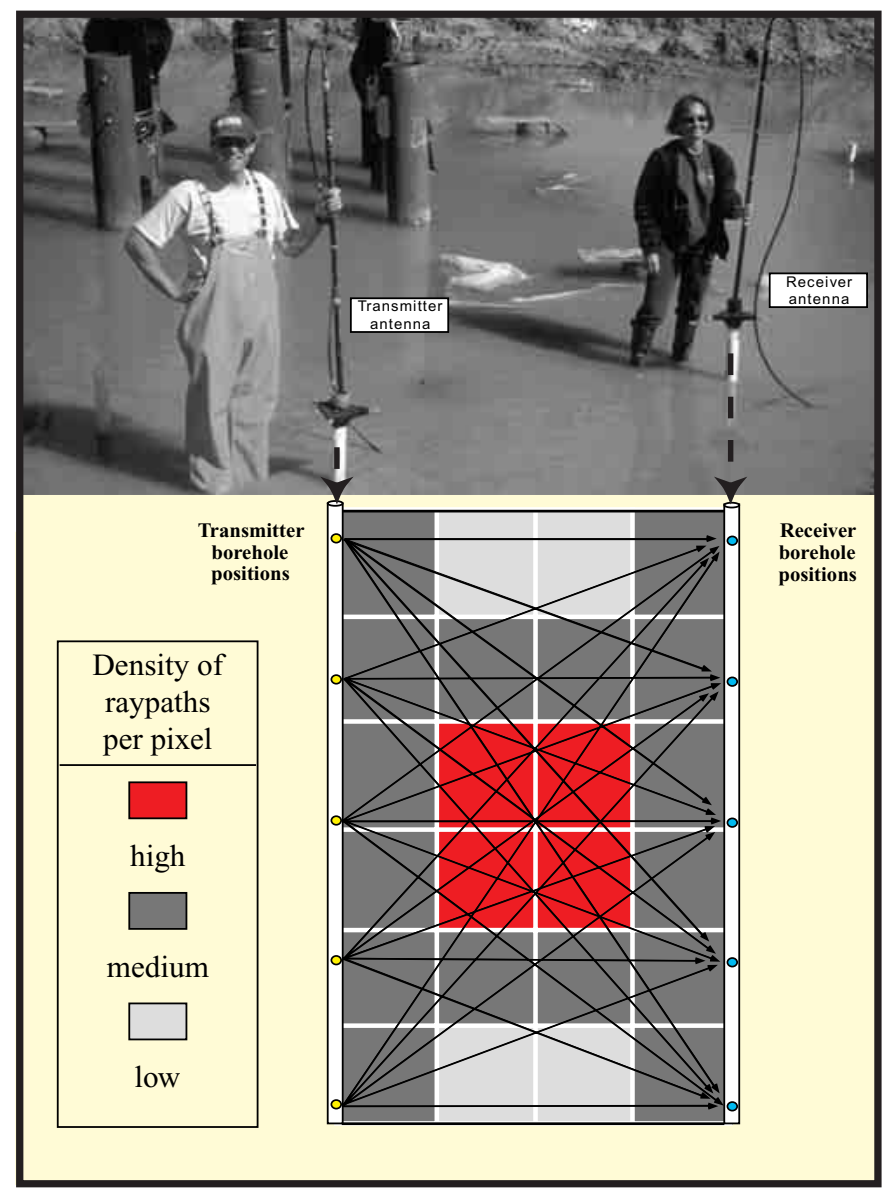

Figure 2.-Borehole radar investigation at Treasure Island testsite. Blast charges were placed between pile group and radar boreholes. Diagram shows below-ground raypaths shot and highest data density within central part of tomogram. vertical pressure-transducer arrays, and peak particle velocity and settlements were measured.

\section{Radar Methods}

Crosshole GPR is a transillumination survey method in which two antennas are lowered down adjacent, parallel boreholes. An example of how the antennas are deployed in the field is shown in figure 2. The transmitter antenna emits a short pulse, or shot, of high-frequency (here, $100 \mathrm{MHz}$ ) electromagnetic energy. The receiving antenna, located in the adjacent borehole, captures the frequency-modulated signal and precisely measures the time required for the signal to travel through the ground, along the plane separating the two boreholes. Traveltimes are one way, and measurements are made with picosecond $\left(10^{-12} \mathrm{~s}\right)$ precision. Transillumination involves passing a waveform through the soil to determine the traveltime and attenuation characteristics of the wave (fig. 2). As such, crosshole GPR requires careful calibration of the outgoing waveform and shot-time zero to establish the signal traveltime. In the field, with antennas in fixed positions, multiple wave-trace records are recorded and stacked. Stacking involves adding together the waves of the multiple shots (32 in our survey) at each point along a profile. Stacking improves data quality by reinforcing the wave signal and suppressing noise. Field wave-trace records are immediately available to the researcher to assess the quality of the survey and individual waveforms.

The accuracy of the traveltime measurement is critical for determining the radar velocity. To determine the electronic-signal delay inherent in all circuits, the antennas are held outside each borehole, and a wave is transmitted through the air. For example, the two antennas shown in figure 2 are being held above the PVC boreholes to shoot a radar wave through the air. The speed of light in air and the borehole separation are known, and so the required wave traveltime can be computed. The electronic-signal delay is calculated as the recorded traveltime through sediment, minus the known time for an electromagnetic wave required to cross the borehole separation in air.

Two different types of crosshole survey were conducted: a constant-offset profile (COP) and a multiple-offset gather (MOG). The COP was used to make a quick reconnaissance survey of the testsite in which both GPR antennas were lowered to equal depths within their respective boreholes for each shot (fig. 3A). The COP allows for rapid collection of radiowave velocities along a horizontal path (assumed bedding) direction, with an equal path length between transmitter and receiver all the way down the soil profile. We used the COP to rapidly identify, in the field, anomalies in traveltime and signal strength that would indicate variations in soil properties. COP data were also used to distinguish the hydraulic fill from bay mud and to design a plan for more detailed GPR surveys in the fill.

The MOG is a more detailed crosshole survey in which the transmitter antenna is fixed at a certain depth in one borehole while the receiver is moved in regular steps down the other 
(fig. 3B). After the receiver collects shots from top to bottom (one complete MOG), the transmitter is lowered a predetermined step-interval and fixed at that new position, and the receiver is again moved down the other borehole. The process is repeated until the transmitter reaches the bottom. In this study, we collected a suite of MOGs, each with a step interval of $0.25 \mathrm{~m}$. Unlike in a COP, the path length in an MOG varies widely from shot to shot. For each transmitter-receiver orientation, the path length is computed. In a perfectly homogeneous and isotropic medium, the first arrivals would form a hyperbola; deviations from a smooth hyperbolic pattern indicate variations in soil properties.

\section{Tomographic Manipulation}

Substantial computation, both in the field and in postacquisition processing, is required before interpretable images can be produced. After wave traces are gathered, the first and, if possible, second wave breaks must be picked. Refracted airwaves are common, especially when the antennas are near the surface, and must be distinguished from direct arrivals. This time-intensive process of event picking enables extraction of the traveltime, amplitude, and period of the transmitted pulse.
Tomographic analysis utilizes the path length and precise measurements of one-way traveltime to determine the velocity structure of the intervening materials. The positions of the transmitter and receiver antennas in the boreholes are well known, and so the raypath distance between the two antennas can be accurately calculated for each shot. The objective of conducting multiple surveys (COP and MOG) between the same boreholes is to collect traveltime data along as many raypaths and as many different angles as possible. The analysis first divides the single plane connecting the boreholes into a grid of cells, or pixels, and calculates the number of raypaths that intersect each cell. The result is a matrix of simultaneous velocity equations with a nonunique solution. The analysis then diverges from an initial estimated model of velocity structure (that is, horizontal layering) to find a "best fit" velocity with the observed data, performing multiple iterations and adjusting the model. The more raypaths or "hits" for each cell (pixel), the better the definition of transmission properties; fewer raypaths provide a less certain solution. Thus, data quality is commonly low at the corners and edges of tomographic images, and so we use only the high-quality data from the center (fig. 2B). For processing, all the COP and MOG traces were merged together into a single data set; first arrivals were picked, and a tomographic image was produced that shows the variations in veloc-
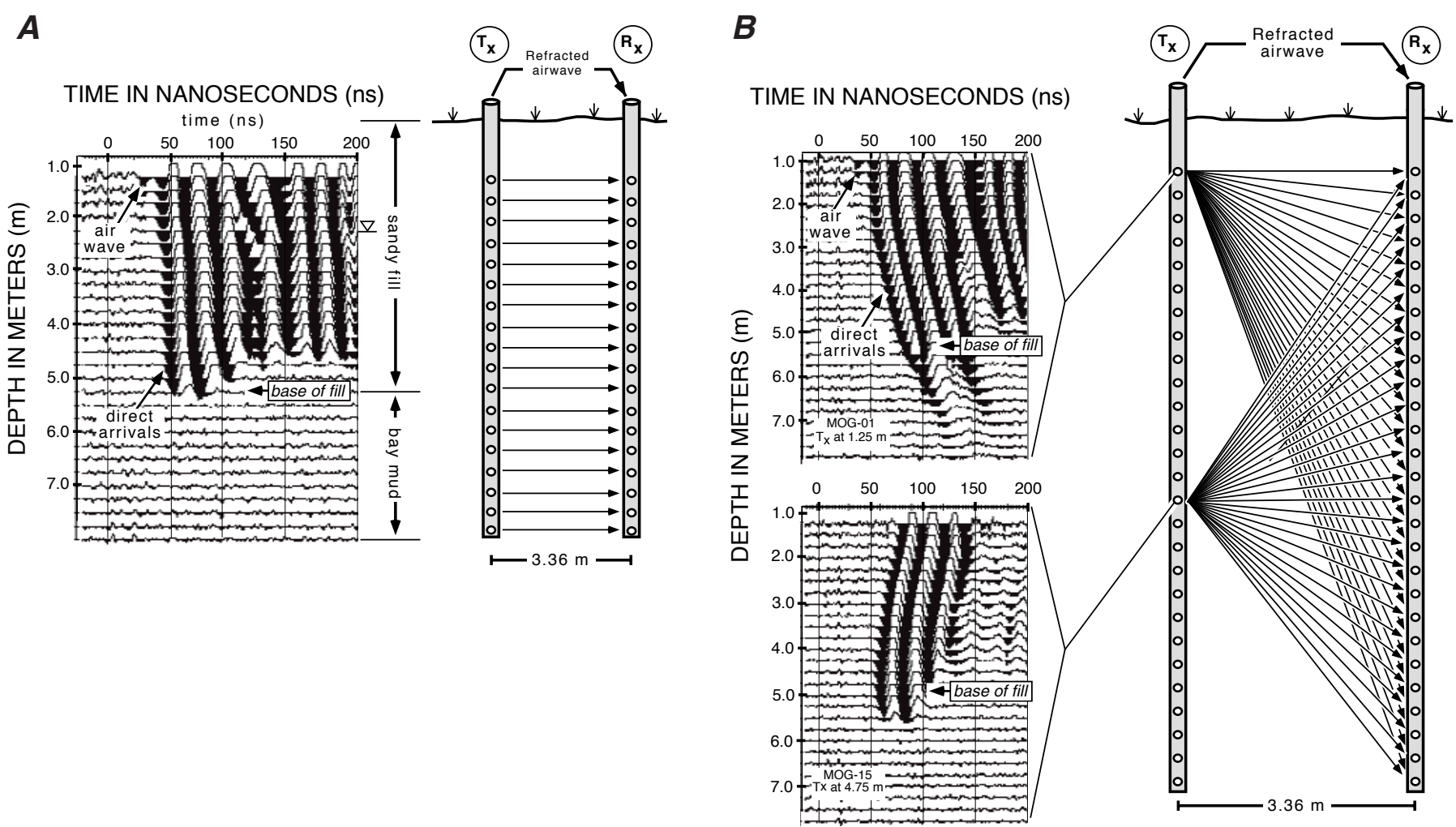

Figure 3.-Crosshole ground-penetrating-radar data and raypath configuration for constant-offset profile $(A)$ and multiple-offset gather $(B)$ on Treasure Island. Depths are relative to original ground surface. Tx, transmitter; Rx, receiver. Circles in boreholes, individual antenna positions. In figure $2 A$, absence of data below $5.25-\mathrm{m}$ depth is due to signal attenuation by conductive bay mud that underlies sandy fill. Inverted triangle, approximate level of water table. In figure $2 B$, transmitter was fixed at a given position for each of 27 data files, only 2 of which are shown here. Depth scale indicates receiver position as it was lowered down borehole. 
ity (fig. 4). Each transmitter-receiver path length was used to convert traveltimes to velocities within the illuminated plane. The pixel footprint within the resulting tomogram contains the velocity averaged from all the waveforms passing through each pixel space.

\section{Relation of Void Ratio to Radar-Wave Velocity and Soil Dielectric Properties}

The velocity of radar waves in the soil mass and in relation to saturated void ratio was studied empirically using the laboratory TDR method of Topp and others (1980). The traveltime of an electromagnetic pulse through a soil mass can be measured through reflection (two-way traveltime), refraction (headwave traveltime along an impedance interface), or transillumination (body transmission) techniques. At Treasure Island, we used a transillumination approach with crosshole GPR to measure traveltimes through a plane in the soil column. Two identical GPR surveys were collected, using the same pair of boreholes, one survey before blasting and another after blasting. A computer-generated tomogram was computed for each survey, showing the velocity structure of the same soil column both before (fig. 4A) and after (fig. 4B) the blast-induced liquefaction. MOGs were taken through the soil plane before and after blast-induced liquefaction, and a computer-generated tomogram was created for the plane.

The earliest study of the empirical relation between soil moisture content (equivalent to porosity when saturated) and radar velocity was by Topp and others (1980). With laboratory TDR, a method similar to our field approach with crosshole GPR, Topp and others determined a unique relation between volumetric soil moisture $\theta_{\mathrm{v}}$ (ratio of volume of water to volume of total soil mass) and the real part of the complex dielectric constant for a wide variety of soil types. The complex dielectric constant of soil,

$$
\varepsilon=\varepsilon^{\prime}+\varepsilon^{\prime \prime} j
$$

is composed of real $\left(\varepsilon^{\prime}\right)$ and imaginary $\left(\varepsilon^{\prime \prime} j\right)$ parts. The radar velocity, $v_{\mathrm{r}}$, depends only on

$$
v_{\mathrm{r}}=\frac{c}{\sqrt{\varepsilon^{\prime}}},
$$

where $c$ is the velocity of light in air. The $\varepsilon^{\prime}$ value ranges from 1 in air $\left(v_{\mathrm{r}}=c=0.3 \mathrm{~m} / \mathrm{ns}\right)$ to more than 30 in fine soil $\left(v_{\mathrm{r}} \sim c / 6 \sim 0.05 \mathrm{~m} / \mathrm{ns}\right)$. The $v_{\mathrm{r}}$ value ranges from less than 0.05 $\mathrm{m} / \mathrm{ns}$ for soft cohesive soil, through $0.06-0.08 \mathrm{~m} / \mathrm{ns}$ in saturated sand, to $0.15 \mathrm{~m} / \mathrm{ns}$ in dry sand. For a suite of soil types, Topp and others (1980) determined the following relation between $\varepsilon^{\prime}$ and $\varepsilon_{\mathrm{v}}$ :

$$
\varepsilon^{\prime}=3.03+9.3 \theta_{\mathrm{v}}^{2}+146 \theta_{\mathrm{v}}^{2}-76.7 \theta_{\mathrm{v}}^{3} \quad\left(\theta_{\mathrm{v}}=0.0-0.6\right)
$$

Saturated soils have all of their void space filled with water. Under such conditions, $\theta=n$, the soil porosity. Solving equation 3 for $\theta_{v}$ and assuming full saturation, $n$ can be determined from $\varepsilon^{\prime}$ as follows:

$$
\begin{gathered}
n=-0.080607+0.037649 \varepsilon^{\prime}-0.0011413\left(\varepsilon^{\prime}\right)^{2} \\
-1.5789 \times 10^{-5}\left(\varepsilon^{\prime}\right)^{3} .
\end{gathered}
$$

In the field, we measure radar velocity rather than dielectric constant. To estimate the soil porosity directly from radar velocity, we use the relation $\varepsilon^{\prime}=\left(c / v_{\mathrm{r}}\right)^{2}($ where $c=0.3 \mathrm{~m} / \mathrm{ns})$ to modify equation 4 , as follows:

$$
n=2.5025-75.54 v_{\mathrm{r}}+920.1 v_{\mathrm{r}}^{2}-4,094.8 v_{\mathrm{r}}^{3}
$$

where $v_{\mathrm{r}}$ is in meters per nanosecond. The geotechnical characterization of a soil's density state is typically done in terms of void ratio $(e)$, which is the void volume normalized by the volume of dry sediment grains. We substitute void ratio for porosity, where $e=n /(n-1)$, in equation 1 and solve for $e$ in terms of $\varepsilon^{\prime}$ and $v_{\mathrm{r}}$ :

$$
\begin{gathered}
e=-0.035129+0.030695 \varepsilon^{\prime}-3.553110^{-4}\left(\varepsilon^{\prime}\right)^{2} \\
+9.6159 \times 10^{-6}\left(\varepsilon^{\prime}\right)^{3}
\end{gathered}
$$

and

$$
e=13.482-533.47 v_{\mathrm{r}}+7,526.4 v_{\mathrm{r}}^{2}-36,615 v_{\mathrm{r}}^{3} .
$$

\section{Results: Void-Ratio Change During Liquefaction}

We use equation 7 and the radar velocity determinations to map the soil void ratio before and after blast-induced soil liquefaction. The radar-velocity and void-ratio tomograms shown here (figs. 4-6) are from the 5-m-wide plane in the 3-4-5-m borehole triangle. To estimate void-ratio changes in the hydraulic fill, the degraded waveforms passing through the bay mud (fig. 4) were truncated from the data set so that an initial homogeneous velocity model could be used; including the bay mud in the data set added poorly constrained velocities. Void ratios before and after liquefaction were analyzed in the central part of the tomogram, on a plane extending from 2 to $4 \mathrm{~m}$ in depth and 0.75 to $2.6 \mathrm{~m}$ in width.

Before liquefaction, the plane was illuminated by GPR, and a velocity tomogram was constructed (fig. 4A). Equation 7 was used to convert the image to a preliquefaction voidratio tomogram. The $v_{\mathrm{r}}$ value in the central part of the soil column at Treasure Island ranged from 0.054 to $0.6 \mathrm{~m} / \mathrm{ns}$, with an average of $0.057 \mathrm{~m} / \mathrm{ns}$. These $v_{\mathrm{r}}$ values translate into void ratios ranging from 0.647 to 0.846 , with an average of 0.738 (fig. $5 A$ ). Generally, a zone of low to intermediate soil void ratio is present in the central part of the tomogram, and a zone of low soil void ratios in the upper-left part. A locally high soil void ratio is visible on the right side of the plane at 2.5- to 2.75-m depth, and a zone of higher void ratios in the lower-left corner of the tomogram.

The blasting event occurred in January 1999, liquefying the hydraulic fill at the testsite. Elevated pore-water pressures were measured in transducer arrays, sand boils were observed at the testsite, and settlements were surveyed and recorded. 

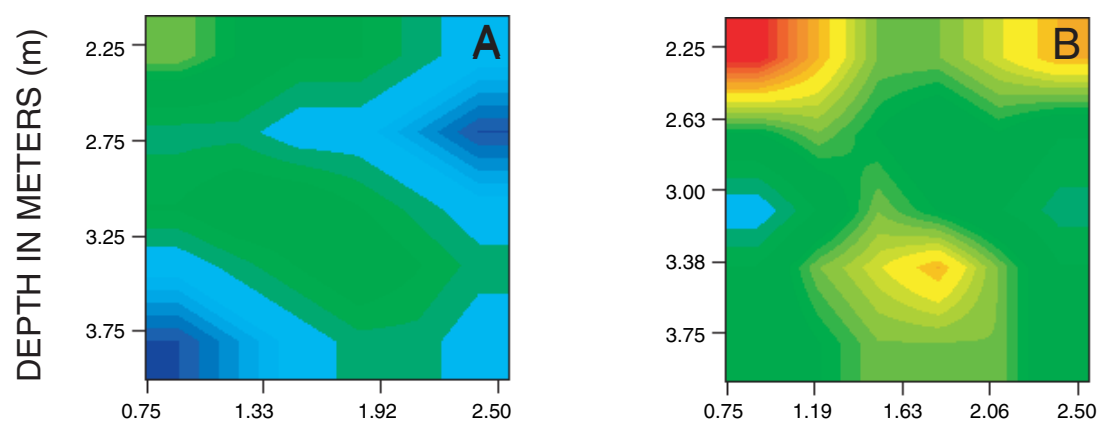

DISTANCE IN METERS (m)
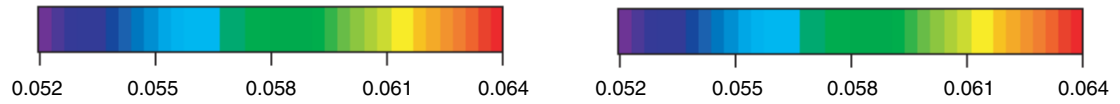

Figure 4.- Radar velocity across tomographic plane before $(A)$ and after $(B)$ blast-induced liquefaction event.
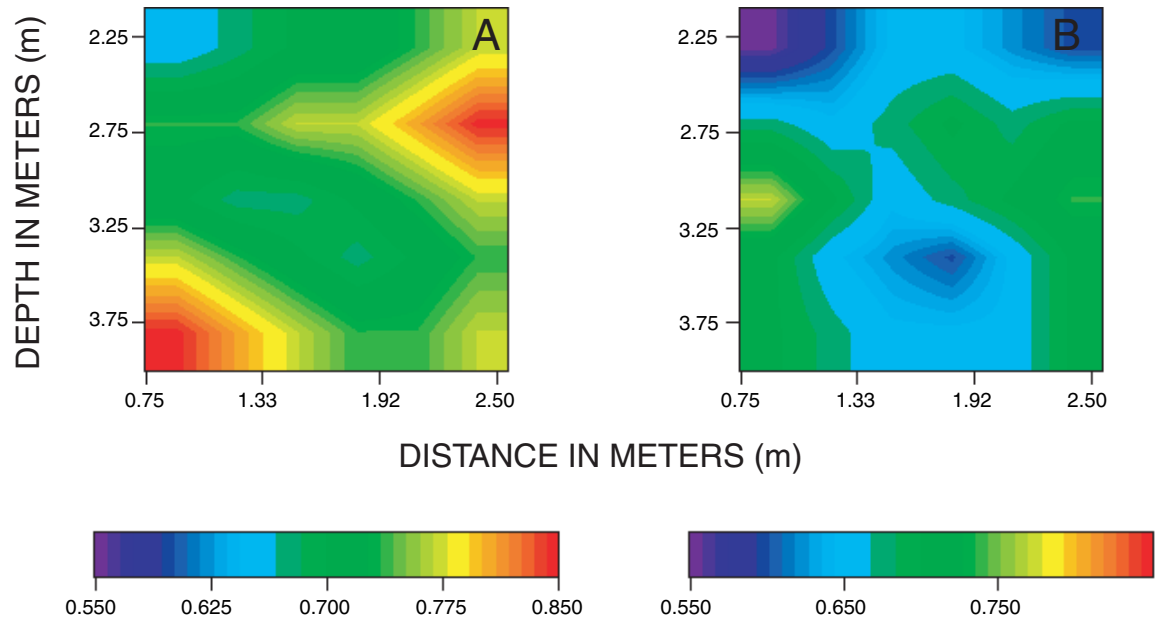

Figure 5.- Void ratio across tomographic plane before $(A)$ and after $(B)$ blast-induced liquefaction event.
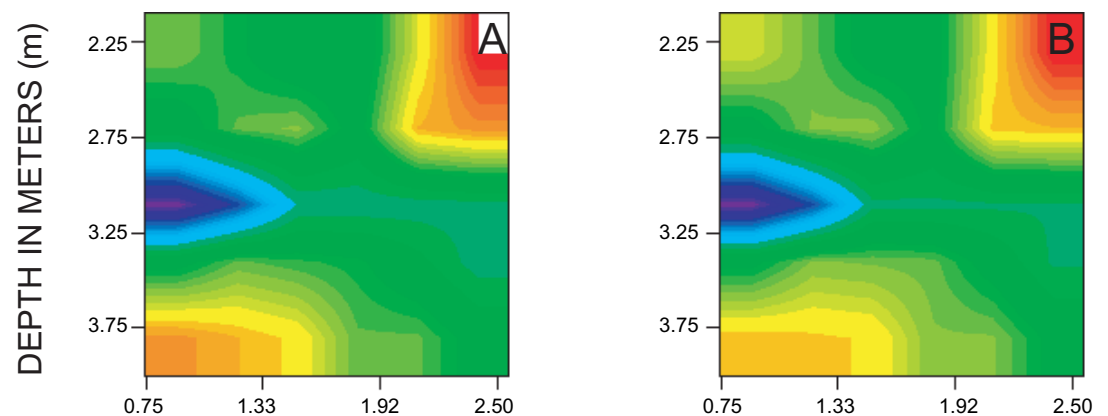

DISTANCE IN METERS (m)
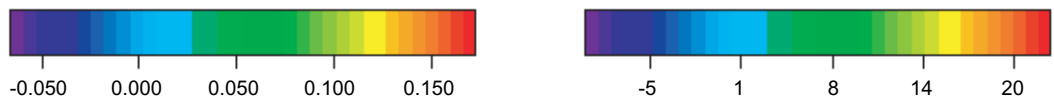

Figure 6.-Void-ratio change $(A)$ and percent reduction $(B)$ across tomographic plane after blast-induced liquefaction event. 
Sand boils and waterflow to the surface was observed adjacent to the radar borehole array. Accordingly, we are confident that liquefaction occurred within the tomographic plane.

After the liquefaction, we resurveyed the 3-4-5-m triangular borehole array and found that $v_{\mathrm{r}}$ values had risen considerably throughout the tomogram. The $v_{\mathrm{r}}$ value for the postliquefaction soil plane ranged from 0.056 to $0.064 \mathrm{~m} / \mathrm{ns}$, with an average of $0.0597 \mathrm{~m} / \mathrm{ns}$ (fig. $4 B$ ). The soil void ratios estimated from the $v_{\mathrm{r}}$ values range from 0.554 to 0.770 , with an average of 0.664 (fig. $5 B$ ). Comparing figures $5 A$ and $5 B$, almost the entire tomographic plane underwent some level of densification (void-space reduction) during liquefaction.

Detailed imagery of the preliquefaction and postliquefaction soil void ratios allows differencing of the two tomograms so that we can see where-void ratio changes occurred within the soil column. A difference tomogram of the preliquefaction minus the postliquefaction void ratios is shown in figure $6 \mathrm{~A}$. The image shows an average densification $e$ of 0.074 . The void-ratio change ranges from -0.066 to 0.172 - that is, the entire tomographic plane densified except for a narrow zone at $3.1-\mathrm{m}$ depth on the left side of the tomogram that apparently loosened during the liquefaction event or formed a void when sand redistributed within the soil column. Void-ratio change, expressed as a percentage of the initial state of void-ratio structure in the soil column (that is, volumetric strain), is plotted in figure $6 B$. The void-ratio change is calculated by taking the values used in figure $6 A$ and dividing them by the initial void ratio, and so the regions of void-ratio change in figures $6 A$ and $6 B$ look similar. The average volumetric strain in the entire tomographic plane due to void-ratio reduction is 4.2 percent. Given the estimated thickness of the liquefied layer at the testsite of 4 to $5 \mathrm{~m}$, this strain would result in 17.0 to $21.3 \mathrm{~cm}$ of one-dimensional vertical settlement (fig. 7).

The observed surface settlement at the testsite can be used as an independent measure of the volumetric strain. The ground level of the testsite was measured before blasting and then afterward. Maximum settlements of 16.7 to 20.7 $\mathrm{cm}$ were measured by Brigham Young University engineers along three transects across the testsite (fig. 9). One transect passed through the centerline of the pile group and load shaft, whereas the other two transects were perpendicular to that centerline. The settlements estimated from the volumetric strain recorded in the radar tomograms agree closely with the observed settlement. Arulanandan and Sybico (1993) reported comparable volumetric strains in liquefied sand during controlled centrifuge modeling tests conducted at the University of California, Davis.

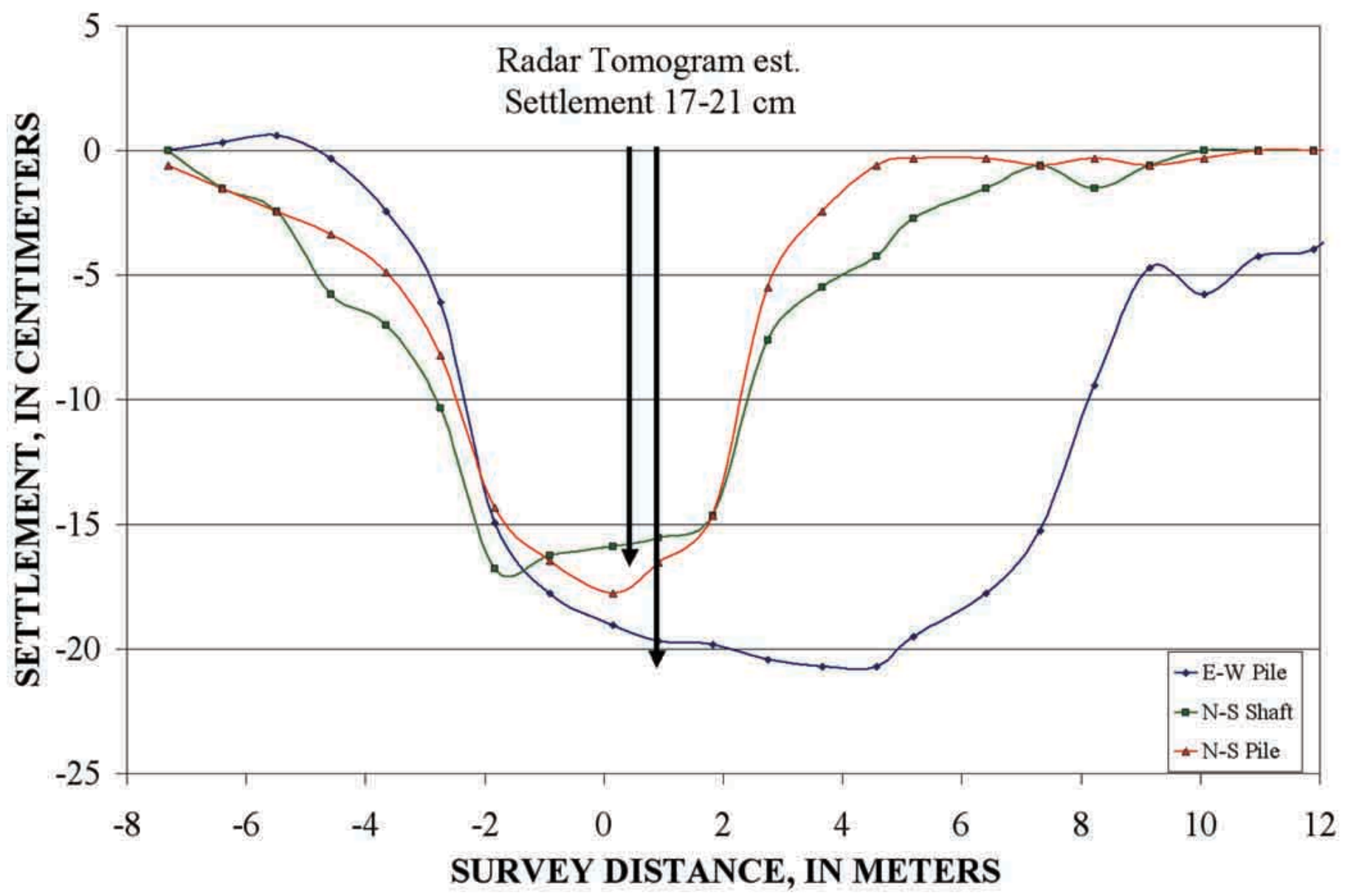

Figure 7.-Comparison of vertical settlements measured at lateral-pile-load testsite on Treasure Island and predicted settlements based on radar-velocity-determined volumetric strain for a 4- to 4.5-m-thick zone of liquefied soil. 


\section{Conclusions}

We found that the imagery created through crosshole GPR surveys was able to quantify in spatial detail both the initial soil void ratio and the void-ratio changes due to a liquefaction event. The volumetric strain associated with the estimated void-ratio changes from the GPR data would result in settlements of 17 to $21.3 \mathrm{~cm}$ for the estimated 4- to 5-m-thick liquefied layer at the testsite. The radar-based estimates of settlement are remarkably close to the ground-level changes at the testsite measured by surveying methods.

This chapter demonstrates the applicability of crosshole GPR for nondestructive imaging of the spatial structure within a large volume of soil, as well as for characterization of the changes in soil volume due to a liquefaction event. The radar-based field observation of soil-fabric collapse and the quantified densification during liquefaction indicates that repeated loading should eventually drive the void ratio in the soil mass to the steady-state line.

\section{References Cited}

Arulanandan, Kandiah, and Sybico, J., Jr., 1993, Post-liquefaction settlement of sands, in Houlsby, G.T., and Schofield, A.N., eds., Predictive Soil Mechanics, Thomas Telford, London UK.

Bennett, M.J., 1994, Subsurface investigation for liquefaction analysis and piezometer calibration at Treasure Island Naval
Station, California, U.S. Geological Survey Open-File Report 94-709, 43 p.

Kayen, R.E., Barnhardt, W.A., Ashford, S.A., and Rollins, Kyle, 2000, Nondestructive Measurement by crosshole radar tomography of soil density changes during liquefaction, Treasure Island, California, in Arulanandan, Kandiah, Anandarajah, Annalinghan, and Li, X.S., eds., Computer simulation of earthquake effects: American Society of Civil Engineers Geotechnical Publication 10, p. 52-65.

Mitchell, J.K., 1993, Fundamentals of soil behavior (2d ed.): New York, John Wiley \& Sons, $437 \mathrm{p}$.

Narin van Court, W.A., and Mitchell, J.K., 1995, New insights into explosive compaction of loose, saturated, cohesionless soils, in Hyrciw, R.D., ed., Soil improvement for earthquake hazard mitigation: American Society of Civil Engineers Geotechnical Publication 49, p. 51-65.

Seed, H.B., and Idriss, I.M., 1982, Ground motions and soil liquefaction during earthquakes (Engineering Monographs on Earthquake Criteria, Structural Design, and Strong Motion Records, no. 5): Berkeley, Calif., Earthquake Engineering Research Institute, $134 \mathrm{p}$.

Studer, Jost, and Kok, Louk, 1980, Blast-induced excess porewater pressure and liquefaction; experience and application: International Symposium on Soils Under Cyclic and Transient Loading, Swansea, U.K., 1980, Proceedings, v. 1, pt. 2, p. 581-593.

Topp, G.C., Davis, J.L., and Annan, A.P., 1980, Electromagnetic determination of soil water content; measurement in coaxial transmission lines: Water Resources Research, v. 16, no. 3, p. 574-582. 


\title{
Biostratigraphy Beneath Central San Francisco Bay Along the San Francisco-Oakland Bay Bridge Transect
}

\author{
By Mary McGann, ${ }^{1}$ Doris Sloan, ${ }^{2}$ and Elmira Wan ${ }^{1}$
}

\section{CONTENTS}

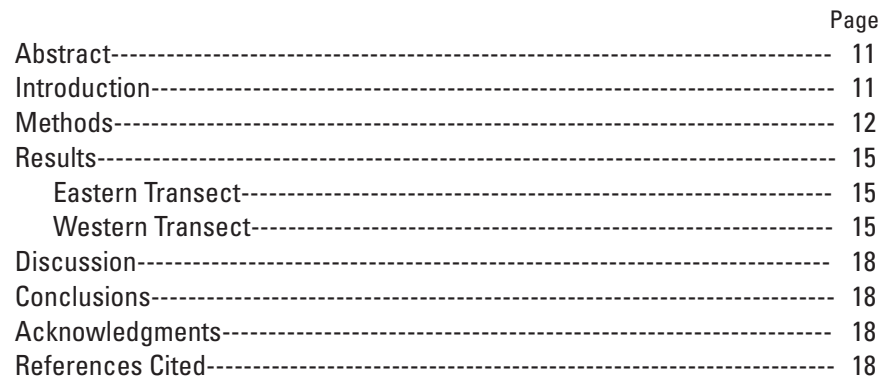

\section{Abstract}

To define the late Pleistocene and Holocene biostratigraphy of the sedimentary deposits beneath San Francisco Bay near the San Francisco-Oakland Bay Bridge and to assess possible fault offsets near Yerba Buena Island, we examined cores taken by the California Department of Transportation for seismic retrofitting of the bridge. We used foraminifers, diatoms, and other microorganisms to identify intervals of Pleistocene and Holocene estuarine and alluvial deposition, and examined the estuarine intervals in greater detail to characterize the bay at the time when the sediment was deposited. Although foraminifers generally were poorly preserved, sufficient microfossils were observed in the estuarine deposits to define three biofacies: biofacies A, dominated by Trochammina inflata and shallow-water diatoms; biofacies B, with Ammonia beccarii and Elphidium excavatum and subtidal diatoms; and biofacies C, with Elphidiella hannai and the diatom Isthmia nervosa. These biofacies indicate progressively deeper or colder estuarine conditions, from intertidal mudflat and marsh to deep subtidal. This biostratigraphy, which correlates with that reported at other transects in the south bay, reflects the late Pleistocene transgressive episode that has been correlated with the latest interglacial (Substage $5 \mathrm{e}, \sim 125-120 \mathrm{ka})$.

The use of microfossils in this study permits a more detailed late Pleistocene stratigraphy at the San Francisco-

${ }^{1}$ U.S. Geological Survey.

${ }^{2}$ University of California, Berkeley.
Oakland Bay Bridge transect than was previously available on the basis of engineering data alone. Holocene samples were too discontinuous to permit definition of a detailed stratigraphy and resolution of the question of faults beneath the bay. More closely spaced, better preserved samples are needed to address these issues.

\section{Introduction}

The objectives of this study were (1) to define the late Pleistocene and Holocene biostratigraphy of the sedimentary deposits beneath San Francisco Bay along the eastern and western spans of the San Francisco-Oakland Bay Bridge (figs. $1,2)$, and (2) to compare the biostratigraphy in adjacent boreholes to assess possible fault offsets near Yerba Buena Island.

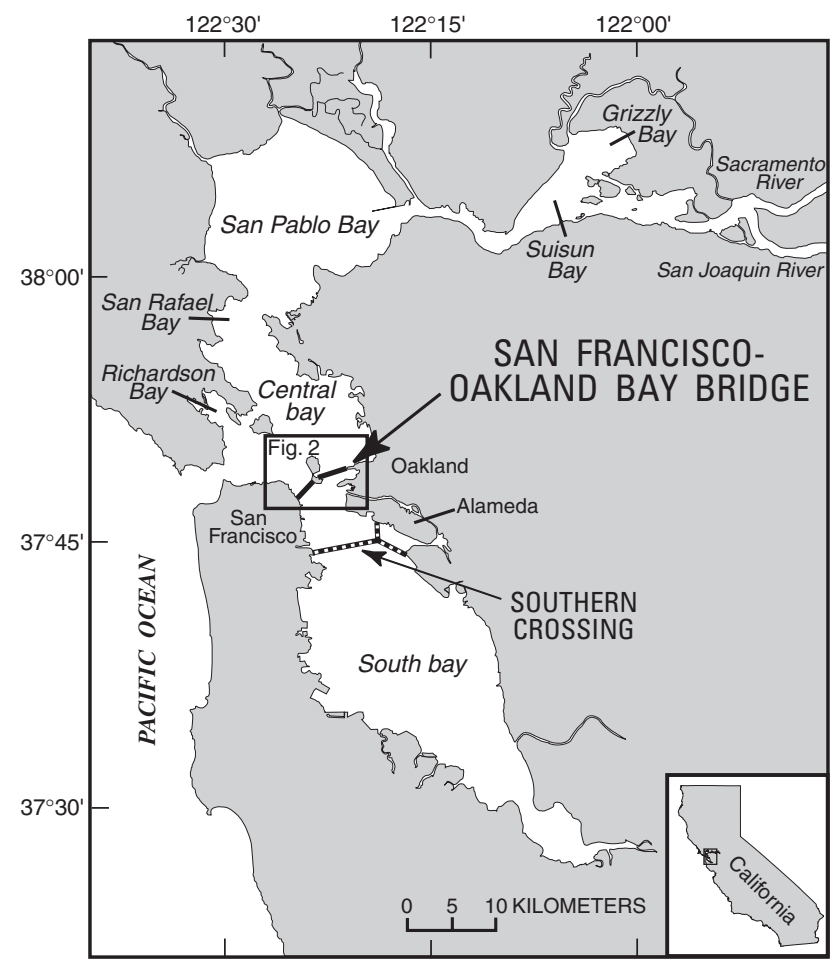

Figure 1.-San Francisco Bay, showing locations of the San Francisco-Oakland Bay Bridge and the Southern Crossing, a proposed bridge between San Francisco and Alameda that was to be constructed just south of the existing San Francisco-0akland Bay Bridge. 
We used core samples from 12 boreholes drilled to bedrock by the California Department of Transportation (Caltrans) for seismic retrofitting of the bridge. We identified intervals of estuarine and alluvial deposition on the basis of foraminifers and other microfossils in the sediment and examined the estu-

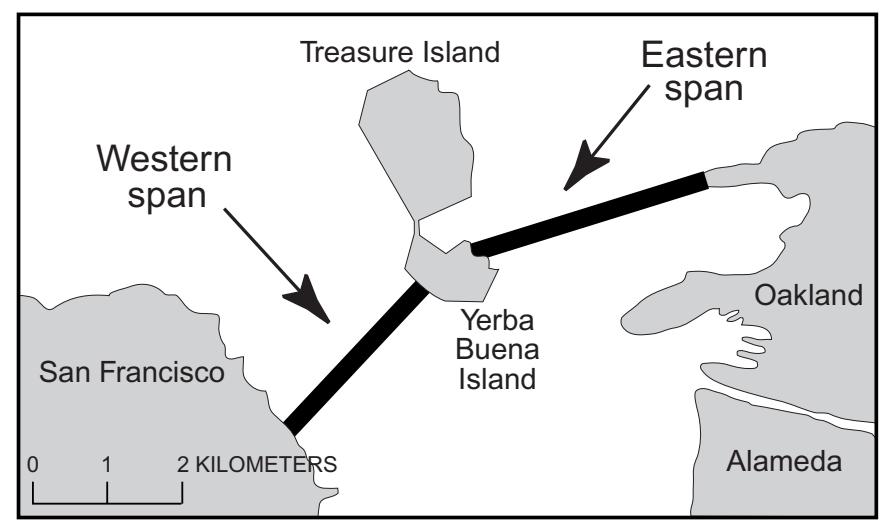

Figure 2.-San Francisco-Oakland Bay Bridge, showing locations of eastern and western spans.

arine intervals in greater detail to characterize San Francisco Bay at the time when the sediment was deposited.

In earlier studies of central San Francisco Bay (fig. 1), Trask and Rolston (1951) identified four sedimentary units along the San Francisco-Oakland Bay Bridge transect: (1) a Pleistocene unit of alluvial and estuarine deposits (Alameda formation), (2) late Pleistocene estuarine deposits (San Antonio formation), (3) alluvial and eolian deposits (Posey Sand and Merritt formation), and (4) Holocene estuarine deposits (bay mud). Wagner (1978) studied foraminifers in cores from the bridge and found that a stronger open-ocean influence existed in the past. Sloan (1992) examined late Pleistocene estuarine deposits at the proposed (but never built) Southern Crossing transect (fig. 1); she informally named them the "Yerba Buena mud member of the San Antonio formation," to distinguish them from alluvial components of the San Antonio formation.

\section{Methods}

To define the stratigraphy beneath San Francisco Bay for this study, we used foraminifers, diatoms, and other microorganisms that previously had proved valuable in defining the biostratigraphy of southern San Francisco Bay (Sloan, 1992). We defined stratigraphic units on the basis of lithology and microfossils, primarily benthic foraminifers and diatoms. Where microfossils were absent, we relied on engineering data to locate the contacts in cores from boreholes east of Yerba Buena Island (fig. $3 A$ ). No engineering data were available on cores from boreholes west of Yerba Buena Island (fig. 3B).

We examined 210 samples of 50 to $300 \mathrm{~g}$ each from eight boreholes east of Yerba Buena Island (fig. $3 A$ ) and 42 samples from four boreholes west of Yerba Buena Island (fig. 3B), using standard paleontologic techniques to recover microfossils. Foraminifers were poorly preserved in most samples, partly because the cores had been stored without refrigeration for more than a year before we acquired them. Gypsum, which was present in many samples (tables 1,2 ), is likely to have formed through the dissolution of foraminifers. Therefore, we considered its presence as evidence of an estuarine depositional environment. In the western cores, foraminifers were better preserved in samples near the top of the core than in the lower part.
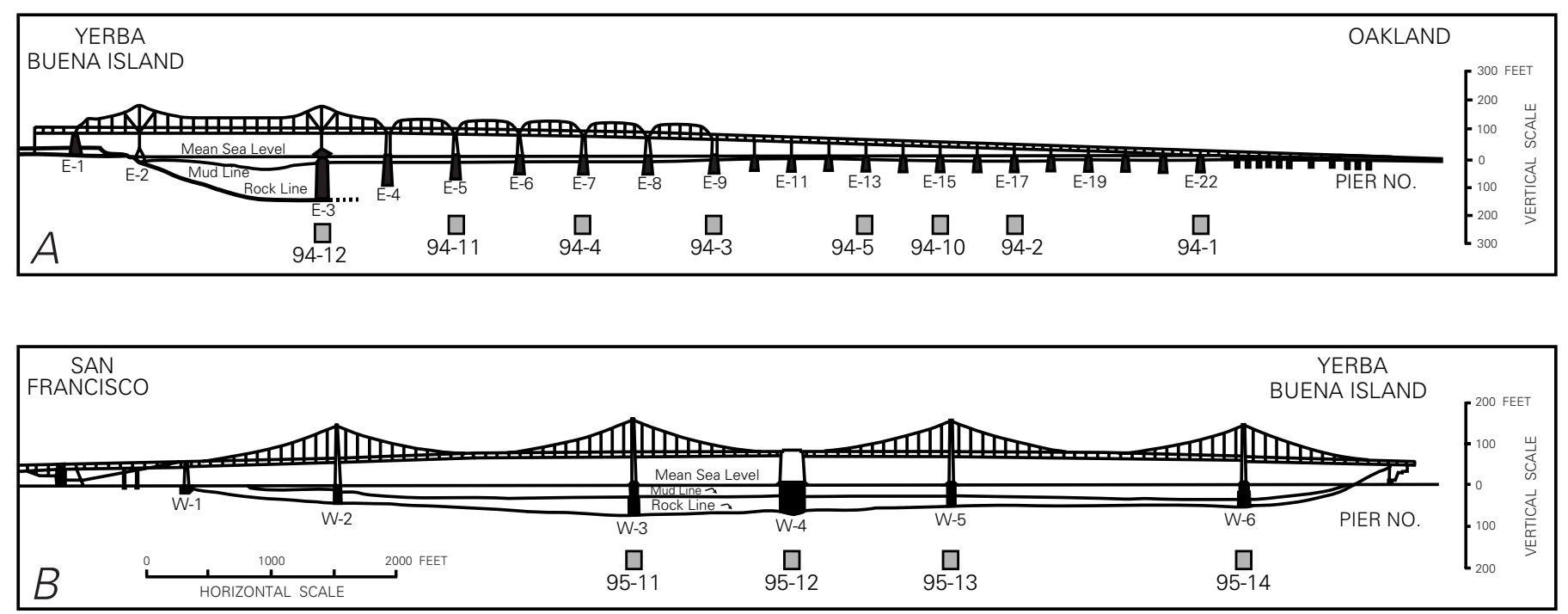

Figure 3.-Schematic diagrams showing approximate placement of boreholes (squares) along the San Francisco-Oakland Bay Bridge (after Trask and Rolston, 1951, and Buell and others, 1997). $A$, Eastern span between Oakland and Yerba Buena Island. $B$, Western span between Yerba Buena Island and San Francisco. 

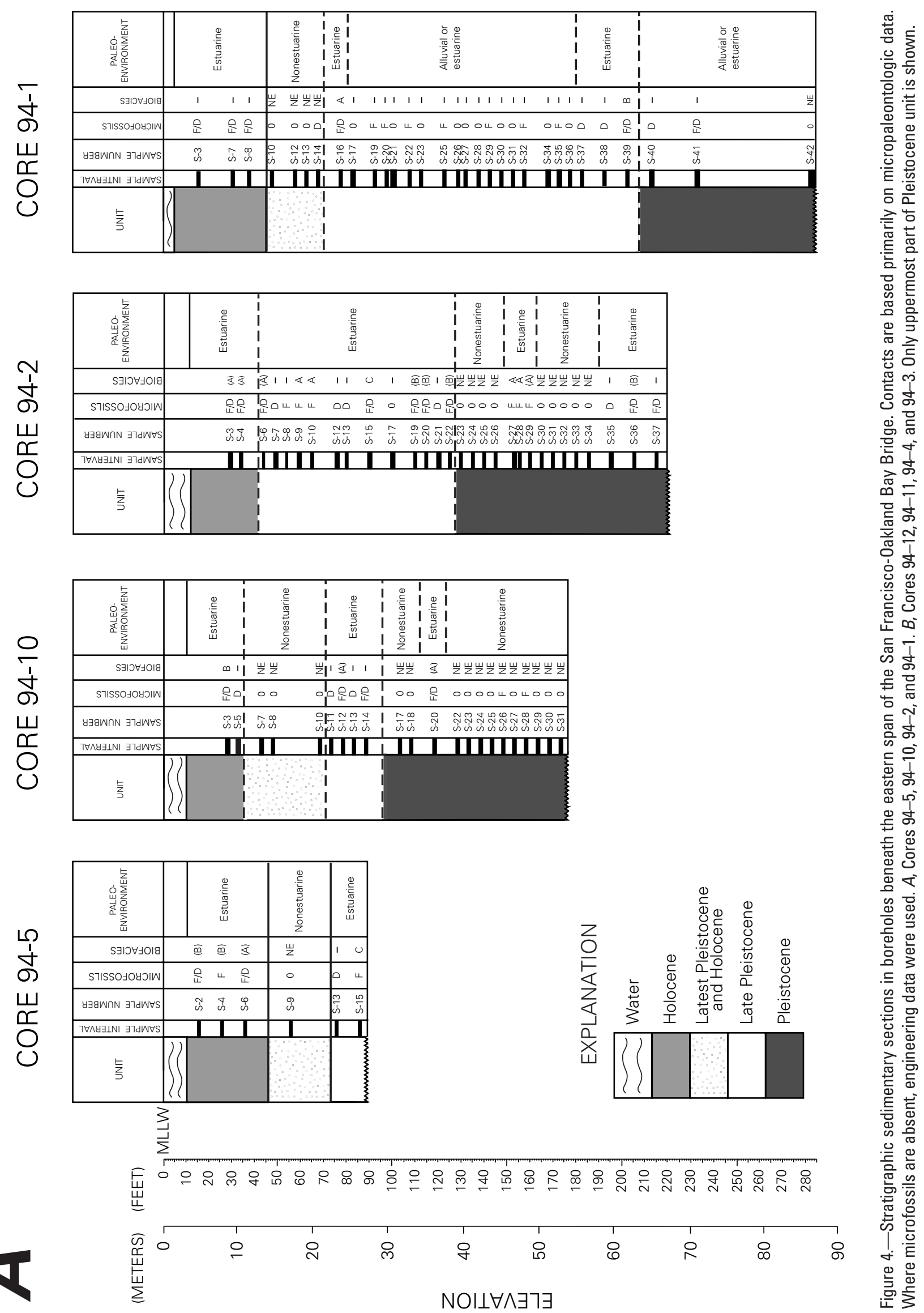

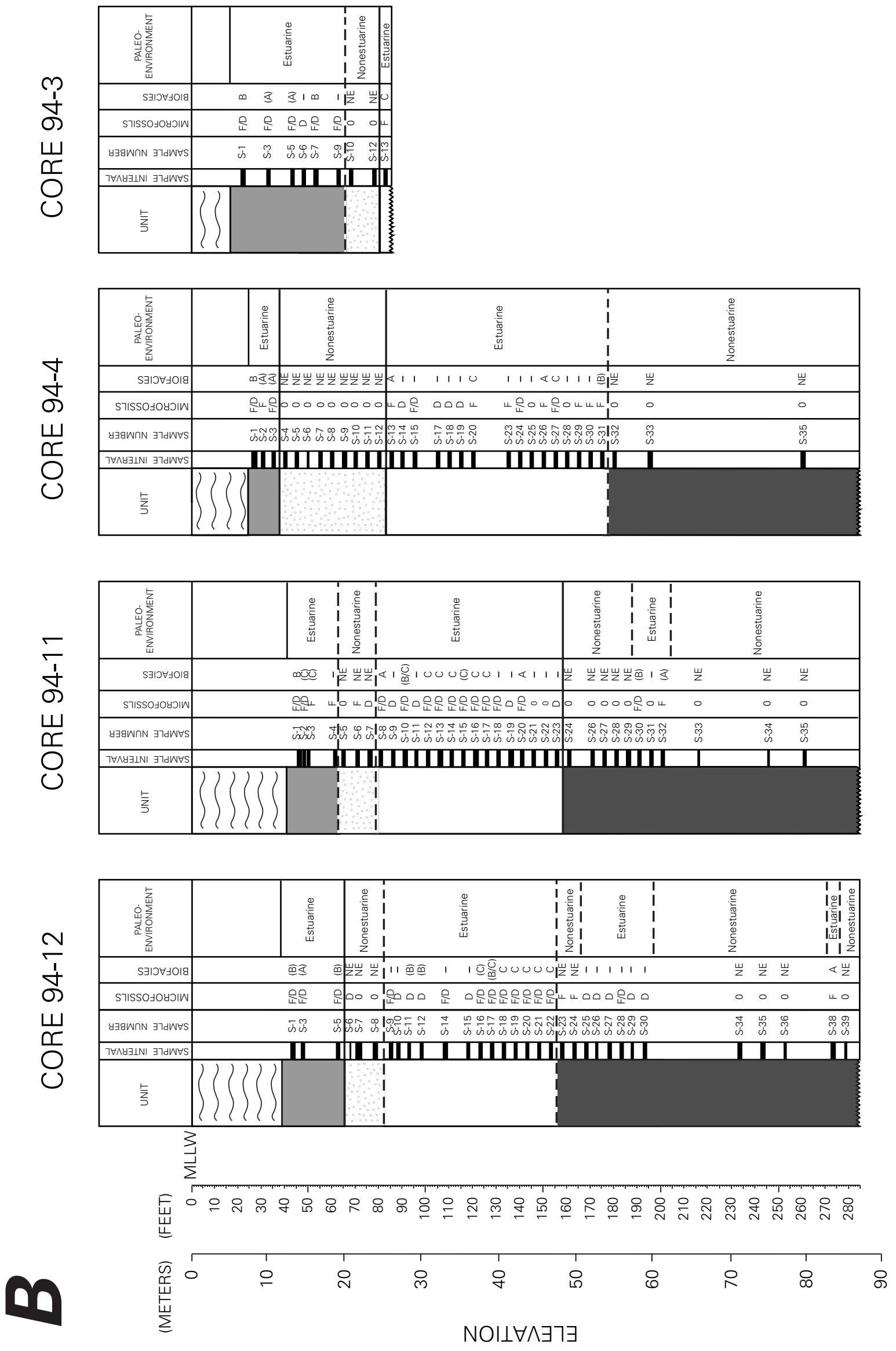
In the eastern cores, only 24 of 210 samples (11 percent) contained more than 300 foraminifers; a total of 37 samples (18 percent) contained more than 100 foraminifers, and an additional 6 samples contained from 50 to 100 foraminifers (3 percent with >50 foraminifers; table 1 ). In two cores, foraminifers were very rare: In core 94-1 (fig. 4A) only two samples (S-16, S-39) contained sufficient foraminifers for reliable analysis; and in core 94-10 (fig. 4A), foraminifers were common only in sample S-3. Preservation was best in cores 94-11 and 94-12 (fig. 4B).

In the western cores, 7 of 42 samples (17 percent) contained more than 300 specimens, all in core 95-14 (fig. 5); a total of 18 samples (43 percent) contained more than 100 foraminifers, and an additional 5 samples contained from 50 to 100 specimens ( 12 percent with > 50 foraminifers; table 2). In many of these samples, the foraminifers are well preserved; however, the samples were spaced too far apart to permit stratigraphic interpretation of the cores. Therefore, in the interest of completeness, we report microfossil occurrences in table 2 without biostratigraphic interpretation.

In many samples containing no or few foraminifers, sufficient diatoms were preserved to permit environmental interpretations. Several samples contained a few foraminifers but no other organic evidence of estuarine deposition. Where the mineral content of the residues appeared to be nonestuarine, we considered the foraminifers to be displaced and interpreted the depositional environment as nonestuarine.

\section{Results}

Lithology and microfossils indicate that the stratigraphy at the Bay Bridge is much like that described in earlier studies (Trask and Rolston, 1951; Wagner, 1978; Sloan, 1992). We identified four sedimentary units (fig. 4): (1) at least $120 \mathrm{ft}$ of Pleistocene alluvial and estuarine deposits, (2) about 15 to $95 \mathrm{ft}$ of late Pleistocene estuarine deposits, (3) 5 to 45 $\mathrm{ft}$ of alluvial and eolian deposits, and (4) 20 to $40 \mathrm{ft}$ of Holocene estuarine deposits. We report here on the biostratigraphy of the two youngest estuarine units. In the earlier Pleistocene deposits, estuarine and alluvial depositional environments were discriminated where sufficient microfossil data were available; however, in many cores, sampling intervals were too widely spaced and microfossils too poorly preserved to permit more detailed stratigraphic analysis.

The dominant species of foraminifers in both the late Pleistocene and Holocene estuarine units are Ammonia beccarii (Linné), Elphidiella hannai (Cushman and Grant), Elphidium excavatum (Terquem), and Trochammina inflata (Montagu) (tables 1, 2). They indicate deposition under intertidal and shallow to deep subtidal estuarine conditions (0- 20 m water depth; salinity, 10- 31 practical salinity units; Arnal and others, 1980; Sloan, 1992; McGann and Sloan, 1999; San Francisco Estuary Institute, 1999; see the U.S. Geological Survey's Water Resources Division San Francisco Bay water-quality Web site at URL http//: sfbay.wr.usgs.gov/access/wqdata/index.html). Trochammina hadai, a species recently introduced into San Francisco Bay (McGann and others, 2000), is present in low numbers in three Holocene samples (core 94-11, samples S-2, S-4; core 94-12, sample S-3T); its presence in subsurface samples is likely due either to bioturbation or to contamination during coring.

The dominant sand-size diatoms in the estuarine units include Actinoptychus, Arachnodiscus, Biddulphia, Campylodiscus, Cymbella, Isthmia, Gyrosigma, and Thalassiosira. These brackish to marine genera are all common in the surface sediment of San Francisco Bay today (Mahood and others, 1986; Laws, 1988).

On the basis of the occurrence of these foraminifers and diatoms, we define three biofacies in the late Pleistocene and Holocene estuarine deposits: biofacies A, dominated by Trochammina inflata and diatoms, including Campylodiscus, Biddulphia, Cymbella, Gyrosigma, Melosira, Nitzschia, Pinnularia, or Thallasiosira; biofacies B, dominated by Ammonia beccarii and Elphidium excavatum, including also the diatoms Actinoptychus and Arachnodiscus; and biofacies C, containing abundant Elphidiella hannai and the diatom Isthmia nervosa. These three biofacies indicate progressively deeper or colder estuarine conditions, from intertidal mudflat and marsh (biofacies A, 0-7-ft depth; maximum salinity, $\sim 10$ practical salinity units), through shallow subtidal (biofacies B, 7-49-ft depth; salinity, 10-30 practical salinity units), to deep subtidal (biofacies C, 39-72-ft depth; salinity, 15-32 practical salinity units).

\section{Eastern Transect}

In the late Pleistocene estuarine deposits, biofacies $\mathrm{C}$ is most common, occurring in 17 samples (figs. 4A, 4B; table 1). Biofacies A and B are present in 14 and 9 samples, respectively, and 2 samples have a biofacies transitional between biofacies $\mathrm{B}$ and $\mathrm{C}$. In most cores, the top and bottom samples contain biofacies $\mathrm{A}$ or $\mathrm{B}$, or too few data are available for reliable interpretation. Biofacies $\mathrm{C}$ occurs near the middle of the unit.

In contrast, in the Holocene estuarine deposits, biofacies $\mathrm{A}$ and $\mathrm{B}$ are most common, occurring in 8 and 9 samples, respectively (figs. $4 A, 4 B$; table 1 ). Biofacies $\mathrm{C}$ is present in only 2 samples. Biofacies A occurs near the base of the unit, except in cores 94-3 and 94-12, where biofacies B is present in the lowermost samples, and in cores 94-10 and 94-11, where biofacies A is absent. Biofacies B occurs in the uppermost samples from all cores except 94-2, in which it is absent.

\section{Western Transect}

In the undifferentiated late Pleistocene and Holocene estuarine deposits, no samples contain biofacies A; however, a biofacies transitional between biofacies $\mathrm{A}$ and $\mathrm{B}$ is present in 1 sample from core 95-13 (S-5-3; fig. 5; table 2). Biofa- 

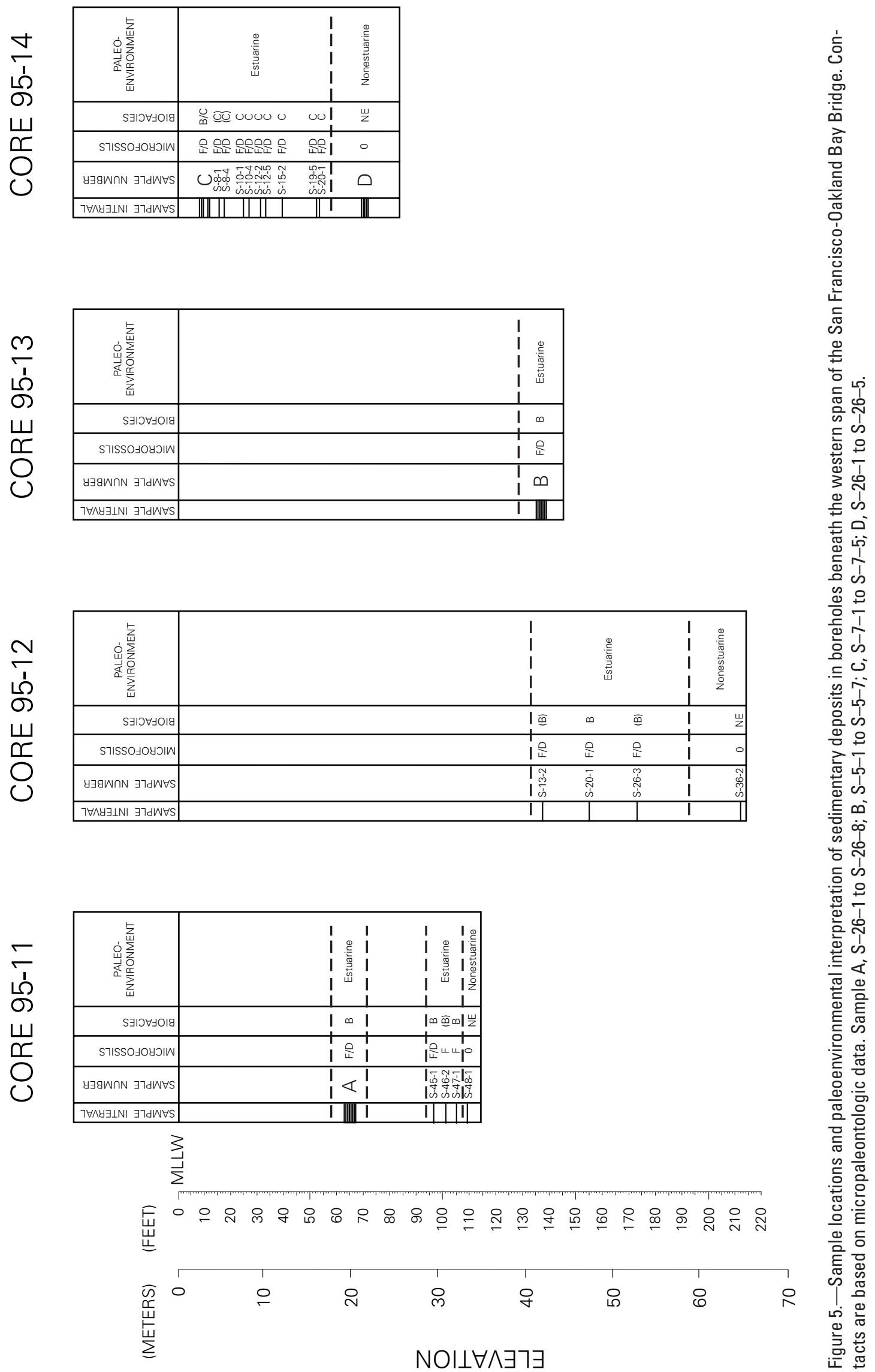


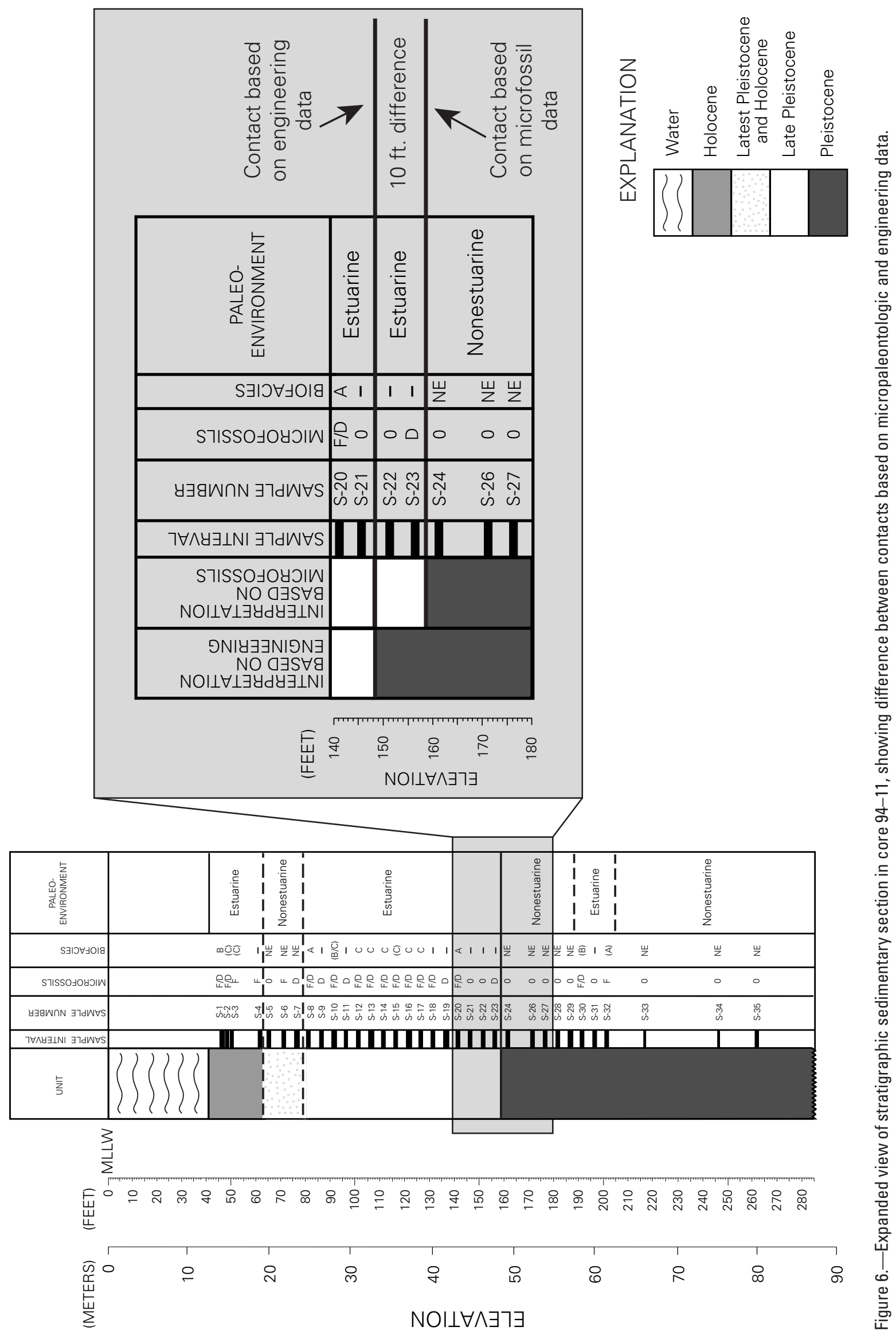


cies B is the only one present in cores 95-11 and 95-12. Biofacies $\mathrm{C}$ is present in 10 of the 14 estuarine samples from core 95-14, and the other 4 samples have a biofacies transitional between biofacies B and C. Little vertical change was noted in any of these four cores.

\section{Discussion}

On the basis of the stratigraphic position of the sedimentary units and the biofacies present in the deposits, the stratigraphy at the San Francisco-Oakland Bay Bridge transect can be correlated with the stratigraphies at the Southern Crossing transect $\sim 6 \mathrm{~km}$ to the south studied by Sloan (1992) and at the San Mateo Bridge transect (Atwater and others, 1977), $\sim 26 \mathrm{~km}$ south of the bridge. The late Pleistocene estuarine unit at the San Francisco-Oakland Bay Bridge transect is correlative with Sloan's informally named Yerba Buena mud of Sangamon age (Substage 5e, 125-120 ka). The Holocene estuarine deposits are present at all three transects.

The biofacies present in the eastern Caltrans cores reflect the same late Pleistocene transgressive episode as that seen at the Southern Crossing (Sloan, 1992) and San Mateo Bridge (Atwater and others, 1977) transects. The intertidal-mudflat and marsh deposits at the base (with biofacies A) are succeeded by shallow subtidal (with biofacies B) and then deep subtidal (with biofacies C) deposits. A subsequent drop in sea level or a tectonic event that created a shallower bay is indicated by the presence of biofacies B or A near the top of the late Pleistocene deposits.

In the Holocene unit east of Yerba Buena Island, the transgressive pattern is less clear, partly because of poor sample coverage. Although biofacies A is present in the lowermost samples from several cores from boreholes east of Yerba Buena Island, in cores 94-3 and 94-12 (fig. 4B) biofacies $\mathrm{A}$ is present in the middle of the unit rather than at the base or top, as in the late Pleistocene unit. This sequence may reflect a shallowing episode or may be an artifact of the spacing of samples or the poor preservation of foraminifers.

The use of microfossils in this study permits a more detailed late Pleistocene stratigraphy at the San FranciscoOakland Bay Bridge transect than was previously available. Most earlier studies relied on engineering properties alone (Hoover-Young Bridge Commission, 1930; Trask and Rolston, 1951). By using foraminifers and diatoms as indicators of estuarine environments, we can locate contacts between the estuarine and alluvial units with greater precision than was previously possible. For example, in core 94-12 (fig. 4B), the micropaleontologic data support a contact between the late Pleistocene and Pleistocene units as defined by Caltrans on the basis of engineering data (Reid Buell, oral commun., 1997). In contrast, in core 94-11, the engineering data suggest that the base of the Yerba Buena mud is lower than set by Caltrans, who located it at $\sim 145 \mathrm{ft}$, below sample 21 (fig. 6). However, the presence of the marine and estuarine diatom Campylodiscus in sample 23 indicates that this sample is not alluvial, and that therefore the contact should be placed another $10 \mathrm{ft}$ lower. Where no microfossil evidence is available, engineering data can provide the necessary control, as in contacts between the latest Pleistocene and Holocene alluvial units and the latest Pleistocene estuarine unit in core 94-5.

Because microfossils were poorly preserved and the cores were discontinuous, samples containing preserved foraminifers were not closely enough spaced to permit us to resolve the question of faults beneath the bay.

\section{Conclusions}

Microfossil and engineering data are both essential to developing a detailed subsurface stratigraphic framework for San Francisco Bay. Microfossils are important in defining the environmental conditions in past estuaries. Both types of information are needed by engineers as they site bridges in the Nation's estuaries or undertake seismic retrofitting of bridges in regions susceptible to earthquake activity, such as San Francisco Bay. If more closely spaced and better preserved samples are available when the sedimentary deposits beneath San Francisco Bay are sampled in the future, the Holocene stratigraphy of the central bay can be further refined.

\section{Acknowledgments}

We thank Reid Buell, John Thorne, Laurel Jensen, and Mark Palmer of Caltrans for providing samples for microfaunal analysis; Bradley Carkin, Jacquelin Letran, May Zhao, and Hai Le for technical assistance; and John Barron and Scott Starratt for their reviews of the manuscript.

\section{References Cited}

Arnal, R.E., Quinterno, P.J., Conomos, T.J., and Gram, Ralph, 1980, Trends in the distribution of Recent foraminifera in San Francisco Bay, in Sliter, W.V., ed., Studies in marine micropaleontology and paleoecology (Bandy volume): Cushman Foundation for Foraminiferal Research Special Publication 18, p. 17-39.

Atwater, B.F., Hedel, C.W., and Helley, E.J., 1977, Late Quaternary depositional history, Holocene sea-level changes, and vertical crustal movement, southern San Francisco Bay, California: U.S. Geological Survey Professional Paper 1014, 15 p.

Buell, Reid, Huyette, C.M., Rogers, Michael, and Thorne, John, 1997, Geologic issues for the proposed new east span of the San Francisco-0akland Bay Bridge: Sacramento, California Department of Transportation, $8 \mathrm{p}$.

Hoover-Young San Francisco Bay Bridge Commission, 1930, San Francisco Bay Bridge: Sacramento, California State Printing Office, $234 \mathrm{p}$.

Laws, R.A., 1988, Diatoms (Bacillariophysceae) from surface sediments in the San Francisco Bay estuary: California Academy of Sciences Proceedings, v. 45, no. 9, p. 133-254. 
Mahood, A.D., Fryxell, G.A., and McMillan, M., 1986, The diatom genus Thalassiosira; species from the San Francisco Bay system: California Academy of Sciences Proceedings, v. 44, no. 8, p. 127-155.

McGann, Mary, and Sloan, Doris, 1999, Benthic foraminifers in the Regional Monitoring Program's San Francisco Estuary samples, in San Francisco Estuary Institute, 1999, 1997 annual report; San Francisco Estuary Regional Monitoring Program for Trace Substances: Richmond, Calif., p. 249-258.

McGann, Mary, and Sloan, Doris, and Cohen, A. N., 2000, Invasion by a Japanese Marine Microorganism in western North America: Hydrobiologia, v. 421, no. 1-3, p. 25-30.
San Francisco Estuary Institute, 1999, 1997 annual report; San Francisco Estuary Regional Monitoring Program for Trace Substances: Richmond, Calif., $276 \mathrm{p}$.

Sloan, Doris, 1992, The Yerba Buena mud, record of the last-interglacial predecessor of San Francisco Bay, California: Geological Society of America Bulletin, v. 104, no. 6, p. 716-727.

Trask, P.D., and Rolston, J.W., 1951, Engineering geology of San Francisco Bay, California: Geological Society of America Bulletin, v. 62 , no. 9, p. 1079-1110.

Wagner, D.B., 1978, Environmental history of central San Francisco Bay with emphasis on foraminifera paleontology and clay mineralogy: Berkeley, University of California, Ph.D. thesis, 274 p. 

TABLES 1, 2 


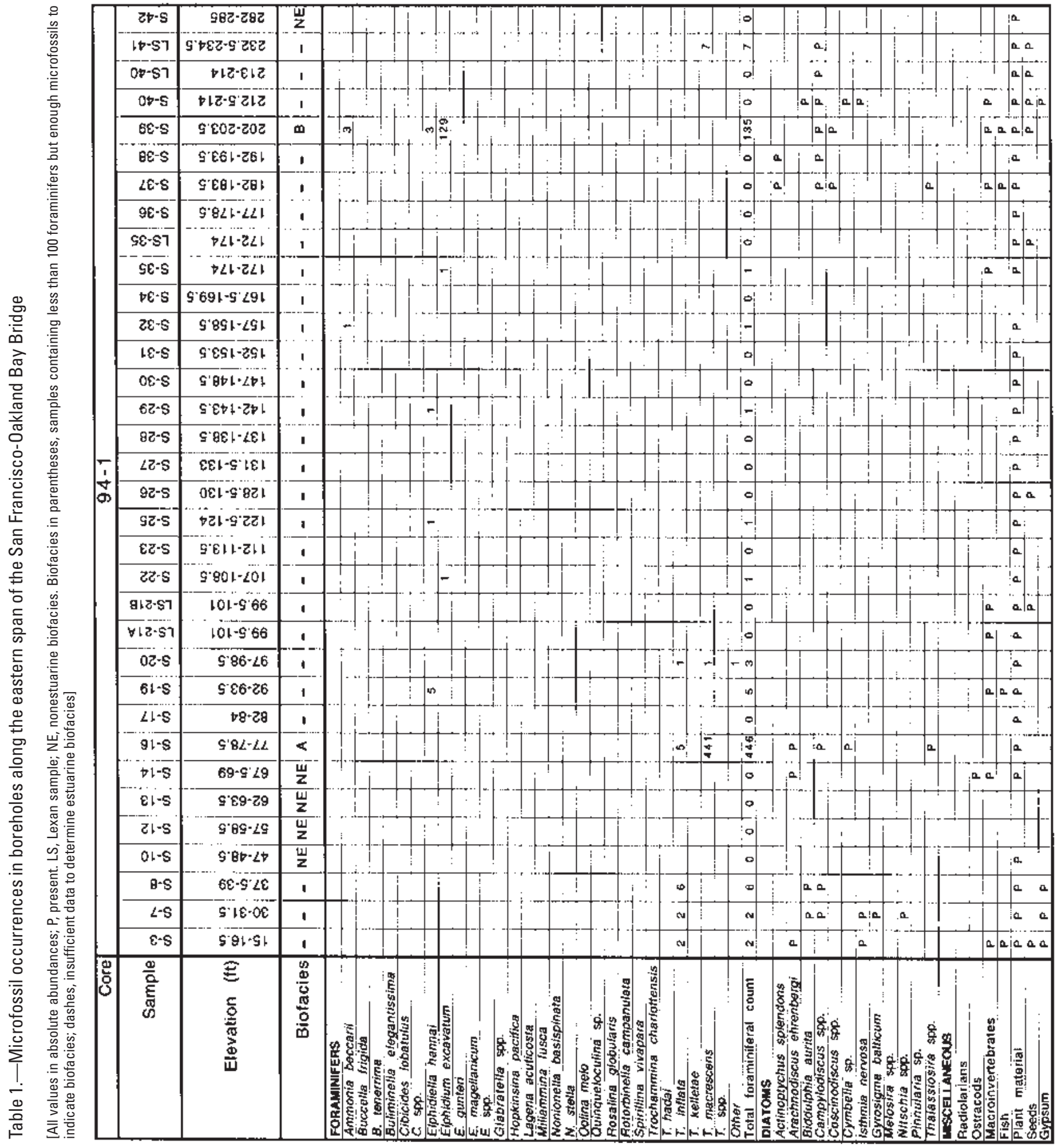




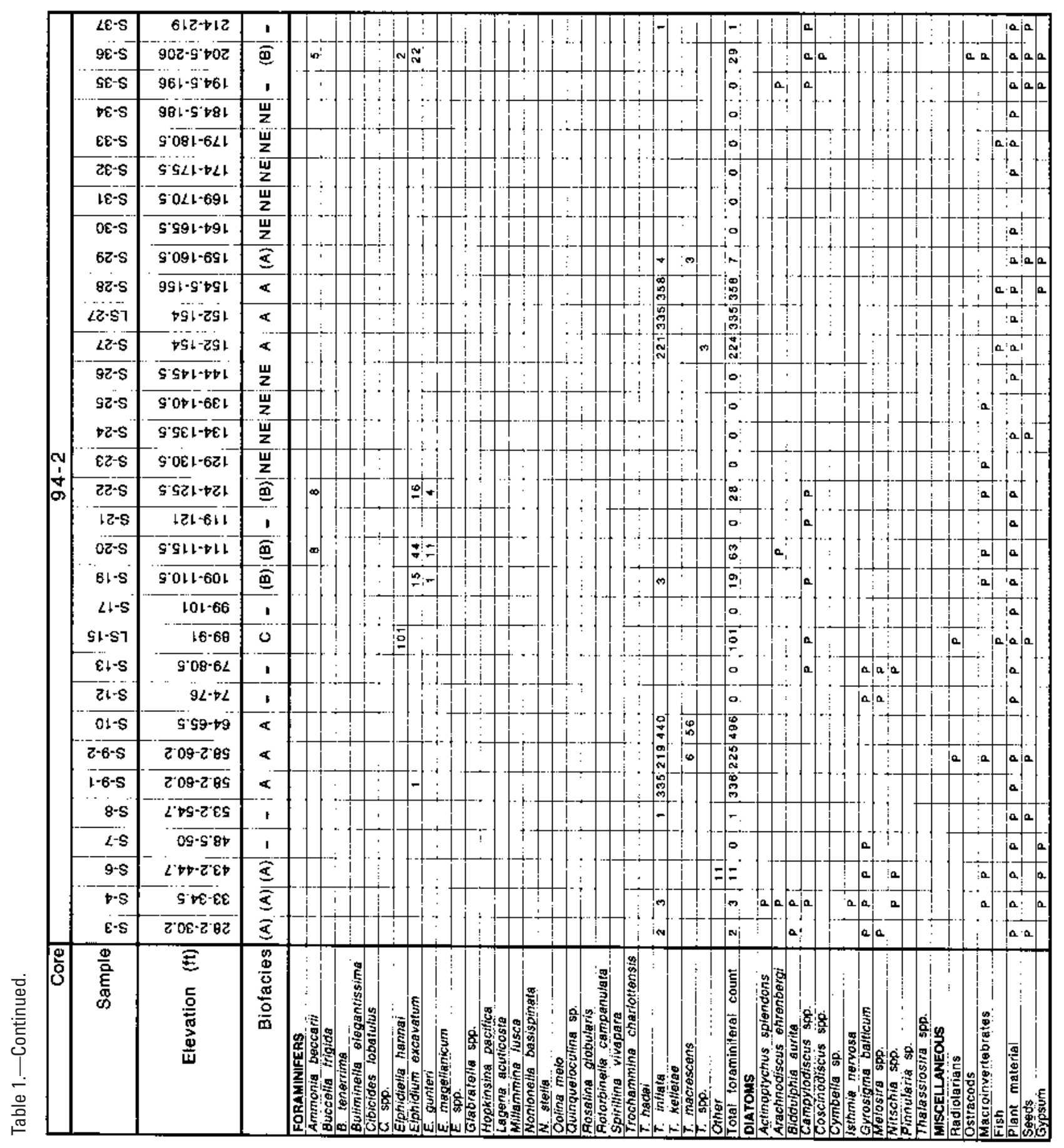




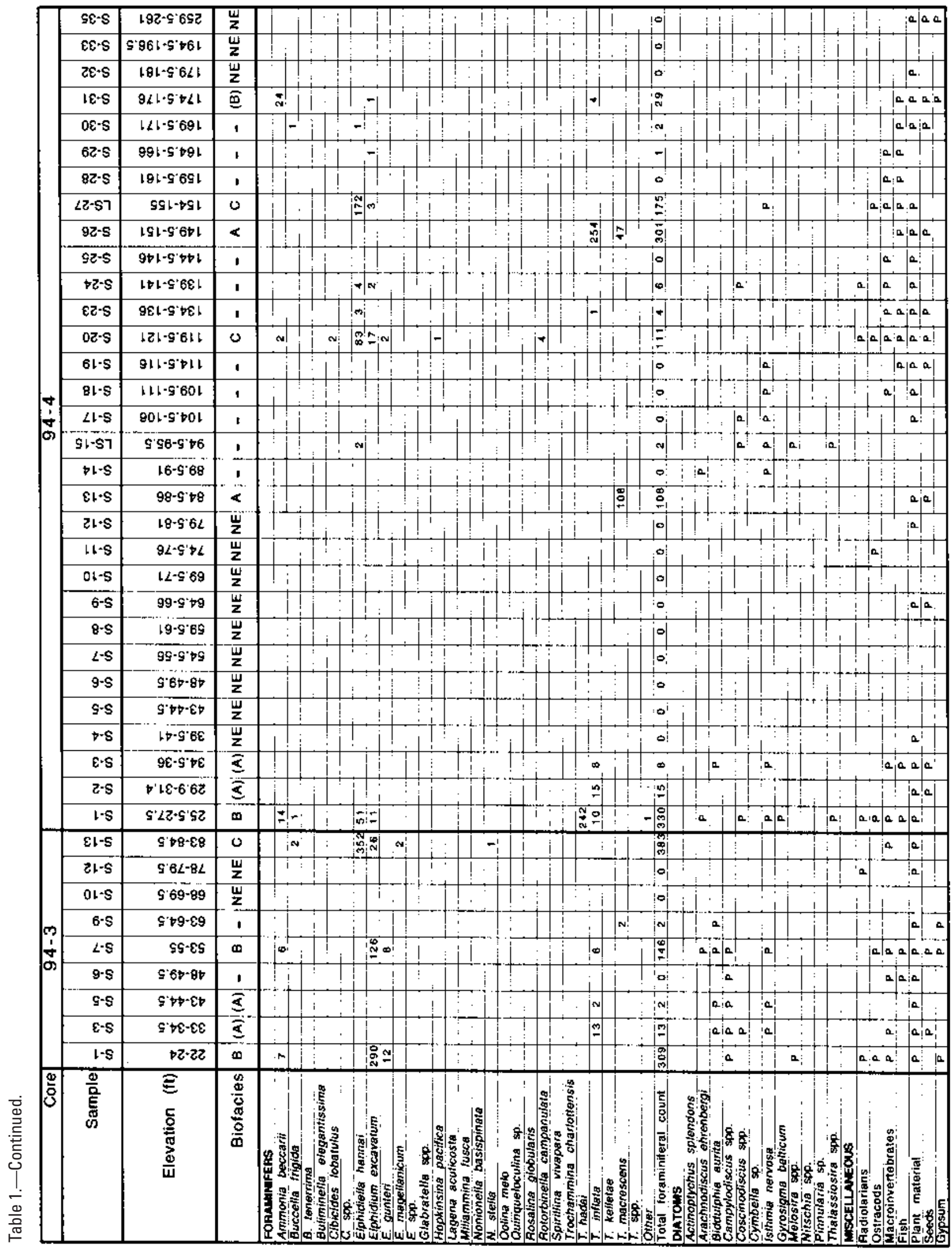




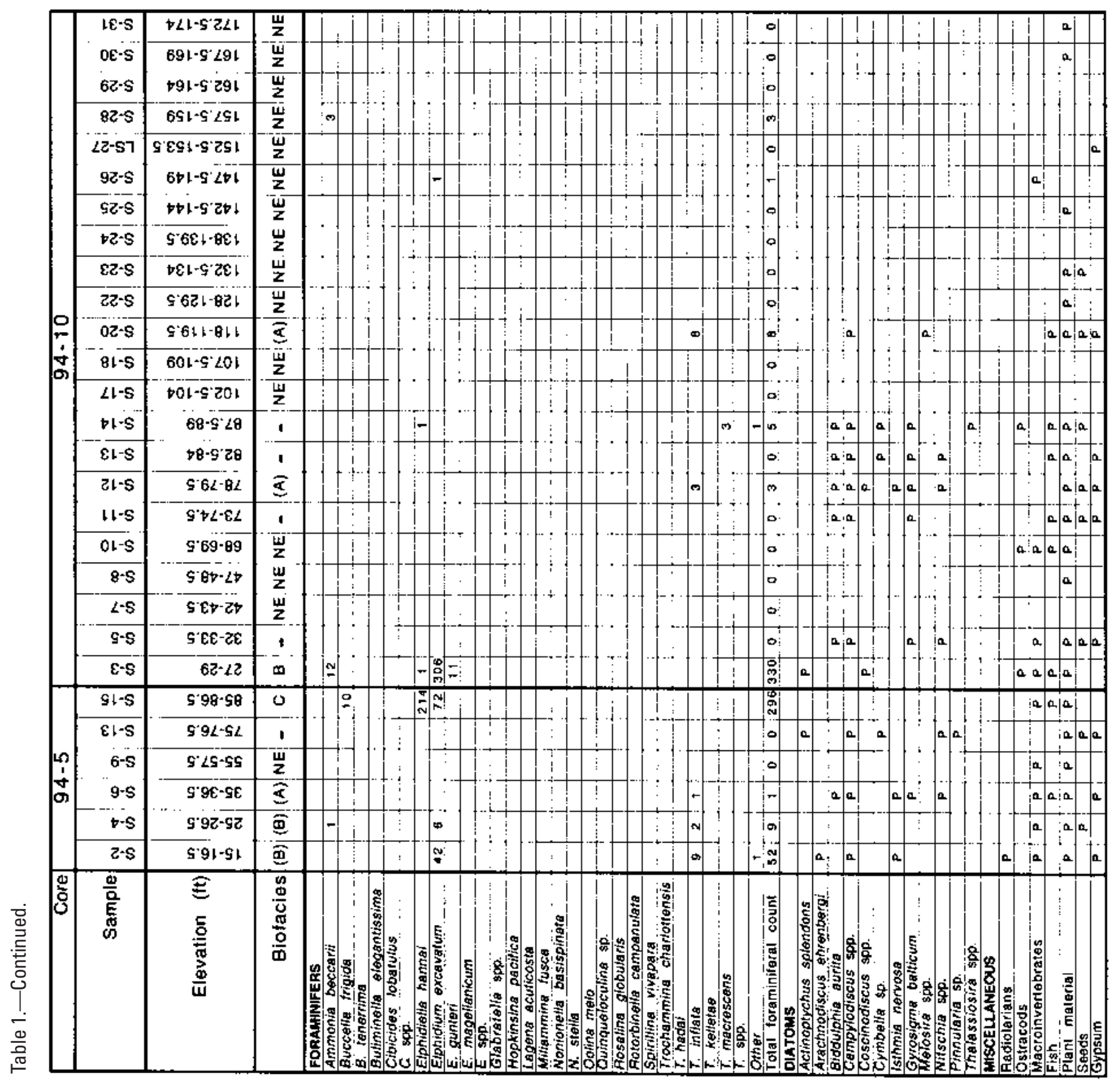




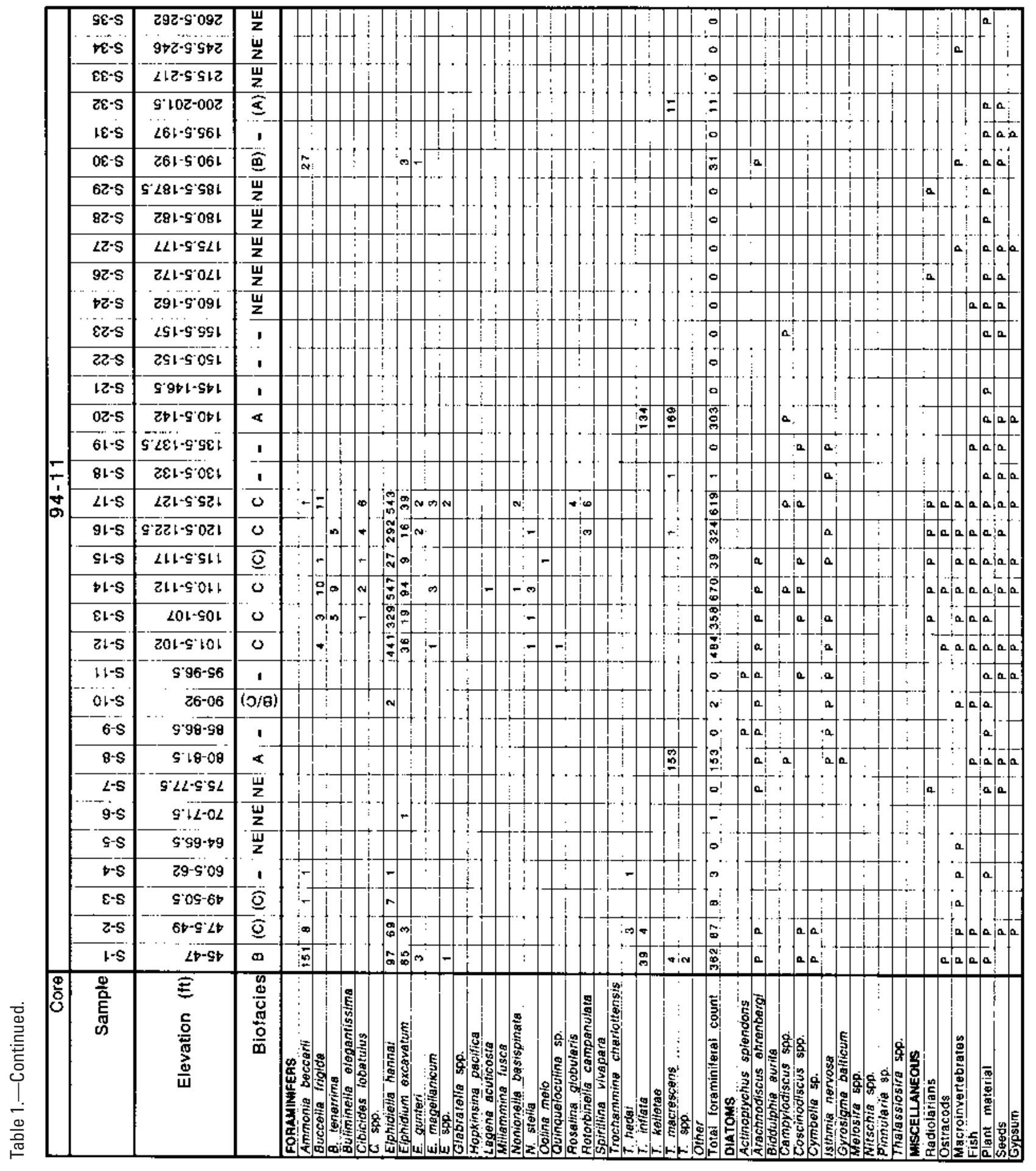




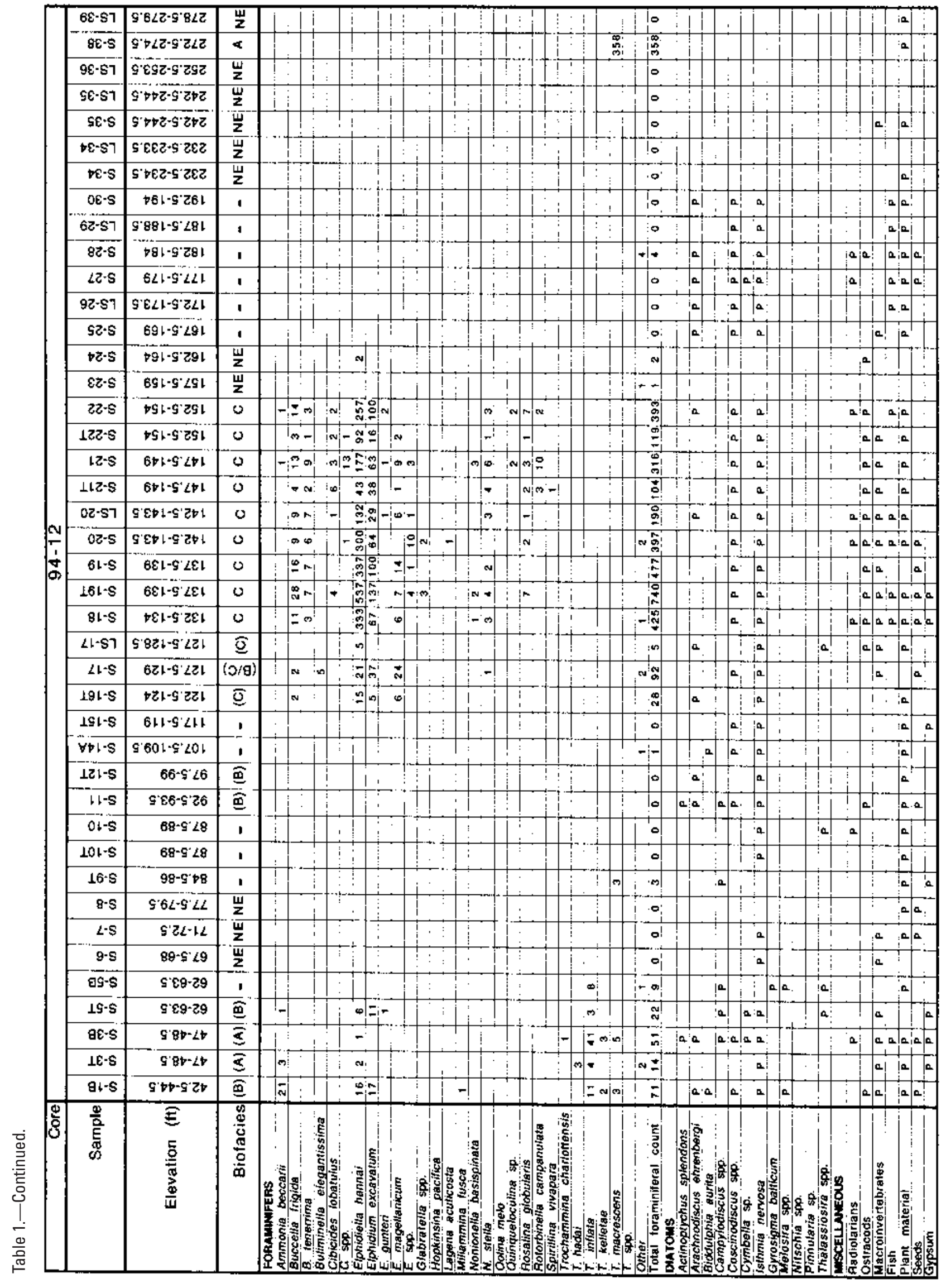

Biostratigraphy Beneath Central San Francisco Bay Along the San Francisco-Oakland Bay Bridge Transect 


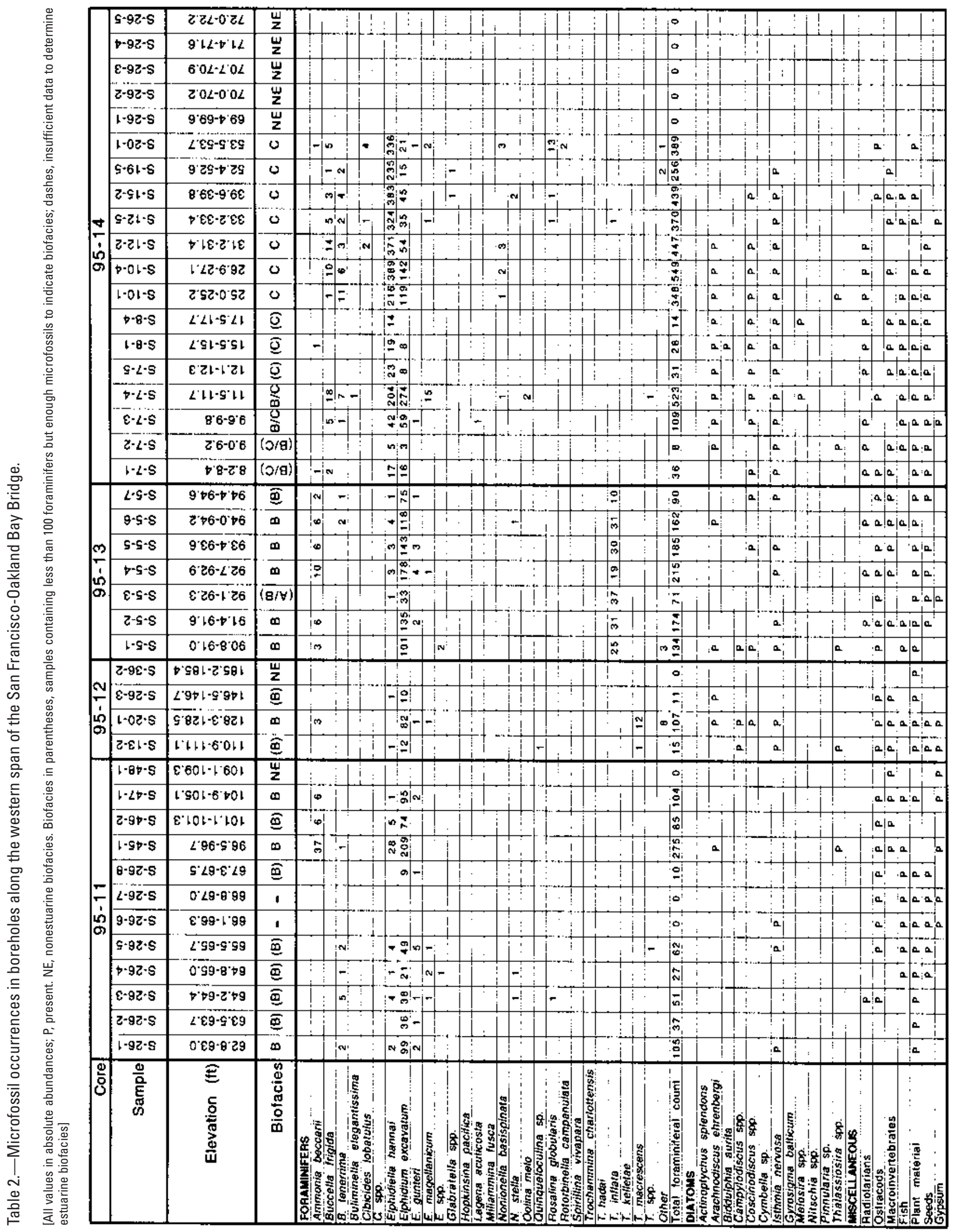




\title{
Examination of the Tsunami Generated by the 1906 San Francisco $\boldsymbol{M}_{w}=7.8$ Earthquake, Using New Interpretations of the Offshore San Andreas Fault
}

\author{
By Eric L. Geist and Mary Lou Zoback
}

\section{CONTENTS}

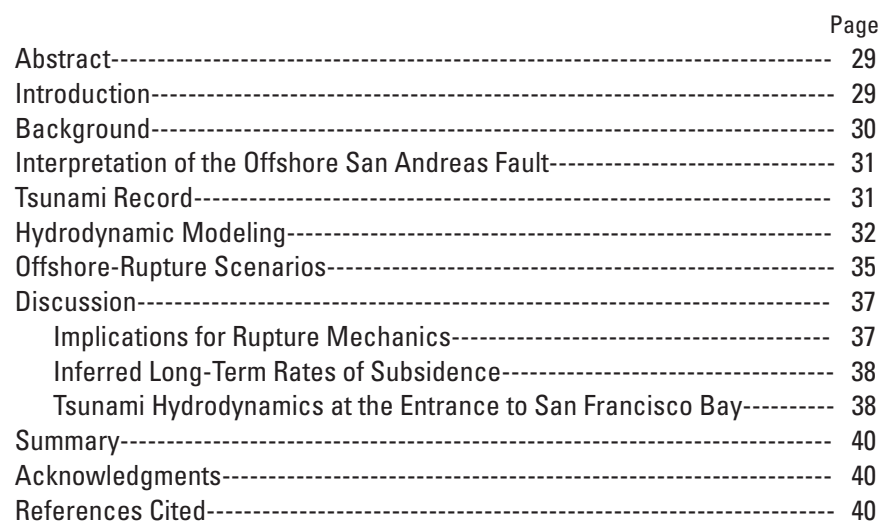

\section{Abstract}

From new interpretations of the geometry of the San Andreas Fault geometry offshore of the Golden Gate, we demonstrate that the tsunami from the great 1906 San Francisco $M_{w}=7.8$ earthquake is best explained by bilateral rupture on discontinuous fault segments starting at an epicentral location near an offshore dilatational stepover north of Lake Merced. To establish this inference, we use elastic dislocation and hydrodynamic models to analyze the tsunami. We compare various scenarios involving different rupture geometries and physical properties with the record of the tsunami at the Presidio tide-gauge station in the northwestern part of San Francisco. A tsunami generated from a continuous rupture on the San Andreas Fault west of the Golden Gate is insufficiently small and has an arrival time earlier than what was observed, whereas a tsunami generated from discontinuous rupture defined by the 3-km dilatational stepover north of Lake Merced and a 1-km compressional stepover south of Bolinas Lagoon better explains the observed arrival time and waveform. It is unclear from our analysis, however, whether the observed peak negative amplitude is better explained by a local change in rake at the dilatational stepover (consistent with analysis of the genetically similar 1995 Kobe, Japan, $M_{w}=6.9$ earthquake) or by large-scale exceedance of the strength of rocks surrounding the fault (modeled by a material that conserves volume during deformation). The apparent epi- central locations for both the 1906 San Francisco and 1995 Kobe, Japan, earthquakes at dilatational stepovers suggest that the initial stress in these regions is conducive to earthquake initiation. With respect to the hydrodynamics of the tsunami, the modeled evolution of the tsunami wavefield propagating from the source region indicates that the oscillations with a dominant period of 40 to 45 minutes observed in the coda of the tsunami record are best explained by the natural resonance of trapped edge waves in the Gulf of the Farallones, rather than by reverberation of the tsunami within San Francisco Bay.

\section{Introduction}

The 1906 San Francisco $M_{w}=7.8$ earthquake is commonly considered a baseline event for defining earthquake hazards in the San Francisco Bay region (fig. 1). Such hazard parameters as peak ground acceleration, accumulated slip, and segmentation all depend on accurate analysis of this event. Although many studies have examined this event, definition of the detailed rupture process is hampered by an absence of nearfield instrumental records. Bolt (1968) and Boore (1977) used the only near-field recording of the earthquake in combination with teleseismic records to constrain the epicentral location of the 1906 earthquake. Wald and others (1993) used recordings of the 1984 Morgan Hill, Calif., $M_{w}=6.2$ earthquake to derive empirical Green's functions for the 1906 earthquake; they were able to resolve an asperity less than $40 \mathrm{~km}$ long in the area between Point Reyes and Fort Ross from teleseismic recordings of the 1906 earthquake. Recently, Thatcher and others (1997) reexamined data from regional and local geodetic networks to infer the slip distribution in places along the fault.

Another type of near-field recording that can aid in the determination of rupture parameters is the tide-gauge record of a tsunami resulting from the 1906 San Francisco earthquake. The 1906 earthquake rupture propagated bilaterally along the offshore section of the San Andreas Fault seaward of the Golden Gate (fig. 1). The only tide gauge in northern California operating at that time was located in San Francisco, only $10 \mathrm{~km}$ from the offshore trace of the San Andreas Fault. In this study, we use this tide-gauge record to constrain the offshore rupture geometry of the 1906 earthquake. The essentials of this study were first presented by Geist and 
Zoback (1999); we present here more detailed information on the modeling technique used, the various source mechanisms examined, and the evolution of the tsunami wavefield in San Francisco Bay and the Gulf of the Farallones.

Because of the small size of the tsunami recorded from the 1906 earthquake, the actual local tsunami hazard in the San Francisco Bay region is low in comparison with the ground-shaking hazard from a similar event. The main contribution of this study is to provide supporting evidence for a 3$\mathrm{km}$ right stepover in the offshore San Andreas Fault, recently discovered by detailed analysis of high-resolution aeromagnetic data (Jachens and Zoback, 1999; Zoback and others, 1999). The effect of a dilatational stepover on rupture dynamics, however, is unclear. Segall and Pollard (1980) showed that the normal stress on the fault decreases for a dilatational step, facilitating sliding, but may also provide a relaxation barrier to rupture, as described by Das and Aki (1977). Evidence from the 1995 Kobe, Japan, earthquake (Wald, 1996) and the 1906 San Francisco earthquake (Zoback and others,
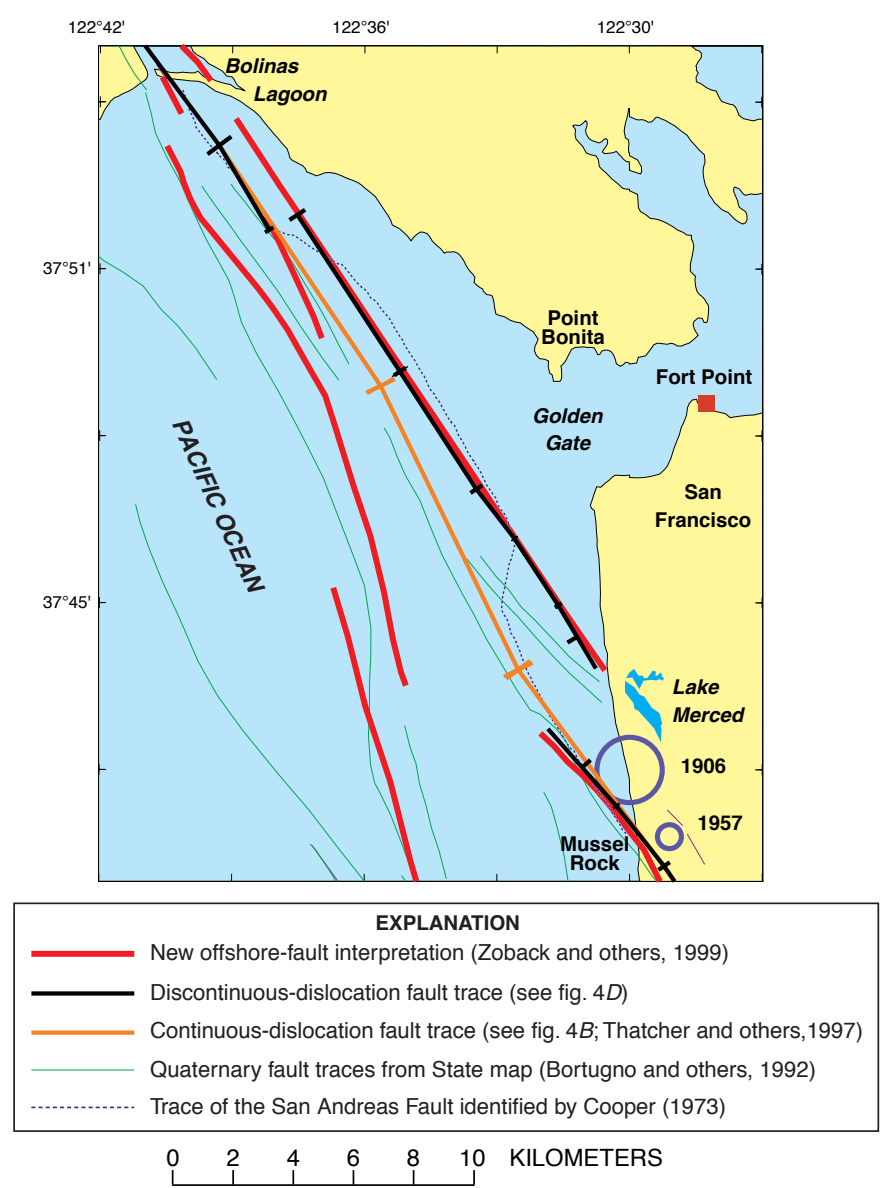

Figure 1.-San Francisco Bay region, showing possible fault geometries on the Golden Gate platform. Inferred offshore fault structure is determined from gradient analysis of new high-resolution aeromagnetic data (Jachens and Zoback, 1999; Zoback and others, 1999). Hachures, boundaries of individual fault segments used in dislocation modeling; circles, epicenters of $1906 M_{w}=7.8$ (Bolt, 1968) and $1957 M=5.3$ probable normal-faulting earthquakes (Marsden and others, 1995).
1999) also suggests that earthquakes may preferentially initiate at dilatational steps. An accurate definition of the rupture geometry near the epicenter of the 1906 earthquake is needed to better understand the rupture dynamics of the San Andreas Fault in the San Francisco Bay region.

\section{Background}

The 1906 San Francisco earthquake, which occurred at 5:12 a.m. P.s.t. on April 18, 1906, was recorded by 96 seismic stations around the world but by only one local seismic station, located at the Lick Observatory on Mount Hamilton (Lawson, 1908). In the months after the earthquake, a comprehensive report was published by Andrew Cowper Lawson describing not only seismic observations but also geologic effects and various circumstantial measurements, including the tidal anomaly recorded at the Presidio tide-gauge station. A review of tidal observations for the 9 years preceding the earthquake showed that for at least the period 1903-6, no change occurred in the sea-level datum at the Presidio. Without the aid of the numerical hydrodynamic models at our disposal today, Lawson was able only to conjecture as to the origin of the recorded tsunami. On the basis of its traveltime, Lawson suggested that the tsunami arose from sea-floor subsidence west of the fault trace, interpolated to the offshore region. Although this suggestion seemed to contradict onland observations of permanent ground movement associated with the earthquake, it was supported at the time by Harry Fielding Reid (who later would develop the theory of elastic rebound; see Reid, 1910) in a note to Lawson:

If a depression occurred on the western side of the faultline, extending for some distance to the westward, it would start a wave of depression towards the Golden Gate which would take 9 minutes to reach Fort Point, and this is just about the time recorded by the gage. The time necessary for the recovery to normal level would depend upon the extent of the area depressed. If this were a narrow block, a wave of elevation would follow quickly upon the wave of depression, and we should have a rapid elevation of the tide-gage above its normal position. As no such wave appeared and recovery was very gradual, we must suppose that the deprest area extends for some distance to the westward, so that the recovery was slow. This is the only explanation so far offered that would produce the effects observed.

Today, we have much better insight as to the tectonic setting of the San Francisco Bay region, as well as to the dynamics of the 1906 earthquake. As we show in this chapter, however, we are still struggling to explain, as was Reid, the unusual tsunami record at the Presidio tide-gauge station.

Previous analysis of this tsunami by Ma and others (1991) focused on determining the pattern of sea-floor deformation from a linear inversion of the tide-gauge record. The resolved pattern of uplift and subsidence is complex but largely reflects subsidence west of the fault, as originally suggested by Lawson (1908). Ma and others (1991) concluded that the subsidence resulted from the overall dilatational fault 
geometry and that a large component of dip slip for the earthquake was not needed to explain the tsunami record.

Since the study by Ma and others (1991), Zoback and others (1999) reinterpreted the seismotectonics of the San Andreas Fault in the San Francisco Bay region. They used high-resolution aeromagnetic and multichannel seismicreflection data, in combination with relocated seismicity and focal-mechanism determinations, to detail the offshore fault geometry of the Golden Gate platform (fig. 1). The newly defined offshore trace of the San Andreas Fault includes a 3-km right (dilatational) step directly northwest of Lake Merced and a smaller, 1-km left (compressional) step near Bolinas Lagoon (fig. 1). Interestingly, the interpreted fault traces are closely aligned with the "recent trace" of the San Andreas Fault identified by Cooper (1973), using older, single-channel seismic-reflection data. Also, the location of the dilatational step northwest of Lake Merced approximately coincides with the epicenter of the 1906 earthquake as determined by Bolt (1968).

In this chapter, we use the offshore fault geometry as newly defined by Zoback and others (1999) and the slip of the event as estimated by Thatcher and others (1997) to construct a forward model for the tsunami. We examine different rupture scenarios in which the stepover geometry and rake of the slip vector vary, and we compare the results with the Presidio tidegauge record. We also investigate whether sources other than rupture on the San Andreas Fault, such as a triggered normalfault earthquake or a coseismically triggered failure of nearby coastal cliffs, could explain the observed tsunami.

In addition to constraining the rupture process of the 1906 earthquake, this tsunami model also helps us better understand the wave dynamics in the offshore region and in San Francisco Bay from a locally generated tsunami. Several sea-level oscillations following the initial wave with an apparent period of 40 to 45 minutes were observed on the Presidio tide-gauge record. Lawson (1908) ascribed this phenomenon to reverberation of the tsunami in San Francisco Bay, between Berkeley and Fort Point (fig. 1). With a calibrated tsunami model, we can better understand the origin of these oscillations and the overall evolution of the tsunami.

\section{Interpretation of the Offshore San Andreas Fault}

In the southern part of the San Francisco peninsula, the San Andreas Fault makes a broad $\left(\sim 10^{\circ}-11^{\circ}\right)$ left (restraining) bend and is situated in a valley following the crest of the late Pliocene through Quaternary Coast Ranges (for example, Bürgmann and others, 1994). Less than $70 \mathrm{~km}$ to the northwest, the San Andreas Fault trace is below sea level. Projection of the onshore traces northwest of Lake Merced and southeast of Bolinas Lagoon suggests a 2- to 3-km right step or bend offshore on the Golden Gate platform (fig. 1). Linear pseudogravity maximum gradients inferred from the shortest wavelengths in a new high-resolution aeromagnetic survey reveal in detail a right-stepping geometry for both the
San Andreas and subparallel San Gregorio Fault zones on the Golden Gate platform (Jachens and Zoback, 1999; Zoback and others, 1999).

In this study, we have incorporated an $\sim 3-\mathrm{km}$ right step in the San Andreas Fault just offshore from Lake Merced (fig. 1), following Jachens and Zoback (1999) and Zoback and others (1999). The position of this inferred right step (fig. 1) is consistent with the interpretation of the "recent trace" of the San Andreas Fault from single-channel highresolution seismic-reflection profiles by Cooper (1973). The newly defined easternmost strand of the San Andreas Fault extends northwestward to the east side of Bolinas Lagoon (fig. 1), whereas the 1906 earthquake rupture lies along the west side of Bolinas Lagoon, implying an additional small ( 1 km) left step offshore. Cooper also identified such a left step in his interpretation of the San Andreas Fault just north of lat $37^{\circ} 51^{\prime}$ N. (fig. 1), where the San Andreas Fault trace mapped by him coincides with the fault segment inferred from aeromagnetic analysis that connects with the surface trace of the 1906 earthquake rupture on the west side of Bolinas Lagoon. Thus, the available offshore data suggest an $\sim 3-\mathrm{km}$ extensional right step and a smaller $(\sim 1 \mathrm{~km})$ compressional left step in the San Andreas Fault on the Golden Gate platform (fig. 1). Bolt's (1968) teleseismic location for the 1906 earthquake is close to the right stepover (fig. 1). Zoback and others (1999) have suggested that the bilateral 1906 earthquake rupture may have initiated in the right stepover region of the San Andreas Fault, on the basis of similarities to the bilateral 1995 Kobe, Japan, earthquake rupture, which also initiated at a similar right step in a right-lateral fault (Wald, 1996). Segall and Pollard (1980) demonstrated that normal traction along a right-lateral fault decreases at a right-stepping discontinuity, facilitating sliding.

\section{Tsunami Record}

The tsunami from the 1906 San Francisco earthquake was recorded at the U.S. Coast and Geodetic Survey's Presidio tide-gauge station, which has been in operation since July 15,1897 . In the early 1900 s, the station was located at the Presidio Wharf at the east end of the Presidio Military Reservation, approximately $1.5 \mathrm{~km}$ east of the tide-gauge station currently operated by the National Oceanic and Atmospheric Administration near Fort Point (fig. 1; Disney and Overshiner, 1925). A detailed description of the standard automatically recording tide gauge was given by Bowditch (1966).

The first arrival of the tsunami from the 1906 earthquake was recorded as a $10-\mathrm{cm}$ lowering of sea level for a period of $\sim 16$ minutes (fig. 2A). Lowering of sea level commenced approximately 7.5 minutes after the earthquake, although absolute timing is uncertain, as described below. Unlike on most tide-gauge recordings of tsunamis (fig. $2 B$ ), no positive deflection of sea level followed the initial solitary depression. A series of two to three oscillations with an apparent period of 40 to 45 minutes and a maximum amplitude of $5 \mathrm{~cm}$ were recorded approximately a half-hour after the initial solitary depression (fig. 2A). Likewise, distant tsunamis recorded at 
this tide-gauge station are characterized by a solitary wave (commonly bipolar, however) followed by an oscillatory coda, as exemplified by the recording of the tsunami from the 1960 Chile $M_{w}=9.6$ earthquake (fig. $2 B$; Lander and others, 1993). During the time of the 1906 earthquake, ambient shortperiod wave energy due to meteorologic effects is apparent in the tide-gauge record for 2 days before the earthquake, slowly diminishing but continuing while the tsunami was recorded (fig. 2A; Disney and Overshiner, 1925).

The tide-gauge record was digitized at a sampling rate of $7 \mathrm{~s}$, corrected to remove the tidal signal, and then analyzed. The tidal signal was removed from the digitized tide-gauge record by calculating tidal harmonic constants for the observation site (Foreman, 1993). Absolute timing of the tidegauge record is uncertain for the following reasons. (1) In comparison with the astronomical clocks stopped by the earthquake, the running clock of the tide gauge was probably too slow, whereby the earthquake was indicated by blurring of the tide-gauge pencil mark (Lawson, 1908). (2) The timing marks on the record are generally ambiguous as to where they cross the sea-level curve. The time interval between the blurring mark and the initial lowering of sea level appears to be 7.5 minutes, although Lawson indicated that the time interval was 9 to 10 minutes. (The direct $P$-wave traveltime would be $\sim 3 \mathrm{~s}$, with a direct $S$-wave arriving $\sim 2 \mathrm{~s}$ later, assuming average $P$ - and $S$ - wave velocities of 5.7 and $3.3 \mathrm{~km} / \mathrm{s}$, respectively; Holbrook and others, 1996.)

We calculated the power spectrum of the tide-gauge record at three different 2-hour time windows to determine the dominant periods of the tsunami (fig. 3). Rabinovich (1997) explained that the nearshore wave spectrum of a tsunami can be separated into components dependent on the source parameters of the earthquake and the natural resonant periods of the nearshore bathymetry. The first time window, 3: 00-5:00 a.m. P.s.t., shows the spectrum for the 2 hours before the tsunami. The short-period-wave energy is mainly within two frequency ranges: 11-13 cycles per hour and 20-24 cycles per hour. Disney and Overshiner (1925) attributed this wave energy to a wind-generated imperfect oscillation across the Golden Gate (fig. 1). In the second time window, 5:00-7: 00 a.m., the tsunami energy is apparent in the frequency range 2-4 cycles per hour and is largely dictated by the source parameters of the earthquake. Interestingly, wave energy at 11 to 13 cycles per hour is subdued during the 2 hours after the earthquake. The wind-generated oscillation across the Golden Gate may have been interrupted by the passage of the tsunami and then gradually resumed (presumably, the wind forcing continued over this time). Conceivably, the seismic compressive waves propagating through the water column may have disrupted the self-organization of the surface waves, in much the same way (though on a smaller scale) that vortex rings produced by raindrops disrupt surface waves (Poon and others, 1992; Tsimplis, 1992). We cannot exclude the possibility, however, that the response of the tide gauge was somehow temporarily affected by the ground shaking. In the third time window, 7:00-9:00 a.m., the wave energy at 11 to 13 cycles per hour is again apparent, as is lower-frequency energy from oscillations excited by the tsunami, owing to resonant periods of the bathymetry within the Gulf of the Farallones (see Eva and Rabinovich, 1997).

Tide gauges are designed to record energy that occurs at tidal periods (diurnal and semidiurnal) and to attenuate shorter-period wave energy. Tsunamis typically occupy a gap in the wave spectrum between tidal periods and the short periods of wind-generated waves. Although tsunami periods are shorter than tidal periods, they are not as greatly attenuated as wind-generated waves. Several workers have examined the response of tide gauges to tsunamis (Cross, 1968; Loomis, 1983; Satake and others, 1988). The response of most tide gauges installed by the U.S. Coast and Geodetic Survey is distinctly different from that of the tide gauges used in Japan (Satake and others, 1988). For U.S. tide gauges, the outflow is faster than the inflow, whereas for Japanese gauges, the opposite is the case. The response of tide gauges is nonlinear and frequency dependent. For tsunami waves of small amplitude $(<1.5 \mathrm{~m})$ and long period (>12 minutes), such as the tsunami from the 1906 San Francisco earthquake, there is little attenuation in amplitude and little lag in the response of the tide gauge relative to the actual wave (Cross, 1968; Loomis, 1983).

\section{Hydrodynamic Modeling}

During an earthquake, coseismic vertical displacement of the sea floor creates a gravitational instability in the water column that generates a tsunami. Because of the large wavelength of the coseismic displacement field, the length of the initial tsunami wave is nearly identical to the displacement at the sea floor. Only when the wavelength of displacement is less than about 3 times the water depth, or in regions of very steep bathymetry, do special modifications need to be made in approximating the initial tsunami wavefield to the vertical coseismic displacement. During propagation, the gravitational potential energy is transferred to kinetic energy, such that the wave travels at a long-wave phase velocity $c$, of $c=\sqrt{g h}$, where $g$ is the gravitational acceleration (in meters per second squared) and $h$ is the water depth (in meters). The large wavelength of tsunamis also permits us to use the following shallow-water-wave equations to describe the evolution of the tsunami during propagation and, eventually, to reconstitute the wave recorded at the tide gauge station:

$$
\frac{\partial(\eta+h)}{\partial}+\nabla \cdot[v(\eta+h)]=0 \quad \text { (continuity equation) }
$$

and

$$
\frac{D v}{D t}+g \nabla \eta+\gamma v=0 \quad \text { (momentum equation) }
$$

where $\eta$ is the water-surface elevation, $v$ is the depth-averaged horizontal-velocity field, and $\gamma$ is the bottom-friction coefficient. The substantial derivative is given by

$$
\frac{D v}{D t}=\frac{\partial}{\partial t}+(v \cdot \nabla)
$$


To model the tsunami from the 1906 San Francisco earthquake, we modify the TRIM (tidal, residual, intertidal mudflat) shallow-water-circulation model of Casulli (1990) and Cheng and others (1993) that has been extensively used to study tidal and residual circulation in San Francisco Bay. Several recent examples have shown how sophisticated estuarinecirculation models can be used for regional tsunami studies (Peraire and others, 1986; Greenberg and others, 1993; Myers and Baptista, 1995; Tinti and Piatanesi, 1996).

The TRIM model is based on a semi-implicit, finitedifference numerical approximation of the nonlinear shallow-water-wave equations. Hydrostatic pressure is assumed, and so dispersive effects, which are commonly observed for far-traveled tsunamis, are unaccounted for. Unlike many fully explicit finite-difference techniques used to model tsunami propagation, the TRIM model uses a semi-implicit technique to achieve unconditional stability, and so does not need to satisfy the Courant-Friederichs-Lewy (CFL) stability condition. The TRIM model also avoids spurious numerical effects at channel constrictions that are present with alternatingdirection implicit (ADI) methods. The velocity-divergence term in the continuity equation and the water-surface-gradient term in the momentum equations are finite-differenced explicitly, whereas the remaining terms are finite-differenced implicitly (Casulli, 1990; Cheng and others, 1993). In addition, a Eulerian-Lagrangian method is used to calculate
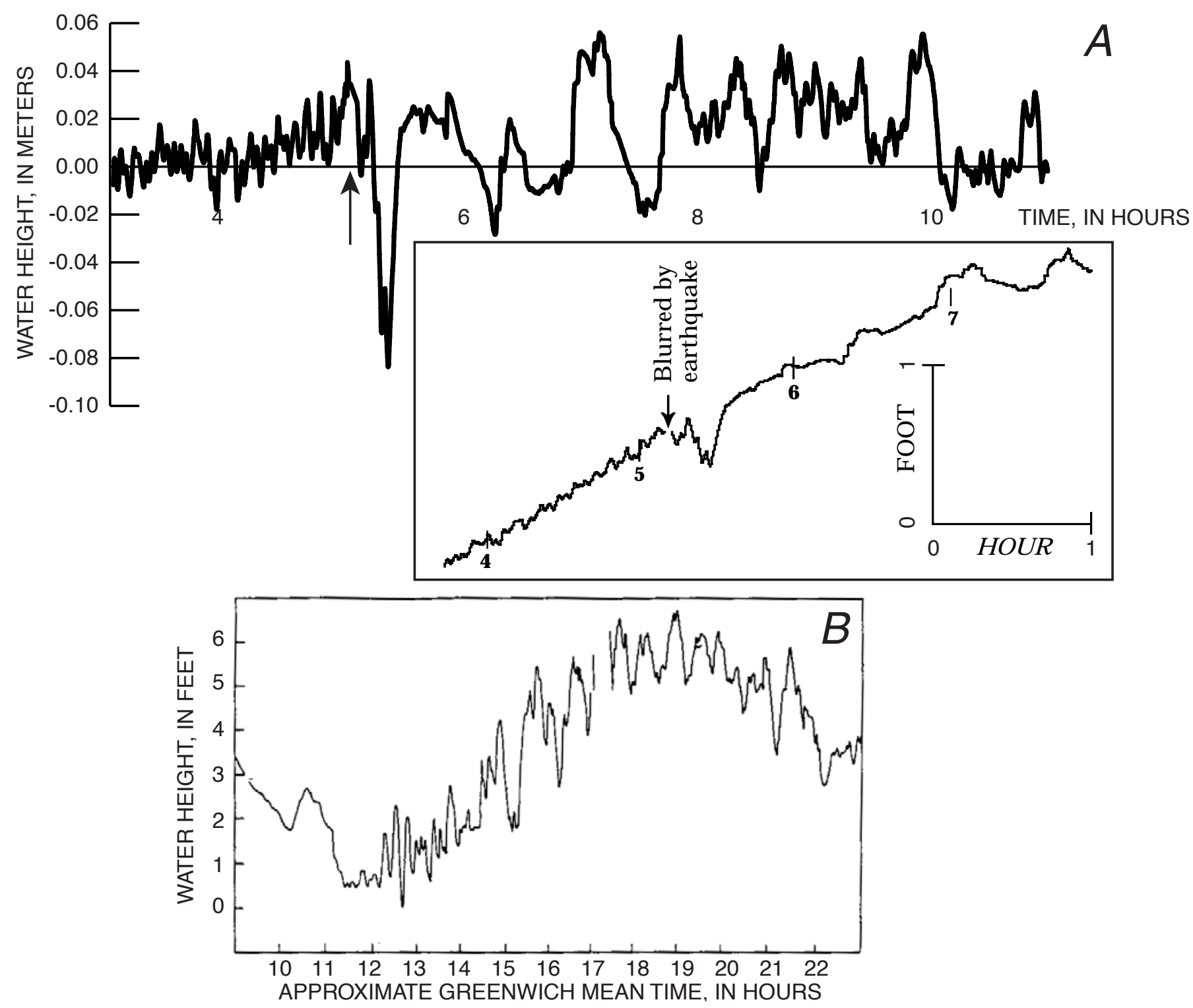

Figure 2.-Tsunami records. A, Tsunami from 1906 San Francisco earthquake recorded at the Presidio tide-gauge station, with tidal signal removed. Arrow denotes approximate origin time of earthquake. Inset shows original, uncorrected record from Lawson (1908). $B$, Tsunami from April 22, 1960, $M_{w}=9.6$ earthquake recorded at the Presidio tide-gauge station (uncorrected). Note difference in waveform of source signal (first arrival), followed by natural resonance excited by tsunami. 
the convective terms. The bilinear interpolation used in the Eulerian-Lagrangian method gives rise to artificial diffusion, which may be a concern for tsunami-propagation applications (P.L.-F. Liu, oral commun., 1998). Cheng and others demonstrated that the artificial diffusion is functionally dependent on the grid size and that for the fine-grid scales used in many regional estuary studies $(\sim 250 \mathrm{~m})$, this artifact is not a significant problem.
To use the TRIM model for tsunami propagation, boundary and initial conditions need to be modified. Because the data for comparison is the residual tide-gauge record with the tidal component removed, tidal forcing along the open boundaries of the model is replaced with passive, radiation boundary conditions (Reid and Bodine, 1968). Assuming incompressibility in the water column, initial conditions are specified by the vertical coseismic displacement field

Hour 3:00-5:00
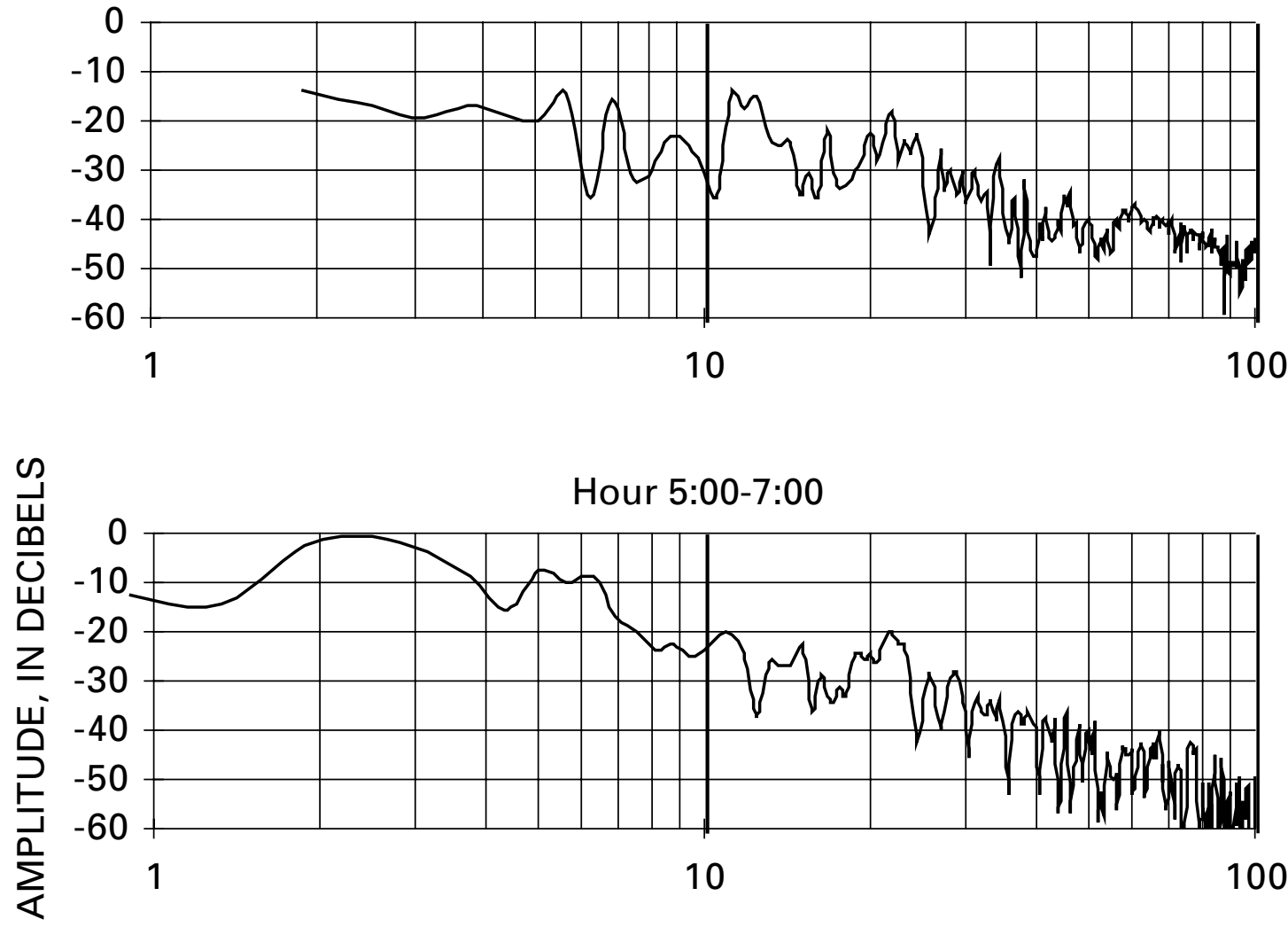

Hour 7:00-9:00

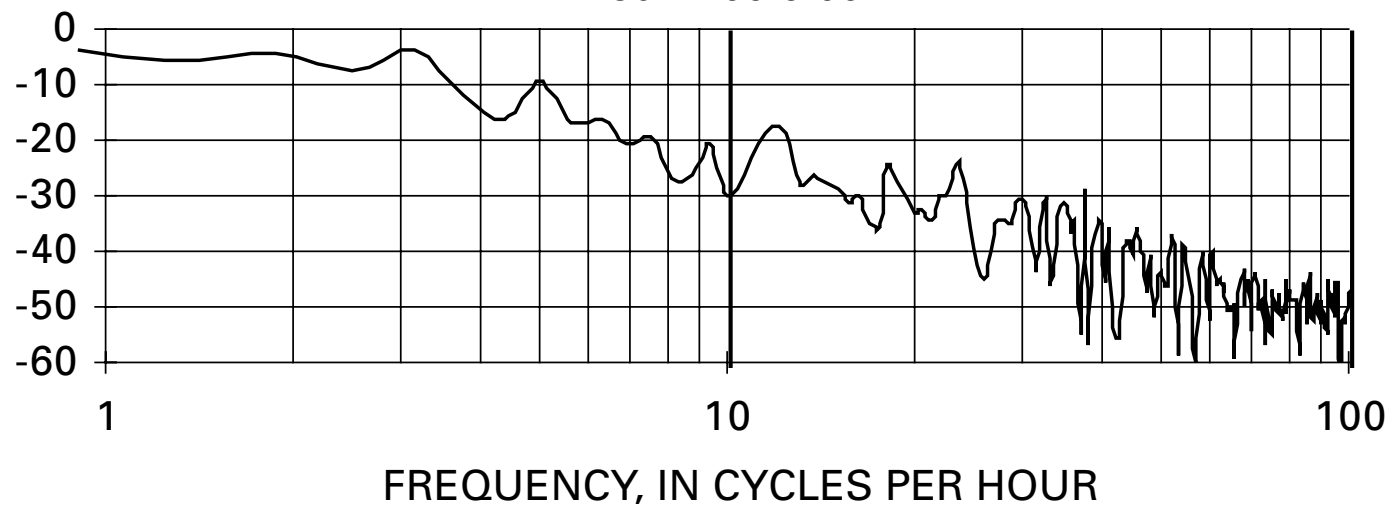

Figure 3.- Spectral analysis of 1906 tide-gauge record for three 2-hour time windows: immediately before (top), during (middle), and after (bottom) passage of initial tsunami. Spectral analysis was performed on residual (tidal component removed) record, using a 1,024-point fast Fourier transform. 
calculated from elastic-dislocation theory (Okada, 1992), using different source parameters for the 1906 San Francisco earthquake, as described in the next section. The water-depthdependent bottom-friction coefficients are the same as those described by Cheng and others (1993). Baroclinic forcing is not considered in this application of the TRIM model, and so initial conditions for salinity do not need to be specified. Similarly, a turbulent-closure scheme used in the model of Cheng and others is not used in this study, although Sato (1996) incorporated a similar scheme to model the effects of wave breaking for much larger tsunamis. One particular advantage of the TRIM model is that the emergence and flooding of shallow and low-lying areas are properly accounted for (Cheng and others, 1993).

Because the source region for the tsunami is along the Golden Gate platform (fig. 1), offshore bathymetry was appended to the bathymetric-data base for San Francisco Bay in the study by Cheng and others (1993). The bathymetry for San Francisco Bay was merged with a gridded offshore bathymetric-data base digitized from hand-contoured maps of U.S. Geological Survey soundings from several cruises in the region. The grid spacing used to model the tsunami from the 1906 San Francisco earthquake was $250 \mathrm{~m}$, corresponding to the gridded bathymetry available for San Francisco Bay most recently used by McDonald and Cheng (1997). A 35-s time interval was used to model the evolution of the tsunami, which is much less than the 9-minute time interval used to model tidal circulation. Because the TRIM model uses the semi-implicit numerical scheme described above, the time interval is not required to satisfy the CFL stability condition ( $\Delta t \quad 5.6 \mathrm{~s}$ ) that applies to fully explicit finite-difference methods.

To estimate how much the results depend on the particular hydrodynamic model used, we compare the synthetic marigram calculated by Ma and others (1991) with that calculated by using the TRIM model (fig. 4A). We use the offshore vertical displacement determined by Ma and others (1991) as initial conditions for the TRIM model. Although the published figure showing the marigram comparison is very small (Ma and others, 1991, fig. 1b), we seem to have approximately reproduced the results of Ma and others (1991) by using the TRIM model. The only difference is that the oscillations after the initial negative pulse may be slightly larger with the TRIM model than with the linear long-wave model of Ma and others.

\section{Offshore-Rupture Scenarios}

We compared modeled tsunami time series at the Presidio tide-gauge station generated by different offshore-rupture scenarios with the observed record. Rather than constructing an inverse model to determine the source parameters for the tsunami, as did Ma and others (1991), we constructed forward models of the tsunami from geodetic analysis (Thatcher and others 1997), geophysical imaging, and coastal ground-failure observations soon after the earthquake (Lawson, 1908).
The first and most likely set of offshore-rupture scenarios are those in which the tsunami is generated solely by slip along either continuous or discontinuous strands of the San Andreas Fault, as interpreted by Jachens and Zoback (1999) and Zoback and others (1999). The second set of offshore rupture scenarios involve slip on nearby faults in addition to the San Andreas Fault. In addition to tsunamis generated by coseismic deformation, we consider a third set of scenarios in which the tsunami is generated by local cliff failures. The predicted and observed tsunami marigrams for each scenario are compared in figures 4 through 7.

For the first set of offshore-rupture scenarios, we use coseismic slip values for the 1906 earthquake rupture interpolated in the offshore region between the Tomales Bay and Colma local geodetic networks by Thatcher and others (1997). Our first objective is to determine whether we can use the tide-gauge record to discriminate between continuous and discontinuous rupture on offshore strands of the San Andreas Fault in generating the tsunami. First, we calculate the tsunami derived from rupture on a continuous strand of the San Andreas Fault. The fault trace is identical to that used by Thatcher and others (1997) in their geodetic analysis. The dominant source region (that is, the region with the largest static vertical displacement) extends over a broad area near the fault bend, directly across from the Golden Gate (fig. 1). Thus, the amplitude of the first arrival from the computed tsunami is smaller and arrives earlier than what was observed (fig. 4B).

We also tested three discontinuous-rupture scenarios to explain the observed tsunamis, using surface traces of the San Andreas Fault as interpreted by Jachens and Zoback (1999) and Zoback and others (1999). Because the available seismograms for the 1906 San Francisco earthquake do not permit a detailed analysis of local changes in source parameters, we use a genetically similar event as a proxy for the 1906 rupture. The fault geometry for the 1906 earthquake is patterned after the source geometry of the 1995 Kobe, Japan, $M_{w}=6.9$ earthquake from the detailed analysis by Wald (1996) and Spudich and others (1998). In the 3-km right-stepover region offshore of Lake Merced (fig. 1), the overlapping strands were specified as dipping $83^{\circ}$ toward each other, such that the fault segments intersect at a presumed hypocentral depth of $10 \mathrm{~km}$ for the 1906 earthquake. This is one possible model of how rupture can be facilitated through a stepover region. However, because we cannot invert the tsunami or seismicwaveform data to determine the detailed fault geometry in the stepover region, the antithetic fault structure fashioned after the 1995 Kobe, Japan, earthquake may not uniquely explain the 1906 tsunami record. For this stepover fault geometry, the initial tsunami amplitude is considerably greater (fig. $4 C$ ) than for the tsunami modeled by using a continuous fault trace (fig. $4 B$ ). The resulting tsunami record more closely matches the predicted first-arrival time (fig. $4 C$ ) than does the synthetic record derived from continuous rupture on the San Andreas Fault (fig. 4B). Nonvertical fault dips in the stepover region result in a greater amount of subsidence, and so the predicted peak negative amplitude in figure $4 C$ is larger than for the 
synthetic record shown in figure $4 B$, though still less than the observed peak negative amplitude.

The second discontinuous-rupture scenario involves both the right stepover and a smaller 1-km left stepover near Bolinas Lagoon (fig. 4D). In comparison with the single-stepover scenario, inclusion of the second stepover results in only slight changes to the synthetic marigram: short-period fluctuations are observed before the peak negative deflection.

The third discontinuous-rupture scenario involves two stepovers as before, but with a local change of rake to $-172^{\circ}$
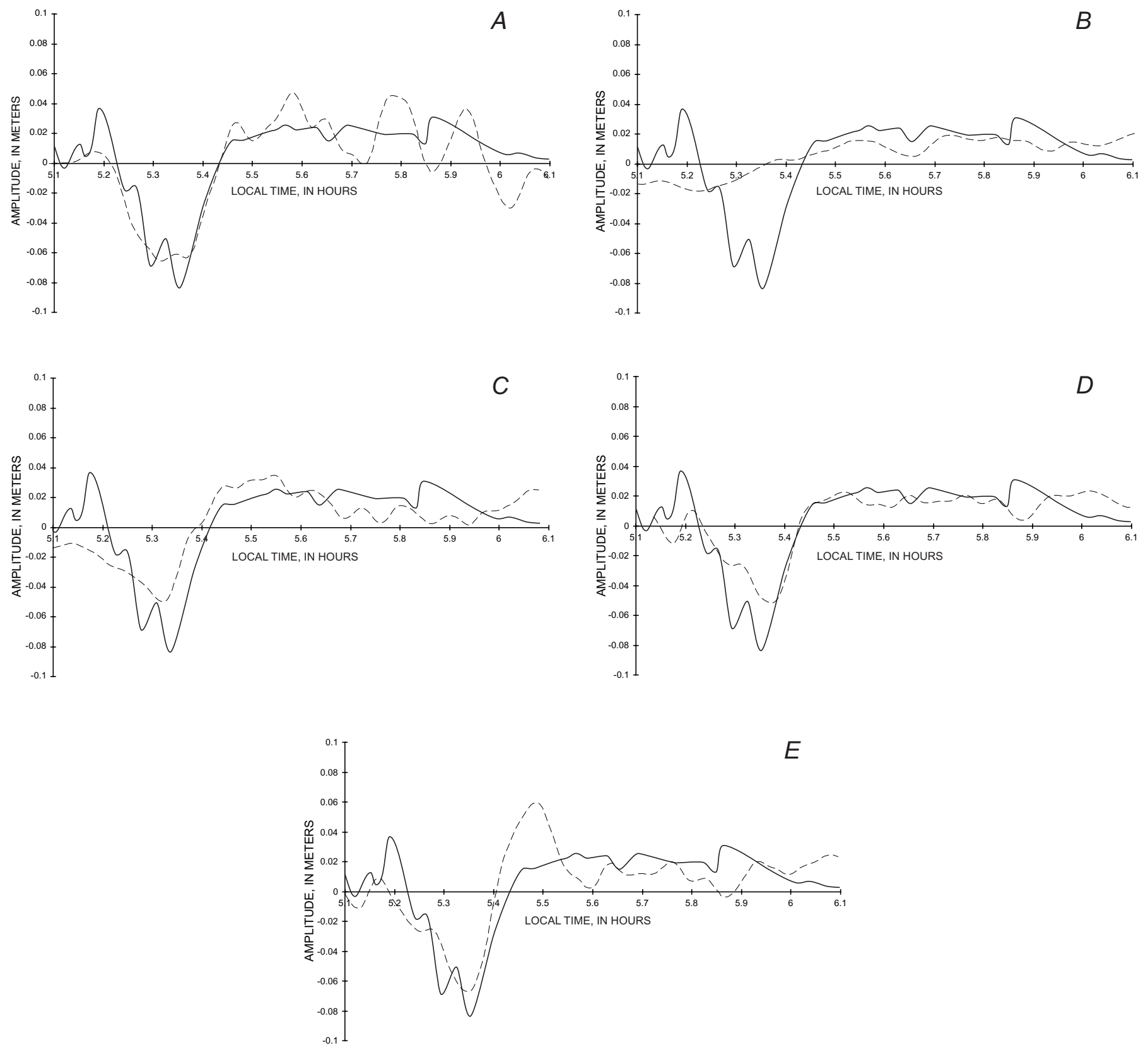

Figure 4.--Observed, residual marigram (solid curve) and synthetic marigram (dashed curve) at the Presidio tide-gauge station calculated for different initial conditions. $A$, Using sea-floor displacement values of Ma and others (1991) calculated from inversion of tide-gauge record (rather from forward modeling using elastic-dislocation solutions, as in this study), such that a good fit with observed marigram is expected. $B$, Using initial conditions specified by static, elastic displacements for rupture on a continuous trace of the offshore San Andreas Fault (fig. 1). $C$, Using initial conditions specified by static, elastic displacements for rupture on a discontinuous trace of the offshore San Andreas Fault that includes a single dilatational stepover north of Lake Merced (fig. 1). Note that observed record is shifted over time with respect to other scenarios by an amount that is within uncertainty of origin time. $D$, Using initial conditions specified by static, elastic displacements for rupture on a discontinuous trace of the offshore San Andreas Fault that includes both dilatational stepover north of Lake Merced and a smaller compressional stepover south of Bolinas Lagoon (fig. 1). E, Using initial conditions specified as in figure $4 D$, but with a local change of rake to $172^{\circ}$ for fault segments bounding dilatational stepover. 
in the region of the right stepover (fig. 4E). Like the assignment of dipping fault segments in the stepover region, the additional assignment of a local change in rake is modeled after the source parameters of the 1995 Kobe, Japan, earthquake. This change results in greater downdropping in the stepover region and thus a larger negative amplitude of the first arrival (fig. $4 E$ ). Although the ratio of the synthetic to observed peak negative amplitude is close to 1 for the this scenario, a trailing positive phase is evident on the synthetic marigram but not on the tide-gauge record. Although an optimal fit that accounts for both the peak negative amplitude of the first arrival and the absence of a trailing positive phase cannot be made with the three discontinuous-rupture scenarios considered, the timing and amplitude predicted from these scenarios strongly support the inference that the 1906 earthquake rupture occurred on discontinuous strands of the offshore San Andreas Fault.

The tsunami is affected not only by the source parameters of the earthquake but also by the response of the surrounding material. The foregoing analysis assumed that the blocks adjacent to the fault deformed as a Poisson solid $(v=0.25)$. Natural variations in the Poisson ratio due to rock type only slightly affect the resulting tsunami (Geist, 1998). For such large events as the 1906 San Francisco earthquake, however, the bulk strength of much of the surrounding material may have been exceeded, such that the effective Poisson ratio was greatly increased. This result is somewhat inconsistent, however, with patterns of permanent deformation that indicate localized subsidence within the graben defined by the dilatational stepover (see next section). To determine the effect on the tsunami from a material that closely preserves volume during deformation, we recalculate the scenarios in figures $4 B, 4 C$, and $4 E$, using a Poisson ratio near $1 / 2(v=0.45)$ (fig. $5)$. Changes in the synthetic marigrams for the continuousrupture scenario (fig. $4 B$ ) are subtle. However, using a high Poisson ratio for the discontinuous-rupture scenario without a local change in rake (fig. $4 \mathrm{C}$ ) results in a larger peak negative amplitude, closer to what was observed. The conclusion that the tsunami resulted from discontinuous rupture remains unchanged, although it remains unclear whether the $10-\mathrm{cm}$ deflection recorded at the Presidio tide-gauge station was caused by a local change in rake in the stepover region or by postelastic failure during the earthquake in the offshore region.

Other scenarios for the source of the tsunami from the 1906 San Francisco earthquake can also be envisioned. For example, localized coseismic slip on neighboring faults may have occurred. Combined slip on the San Gregorio and San Andreas Faults results in slight changes to the coda of the tsunami but does not greatly alter the signature of the first arrival. In addition, normal faulting on the Golden Gate platform (fig. 1) is indicated by seismic-reflection data and focal mechanisms (Zoback and others, 1999). Combined slip on a continuous strand of the San Andreas Fault and on a normal fault west of the San Gregorio Fault does not significantly increase the amplitude of the tsunami at the Golden Gate over using a continuous rupture on the San Andreas Fault alone (fig. 6), primarily because earthquake-scaling relations permit only a limited amount of slip for the maximum possible length of normal faults in the offshore region.

Finally, ground shaking from the earthquake may have caused a massive seacliff failure as the source for the tsunami. One particular example of seacliff failure was well documented by Lawson (1908). Near Mussel Rock, where the onshore strand of the San Andreas Fault south of the stepover intersects the coastline, Lawson noted that "The cliff was severely shaken, and great quantities of earth and rock were caused to fall or slip down." Although it is exceedingly difficult to formulate an accurate model of a tsunami generated from slides without knowing the exact dimensions and time history, traveltime information for the tsunami alone can be used to test whether seacliff failures may have caused or contributed to the tsunami. For the Mussel Rock landslide, the tsunami would have arrived too late to explain the record at the Presidio tide gauge station (fig. 7). Likewise, a possible slide near Point Bonita would have arrived too early (fig. 7). In summary, in only a few places could a massive slide triggered by the earthquake have occurred to explain the observed arrival time of the tsunami.

\section{Discussion}

\section{Implications for Rupture Mechanics}

The conclusion that the 1906 earthquake rupture occurred on discontinuous fault strands has specific implications for the rupture mechanics of this section of the San Andreas Fault. The influence of dilatational stepovers (for example, north of Lake Merced, fig. 1) and compressional stepovers (for example, south of Bolinas Lagoon) on the mechanics of fault rupture has been studied by using quasi-static models by Segall and Pollard (1980) and by using dynamic models by Harris and others (1991), Harris and Day (1993), and Kase and Kuge (1998). Results from these models indicate that generally rupture is facilitated at dilatational stepovers and inhibited by compressional stepovers. Whether dynamic rupture propagates through a stepover region, however, depends on the separation distance, the velocity of rupture, and the state of pore pressure (Harris and Day, 1993). Because of the small separation distance of the compressional stepover south of Bolinas Lagoon (fig. 1), the stepover would probably not present a barrier to rupture propagation. In addition, given the dimension of the dilatational stepover north of Lake Merced, a fault rupture propagating from either the north or the south would probably propagate through the stepover, unless the pore fluids in the region were in an "undrained" state (see Sibson, 1985, 1986). More information on the geometry and secondary faulting of the dilational stepover is needed to critically assess whether this stepover may be a likely barrier to rupture propagation.

The fact that the epicenters for both the 1906 San Francisco earthquake (as determined by Bolt, 1968, and Boore, 1977) and the 1995 Kobe, Japan, earthquake occurred at dilatational stepovers also suggests that the state of stress in these 
regions facilitates not only continued propagation of rupture but also initiation of rupture (Zoback and others, 1999). Because the orientation of principal stresses varies with the geometry of the stepover region (Rodgers, 1980; Segall and Pollard, 1980), probably only those stepovers with a specific range of fault overlap can serve as sites for preferential earthquake initiation. Although some progress has been made in determining whether stepovers serve as barriers to rupture propagation, little theoretical work has examined the state of initial stress at stepover regions during the period when faults are locked.

\section{Inferred Long-Term Rates of Subsidence}

An approximately 3-km-wide Pliocene and Quaternary basin that may be an older equivalent of the active pullapart basin offshore is exposed onland directly northeast of the San Andreas Fault on the northernmost part of the San Francisco peninsula, in the sequence of $\sim 3.0$ - to 0.2-Ma shallow marine to estuarine deposits known as the Pleistocene Merced Formation (Ingram, 1992). Jachens and Zoback (1999) interpreted detailed gravity data on the northern part of the peninsula to indicate a 2- to 3-km-wide, southeast-trending trough filled locally with more than $1 \mathrm{~km}$ of young deposits, bounded on the southwest by the onshore San Andreas Fault and on the northeast by the onshore extension of the right-step strand. This trough coincides closely with the narrow belt of outcropping Merced Formation and shallows gradually to the southeast over a distance of about $10 \mathrm{~km}$, just as the Merced Formation thins to the southeast. Hengesh and Wakabayashi (1995) argued that the Merced Formation was deposited in a marine basin developed within a pullapart structure which has migrated with the Pacific Plate (and currently lies offshore from the Golden Gate, fig. 1), an interpretation consistent with the geophysical data.

The tsunami modeling presented here suggests that the estimated 3.65 to $4.5 \mathrm{~m}$ of strike-slip offset in the 1906 San

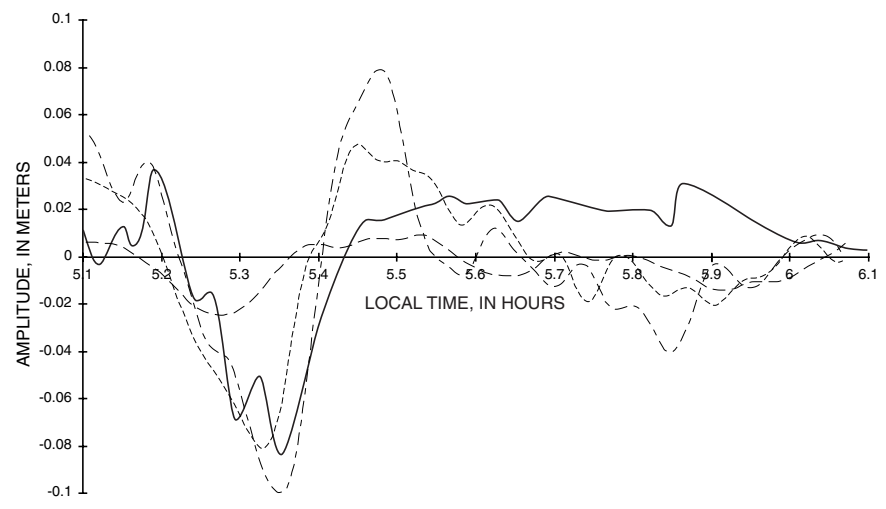

Figure 5.-Observed, residual marigram (solid curve) and synthetic marigrams calculated using a Poisson ratio $(n)$ of 0.45 for initial conditions in figures $4 B$ (long-dashed curve), $4 C$ (short-dashed curve), and $4 E$ (alternating short- and long-dashed curve).
Francisco earthquake on the Golden Gate platform (fig. 1; Thatcher and others, 1997) may have been accompanied by an average tectonic subsidence of about $0.65 \mathrm{~m}$ within a $6.25-\mathrm{km}^{2}$ area centered on the stepover. Assuming that the right stepover in the San Andreas Fault is a long-term geologic feature which represents a "moving" depocenter for the Merced Formation (Hengesh and Wakabayashi, 1995), then this "secondary" subsidence accompanying major strike-slip earthquakes can be compared with geologically determined subsidence rates for the Merced Formation. The estimated recurrence interval for large San Andreas Fault events ranges from 250 to 300 years (Schwartz and others, 1998). If the ratio of subsidence to horizontal slip that occurred here in 1906 is typical, this interval implies a subsidence rate of $2.36 \mathrm{~m}$ per $10^{3}$ years $(0.65 \mathrm{~m}$ per $275 \mathrm{yr})$, substantially greater than the geologically estimated subsidence rate of about $0.6 \mathrm{~m}$ per $10^{3}$ years determined from a total of $1,750 \mathrm{~m}$ of sedimentary section accumulated over 2.9 m.y. Clifton (1988) originally suggested a subsidence rate of 1 to $1.5 \mathrm{~m}$ per $10^{3}$ years for the Merced Formation, assuming that it was entirely Pleistocene (past 1.6 m.y.). Ingram (1992) used Sr-isotopic data and sedimentation rates to determine ages of $3.1 \mathrm{Ma}$ for the base of the formation and about $0.2 \mathrm{Ma}$ for the top-hence our updated rate. The source of the discrepancy may be that much of the slip on the San Andreas Fault occurs along shorter segments that do not break through the Golden Gate stepover. In addition, possible interevent changes in the rake of the slip vector, as well as the overall complexity of rupture through the stepover region, makes quantification of long-term subsidence rates difficult. More research is needed to reconcile the coseismic deformation inferred from the 1906 earthquake with long-term geologic observations along the Golden Gate platform.

\section{Tsunami Hydrodynamics at the Entrance to San Francisco Bay}

In comparison with tsunamis generated more commonly by subduction-zone earthquakes, the propagation of the tsunami generated by the 1906 San Francisco earthquake is highly unusual. Because the dominant source region for the tsunami (the 3-km right stepover) is very near shore, the negative-polarity first arrival recorded at the Presidio tide-gauge station propagated northward as a trapped wave (fig. 8). This tsunami contrasts with tsunamis from subduction-zone earthquakes in which the largest coseismic displacements are typically far offshore and the first-arrival broadside from the source region propagates as a direct wave. For those rupture scenarios of the 1906 earthquake that result in large displacements at the stepover, soon after the negative-polarity phase leaves the source region, a positive phase emanates from the source region, as suggested by H.F. Reid (in Lawson, 1908) and as shown in early theoretical work by Momoi (1964). Because of the large-amplitude changes, horizontal currents near the source region are significantly higher than anywhere 
else during propagation. It is unclear why a strong trailing positive pulse is not predicted at the Presidio tide-gauge station for the scenario with two stepovers and horizontal rake (fig. 4D). Analysis of the evolution of the tsunami wavefield indicates that although trailing pulses of opposite polarities are generated by the two stepovers, the phase propagating southward from the compressional stepover is scattered at Point Bonita before reaching the Golden Gate (fig. 8), such that the positive trailing pulse from the dilatational stepover is not obviously eliminated through destructive interference. The combination of a complex shoreline geometry and a nearshore source that excites coastally trapped edge waves precludes a simplified analysis of observed phases at the Presidio tide-gauge station.

Although it is difficult to track individual phases of the tsunami, coastally trapped edge waves do seem have caused the fluctuations observed in the coda of the tsunami record, with an apparent period of 40 to 45 minutes. Edge waves propagate parallel to the shoreline and occur in distinct modes, with highest amplitudes near the shoreline (LeBlond and Mysak, 1978; Carrier, 1995). Sharp changes in the shape of the shoreline will cause edge waves to scatter, reflect back, and generate nontrapped modes. The phase and group velocity for edge waves depend on the shelf slope (Ishii and Abe, 1980) and are typically much lower than for nontrapped modes. (Most of the nontrapped energy from the 1906 tsunami was directed offshore.) Largely because of edge waves, the response from a tsunami at different places along a coastline can vary drastically, as evidenced by the tsunami from the 1992 Cape Mendocino, Calif., earthquake (González and others, 1995). The dominant 40- to 45-minute period observed on the tide-gauge record of the 1906 tsunami most likely reflects the natural resonance of edge waves within the Gulf of the Farallones. The suggestion by Lawson (1908) that the 40- to 45-minute periodic waves resulted from reverberation within San Francisco Bay does not conform with the results from hydrodynamic modeling. The Golden Gate (fig.

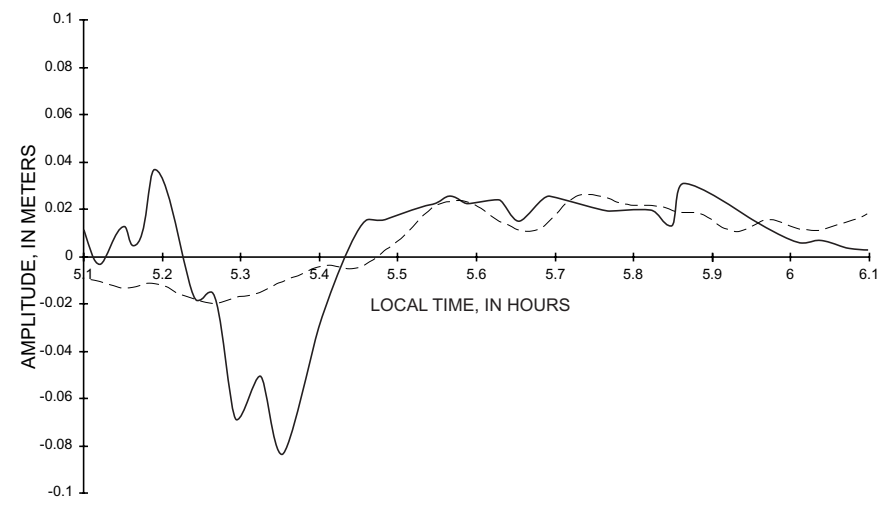

Figure 6. - Observed, residual marigram (solid curve) and synthetic marigram (dashed curve) at the Presidio tide-gauge station, calculated for initial conditions specified by static, elastic displacements for coseismic rupture on an offshore normal fault in addition to continuous rupture of the San Andreas Fault (fig. 4B).

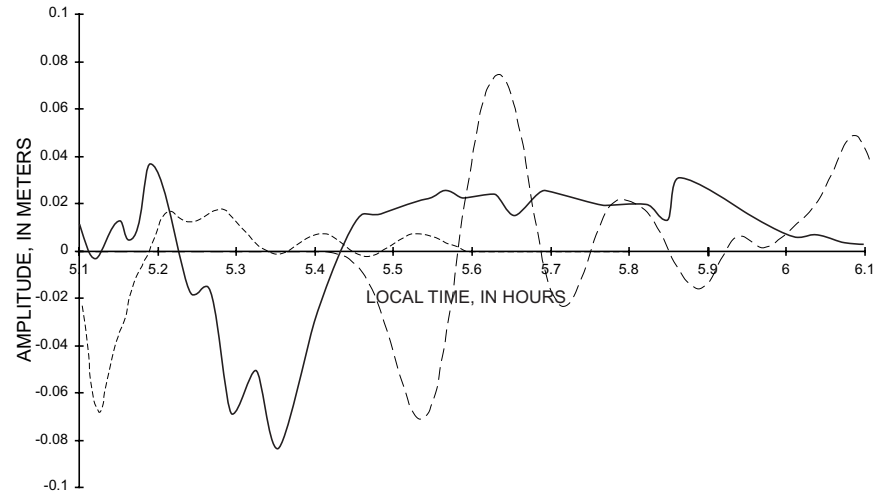

Figure 7.--Observed, residual marigram (solid curve) and synthetic marigram (dashed curve) at the Presidio tide-gauge station calculated for initial conditions specified by coseismically triggered seacliff failures at Mussel Rock (long-dashed curve) and at Point Bonita (shortdashed curve). Initial conditions are assumed such that predicted amplitude of marigrams is arbitrary. Traveltime predictions alone argue against generation of tsunami by seacliff failure.

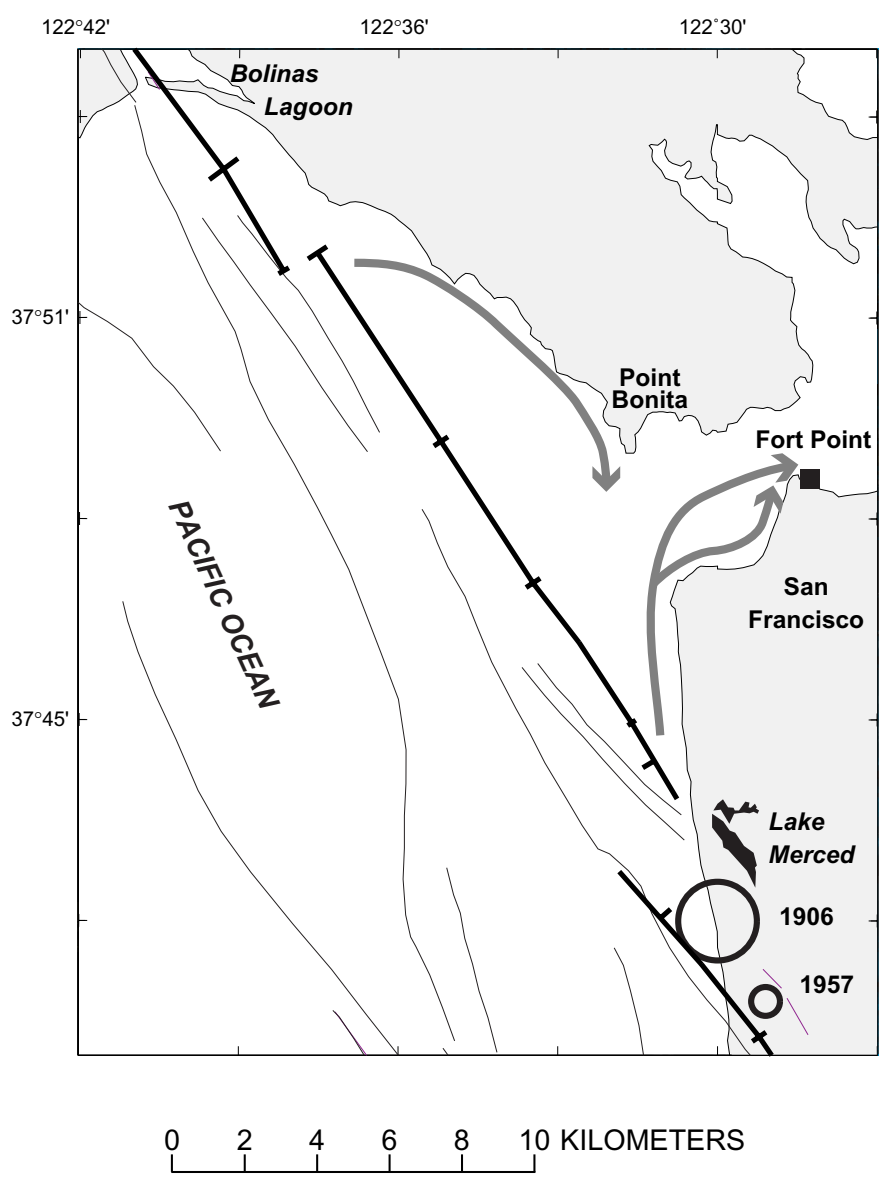

Figure 8.-San Francisco Bay region, showing primary pathways for tsunami first arrivals generated by dilatational stepover (negative polarity) north of Lake Merced and by compressional stepover (positive polarity) south of Bolinas Lagoon. Most energy propagates as coastally trapped edge waves. Southward-propagating edge wave from compressional stepover is scattered at Point Bonita. Same symbols as in figure 1. 
1) permits only a limited amount of tsunami energy to enter San Francisco Bay. Once through the Golden Gate, tsunami energy is further attenuated during slow propagation through the shallow reaches of the bay. Because little tsunami energy is reflected back through the Golden Gate from the bay, the most likely source of the periodic oscillations is reflected and scattered edge waves outside the Golden Gate.

\section{Summary}

On the basis of new interpretations of the fault geometry west of the Golden Gate (fig. 1) by Jachens and Zoback (1999) and Zoback and others (1999), we have shown that the tsunami from the 1906 San Francisco earthquake originated from localized coseismic subsidence associated with a 3-km dilatational stepover just offshore of Lake Merced. On the basis of traveltime, amplitude, and phase characteristics of the tsunami record, the 1906 earthquake rupture most likely occurred on discontinuous strands of the San Andreas Fault bounding the dilatational stepover. Although derivation of the tsunami from rupture on an antithetic fault structure in the stepover region with a small amount of dip slip (analogous to the 1995 Kobe, Japan, earthquake rupture) provides the best match to the tsunami record, we cannot reliably determine the uniqueness of this model of rupture through the dilatational stepover from these data alone. However, the fact that both the 1906 San Francisco and 1995 Kobe, Japan, earthquakes initiated at a dilatational stepover and propagated bilaterally suggests that the initial state of stress at dilatational stepovers is conducive to the initiation of such large events. We have also shown in this study that estuarine-circulation models, such as that constructed for San Francisco Bay by Casulli (1990) and Cheng and others (1993), are particularly well suited to study near-shore, local tsunamis. The evolution of the tsunami wavefield predicted by this model indicates that (1) the first arrival at the Presidio tide-gauge station was primarily a coastally trapped edge wave, (2) tsunami wave energy was restricted through the Golden Gate such that reverberation within San Francisco Bay is unlikely the source of the 40- to 45-minute oscillations in the coda of the tsunami record, and (3) instead, the source of these oscillations is most likely the natural resonance of reflected and scattered edge waves within the Gulf of the Farallones.

\section{Acknowledgments}

We gratefully acknowledge reviews of the manuscript by Tom Parsons and Patrick Hart, editing by George Havach, and engaging discussions with Robert Simpson, Ralph Cheng, Jeff Gartner, and Kuo-Fong Ma.

\section{References Cited}

Bolt, B.A., 1968, The focus of the 1906 California earthquake: Seismological Society of America Bulletin, v. 58, no. 1, p. 457-471.
Boore, D.M., 1977, Strong-motion recordings of the California earthquake of April 18, 1906: Seismological Society of America Bulletin, v. 67, no. 3, p. 561-577.

Bortugno, E.J., McJunkin, R.D., and Wagner, D.L., 1992, Map showing recency of faulting, San Francisco-San Jose quadrangle, California: California Division of Mines and Geology Regional Geologic Map Series Map 51, sheet 5, scale 1:250,000.

Bowditch, Nathaniel, 1966, American practical navigator: Washington, D.C., U.S. Navy, Hydrographic Office, 1,524 p.

Bürgmann, Ronald, Arrowsmith, J.R., Dumitru, Trevor, and McLaughlin, R.J., 1994, Rise and fall of the southern Santa Cruz Mountains, California, from fission tracks, geomorphology, and geodesy: Journal of Geophysical Research, v. 99, no. B10, p. 20181-20202.

Carrier, G.F., 1995, On-shelf tsunami generation and coastal propagation, in Tsuchiya, Yoshito, and Shuto, Nobuo, eds., Tsunami; progress in prediction, disaster prevention and warning (Advances in Natural and Technological Hazards Research, v. 1): Dordrecht, Kluwer Academic Publishers, p. 1-20.

Casulli, Vincenzo, 1990, Semi-implicit finite difference methods for the two-dimensional shallow water equations: Journal of Computational Physics, v. 86, p. 56-74.

Cheng, R.T., Casulli, Vincenzo, and Gartner, J.W., 1993, Tidal, residual, intertidal mudflat (TRIM) model and its applications to San Francisco Bay, California: Estuarine, Coastal and Shelf Science, v. 36, no. 3, p. 235-280.

Clifton, H.E., 1988, Sedimentologic approaches to paleobathymetry with applications to the Merced Formation of central California: Palaios, v. 3, no. 5, p. 507-522.

Cooper, A.K., 1973, Structure of the continental shelf west of San Francisco, California: U.S. Geological Survey Open-File Report 73-1907, $65 \mathrm{p}$.

Cross, R.H., 1968, Tide gage frequency response: American Society of Civil Engineers Proceedings, Waterways and Harbors Division Journal, v. 94, no. 3, p. 317-330.

Das, Shamita, and Aki, Keitti, 1977, Fault plane with barriers; a versatile earthquake mode: Journal of Geophysical Research, v. 82, no. 36, p. 5658-5670.

Disney, L.P., and Overshiner, W.H., 1925, Tides and currents in San Francisco Bay: U.S. Coast and Geodetic Survey Special Publication $115,125 \mathrm{p}$.

Eva, Claudio, and Rabinovich, A.B., 1997, The February 23, 1887, tsunami recorded on the Ligurian coast, western Mediterranean: Geophysical Research Letters, v. 24, no. 17, p. 2211-2214.

Foreman, M.G.G., 1993, Manual for tidal height analysis and prediction (revised): Sidney, British Columbia, Canada, Institute of Ocean Sciences Pacific Marine Science Report 77-10, 66 p.

Geist, E.L., 1998, Local tsunamis and earthquake source parameters, in Dmowska, Renata, and Saltzman, Barry, eds., Tsunamigenic earthquakes and their consequences (Advances in Geophysics, v. 39): New York, Academic Press, p. 117-209.

Geist, E.L., and Zoback, M.L., 1999, Analysis of the tsunami generated by the $M_{w} 7.81906$ San Francisco earthquake: Geology, v. 27, no. 1, p. 15-18.

González, F.I., Satake, Kenji, Boss, E.F., and Mofjeld, H.O., 1995, Edge waves and non-trapped modes of the 25 April 1992 Cape Mendocino tsunami: Pure and Applied Geophysics, v. 144, no. 3, p. 409-426.

Greenberg, D.A., Murty, T.S., and Ruffman, Alan, 1993, A numerical model for the Halifax Harbor tsunami due to the 1917 explosion: Marine Geodesy, v. 16, no. 2, p. 153-167.

Harris, R.A., and Day, S.M., 1993, Dynamics of fault interaction; paral- 
lel strike-slip faults: Journal of Geophysical Research, v. 98, no. B3, p. 4461-4472.

Harris, R.A., Archuleta, R.J., and Day, S.M., 1991, Fault steps and the dynamic rupture process; 2-D numerical simulations of a spontaneously propagating shear fracture: Geophysical Research Letters, v. 18, no. 5, p. 893-896.

Hengesh, J.V., and Wakabayashi, John, 1995 Dextral translation and progressive emergence of the Pleistocene Merced Basin and implications for timing of initiation of the San Francisco peninsula segment of the San Andreas Fault, in Sangines, E.M., Andersen, D.W., and Buising, A.V., eds., Recent geologic studies in the San Francisco Bay area:, Society of Economic Paleontologists and Mineralogists, Pacific Section Special Publication 76, p. 47-54.

Holbrook, W.S., Brocher, T.M., ten Brink, U.S., and Hole, J.A., 1996, Crustal structure of a transform plate boundary; San Francisco Bay and the Central California continental margin: Journal of Geophysical Research, v. 101, no. B10, p. 22311-22334.

Ingram, B.L., 1992, Paleoclimatic and paleoceanographic studies of estuarine and marine sediments using strontium isotopes: Stanford, Calif., Stanford University, Ph.D. thesis, 236 pp.

Ishii, Hiroshi, and Abe, Kuniaki, 1980, Propagation of tsunami on a linear slope between two flat regions. pt. 1, Edge wave: Journal of Physics of the Earth, v. 28, no. 5, p. 531-541.

Jachens, R.C., and Zoback, M.L., 1999, The San Andreas Fault in the San Francisco Bay region, California; structure and kinematics of a young plate boundary: International Geology Review, v. 41, no. 3, p. 191-205.

Kase, Yuto, and Kuge, Keiko, 1998, Numerical simulation of spontaneous rupture processes on two non-coplanar faults; the effect of geometry on fault interaction: Geophysical Journal International, v. 135, no. 3, p. 911-922.

Lander, J.F., Lockridge, P.A., and Kozuch, M.J., 1993, Tsunamis affecting the west coast of the United States 1806-1992: Boulder, Colo., U.S. National Geophysical Data Center, NGDC Key to Geophysical Records Documentation 29, 242 p.

Lawson, A.C., chairman, 1908, The California earthquake of April 18, 1906; report of the State Earthquake Investigation Commission: Carnegie Institution of Washington Publication 87, $2 \mathrm{v}$.

LeBlond, P.H., and Mysak, L.A., 1978, Waves in the ocean (Oceanography Series, v. 20): Amsterdam, Elsevier, 602 p.

Loomis, H.G., 1983, The nonlinear response of a tide gage to a tsunami: Tsunami Symposium, Hamburg, Germany, 1983 Proceedings, p. 177-185.

Ma, K.F., Satake, Kenji, and Kanamori, Hiroo, 1991, The origin of the tsunami excited by the 1906 San Francisco earthquake: Seismological Society of America Bulletin, v. 81, no. 4, p. 1396-1397.

Marsden, Richard, Zoback, M.L., Dreger, D.S., Julian, B.R., Olson, J.A., and Parsons, T.E., 1995, M5.3 normal? faulting event adjacent to the San Andreas Fault on the San Francisco Peninsula [abs.]: Eos (American Geophysical Union Transactions), v. 76, no. 46, supp., p. 423-424.

McDonald, E.T., and Cheng, R.T., 1997, A numerical model of sediment transport applied to San Francisco Bay, California: Journal of Marine Environmental Engineering, v. 4, no. 1, p. 1-41.

Momoi, Takao, 1964, Tsunami in the vicinity of a wave origin (I): University of Tokyo, Earthquake Research Institute Bulletin, v. 42, no. 1, p. 133-146.

Myers, E.P., and Baptista, A.M., 1995, Finite element modeling of the July 12, 1993 Hokkaido Nansei-Oki tsunami: Pure and Applied Geophysics, v. 144, no. 3-4, p. 769-801.
Okada, Yoshimitsu, 1992, Internal deformation due to shear and tensile faults in a half-space: Seismological Society of America Bulletin, v. 82, no. 2, p. 1018-1040.

Peraire, J., Zienkiewicz, O.C., and Morgan, K., 1986, Shallow water problems; a general explicit formulation: International Journal for Numerical Methods in Engineering, v. 22, p. 547-574.

Poon, Y.K., Tang, Shih, and Wu, Jin, 1992, Interactions between rain and wind waves: Journal of Physical Oceanography, v. 22, no. 9, p. 976-987.

Rabinovich, A.B., 1997, Spectral analysis of tsunami waves; separation of source and topography effects: Journal of Geophysical Research, v. 102, no. C6, p. 12663-12676.

Reid, H.F., 1910, The mechanics of the earthquake, v. 2 of Lawson, A.C., chairman, The California earthquake of April 18, 1906; report of the State Earthquake Investigation Commission: Carnegie Institution of Washington Publication 87, $192 \mathrm{p}$. [reprinted, 1969].

Reid, R.O., and Bodine, B.R., 1968, Numerical model for storm surges in Galveston Bay: American Society of Civil Engineers Proceedings, Waterways and Harbors Division Journal, v. 94, no. 1, p. 33-57.

Rodgers, D.A., 1980, Analysis of pull-apart basin development produced by en echelon strike-slip faults, in Ballance, P.F., and Reading, H.G., eds., Sedimentation in oblique-slip mobile zones: International Association of Sedimentologists Special Publication 4, p. 27-41.

Satake, Kenji, Okada, Masami, and Abe, Kuniaki, 1988, Tide gauge response to tsunamis; measurements at 40 tide gauge stations in Japan: Journal of Marine Research, v. 46, no. 3, p. 557-571.

Sato, Shinji, 1996, Numerical simulation of the propagation of the 1993 southwest Hokkaido earthquake tsunami around Okushiri Island: Science of Tsunami Hazards, v. 14, no. 2, p. 119-134.

Schwartz, D.P., Pantosti, Daniela, Okumura, Koji, Powers, T.J., and Hamilton, J.C., 1998, Paleoseismic investigations in the Santa Cruz Mountains, California; implications for recurrence of large-magnitude earthquakes on the San Andreas Fault: Journal of Geophysical Research, v. 103, no. B8, p. 17985-18001.

Segall, Paul, and Pollard, D.D., 1980, Mechanics of discontinuous faults: Journal of Geophysical Research, v. 85, no. B8, p. 4337-4350.

Sibson, R.H., 1985, Stopping of earthquake ruptures at dilational fault jogs: Nature, v. 316, no. 6025, p. 248-251. 1986, Rupture interactions with fault jogs, in Das, Shamita, Boatwright, John, and Scholz, C.H., eds., Earthquake source mechanics: American Geophysical Union Geophysical Monograph 37, p. 157-167.

Spudich, Paul, Guatteri, M.G., Otsuki, Kenshiro, and Minagawa, Jun, 1998, Use of fault striations and dislocation models to infer tectonic shear stress during the 1995 Hyogo-ken Nanbu (Kobe) earthquake: Seismological Society of America Bulletin, v. 88, no. 2, p. 413-427.

Thatcher, W.R., Marshall, G.A., and Lisowski, Michael, 1997, Resolution of fault slip along the 470-km-long rupture of the great 1906 San Francisco earthquake and its implications: Journal of Geophysical Research, v. 102, no. B3, p. 5353-5367.

Tinti, Stefano, and Piatanesi, Alessio, 1996, Numerical simulations of the tsunami induced by the 1627 earthquake affecting Gargano, southern Italy: Journal of Geodynamics v. 21, no. 2, p. $141-160$.

Tsimplis, M.N., 1992, The effect of rain in calming the sea: Journal of Physical Oceanography, v. 22, no. 4, p. 404-412. 
Wald, D.J., 1996, Slip history of the 1995 Kobe, Japan, earthquake determined from strong-motion, teleseismic, and geodetic data: Journal of Physics of the Earth, v. 44, no. 5, p. 489-503.

Wald, D.J., Kanamori, Hiroo, Helmberger, D.V., and Heaton, T.H., 1993, Source study of the 1906 San Francisco earthquake: Seismo- logical Society of America Bulletin, v. 83, no. 4, p. 981-1019.

Zoback, M.L., Jachens, R.C., and Olson, J.A., 1999, Abrupt alongstrike change in tectonic style; San Andreas Fault zone, San Francisco Peninsula: Journal of Geophysical Research, v. 104, no. B5, p. 10719-10742. 


\title{
Concealed Strands of the San Andreas Fault System in the Central San Francisco Bay Region, As Inferred from Aeromagnetic Anomalies
}

\author{
By Robert C. Jachens, Carl M. Wentworth, Mary Lou Zoback, Terry R. Bruns, and Carter W. Roberts
}

\section{CONTENTS}

\begin{tabular}{|c|c|}
\hline & Page \\
\hline 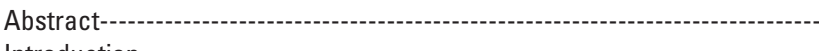 & 43 \\
\hline - & 43 \\
\hline evious Work & 45 \\
\hline ew Aeromagnetic Surveys--. & 46 \\
\hline eologic Map--e. & -46 \\
\hline 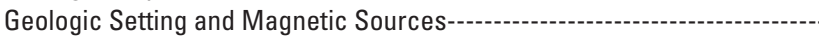 & --47 \\
\hline East Bay Hills Block-- & 47 \\
\hline 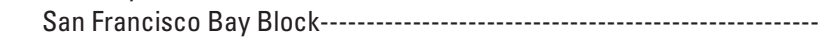 & 47 \\
\hline 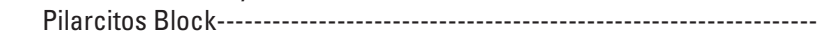 & 48 \\
\hline Montara Block-o & 48 \\
\hline Offshore Block West of the San Gregorio Fault Zone---------. & 48 \\
\hline lagnetic Anomalies, Magnetic Boundaries, and Faults----------------- & 49 \\
\hline Hayward Fault-- & 49 \\
\hline 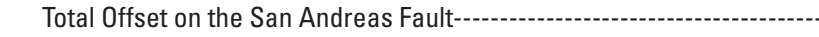 & 50 \\
\hline 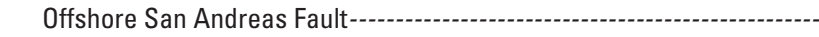 & 51 \\
\hline Pilarcitos Fault--1.-1 & 51 \\
\hline San Gregorio Fault Zone-------. & 52 \\
\hline 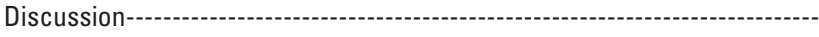 & 52 \\
\hline San Andreas-San Gregorio Fault Junction--- & 52 \\
\hline San Gregorio-Pilarcitos Fault Junction---- & 54 \\
\hline Structure of the Pilarcitos Block- & 54 \\
\hline Detailed Structure of the Right Step in the San Andreas Fault-------. & 55 \\
\hline 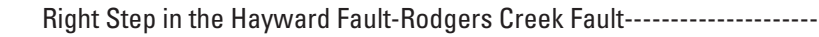 & 55 \\
\hline ditional Considerations- & 58 \\
\hline ferences Cited-1- & 58 \\
\hline
\end{tabular}

\section{Abstract}

Modern high-resolution aeromagnetic surveys over the San Andreas Fault system in the San Francisco Bay region provide detailed information about the positions, shapes, and offset histories of various fault segments concealed beneath water or young alluvium. The presence of coherent, nondisrupted magnetic rock bodies within the top few kilometers of the crust beneath San Pablo Bay and spanning the rightstepover region between the Hayward and Rodgers Creek Faults precludes a simple connection between these two active faults, at least in the upper crust. The data do permit a simple midcrustal connection between the two faults, provided that discrete offset at depth is reflected in the upper crust as distributed deformation, folding, and basin subsidence. Offset pairs of distinctive geologic units and characteristic tabular magnetic rock bodies indicate that the Peninsular segment of the San Andreas Fault accommodates only $22 \mathrm{~km}$ of total offset, even though offsets on strands of the San Andreas Fault to the north and south are measured in the hundreds of kilometers. On the basis of interpreted aeromagnetic data, the San Andreas
Fault offshore west of San Francisco exhibits an abrupt right step of $3 \mathrm{~km}$ about in the hypocentral zone of the great 1906 San Francisco earthquake. A local, >1-km-deep basin lying southeast of this right step is compatible with its having formed as a pullapart basin southeast of (behind) a right step in a right-lateral strike-slip-fault system. Slight local nonparallelism of the two fault segments entering the right step from the north and south can explain the puzzling fact that young sedimentary materials deposited in an extensional, pullapart basin have undergone compressional deformation and uplift within an along-strike distance of $5 \mathrm{~km}$ from the extensional right step. The local geometry of the fault system indicates that the original 3-km-wide depositional basin is compressed to a 2-km width over an along-strike distance of $10 \mathrm{~km}$ from the right step by continued relative motion across the San Andreas Fault. The Pilarcitos Fault, the presumed active strand of the San Andreas Fault before the initiation of movement on its Peninsular segment, bends into the San Gregorio Fault zone offshore, leaving open the question of whether the Pilarcitos Fault is truncated at the San Gregorio Fault or simply once coincided with what is now the northernmost segment of the San Gregorio Fault. Examination of high-resolution aeromagnetic data over the San Andreas Fault system as far north as Point Arena reveals possible offset counterparts to the pronounced magnetic anomaly that defines the Pilarcitos Fault in the San Francisco Bay region. These magnetic anomalies lie west of the San Andreas Fault and about $150 \mathrm{~km}$ north of the San Gregorio-Pilarcitos Fault junction. However, detailed study of the geology of this northern area is needed before a definite tie with the Pilarcitos Fault magnetic anomaly can be established. The aeromagnetic data indicate that the San Gregorio Fault zone in the Gulf of the Farallones west of San Francisco is composed of at least two long, right-stepping strands, the northernmost of which connects with a mapped strand of the San Andreas Fault at Bolinas Lagoon northwest of San Francisco. The right-stepping behavior of the San Gregorio Fault zone is consistent with the generally extensional (right step) junction between the San Gregorio-San Andreas Fault junction northwest of San Francisco.

\section{Introduction}

The active San Andreas Fault system in the San Francisco Bay region consists of several subparallel strands, including, from east to west, the Calaveras, Rodgers Creek, 
Hayward, San Andreas, and Pilarcitos Faults and the San Gregorio Fault zone (fig. 1), as well as other strands farther east. Onshore, these potentially dangerous faults are reasonably well known from geologic mapping of offset geologic units, geomorphic features, and ground rupture after historical earthquakes (Bonilla, 1971; Galloway, 1977; Lienkamper,
1992; Pampeyan, 1994). However, significant reaches of many of these faults lie offshore, concealed from direct observation by water and young sedimentary deposits. Here, the positions and characteristics of the faults are known primarily from geophysical observations and the distribution of seismicity and are much less certain.

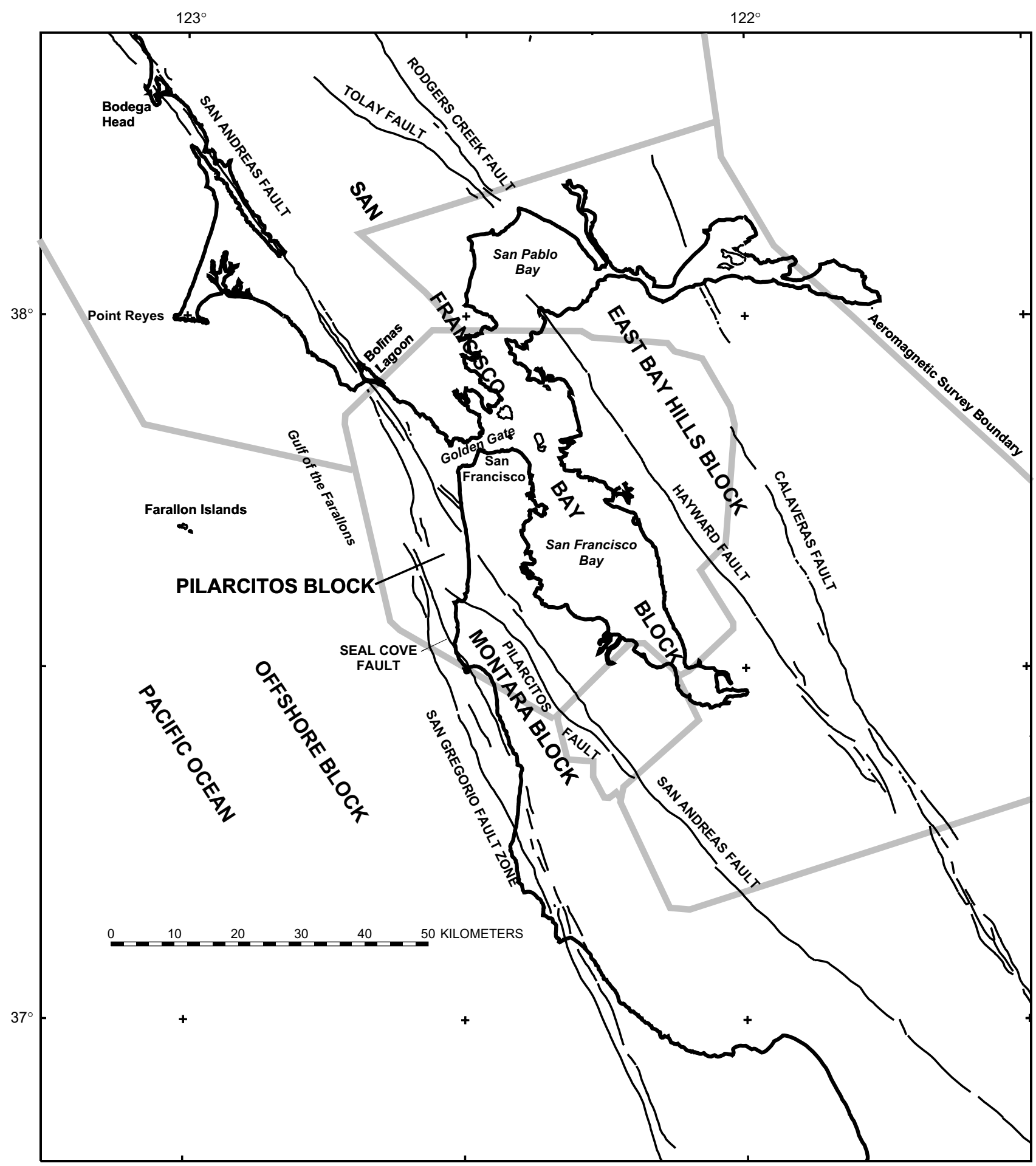

Figure 1.-San Francisco Bay region, showing locations of strands of the San Andreas Fault system, major crustal blocks discussed in this study, and boundaries of aeromagnetic surveys used to compile aeromagnetic map (see pl. 1). 
It is important to understand submarine faults in order to evaluate the potential hazard they present, especially when they lie close to such heavily developed areas as the San Francisco Bay region. Precise locations of faults are needed to assess the possible distribution of damage during an earthquake, and information about the detailed structure of the faults can be useful in predicting the type of deformation likely to accompany the rupture of a specific strand. In addition, local irregularities in fault geometry, such as the concealed right step apparently required to connect the Hayward Fault with the Rodgers Creek Fault or Tolay Fault beneath San Pablo Bay (fig. 1; Smith, 1992; Wright and Smith, 1992), or a comparable right step in the San Andreas Fault offshore southwest of the Golden Gate (Cooper, 1973; Hengesh and Wakabayashi, 1995; Zoback and others, 1999; Jachens and Zoback, 1999), may be important features in understanding the initiation of earthquakes on these faults and on major strike-slip faults in general.

\section{Previous Work}

Information about submarine strands of the San Andreas Fault system in the San Francisco Bay region has come mainly from marine geophysical surveys and aeromagnetic surveys. In his study of the structure of the Continental Shelf west of San Francisco, Cooper (1973) summarized previous investigations and compiled marine seismic-reflection data and other geophysical information. He recognized numerous faults on the basis of offset beds or disruptions in the Cenozoic sedimentary section, and he was able to correlate some of these faults across several separate profiles. Although the aeromagnetic data available for his study were sparsely distributed and of limited quality, Cooper observed that faultbounded blocks in the area east of the Seal Cove Fault (fig. 1; now included as a strand of the San Gregorio Fault zone) produced magnetic anomalies that were related to the faults. In addition, he showed, on one profile containing both seismicreflection and aeromagnetic data, a detailed correspondence of the faults visible in the sedimentary section with magnetic anomalies, presumably caused by basement rocks (Cooper, 1973, fig. 9, profile 5). He presented a fault map inferred from the seismic-reflection and aeromagnetic data for the area just west of San Francisco that includes several minor faults, as well as proposed locations for the Seal Cove, Pilarcitos, and San Andreas Faults, which cross the entire area from the San Francisco peninsula to the Point Reyes peninsula.

McCulloch (1987) analyzed additional marine seismicreflection data for the shelf area west of San Francisco and recognized other faults that were traceable across multiple profiles. In the area east of the San Gregorio Fault zone, he also recognized the relation between faults and the magnetic anomalies shown on an aeromagnetic map (Brabb and Hanna, 1981), and used this information to help link faults seen on individual marine seismic profiles into long, throughgoing features.

Brabb and Hanna (1981) compiled an aeromagnetic map of the San Francisco Bay region south of lat $37^{\circ} 52.5^{\prime}$ N. that they used, in conjunction with mapped geology, locations of onshore faults, and recent seismicity, to identify concealed, potentially hazardous faults. On the basis of the known correspondence between linear magnetic anomalies produced by tabular bodies of serpentinite and such mapped faults as the Hayward Fault and the Hunters Point shear zone (compare pls. 1, 2), they identified as possible faults virtually every strong linear magnetic anomaly believed to be caused by serpentinite.

Lienkaemper and others (1991), on the basis of regional gravity data (Chapman and Bishop, 1968), projected the Hayward Fault on strike northwestward across most of San Pablo Bay. This interpretation was based on their identification of the Hayward Fault with the sharp linear southwest flank of a deep gravity low over the eastern part of San Pablo Bay, a low that extends both northwestward and southeastward from the bay. Near the north shore of the bay, Lienkaemper and others proposed a rightward (releasing) bend in the fault system over a distance of $\sim 6 \mathrm{~km}$ to connect the active Hayward Fault with the active Rodgers Creek Fault.

Smith (1992) presented a more detailed gravity map of San Pablo Bay and vicinity (inset, pl. 1) that better defined the gravity anomaly associated with the Hayward Fault and its possible northwestward continuation. He also interpreted the sharp, linear southwest flank of this gravity low as the extension of the Hayward Fault beneath the bay and, on the basis of the continuity of this gravity feature, connected the Hayward Fault with the Tolay Fault, a connection that requires a more abrupt rightward bend or right step near the north shore of the bay than that shown by Lienkaemper and others (1991). This interpretation was made in the context of the continuity of structural elements (faults) that bound the west side of the Tertiary basin underlying the eastern part of San Pablo Bay. As such, Smith's (1992) interpretation was not directed toward identifying the active strand of the Hayward Fault system north of San Pablo Bay.

Wright and Smith (1992), using the same gravity data set as Smith (1992), located the Hayward Fault beneath San Pablo Bay in the same way as Smith (1992) and recognized that the Rodgers Creek Fault has no obvious gravity expression. However, they also used information from seismic-reflection surveys in San Pablo Bay and from deep wells in the surrounding area to project the Rodgers Creek Fault southeastward from its southernmost mapped position to a point near the center of the bay (see pl. 1). They argued that their data preclude any direct connection between the Hayward and Rodgers Creek Faults, and speculated about how slip is transferred from one fault to the other across a right step.

Although these studies all provide information that helps to define the positions and characteristics of concealed strands of the San Andreas Fault system in the San Francisco Bay region, important questions still remain unanswered. More detailed information is required about fault positions and local irregularities in the fault system to understand the behavior of individual faults and to properly assess the potential hazard they pose. New high-resolution aeromagnetic data provide some of this additional information. 


\section{New Aeromagnetic Surveys}

A high-resolution aeromagnetic survey of the central part of the San Francisco Bay region (fig. 1; U.S. Geological Survey, 1996) was flown on contract to the U.S. Geological Survey (USGS) during March 1995. The purpose of this survey was to provide information on concealed strands of the San Andreas Fault system as part of the USGS Earthquake Hazards Reduction Program. Total-magnetic-field data were collected with a fixed-wing aircraft along northeast-southwest-oriented flightlines spaced $500 \mathrm{~m}$ apart and controlled by precise Global Positioning System (GPS) navigation. The aircraft maintained a nominal height of $250 \mathrm{~m}$ above the surface in water-covered areas and $300 \mathrm{~m}$ above the land surface in developed onshore areas. Because of extreme topographic relief in some places, the aircraft was not always able to maintain a constant altitude above the land surface and typically passed closer to the ridgetops than to the bottoms of the intervening valleys. Data were collected about every $50 \mathrm{~m}$ along the flightlines.

The aeromagnetic data were corrected for diurnal fluctuations in the Earth's field, and the International Geomagnetic Reference Field (Langel, 1992), updated to the dates of the survey, was subtracted from the observations to yield residual-magnetic-field data (total-magnetic-field anomalies). The residual-magnetic-field values were interpolated to a square grid (grid interval, $100 \times 100 \mathrm{~m}$; projection, Universal Transverse Mercator; central meridian, $123^{\circ} \mathrm{W}$.; base latitude, $0^{\circ}$ ) by a numerical technique based on the principle of minimum curvature (Briggs, 1974).

Data from three other high-resolution aeromagnetic surveys were added along the edges of the new survey area (fig. 1) to extend the map coverage northward to include the important junctions of the Hayward and Rodgers Creek Faults beneath the waters of San Pablo Bay and of the San Andreas and San Gregorio Faults northwest of San Francisco, and southward to cover important segments of the San Andreas Fault. Data from the aeromagnetic survey of Livermore, Calif., and vicinity (U.S. Geological Survey, 1992) were collected in fall 1991 along flightlines oriented N. 70 E. $-\mathrm{S} .70^{\circ} \mathrm{W}$., with the same survey specifications as the 1995 survey. Data from the aeromagnetic survey of Palo Alto, Calif., and vicinity (Abrams and others, 1991) were collected along flightlines oriented northeast-southwest, with the same specifications as for the survey of the central part of the San Francisco Bay region, but with a flightline spacing of 400 $\mathrm{m}$. Data from the aeromagnetic survey of Santa Rosa, Calif., and vicinity (U.S. Geological Survey, 1997a) were collected in 1996 and 1997 along flightlines oriented east-west, with the same survey specifications as for the survey of the central part of the San Francisco Bay region. The data from all these surveys were reduced and interpolated to a square grid in the same way as for the central part of the San Francisco Bay region and were merged by smooth interpolation across a 500-m-wide buffer zone between adjacent surveys. These data are shown on the aeromagnetic map (pl. 1) as a color shaded-relief map with a color band of $25 \mathrm{nT}$.
The use of GPS navigation and high-resolution magnetic sensors in the surveys of Livermore, Santa Rosa, and the central San Francisco Bay region yielded high-quality data sets that contain coherent magnetic anomalies (local distortions of the Earth's magnetic field) spanning multiple flightlines, with some amplitudes as small as $1 \mathrm{nT}$ or less. Although GPS navigation was unavailable for the aeromagnetic survey of Palo Alto, the small size of the survey area and careful reduction of the positioning data yielded reduced aeromagnetic data of a quality similar to that in the other three surveys.

In addition to the basic aeromagnetic data, inferred locations of the edges of magnetic rock bodies in the central part of the San Francisco Bay region are shown on the aeromagnetic map (lines of plus signs, pl. 1). These locations were determined automatically by means of a numerical technique applied to the aeromagnetic data which is a slight modification of that of Cordell and Grauch (1985) as implemented by Blakely and Simpson (1986). The original technique locates the edges of magnetic bodies by the use of a linear filter, the pseudogravity transform (Baranov, 1957), which converts a magnetic anomaly into an equivalent gravity anomaly. In the same way that the maximum horizontal gradients of a gravity anomaly produced by a shallowly buried body lie nearly over the edges of the body, especially if the sides dip steeply, the maximum horizontal gradients of a pseudogravity anomaly define the edges of the magnetic body that cause the magnetic anomaly. For the present study, we modified this edge-location technique slightly by applying it not to a simple pseudogravity transformation of the total-magnetic-field data for the San Francisco Bay region, but to the difference between the transformed aeromagnetic data and those same data continued upward $200 \mathrm{~m}$. Upward continuation of potential-field data suppresses the shorter-wavelength components of a magnetic anomaly, such as those produced by the shallowest parts of a body, at the expense of the longer-wavelength components that reflect the deeper parts of the body (Blakely, 1995). By applying the edge-location technique to the difference, we focused on the shallowest parts of the magnetic bodies, namely, the top edges.

\section{Geologic Map}

The accompanying geologic map (pl. 2) represents a generalized version of the map by Ellen and Wentworth (1995). For the purposes of our study, rock units that are known or suspected to be magnetic were retained as shown on the original map, but many other units were combined into single units, mostly on the basis of similarities in age and major rock type. Potentially magnetic units include serpentinite, igneous rocks of various ages, and some Tertiary sedimentary rocks. Major faults of the San Andreas Fault system are shown as on the original map and do not correspond in detail to those highlighted on the aeromagnetic map (pl. 1), on which the mapped faults of the San Andreas Fault system emphasize the most recently active strands and so do not everywhere correspond to geologic-unit boundaries. 


\section{Geologic Setting and Magnetic Sources}

The strands of the San Andreas Fault system in the San Francisco Bay region have undergone offsets measured in tens to hundreds of kilometers and, thus, typically juxtapose diverse rock types. These faults divide the region into a mosaic of crustal blocks (fig. 1) that, because of their characteristic geology and magnetic rock types, serve as a convenient framework for discussing the relations between the geology and the magnetic anomalies and the types of magnetic features that are likely to be indicators of faults in areas where the geology is not exposed. The subsequent discussion is organized according to crustal block and generally progresses from east to west. The aeromagnetic data are shown on the aeromagnetic map (pl. 1) at a scale of 1:150,000, along with a generalized geologic map (pl. 2) of the same area at the same scale. The reader also may find it helpful at times to refer to published geologic maps of the study area, for example, the Santa Rosa $1^{\circ} \times 2^{\circ}$ quadrangle (Wagner and Bortugno, 1982), the combined San FranciscoSan Jose quadrangle (Wagner and others, 1991), and the more detailed maps referenced in these publications. In the following sections, where specific magnetic anomalies and their sources are discussed, the anomalies and their geologic sources are identified on both maps by letter designations where appropriate.

\section{East Bay Hills Block}

The East Bay Hills block (fig. 1), immediately east of the Hayward and Rodgers Creek Faults, is made up of elements of a geologic section that, in simplest form, includes, from bottom to top, subduction-related rocks of the Franciscan Complex; the Coast Range ophiolite; forearc sedimentary rocks of the Mesozoic Great Valley sequence; and Cenozoic (mostly Miocene and younger) marine and continental sedimentary rocks and associated volcanic rocks (see pl. 2; Page, 1992). The Coast Range ophiolite, which is the depositional basement of the Great Valley sequence, structurally overlies the Franciscan Complex across the Coast Range Fault (Bailey and others, 1970) but commonly is found also as slivers and tabular bodies intimately associated with, and enclosed within, the Franciscan basement. Strong gravity lows over outcrops of the Great Valley sequence and younger sedimentary rocks of this block, relative to the gravity anomalies over exposed Franciscan basement in the surrounding area (Roberts and Jachens, 1993), indicate that the sedimentary cover of this block typically is more than $1 \mathrm{~km}$ thick and, in places, is many kilometers thick. This gravity interpretation is supported by limited drill-hole data (Smith, 1964; California Division of Oil and Gas, 1982; Wright and Smith, 1992) and seismic profiles (Meltzer and others, 1987; Smith, 1992), as well as cross sections based on geologic mapping (Jones and others, 1994; Crane, 1995).

Magnetic anomalies over this block are produced by mafic, ultramafic, and volcanic components of the Coast
Range ophiolite (magnetic anomaly a, pl. 1); by Tertiary volcanic rocks, such as the Bald Peak basalt (magnetic anomaly b); and Late Tertiary sedimentary rocks of the San Pablo and Contra Costa Groups (magnetic anomaly c) and related rocks (Wagner and others, 1991; Wagner and Bortugno, 1982). The strongest magnetic high shown on the aeromagnetic map (a 35-km-long, 10-km-wide magnetic high near the northeast corner, pl. 1) is likely caused by a tabular body of mafic and ultramafic rocks of the Coast Range ophiolite, but most of this body is concealed, possibly cropping out only in a small window at Mount Diablo. Although sedimentary rocks seldom produce anomalies on aeromagnetic maps, the unusual magnetic rocks of the San Pablo and Contra Costa Groups are responsible for most of the linear, northwest-trending magnetic anomalies east of the Hayward Fault shown on the aeromagnetic map (pl. 1). These magnetic anomalies result from complex folding and faulting of the magnetic sedimentary rocks of these units. One exception is the strong magnetic high (magnetic anomaly b) that overlies outcrops of the Tertiary Bald Peak basalt.

\section{San Francisco Bay Block}

The central San Francisco Bay block (fig. 1), lying between the Hayward-Rodgers Creek Fault system and the San Andreas Fault, includes Franciscan rocks as its basement, together with rocks of the Coast Range ophiolite (Wagner and others, 1991) and, possibly, ophiolitic rocks related to the oceanic plate originally at the base of the Franciscan Complex. Franciscan rocks of the San Francisco Bay block belong to several distinct tectonostratigraphic terranes, including the Alcatraz, Central, Marin Headlands, Novato Quarry, Permanente, San Bruno Mountain, and Yolla Bolly terranes (Blake and others, 1984). A major difference between the central part of the San Francisco Bay block and the East Bay Hills block is in the amount of sedimentary cover overlying the Franciscan basement. Most of the central part of the San Francisco Bay block has only a thin veneer of sedimentary cover, typically no more than a few hundred meters thick (Page, 1992; Wright and Smith, 1992; Jachens and others, 1995a). Some parts of the San Francisco Bay block north and south of the map area (pl. 1) contain substantial thicknesses of Cenozoic sedimentary deposits (California Division of Oil and Gas, 1982; Wright and Smith, 1992; Jachens and others, 1995a; Stanley and others, 1996). Within the map area, however, the sedimentary cover is as much as $\sim 1 \mathrm{~km}$ thick in only a few places, for example, west of San Leandro, adjacent to the Peninsular segment of the San Andreas Fault near Lake Merced, and in a sliver north of San Pablo Bay between the Rodgers Creek and Tolay Faults (Wright and Smith, 1992; Zoback and others, 1995; Jachens and Zoback, 1999; Marlow and others, 1999).

Ultramafic ophiolitic rocks cause many of the conspicuous northwest-trending magnetic anomalies within the San Francisco Bay block shown on the aeromagnetic map (pl. 1; Brabb and Hanna, 1981). The magnetic ophiolitic bodies gen- 
erally occur in tabular, sheetlike masses, commonly along the sutures between terranes or along active fault zones (Brabb and Hanna, 1981). The Tertiary Sonoma Volcanics (magnetic anomaly d, pl. 1) also is magnetic and probably causes some of the smaller magnetic anomalies within the San Francisco Bay block along the north edge of the map area.

The sources of the large magnetic anomalies just northwest of San Francisco (magnetic anomaly e, pl. 1) are mostly metabasalts of the Franciscan Marin Headlands terrane (Blake and others, 1984). These rocks are unusually magnetic relative to Franciscan metabasalts in other terranes of the San Francisco Bay region, which have a very low magnetic susceptibility and do not produce measurable aeromagnetic anomalies (Brabb and Hanna, 1981). Other metabasalts of the Marin Headlands terrane, however, also produce moderate to strong magnetic anomalies, such as those in the western hills of metropolitan San Francisco (magnetic anomaly f), in the Coyote Hills (magnetic anomaly g) on the eastern margin of southern San Francisco Bay, and, probably, along the east side of the San Andreas Fault on the central part of the San Francisco peninsula (Blake and others, 1984). Because the distribution of rocks of the Marin Headlands terrane is poorly known in the covered areas of the San Francisco Bay block, both ultramafic ophiolitic rocks and metabasalts must be considered as possible sources of the magnetic anomalies where these sources are concealed.

\section{Pilarcitos Block}

The Pilarcitos block is triangular crustal block bounded by the Pilarcitos Fault, the San Gregorio Fault zone, and the Peninsular segment of the San Andreas Fault (fig. 1). Although the San Andreas Fault system has accommodated hundreds of kilometers of total offset north and south of the San Francisco Bay region (Irwin, 1990), Bailey and others (1964) long ago recognized that its Peninsular segment was unusual in that it did not appear to accommodate nearly as much total offset as the rest of the fault system. They noted that characteristic Calera limestone-bearing units of the Franciscan Complex (magnetic anomaly h, pl. 2) are present both east and west of the San Andreas Fault, indicating that its Peninsular segment has accommodated only 20 to $30 \mathrm{~km}$ of total right-lateral offset. An important implication of this limited offset is that the geology of the Pilarcitos block (see pl. 2) is similar to that of parts of the San Francisco Bay block, with crossfault Franciscan basement counterparts exposed east of the fault on the San Francisco peninsula and southward (Bailey and others, 1964; Blake and others, 1984; Page, 1990; Wagner and others, 1991).

The Franciscan basement of the Pilarcitos block includes rocks of the Permanente terrane in the southwestern part and, probably, rocks of the Marin Headlands terrane in the northeastern part of the block (Blake and others, 1984; Pampeyan, 1994; R.J. McLaughlin, oral commun., 1996), although the position of the contact between these two terranes is undefined. The dominant sources of magnetic anomalies within the
Permanente terrane are ultramafic ophiolitic rocks and metabasalts, whereas over the Marin Headlands terrane they are probably metabasalts. No other sources of magnetic anomalies are known in the Pilarcitos block.

\section{Montara Block}

The Montara block, between the San Andreas Fault and the San Gregorio Fault zone south of the Pilarcitos Fault (fig. 1), is composed of Cretaceous plutons and Sur Series metamorphic rocks of the Salinia terrane overlain by Cenozoic sedimentary and volcanic rocks (McCulloch, 1987; Wagner and others, 1991). The relative rarity of strong magnetic anomalies over this block (pl. 1; fig. 1) and over similar rocks to the south, coupled with the extremely low magnetic susceptibilities (avg < $0.0001 \mathrm{cgs}$ units) of samples from the Montara Mountain pluton indicates that the plutonic and metamorphic rocks of the Salinia terrane in the San Francisco Bay region are typically nonmagnetic. Isolated magnetic anomalies over outcrops of plutonic rock (for example, magnetic anomaly i, pl. 1) indicate that small magnetic zones may exist within the predominantly nonmagnetic plutons.

Two types of magnetic source rocks exist in the Cenozoic section above the Salinian basement. The Mindego basalts of Miocene age (Wagner and others, 1991) produce magnetic anomalies of both positive (magnetic anomaly j, pl. 1) and negative polarity (Brabb and Hanna, 1981), but these rocks have only limited areal extent. Sedimentary rocks of the Pliocene Purisima Formation, which are more widespread (Wagner and others, 1991), are known to be magnetic in the Santa Cruz Mountains part of the Salinia terrane $20 \mathrm{~km}$ to the south (Jachens and Roberts, 1993); their magnetic properties presumably are due to abundant lithic fragments of andesitic composition.

\section{Offshore Block West of the San Gregorio Fault Zone}

The basement of the offshore block west of the San Gregorio Fault zone in the Gulf of the Farallones (fig. 1) is believed to be composed of plutonic rocks and Sur Series metamorphic rocks of the Salinia terrane (McCulloch, 1987), comparable to those found in the Montara block. Basement rocks of this offshore block crop out only on the Farallon Islands, on the Point Reyes peninsula, and at Bodega Head, $50 \mathrm{~km}$ west, $40 \mathrm{~km}$ northwest, and $90 \mathrm{~km}$ northwest, respectively, of San Francisco, and, as such, give only limited information on the specific rocks adjacent to the San Gregorio Fault zone in the study area (fig. 1). Restoring approximately $150 \mathrm{~km}$ of total right-lateral offset across the San Gregorio Fault zone, however, as proposed by Clark and others (1984) on the basis of detailed crossfault geologic correlations and by Jachens and others (1998) on the basis of magnetic anomalies, suggests that the basement rocks of this offshore block have onshore counterparts in the plutonic and metamorphic 
rocks of the Salinia terrane exposed near Monterey (Clark and others, 1984), about $20 \mathrm{~km}$ south of the south edge of the study area (fig. 1).

The absence of strong magnetic anomalies over this block (see pl. 1) indicates that its plutonic and metamorphic basement rocks are, at most, weakly magnetic, a conclusion consistent with the subdued magnetism of the comparable Montara block discussed above and with the absence of strong magnetic anomalies over the basement rocks exposed on the Point Reyes peninsula (U.S. Geological Survey, 1997a) and near Monterey (McCulloch and Chapman, 1977). By analogy with the Montara block, possible sources of other magnetic anomalies over this block include counterparts to the Mindego basalts and sedimentary rocks of the Purisima Formation. Weakly magnetic Tertiary sedimentary rocks may be responsible for the pattern of low-amplitude (10 nT), short-wavelength magnetic anomalies over this block that are evident on the detailed contour presentation of the aeromagnetic data (U.S. Geological Survey, 1996).

\section{Magnetic Anomalies, Magnetic Boundaries, and Faults}

The numerous magnetic anomalies (see pl. 1) over the Franciscan blocks in the central part of the San Francisco Bay region (East Bay Hills block, San Francisco Bay block, and Pilarcitos block) document the pervasive distribution of magnetic source rocks throughout these blocks and provide a regional framework for identifying faults within and at the boundaries of the blocks. The wide variety of anomaly characteristics (amplitude, wavelength, trend, linearity, base level) within these blocks make it almost certain that any major fault cutting or bounding any of these blocks with more than a few kilometers of total offset will juxtapose rocks with different magnetizations, thus producing magnetic anomalies that directly define the faults. Furthermore, geologic mapping in the California Coast Ranges has demonstrated that tabular bodies of magnetic serpentinite commonly occupy both active strike-slip-fault zones and ancient suture zones within the Franciscan terranes (Brabb and Hanna, 1981) and cause linear magnetic anomalies aligned along the faults. As a result, we have sound geologic reasons to expect that the major faults of the San Andreas Fault system will be expressed in the total magnetic field of the San Francisco Bay region and that the locations of these faults will be defined by magnetic anomalies, even in areas where the faults are concealed.

Fault locations defined by magnetic anomalies should be closely related to mapped fault traces but commonly may not correspond precisely to any or all mapped strands. First, faults delineated by means of magnetic anomalies typically represent long-term positions of the faults (those defined by offset geologic units), whereas mapped fault traces commonly reflect only the most recent movement, especially in areas where the basement is covered by alluvium. Second, in areas where magnetic rocks lie in the basement buried beneath nonmagnetic cover, any dip on a fault will result in a systematic offset between the fault trace and the fault position determined from magnetic anomalies. Third, offsets of many kilometers on major faults rarely occur on single surfaces but rather are accommodated across fault zones a few hundred to a few thousand meters wide. We give examples of each of these situations for the specific faults discussed below

\section{Hayward Fault}

The Hayward Fault in the central San Francisco Bay region is marked by a distinct, discontinuous magnetic high, varying in width and amplitude (magnetic anomalies a, $\mathrm{k}$, 1, pl. 1), that extends for more than $50 \mathrm{~km}$. The magnetic high is caused by truncation at the fault of diverse magnetic rock units that lie northeast of the fault in the East Bay Hills block. In its central part (magnetic anomaly a), the magnetic high is caused largely by the upturned edge of a tabular body composed of serpentinite and igneous rocks of the Coast Range ophiolite (Wagner and others, 1991; Graymer and others, 1996) that has been folded and slivered up along the fault (Jones and others, 1994). Farther north, where magnetic anomaly 1 widens (just south of San Pablo Bay and extending northward beneath the bay). the magnetic source rocks are most likely Tertiary volcanic rocks (see Wright and Smith, 1992, profile B-B'), also folded up along the fault. In addition, magnetic sedimentary rocks of the San Pablo and Contra Costa Groups (magnetic anomaly c) that abut the Hayward Fault north of magnetic anomaly b probably contribute to the magnetic high along the fault in this area. Slabs of magnetic ophiolite probably also underlie the magnetic Tertiary rocks.

Recently active strands of the Hayward Fault (Lienkaemper, 1992) are closely correlated with the composite magnetic body and its associated magnetic anomaly (pl. 1) and generally lie within a few hundred meters of its magnetically defined southwest edge except near San Leandro (northern segment of magnetic anomaly a). Here, over a reach of about $6 \mathrm{~km}$ where the exposed ophiolite is more than $2 \mathrm{~km}$ wide, the active strand of the fault cuts across the center of the body rather than being confined along its southwest edge. The absence of apparent dissection of this body along the fault suggests that the currently active strand here accommodates a right-lateral offset of no more than $1 \mathrm{~km}$, possibly much less. To the northwest along the entire 15-km-long reach of the Hayward Fault immediately southeast of San Pablo Bay, active strands of the Hayward Fault coincide with or lie within $400 \mathrm{~m}$ (northeast) of the sharply and continuously defined southwest edge of the composite magnetic body (pl. 1). We identify this magnetic boundary as the long-term position of the Hayward Fault trace immediately southeast of San Pablo Bay. Interpretation of the long-wavelength part of the total magnetic field over the Hayward Fault indicates that the fault dips steeply, at least to about 5-km depth (Jachens and others, 1995b)

We extend the Hayward Fault northwestward across San Pablo Bay (pl. 1) on the basis of continuity of the Hay- 
ward Fault magnetic anomaly and, primarily, the inferred southwest edge of the source of this anomaly. This offshore extension of the fault is onstrike with the onshore section to the southeast, is nearly linear, and intersects the north shore of the bay at a point about $1 \mathrm{~km}$ east of the mouth of the Petaluma River. Of the 16-km length of this inferred reach of the Hayward Fault, the magnetic anomaly that defines the southeast $5 \mathrm{~km}$ is nearly identical to its counterpart onshore immediately to the southeast. Over the next $8 \mathrm{~km}$, however, the magnetic anomaly (1) widens and increases in amplitude, suggesting a change in the geometry of the magnetic source rocks. Nevertheless, the southwest edge of this magnetic body is mostly well defined and is aligned with the Hayward Fault to the southeast. A complexity occurs near the northwest end of this 8-km reach where a magnetic high (magnetic anomaly $\mathrm{m}$ ) indicates the presence of magnetic rocks southwest of our inferred Hayward Fault. The presence of this body southwest of the fault complicates the identification of a continuous magnetic boundary that defines the Hayward Fault adjacent to this body, but the reemergence of a welldefined magnetic boundary a few kilometers to the northwest and on strike with the fault to the southeast, together with the interpretation of gravity data discussed below, leads us to locate the Hayward Fault as shown on the aeromagnetic map (pl. 1).

Detailed underwater gravity data from San Pablo Bay and from onshore surveys southeast of the bay (inset, pl. 1) indicate that the mapped Hayward Fault consistently lies near the top of a pronounced, northeast-facing gravity gradient and that this gradient continues all the way across San Pablo Bay. The Hayward Fault occupies a similar position with respect to the gravity anomaly south of this area (inset, pl. 1; Chapman and Bishop, 1968; Roberts and Jachens, 1993). Our location of the Hayward Fault beneath San Pablo Bay, as inferred from aeromagnetic data, mostly coincides with its location by Smith (1992) on the basis of gravity data, and is in the same relative position with respect to the gravity gradient (inset, pl. 1) as the mapped fault onshore to the southeast. The gravity data furthermore show that the magnetic body (magnetic anomaly $\mathrm{m}$ ) beneath San Pablo Bay that we inferred to lie southwest of the fault is characterized by a gravity high and, thus, differs from the other magnetic sources in the immediate vicinity (inset, pl. 1). In fact, the nearest large magnetic body adjacent to and northeast of the Hayward Fault that is also characterized by a gravity high (Roberts and Jachens, 1993) is the magnetic body that causes the strong magnetic high near San Leandro (northern segment of magnetic anomaly a) about $40 \mathrm{~km}$ to the southeast. The dense magnetic body beneath San Pablo Bay could be a crossfault counterpart to the San Leandro body (magnetic anomaly a), suggesting a total offset on the Hayward Fault of at least $38 \mathrm{~km}$.

We tentatively extend the Hayward Fault about $3 \mathrm{~km}$ northwestward of the north shore of San Pablo Bay, on the basis of magnetic anomalies and boundaries (pl. 1). However, the westerly divergence of this strand from the trend of the Hayward Fault to the southeast and its divergence from the strong gravity gradient that characterizes the rest of the fault (inset, pl. 1) suggest that it probably does not represent a strand which accommodates much total offset.

\section{Total Offset on the San Andreas Fault ${ }^{1}$}

The Peninsular segment of the San Andreas Fault that ruptured during the 1906 San Francisco earthquake (pl. 1; location from Brabb and Olson, 1986; Pampeyan, 1994; Bonilla, 1971) is not characterized by a continuous magnetic anomaly, as is the Hayward Fault, but by truncation at the fault of several elongate magnetic anomalies (pl. 1) reflecting magnetic rock bodies that trend into the fault at low to moderate angles and are cut by the fault. Because these magnetic rock bodies are interspersed with relatively nonmagnetic rocks, the San Andreas Fault is defined by a discontinuous set of short, aligned magnetic boundaries situated where the magnetic bodies, both east and west of the fault, abut the fault plane. A fault defined by aligned, discontinuous magnetic boundaries is more difficult to recognize than one that is characterized by a continuous magnetic anomaly, such as the Hayward Fault. However, when the fault is located from geologic mapping or other information, then elongate magnetic rock bodies within the basement and truncated by the fault provide a means for estimating the total offset on the fault from the aeromagnetic map (pl. 1). Truncated magnetic rock bodies in the basement and their associated magnetic anomalies on one side of the fault should have counterparts on the opposite side of the fault separated by an along-fault distance equal to the total offset on the fault.

A strong, distinctive linear magnetic high (magnetic anomaly p, pl. 1) that lies mostly along the southwest edge of the Pilarcitos block, trending into the San Andreas Fault at an angle of $10^{\circ}$, reflects a magnetic body with a northeast edge that intersects the fault at point A (pl. 1). This body should have a crossfault counterpart with an associated magnetic anomaly that could be used to estimate the total offset on the Peninsular segment of the San Andreas Fault. The only magnetic anomaly east of the fault that is comparable to the anomaly at point A and is within the 20 - to $30-\mathrm{km}$ offset distance indicated by two displaced geologic units-a distinctive limestone-bearing unit (Bailey and others, 1964) of the Franciscan Complex (magnetic anomaly h, pl. 2) and an unusual gravel unit (Cummings, 1968) also cut by the fault-lies $22 \mathrm{~km}$ to the southeast and reflects a linear magnetic body whose north edge intersects the fault at point A (pl. 1). Pieces of ophiolite are found near both points A (Brabb and others, 1998) and A' (Miller-Hoare and Liou, 1980).

${ }^{1}$ Much of the discussion contained in this and the following section, and in the section below entitled "Detailed Structure of the Right Step in the San Andreas Fault," is based on the report by Jachens and Zoback (1999) and is included here for the sake of internal consistency and completeness. 
If the 22-km separation along the fault between the magnetic bodies at points $\mathrm{A}$ and $\mathrm{A}$ (pl. 1) represents the total offset on the Peninsular segment of the San Andreas Fault, then other magnetic anomalies west of and truncated at the fault on the aeromagnetic map (pl. 1) should have crossfault counterparts east of the fault that are also offset by $22 \mathrm{~km}$. The magnetic body that lies west of and abuts the San Andreas Fault between points $\mathrm{B}$ and $\mathrm{C}$ has a crossfault counterpart between points $\mathrm{B}^{\prime}$ and $\mathrm{C}^{\prime}, 22 \mathrm{~km}$ to the southeast. Magnetic metabasalts crop out in both places, but the sources of the magnetic anomalies between points $\mathrm{B}$ and $\mathrm{C}$ and between points $\mathrm{B}^{\prime}$ and $\mathrm{C}^{\prime}$ are difficult to precisely identify because the anomaly west of the fault is mostly offshore and the anomaly east of the fault is partly caused by a sheet of serpentinite.

Restoration of $22 \mathrm{~km}$ of right-lateral offset places the broad, low-amplitude magnetic high that abuts the fault along the reach between 3 and $9 \mathrm{~km}$ southeast of point B (pl. 1) against the fault-terminated ends (along the reach between 4 and $10 \mathrm{~km}$ southeast of point $\mathrm{B}^{\prime}$ ) of the horseshoe-shaped magnetic high east of the fault. Although this match does not provide compelling evidence for $22 \mathrm{~km}$ of right-lateral offset, given the $22 \mathrm{~km}$ of offset clearly defined by the matches $\mathrm{A}-\mathrm{A}^{\prime}, \mathrm{B}-\mathrm{B}^{\prime}$, and $\mathrm{C}-\mathrm{C}^{\prime}$, the anomalies southeast of points $\mathrm{B}$ and $\mathrm{B}^{\prime}$ are similar enough to constitute supporting evidence. Thus, the magnetic anomalies in the vicinity of the Peninsular segment of the San Andreas Fault support the geologic inference that only a few tens of kilometers of total offset are accommodated on this segment of the fault, and refine the estimate of the offset to $22 \pm 1 \mathrm{~km}$.

\section{Offshore San Andreas Fault}

For the purposes of this study, the northwesternmost reach of the San Andreas Fault on the San Francisco peninsula is well defined magnetically (near point B', pl. 1). Here, for an onshore distance of $5 \mathrm{~km}$, the long-term position of the fault coincides with the northeast boundary of a body probably composed of magnetic Franciscan metabasalt (see pl. 2). The northeast edge of this body as defined magnetically lies parallel to and 200 to $400 \mathrm{~m}$ northeast of the mapped trace of the San Andreas Fault (pl. 1), an apparent misalignment that we attribute to a steep northeastward dip on the upper part of the San Andreas Fault plane (U.S. Geological Survey, 1997b). The magnetic anomaly produced by this body is strongest near the coast and continues $5 \mathrm{~km}$ offshore as a strong, consistent magnetic feature (high values to the southwest, low values to the northeast). We interpret the offshore 5-km-long northeast boundary of the body causing this anomaly to be the continuation of the San Andreas Fault (pl. 1), on the basis of the relation of this boundary to the fault trace onshore and the fact that it is a direct onstrike projection of the onshore fault.

We end this strand of the San Andreas Fault $5 \mathrm{~km}$ offshore at point $\mathrm{C}$ (pl. 1) for the following reasons. (1) A distance of 5 $\mathrm{km}$ is as far as the aeromagnetic data define a boundary (separating magnetic rocks to the southwest from less magnetic rocks to the northeast) that is continuous with and consistent with the magnetically defined San Andreas Fault at the coast. (2) Northwest of this point, the projection of the fault enters a region of magnetic rocks that, though not uniform in magnetic properties, apparently belong to a single large triangular block, $6 \mathrm{~km}$ wide at its base, which extends $12 \mathrm{~km}$ northwestward from point $\mathrm{C}$. The magnetic anomalies over this block suggest that the source is composed of the same types of rocks (of the Permanente and Headlands terranes) as the Pilarcitos block onshore and southwest of the fault. (3) If the San Andreas Fault were to continue on strike northwestward of point $\mathrm{C}$, within $6 \mathrm{~km}$ it would be truncated at, but not offset, the strong north-northwest-trending magnetic lineation to the west that we identify as a strand of the San Gregorio Fault zone (see discussion below). Truncation of the Peninsular segment of the San Andreas Fault against the San Gregorio Fault zone would preclude accommodation of the $22 \mathrm{~km}$ of total offset on this segment documented in the previous section.

Although no continuous magnetic boundary connects the mapped trace of the Peninsular segment of the San Andreas Fault with the mapped traces at Bolinas Lagoon, a major linear offshore magnetic boundary, more than $20 \mathrm{~km}$ long, projects into the northeastern strand of the San Andreas Fault at Bolinas Lagoon (pl. 1). This boundary nearly parallels the Peninsular segment of the fault and occupies the same relative position with respect to magnetic rocks of the Pilarcitos block as does the Peninsular segment to the south (that is, it forms the northeast boundary of the magnetic Pilarcitos block). We identify this magnetic boundary as the location of the offshore southeastward extension of the San Andreas Fault mapped at Bolinas Lagoon. Furthermore, on the basis of the profound magnetic contrast across this segment, we interpret it to be the main strand of the San Andreas Fault that accommodates offset between the San Francisco Bay block and the Pilarcitos block across the mouth of the Golden Gate. This strand, here informally called the Golden Gate segment of the San Andreas Fault, projects southeastward to the San Francisco peninsula, intersecting the coast near Lake Merced. Although no fault is recognized in the seacliff at this place, an abrupt change in the dip of strata of the Merced Formation is visible here (Clifton and Hunter, 1987), a feature characteristic of the Golden Gate segment offshore as seen in marine seismic-reflection records (see Bruns and others, this volume). The inferred northwest end of the Peninsular segment and the inferred southeast end of the Golden Gate segment of the San Andreas Fault do not connect but are separated in a right-step sense by $3 \mathrm{~km}$ normal to strike. Although several workers (for example, Cooper, 1973; McCulloch, 1987; Hengesh and Wakabayashi, 1995; Zoback and others, 1999) have recognized the need for a rightward bend or right step in the San Andreas Fault offshore west of San Francisco, the interpretation presented here provides details of the position and geometry of this right step (informally called the Lake Merced right step).

\section{Pilarcitos Fault}

The northwesternmost $14 \mathrm{~km}$ of the onshore Pilarcitos Fault (Pampeyan, 1994) coincides closely with a strong mag- 
netic boundary (pl. 1) that separates magnetic Franciscan basement rocks of the Pilarcitos block from mostly nonmagnetic granitic rocks of the Montara block. This magnetic boundary, which extends northwestward an additional $8 \mathrm{~km}$ offshore, is inferred to mark the offshore extension of the Pilarcitos Fault. The northwest end of this extension bends slightly northward and merges with a set of north-northwesttrending magnetic boundaries that we infer to mark the San Gregorio Fault zone (see next subsection). Magnetic modeling indicates that onshore, the Pilarcitos Fault, where magnetically well defined, is nearly vertical at least to about 4-km depth, in accord with the conclusions of Parsons and Zoback (1997), who defined a vertical attitude for the Pilarcitos Fault to 7-km depth, using lateral-velocity changes inferred from seismic tomography.

\section{San Gregorio Fault Zone}

A set of long, linear, north-northwest-trending echelon magnetic boundaries (magnetic anomaly q, pl. 1) lies in a 1- to 2-km-wide zone that marks the west offshore edge of magnetic rocks of the Pilarcitos block (pl. 1). The relative straightness of these boundaries and the profound difference in magnetism of the rocks on either side of the zone strongly suggest that these features reflect individual strands within a fault zone that has accommodated major lateral offset. Although this interpretation cannot be corroborated by correlation with aligned onshore faults to the southeast, the northernmost offshore strand projects across a 3-km gap directly into the southwesternmost mapped strand of the San Andreas Fault at Bolinas Lagoon. Recent detailed marine seismicreflection profiling (see Bruns and others, this volume) also has shown that the magnetic boundaries within this offshore zone coincide with major faults in the sedimentary section (fig. 2).

We conclude that the north-northwest-trending set of linear magnetic boundaries identified on the aeromagnetic map (pl. 1) along the west edge of the Pilarcitos block delineates the location of the San Gregorio Fault zone between Half Moon Bay and Bolinas Lagoon, for the following reasons: (1) the zone containing the magnetic boundaries regionally lies on the northward projection of the San Gregorio Fault zone (for example, Graham and Dickinson, 1978; McCulloch, 1987); (2) the magnetic boundaries coincide with faults identified by marine seismic-reflection profiling; (3) the lengths (one is $>20 \mathrm{~km}$ long) and straightness of the boundaries suggest major strike-slip faults; (4) the north end of the northernmost boundary projects directly into the western strand in the San Andreas Fault zone at Bolinas Lagoon, the strand that defines the east boundary of nonmagnetic Cretaceous granitic rocks and separates Franciscan basement on the east from Salinian basement on the west (Galloway, 1977; Wagner and Bortugno, 1982; Wagner and others, 1991; Clark and Brabb, 1997); and (5) the south end of the southernmost boundary coincides with a scarp on the sea floor that projects directly into the onshore Seal
Cove Fault (Glen, 1959), now included as a strand of the San Gregorio Fault.

\section{Discussion}

The newly acquired high-resolution aeromagnetic surveys constitute a rich source of structural information about strands of the San Andreas Fault system concealed beneath young sedimentary deposits and (or) water in the San Francisco Bay region. The uniform areal coverage of these aeromagnetic surveys, in combination with the clear expression of many of the faults in the aeromagnetic data, provides a coherent framework within which to integrate the exposed bedrock geology and sparsely distributed subsurface data. In addition, these data constitute a bridge between onshore geologic information and marine geophysical surveys and provide an areally uniform image of the entire fault system in the San Francisco Bay region that we have lacked in the past. Included in the data are new clues into structures at the intersections of branching major fault strands, structures within a block caught between major faults, and detailed geometries in areas of extensional stepovers within the strikeslip system.

\section{San Andreas-San Gregorio Fault Junction}

The fault strands inferred from the aeromagnetic map (pl. 1) provide new information on the structure at the San Andreas-San Gregorio Fault junction north of San Francisco. The Golden Gate segment of the San Andreas Fault connects at Bolinas Lagoon with the northeasternmost of the three onshore strands in the San Andreas Fault zone mapped by Galloway (1977). Galloway's northeastern strand, like the Golden Gate segment offshore, has Franciscan basement on both sides, even though the basement sliver to the southwest is quite narrow and largely concealed beneath Cenozoic deposits.

We correlate the northernmost strand of the inferred offshore San Gregorio Fault zone with the westernmost onshore strand in the San Andreas Fault zone at Bolinas Lagoon because (1) the northern offshore strand of the San Gregorio Fault zone, where last clearly delineated by the aeromagnetic data, projects directly into the southwestern mapped strand in the San Andreas Fault zone at Bolinas Lagoon; and (2) the onshore and offshore strands occupy the same structural position, separating Franciscan basement rocks on the northeast from Salinian granitoids on the southwest. Thus, we argue for continuity of the westernmost strand in the San Andreas Fault zone at Bolinas Lagoon southeastward with the San Gregorio Fault zone. Cooper (1973) also connected the onshore westernmost strand in the San Andreas Fault zone at Bolinas Lagoon with a strand of the San Gregorio Fault zone (the Seal Cove Fault), but the details of his connection in the offshore differ somewhat from the path proposed here.

Within 10 to $15 \mathrm{~km}$ northwestward from Bolinas Lagoon, the several mapped fault strands converge smoothly 


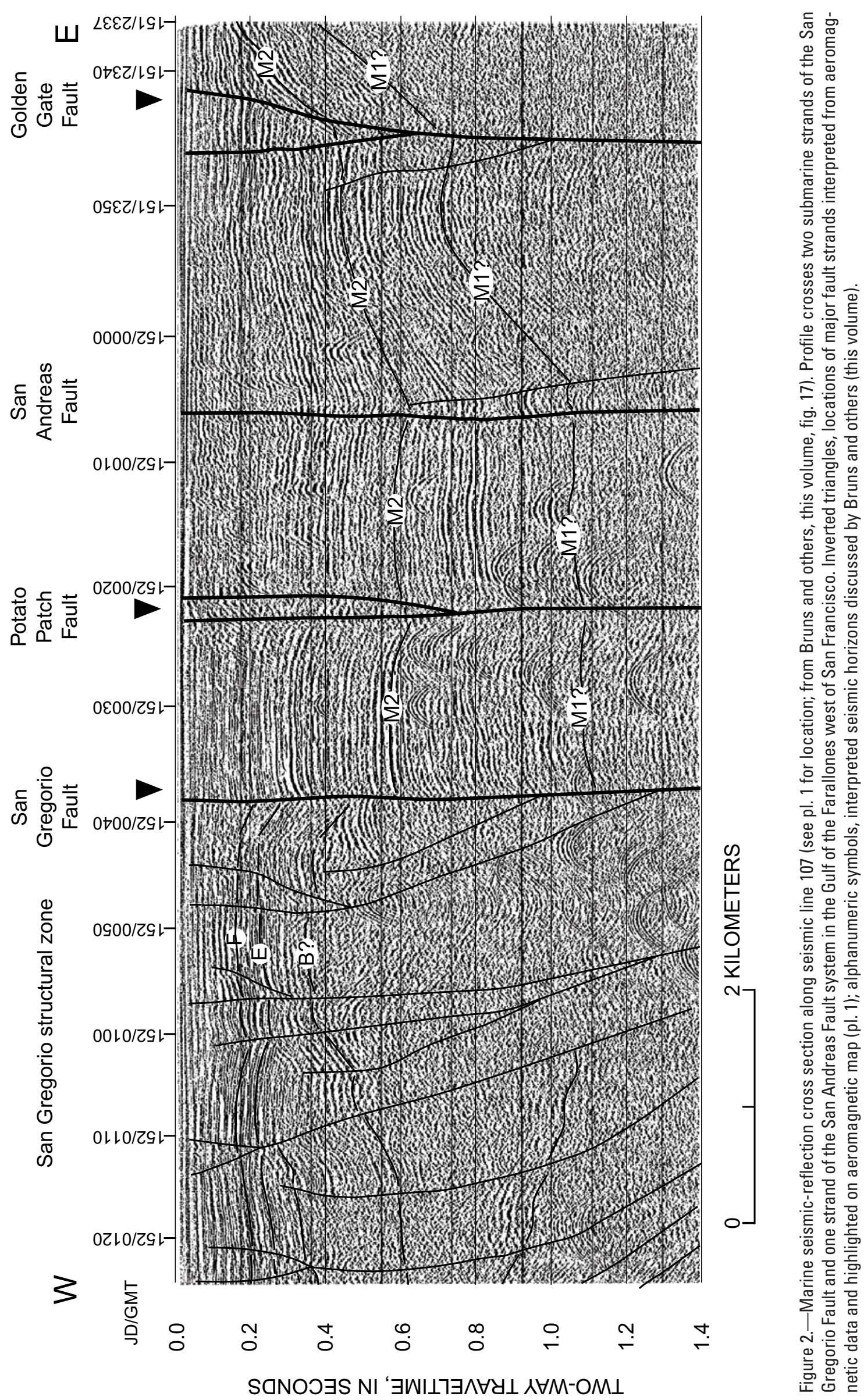

Concealed Strands of the San Andreas Fault System in the Central San Francisco Bay Region 
into a zone less than about $1 \mathrm{~km}$ wide. Thus, on the basis of our correlation of the San Andreas and San Gregorio Fault zones at Bolinas Lagoon, the junction of these two major fault zones is characterized by the simple northwestward merging of strands into a very narrow zone. Structurally, this junction seems somewhat simpler than the junctions of other major strands of the San Andreas Fault system, such as the San Andreas-Calaveras Fault junction (Jennings and Strand, 1959), the Hayward-Calaveras Fault junction (Wagner and others, 1991; Jones and others, 1994), and the San Andreas-San Jacinto Fault junction (Morton and Matti, 1993). Those junctions are characterized by broad, complex zones where major strands of the converging fault zones remain separated by a few kilometers or more over along-strike distances of tens of kilometers. The apparent simplicity of the San Gregorio-San Andreas Fault junction may be related to the releasing-bend nature of the junction. Alternatively, the San Gregorio-San Andreas Fault junction is fundamentally an intersection of basement faults, whereas the fault junctions mentioned above are mostly expressed by faults in a young sedimentary section. These young sedimentary materials may respond to active faulting more complexly than the underlying basement rocks.

\section{San Gregorio-Pilarcitos Fault Junction}

The San Gregorio-Pilarcitos Fault junction lies $\sim 5 \mathrm{~km}$ offshore (pl. 1). Although the nominal strikes of the two faults differ by $\sim 45^{\circ}$, the Pilarcitos Fault offshore bends smoothly northward, ultimately merging with the San Gregorio Fault zone or intersecting it at an angle of $<15^{\circ}$.

Whether the Pilarcitos Fault merges smoothly with the San Gregorio Fault zone or truncates against it is important for understanding the development of total offset on, and partitioning of offset among, the various strands of the San Andreas Fault system in northern California (Jachens and others, 1998). Either the Pilarcitos Fault was cut by the San Gregorio Fault zone (Graham and Dickensen, 1978; Griscom and Jachens, 1989), or the Pilarcitos Fault always merged smoothly with the San Gregorio Fault zone. In the first case, the rightward bend at the northwest end of the Pilarcitos Fault is the result of an initial high-angle truncation of the Pilarcitos Fault at the San Gregorio Fault zone that was subsequently deformed by drag associated with continued right-lateral strike-slip movement on the San Gregorio Fault zone. In the second case, before initiation of movement on the Peninsular segment of the San Andreas Fault a few million years ago, the main plate-boundary fault separating granitic and Franciscan terranes consisted of the Pilarcitos Fault and that segment of the San Gregorio Fault zone to its north. Possible warping of this proposed Pilarcitos-northern San Gregorio Fault segment into a leftward bend (restraining bend) geometry could have ultimately resulted in abandonment of the Pilarcitos Fault when the San Andreas Fault broke through on the straighter Peninsular segment a few million years ago and movement contin- ued on the San Gregorio Fault zone (Griscom and Jachens, 1989; Jachens and Zoback, 1999).

If the first case applies, then the offset counterpart of the strong magnetic anomaly that defines the Pilarcitos Fault on the San Francisco peninsula should exist west of, and be truncated at, the San Andreas Fault somewhere north of San Francisco (Graham and Dickensen, 1978; Griscom and Jachens, 1989). Identification of a crossfault counterpart to this anomaly would tightly constrain the total offset on a segment of the San Andreas Fault system and would document the existence of an offset strand of the fault system that would need to be taken into account in any attempt to understand the partitioning of total slip on the fault system.

If the second case applies, then no crossfault counterpart to the Pilarcitos Fault or its associated magnetic anomaly would be expected, and one potential fault element from the total San Andreas Fault system would be removed. The latest aeromagnetic survey over part of the northern section of the San Andreas Fault and adjacent Continental Shelf (U.S. Geological Survey, 1997a) shows no likely offset counterpart of the Pilarcitos Fault anomaly at least as far north as Gualala, Calif., about $150 \mathrm{~km}$ north of the San Gregorio-Pilarcitos Fault junction (Jachens and others, 1998). An older aeromagnetic survey of the Point Arena, Calif., area (Gulf Research and Development Co., unpub. data) reveals a possible offset counterpart of the Pilarcitos Fault magnetic anomaly west of the San Andreas Fault about $50 \mathrm{~km}$ farther north near Point Arena. However, more detailed study of the subsurface geology and geophysics of the Point Arena area is needed to establish whether the magnetic anomalies in this area correlate with the Pilarcitos Fault magnetic anomaly in the San Francisco Bay region.

\section{Structure of the Pilarcitos Block}

The presence of a major right step in the San Andreas Fault strand bounding the northeast side of the Pilarcitos block, and the existence of right-stepping echelon strands of the San Gregorio Fault zone bounding the west side of the Pilarcitos block, suggest that at least the north half of this block lies in an extensional setting. This interpretation is compatible with the general releasing-bend geometry of the San Andreas-San Gregorio Fault junction and with the high level of seismicity within the block dominated by normal faulting on northerly trending fault planes (Zoback and others, 1998). A young, thick sedimentary section on the Continental Shelf between the San Andreas Fault and the San Gregorio Fault zone, as indicated by a gravity low, seismic-reflection profiling (Cooper, 1973), and wide-angle seismic-refraction profiling (Hole and others, 1993) and defined areally by new high-resolution seismic-reflection data (see Bruns and others, this volume), are also consistent with an extensional setting for the northern part of the Pilarcitos block. Bruns and others (this volume) examine the extensional regime of this block in greater detail. 


\section{Detailed Structure of the Right Step in the San Andreas Fault}

Understanding the right step in the San Andreas Fault near Lake Merced is important because it places an active segment (Golden Gate segment) of the San Andreas Fault system $3 \mathrm{~km}$ closer to downtown San Francisco than previously thought (previous distance, $10-15 \mathrm{~km}$ ). The position of this segment and its proximity to the highly developed downtown area must be taken into account when estimating the local shaking from an earthquake on the San Andreas Fault here. This right step may also provide insights into conditions controlling the initiation of great strike-slip earthquakes because the epicenter of the great 1906 San Francisco earthquake is believed to lie within the right-step region (Bolt, 1968; Boore, 1977).

As several workers have pointed out, a right step in a right-lateral fault system implies, with continued movement, the formation of a pullapart basin bounded by the two fault strands composing the right step or their onstrike projections (for example, Aydin and Nur, 1982, 1985). Thus, a pullapart basin about $3 \mathrm{~km}$ wide might be expected to exist along the San Andreas Fault southeastward from the Lake Merced right step. Because the Peninsular segment of the San Andreas Fault has accommodated only $22 \mathrm{~km}$ of offset (see preceding section) and probably has been active for only a few million years (Hengesh and Wakabayashi, 1995), the pullapart basin should be filled with young, low-density sedimentary deposits and be accompanied by a gravity low.

Detailed gravity measurements on the San Francisco peninsula (Roberts, 1991) reveal such a gravity anomaly, a pronounced gravity low 2 to $3 \mathrm{~km}$ wide, aligned along the San Andreas Fault and bounded by the fault on the southwest. Inversion of this gravity anomaly to estimate the thickness of Cenozoic deposits above the Franciscan basement, using a slight modification of the technique of Jachens and Moring (1990), indicates a basin along the San Andreas Fault with the characteristics expected of a pullapart basin resulting from the right step in the San Andreas Fault offshore of the San Francisco peninsula (fig. 3). The basin, about $3 \mathrm{~km}$ wide and $1 \mathrm{~km}$ deep at the coast, both shallows and narrows away from the right step southeastward along the San Andreas Fault. At the coast, the northeastern margin of the basin coincides with the onshore projection of the Golden Gate segment of the San Andreas Fault (fig. 3), as expected of a pullapart caused by the inferred right step. Thus, the onshore gravity data provide strong support for the inferred $3 \mathrm{~km}$ right step in the San Andreas Fault system offshore from San Francisco. However, almost no gravity data are available in the critical offshore area of the right step, and so at present the gravity analysis cannot be extended into the offshore area.

Understanding the detailed structure and evolution of the Lake Merced right step may also help to explain the cause of northeastward-directed thrust faulting along the San Andreas Fault on the northern part of the San Francisco peninsula and the somewhat puzzling uplift of deposits of the Merced Formation (pl. 2) northeast of the fault, deposits that just a few million years ago or less had accumulated in a subsiding, presumably extensional environment (Hengesh and Wakabayashi, 1995). We suggest that the explanation for both of these processes lies in the detailed fault geometry within in the right-step region. The inferred Golden Gate segment of the San Andreas Fault is extremely straight and almost exactly parallels all but the northernmost section of the San Andreas Fault on the central part of the San Francisco peninsula (pl. 1). The northernmost section of this Peninsular segment ( $5 \mathrm{~km}$ offshore and $5 \mathrm{~km}$ onshore) strikes as much as $10^{\circ}$ more westerly than the section to the south, leading to a decrease in fault-normal separation of the right-step strands from $3 \mathrm{~km}$ at point $\mathrm{C}$ to $2 \mathrm{~km}$ southeast of point $\mathrm{C}$ (pl. 1). The pullapart basin resulting from the right-step geometry is actively subsiding and filling immediately behind (southeast of) the right step and, on the basis of offsets mapped after the 1906 San Francisco earthquake, is progressively moving southeastward with the San Francisco Bay block. Thus, the basin is filling at a place where it is $3 \mathrm{~km}$ wide, but is then progressively compressed to a width of only $2 \mathrm{~km}$ during its subsequent $10 \mathrm{~km}$ of travel southeastward with the San Francisco Bay block. This progressive southeastward narrowing of the basin is evident in the flanks of the basin, as defined by the gravity inversion (fig. 3). The space problem created by the conditions described above would likely result in faultnormal compression across the basin, causing thrusting and uplift of the basin deposits. Thus, the seemingly contradictory conditions of extension and uplift within a small area may simply be the result of progressive evolution of a pullapart basin with nonparallel bounding faults.

Finally, because the Lake Merced right step lies offshore, it is concealed from direct observation. However, before the inception of movement on the Peninsular and Golden Gate segments of the San Andreas Fault, point C' (pl. 1) would have been located at the future position of the Lake Merced right step. Therefore, today the area around point $C^{\prime}$ might be a good place to look for evidence reflecting the initiation of major strike-slip faulting and the early evolution of a right step in a right-lateral strike-slip system.

\section{Right Step in the Hayward Fault-Rodgers Creek Fault}

Geologic mapping (Wagner and Bortugno, 1982) and geophysical interpretations (Wright and Smith, 1992) indicates that the Hayward Fault does not continue far northward of San Pablo Bay, a conclusion consistent with the geophysical data presented above in the section entitled "Hayward Fault." Analyses of seismicity and other evidence of active faulting (Hill and others, 1990; Budding and others, 1991) indicate that slip on the Hayward Fault south of San Pablo Bay probably is now accommodated on the Rodgers Creek Fault north of the bay. The relative positions of the northern section of the Hayward Fault and the southern section of the Rodgers Creek Fault (pl. 1; fig. 1) suggest a right step of about $6 \mathrm{~km}$ in the Hayward-Rodgers Creek Fault system, pos- 
sibly similar to the right step in the San Andreas Fault system near Lake Merced. The details of the structure of this right step and the method of slip transfer are uncertain because the transfer region is largely concealed beneath San Pablo Bay.

The amount of right-lateral offset likely to have taken place during the lifetime of the right step is not well constrained but probably more than $10 \mathrm{~km}$. Wright and Smith (1992) suggested that early slip on the Hayward Fault was taken up on the Tolay Fault to the north, but because the Tolay Fault offsets units no younger than early Pleistocene (Hart, 1982), Holocene slip must be accommodated elsewhere. If the present slip rate on the Hayward Fault ( $\sim 9 \mathrm{~mm} /$ yr; Working Group on California Earthquake Probabilities, 1999) has persisted since the early Pleistocene, then at least 15 to $20 \mathrm{~km}$ of offset could have accumulated while the right step was in existence. Even more offset is predicted by the work of R.W. Graymer (unpub. data, 1999), who used offset volcanic deposits of Tertiary age to estimate the total offset on various faults east of San Francisco Bay. He estimated that the Hayward Fault accommodates $82 \mathrm{~km}$ of total offset, of which $39 \mathrm{~km}$ is partitioned onto the Tolay Fault and the remaining $43 \mathrm{~km}$ onto the Rodgers Creek Fault. Although these two estimates of offset differ substantially, they both suggest that a significant amount of offset has occurred across the right step from the Hayward Fault to the Rodgers Creek Fault during its lifetime.

The inferred geometry and slip history of the right step beneath San Pablo Bay (6-km-wide step, tens of kilometers of offset) are similar enough to those of the right step in the San Andreas Fault near Lake Merced to suggest that the features which characterize the Lake Merced right step might also be associated with the right step beneath San Pablo Bay. These features might include a pronounced linear gravity low extending southeastward along the Hayward Fault from

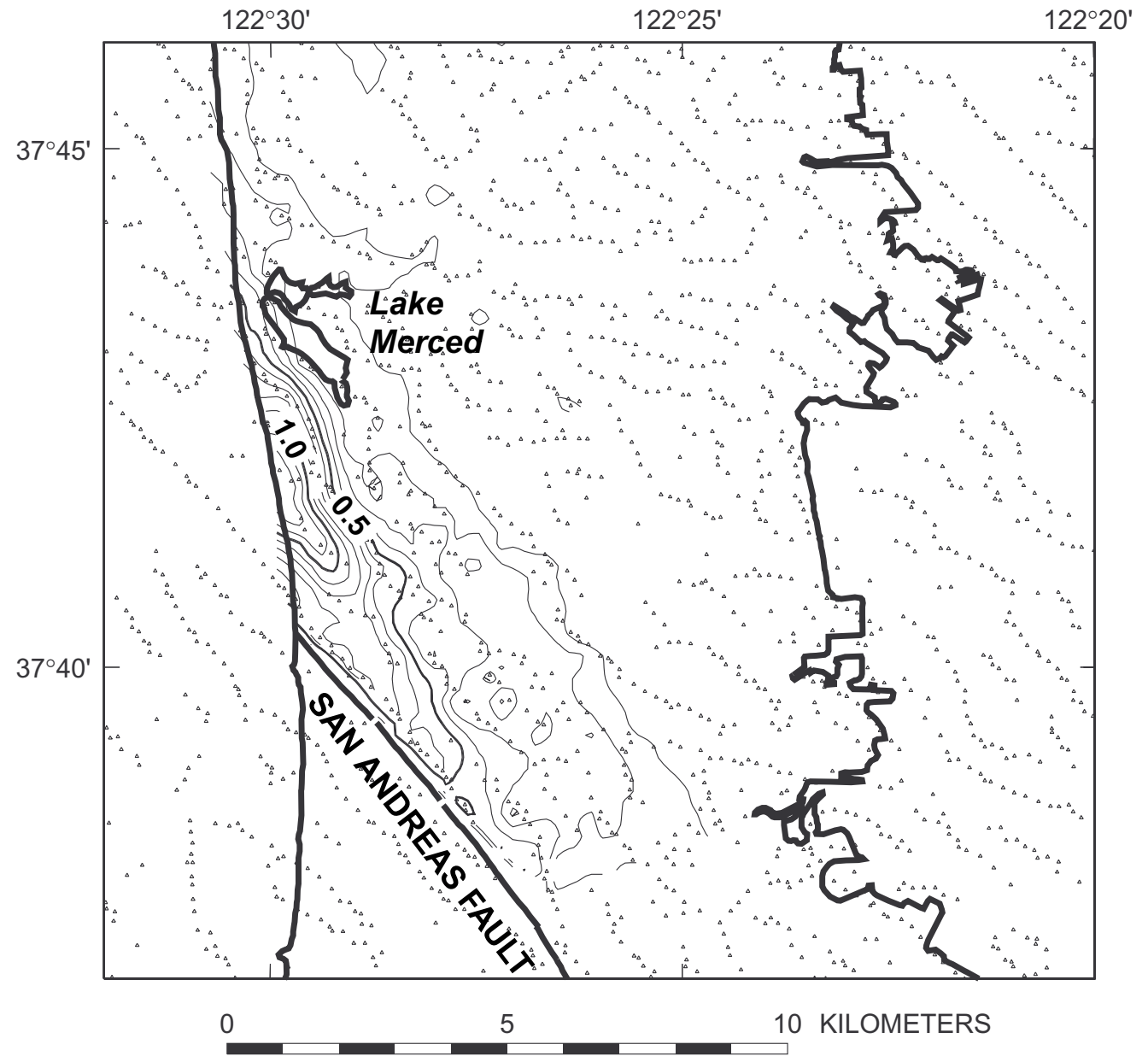

Figure 3.-Lake Merced area (see pl. 1 for location), showing thickness of Pliocene and Quaternary deposits of the Merced Formation and younger sedimentary deposits that fill inferred pullapart basin southeast of right step in the San Andreas Fault offshore. Map was produced by three-dimensional inversion of detailed gravity data (Roberts, 1991) constrained by drill-hole data and outcrop geology, using procedure of Jachens and Moring (1990) modified slightly to allow for explicit incorporation of drill-hole constraints. Contour interval, $0.1 \mathrm{~km}$. Same scale as in plates 1 and $2(1: 150,000)$. 
San Pablo Bay, a corresponding deep linear basin $6 \mathrm{~km}$ wide and filled with Quaternary deposits in the wake of the right step, and disrupted geologic units and structural features that predate the right step and have been dismembered by faulting associated with the recent linkage of the Hayward and Rodgers Creek Faults.

Wright and Smith (1992) presented a structural analysis of the right step beneath San Pablo Bay based on detailed onshore and bay-bottom gravity surveys, drill-hole data, and marine seismic reflection profiles. They determined that the Hayward and Tolay Faults occupy similar structural positions at the northeast edge of uplifted Franciscan rocks of the San Francisco Bay block and that the gravity data indicate that the two faults are connected by a 4-km right step beneath the north shore of San Pablo Bay. They concluded that the Tolay and Rodgers Creek Faults are separate, parallel features which bound opposite sides of a deep Late Cenozoic structural trough, a relation that precludes a direct connection between the Hayward and Rodgers Creek Faults in the upper seismogenic zone, at least north of about the center of San Pablo Bay. They projected the Rodgers Creek Fault $13 \mathrm{~km}$ southeastward from its outcrop area (pl. 1) on the basis of an abrupt change in the dip of Tertiary beds, as determined from drill-hole logs and seismic-reflection profiles. Finally, they identified a trough filled with sedimentary and volcanic materials beneath San Pablo Bay between the Hayward Fault and the southeastward projection of the Rodgers Creek Fault that is consistent with a pullapart basin behind a right step from the Hayward Fault to the Rodgers Creek Fault.

The gravity data of Smith (1992) reveal an enormous gravity low northeast of the Hayward Fault and over San Pablo Bay and surrounding areas (inset, pl. 1). However, the low extends more than $10 \mathrm{~km}$ northeastward of the projection of the Rodgers Creek Fault beneath the bay, too far northeastward to be caused by an extensional basin associated with the present right step. This low might more appropriately reflect an extensional collapse associated with an earlier right step between the Hayward-Tolay Fault system and the Franklin-Carneros Fault system. The expected local gravity low between the Hayward and Rodgers Creek Faults is not obvious on the inset on plate 1, although a low of only a few milligals might exist but would be difficult to identify because it would be superposed on the steep northeast-facing gravity gradient associated with the transition from a thick sedimentary section of the East Bay Hills block to Franciscan basement rocks of the San Francisco Bay block.

Two interpreted cross sections across San Pablo Bay approximately normal to the Hayward Fault (Wright and Smith (1992), one along the north edge of the bay and the other about $5 \mathrm{~km}$ to the southeast, show a unit of Tertiary and Quaternary rocks 2+ km thicker between the Hayward and Rodgers Creek Faults than in areas to the northeast and southwest. This anomalously thick section of young deposits is not easily reconciled with the absence of a pronounced corresponding gravity low. The anomalously thick part of this section may be largely Tertiary and thus denser than the Quaternary deposits, as suggested by the tentative identification of an interface (angular unconformity?) in the upper part of this section on the southernmost cross section that shows only 0.5 to $0.9 \mathrm{~km}$ of thickening. Finally, no narrow, linear basin filled with Quaternary deposits extends more than a few kilometers onshore southeast of San Pablo Bay, as might be expected from a right step that accommodated tens of kilometers of offset.

The magnetic anomalies over San Pablo Bay and vicinity (pl. 1) support the interpretation by Wright and Smith (1992) and may provide some additional constraints on allowable mechanisms for slip transfer between the Hayward and Rodgers Creek Faults. A southeast-trending magnetic high (magnetic anomaly $\mathrm{n}$ ) reflects a magnetic source body, most likely composed of Tertiary volcanic rocks (Wright and Smith, 1992), deep in the structural trough between the Tolay and Rodgers Creek Faults. The continuation of this magnetic anomaly beneath San Pablo Bay indicates that the source body bends southward and ultimately truncates against the Hayward Fault from 8 to $13 \mathrm{~km}$ northwest of Pinole Point (pl. 1). The continuity of this magnetic source body precludes any direct connection between the upper parts of the Hayward and Rodgers Creek Faults north of the south edge of this body because any such fault that accommodated significant strikeslip offset would necessarily have offset the magnetic source body. A second magnetic high (magnetic anomaly o) parallels and lies east of both magnetic anomaly $\mathrm{n}$ and the Rodgers Creek Fault. Although magnetic anomaly o becomes less distinct as it continues beneath San Pablo Bay, it also suggests a source body that bends southward and continues beneath the bay in a manner conformal to the source of magnetic anomaly $\mathrm{n}$, finally ending near the Hayward Fault $~ 3-5 \mathrm{~km}$ northwest of Pinole Point. The apparent continuity of the source of magnetic anomaly o appears to preclude any shallow connection between the Hayward and Rodgers Creek Faults southeast of about Pinole Point and also seems to rule out any significant strike-slip offset on an onstrike extension of the Rodgers Creek Fault southeast of its southeasternmost location on the aeromagnetic map (pl. 1). Although magnetic anomaly o is admittedly weak and difficult to trace beneath the bay, we have examined its location and continuity with several data processing and enhancement techniques and conclude that its characteristics are robust enough to support the above-stated conclusions.

In summary, the detailed structure and kinematics of slip transfer are far less clear for the right step between the Hayward and Rodgers Creek Faults than for the comparable right step in the San Andreas Fault near Lake Merced. If a direct connection exists between the Hayward and Rodgers Creek Faults in the uppermost few kilometers of crust, then it likely lies beneath San Pablo Bay somewhere between magnetic anomalies $\mathrm{n}$ and $\mathrm{o}$ (pl. 1). Alternatively, a direct connection between the two faults may exist at depth, with the uppermost few kilometers of crust decoupled in such a way as to retain continuity of older, shallow geologic units. In either case, the absence of a pronounced gravity low between the two fault strands, and the presence of possibly only a modest extensional basin filled with Quaternary deposits beneath the 
bay and no basin at all south of the bay, are puzzling, given the likelihood that 15 to $40 \mathrm{~km}$ of offset has occurred on the Rodgers Creek Fault. Complex interactions of local subsidence and uplift may have complicated the present picture, or else the Hayward and Rodgers Creek Faults may have been colinear during most of the time when slip was accumulating on the Rodgers Creek Fault, with some superposed deformational event causing the right step to form only very recently. Some combination of these possible interpretations, or others that we have not considered, may be needed to fully understand the nature of the right step beneath San Pablo Bay.

\section{Additional Considerations}

The above discussion, though providing new insights into the structure, kinematics, and dynamics of the San Andreas Fault system in the San Francisco Bay region, has in no way exhausted the potential of the aeromagnetic data presented here for providing a new understanding of the geology and tectonics of the region. For example, we have discussed only active or recently active strands of the San Andreas Fault system. The aeromagnetic map (pl. 1), however, reveals numerous long, linear magnetic boundaries or aligned boundary segments, many of which evidently reflect faults. These features may be ancient faults left over from the initial tectonic assembly of the crust of the region many millions of years ago. Alternatively, they may be faults that are presently dormant but still represent a potential seismic hazard in the near future. As another but slightly different example, many of the magnetic anomalies shown on the map are caused by sheets of serpentinite within the basement, sheets that often are hidden beneath young sedimentary deposits. Thus, the map directly indicates in detail the distribution of serpentinite in the subsurface, information that is of possible interest because of the common association of potentially hazardous mercury and asbestos with serpentinite in the California Coast Ranges.

In more general terms, the aeromagnetic data presented here provide a type of three-dimensional "image" of the crustal geology of the San Francisco Bay region, at least insofar as this geology is reflected by the shape and distribution of magnetic rocks, even in such highly urbanized areas as those surrounding San Francisco Bay, where the deeper geology is hidden beneath alluvial deposits and where urban development has destroyed much of the geologic evidence once present at the surface. Although interpretations of magnetic anomalies are known to be ambiguous (different bodies can sometimes produce identical magnetic anomalies), nevertheless, every recognizable magnetic anomaly contains some three-dimensional information about the rock body that produces it. This three-dimensional information can be derived from the geometric characteristics of the magnetic anomalies, from their areal distribution, and from forward modeling of them with constraints imposed by geology, drill-hole data, and other geophysical information. In such areas as the San Francisco Bay region where magnetic rocks are abundant and reasonable well known, aeromagnetic data provide a powerful tool for helping to unravel the concealed geology.

Because we recognize the potential usefulness of aeromagnetic data for solving a host of other problems not discussed in this report, we have provided the aeromagnetic map (pl. 1) at a large scale and included the full suite of automatically determined magnetic boundaries (small pluses) over the entire map area, not simply those that are directly related to our interpretation. Furthermore, we have released the data for the central part of the map area in contour form at a scale of 1:100,000 (U.S. Geological Survey, 1996), along with all the digital data that went into the production of the map, through the National Geophysical Data Center (325 Broadway, Boulder, CO 80303-3328).

\section{References Cited}

Abrams, G.A., Kucks, R.P., and Braken, R.E., 1991, Aeromagnetic map of Palo Alto and vicinity, California: U.S. Geological Survey Open-File Report 91-336, scale 1:62,500.

Aydin, Atilla, and Nur, Amos, 1982, Evolution of pull-apart basins and their scale independence: Tectonics, v. 1, no. 1, p. 11-21.

Aydin, Atilla, and Nur, Amos, 1985, The types and role of stepovers in strike-slip tectonics, in Biddle, K.T., and Christie-Blick, Nicholas, eds., Strike-slip deformation, basin formation, and sedimentation: Society of Economic Paleontologists and Mineralogists, Pacific Section Special Publication 37, p. 35-44.

Bailey, E.H., Blake, M.C. Jr., and Jones, D.L., 1970, On-land Mesozoic oceanic crust in California Coast Ranges, in Geological Survey research, 1970: U.S. Geological Survey Professional Paper 700-C, p. C70-C81.

Bailey, E.H., Irwin, W.P., and Jones, D.L., 1964, Franciscan and related rocks, and their significance in the geology of western California: California Division of Mines and Geology Bulletin 183, $177 \mathrm{p}$.

Baranov, Vladimir, 1957, A new method for interpretation of aeromagnetic maps; pseudo-gravimetric anomalies: Geophysics, v. 22, no. 2, p. 359-383.

Blake, M.C. Jr., Howell, D.G., and Jayko, A.S., 1984, Tectonostratigraphic terranes of the San Francisco Bay region, in Blake, M.C. Jr., ed., Franciscan geology of northern California: Society of Economic Paleontologists and Mineralogists, Pacific Section Special Publication, v. 43, p. 5-22.

Blakely, R.J., 1995, Potential theory in gravity and magnetic applications: Cambridge, U.K., Cambridge University Press, 441 p.

Blakely, R.J., and Simpson, R.W., 1986, Approximating edges of source bodies from magnetic or gravity anomalies: Geophysics, v. 51, no. 7, p. 1494-1498.

Bolt, B.A., 1968, The focus of the 1906 California earthquake: Seismological Society of America Bulletin, v. 58, no. 1, p. 457-471.

Bonilla, M.G., 1971, Preliminary geologic map of the San Francisco South quadrangle and part of the Hunters Point quadrangle, California: U.S. Geological Survey Miscellaneous Field Studies Map MF-311, scale 1:24,000, 2 sheets.

Boore, D.M., 1977, Strong-motion recordings of the California earthquake of April 18, 1906: Seismological Society of America Bulletin, v. 67, no. 3, p. 561-577.

Brabb, E.E., Graymer, R.W., and Jones, D.L., 1998, Geology of the onshore part of San Mateo County, California; a digital data- 
base: U.S. Geological Survey Open-File Report 98-137, 9 p.

Brabb, E.E., and Hanna, W.F., 1981, Maps showing aeromagnetic anomalies, faults, earthquake epicenters, and igneous rocks in the southern San Francisco Bay region, California: U.S. Geological Survey Geophysical Investigations Map GP-932, scale $1: 125,000,3$ sheets.

Brabb, E.E., and Olsen, J.A., 1986, Map showing faults and earthquake epicenters in San Mateo County, California: U.S. Geological Survey Miscellaneous Investigations Series Map I-1257-F, scale 1:62,500.

Briggs, I.C., 1974, Machine contouring using minimum curvature: Geophysics, v. 39, no. 1, p. 39-48.

Budding, K.E., Schwartz, D.P., and Oppenheimer, D.H., 1991, Slip rate, earthquake recurrence, and seismogenic potential of the Rodgers Creek Fault zone, northern California: Initial results: Geophysical Research Letters, v. 18, no. 3, p. 447-450.

California Division of Oil and Gas, 1982, Oil and gas prospect wells drilled in California through 1980: Publication TR01, 257 p.

Chapman, R.H., and Bishop, C.C., compilers, 1968, Bouguer gravity map of California, San Francisco sheet: San Francisco, California Division of Mines and Geology, scale 1:250,000.

Clark, J.C, and Brabb, E.E., 1997, Geology of Point Reyes National Seashore and vicinity, California; a digital database: U.S. Geological Survey Open-File Report 97-456, 17 p.

Clark, J.C., Brabb, E.E., Greene, H.G., and Ross, D.C., 1984, Geology of the Point Reyes peninsula and implications for San Gregorio Fault history, in Crouch, J.K., and Bachman, S.B., eds., Tectonics and sedimentation along the California margin: Society of Economic Paleontologists and Mineralogists, Pacific Section Special Publication, v. 38, p. 67-86.

Clifton, H.E., and Hunter, R.E., 1987, The Merced Formation and related beds; a mile-thick succession of late Cenozoic coastal and shelf deposits in Hill, M.L., ed., The seacliffs of San Francisco, California (Centennial Field Guide, v. 1): Boulder, Colo., Geological Society of America, p. 257-262.

Cooper, A.K., 1973, Structure of the continental shelf west of San Francisco, California: U.S. Geological Survey Open-File Report $73-48,65 \mathrm{p}$.

Cordell, Lindrith, and Grauch, V.J.S., 1985, Mapping basement magnetization zones from aeromagnetic data in the San Juan basin, New Mexico, in Hinze, W.J., ed., The utility of regional gravity and magnetic anomaly maps: Tulsa, 0 kla., Society of Exploration Geophysicists, p. 181-197.

Crane, R.C., 1995, Geology of the Mt. Diablo region and east bay hills, in Sangines, E.M., Anderson, D.W., and Buising, A.V., eds., Recent geologic studies in the San Francisco Bay area: Society of Economic Paleontologists and Mineralogists, Pacific Section Special Publication 76, p. 87-114.

Cummings, J.C., 1968, The Santa Clara Formation and possible postPliocene slip on the San Andreas Fault in central California, in Dickensen, W.R., and Grantz, Arthur, eds., Proceedings of conference on geologic problems of San Andreas Fault system: Stanford, Calif., Stanford University Publications in the Geological Sciences, v. 11, p. 191-207.

Ellen, S.D., and Wentworth, C.M., 1995, Hillside materials and slopes of the San Francisco Bay region, California: U.S. Geological Survey Professional Paper 1357, 215 p.

Galloway, A.J., 1977, Geology of the Point Reyes peninsula, Marin County, California: California Division of Mines and Geology Bulletin 202, 72 p.

Glen, William, 1959, Pliocene and lower Pleistocene of the western part of the San Francisco Peninsula: University of California
Publications in Geological Sciences, v. 36, no. 2, p. 147-197.

Graham, S.A., and Dickinson, W.R., 1978, Apparent offsets of on-land geologic features across the San Gregorio-Hosgri Fault trend, in Silver, E.A., and Normark, W.R., eds., San Gregorio-Hosgri Fault zone, California: California Division of Mines and Geology Special Publication 137, p. 13-23.

Graymer, R.W., Jones, D.L., and Brabb, E.E., 1996, Preliminary geologic map emphasizing bedrock formations in Alameda County, California; a digital database: U.S. Geological Survey Open-File Report 96-252, $14 \mathrm{p}$.

Griscom, Andrew, and Jachens, R.C., 1989, Tectonic history of the north portion of the San Andreas fault system, California, inferred from gravity and magnetic anomalies: Journal of Geophysical Research, v. 94, no. B3, p. 3089-3099.

Hart, E.W., 1982, Tolay fault; Sears Point, Petaluma River, Glen Ellen, Cotati, and Two Rock 7.5-minute quadrangles, California: California Division of Mines and Geology Fault Evaluation Report FER-140.

Hengesh, J.V., and Wakabayashi, John, 1995, Dextral translation and progressive emergence of the Pleistocene Merced Basin and implications for timing of initiation of the San Francisco peninsula segment of the San Andreas Fault, in Sangines, E.M., Anderson, D.W., and Buising, A.V., eds., Recent geologic studies in the San Francisco Bay area: Society of Economic Paleontologists and Mineralogists, Pacific Section Special Publication 76, p. 47-54.

Hill, D.P., Eaton, J.P., and Jones, L.M., 1980, Seismicity, 1980-86, chap. 5 of Wallace, R.E., ed., The San Andreas fault system, California: U.S. Geological Survey Professional Paper 1515, p. 115-151.

Hole, J.A., Holbrook, W.S., Klemperer, S.L., Ten Brink, U.S., and Brocher, T.M., 1993, Crustal structure in the San Francisco Bay area from wide-angle seismic refraction data: Eos (American Geophysical Union Transactions), v. 74, no. 43, supp., p. 445.

Irwin, W.P., 1990, Geology and plate-tectonic development, chap. 3 of Wallace, R.E., ed., The San Andreas fault system, California: U.S. Geological Survey Professional Paper 1515, p. 60-80.

Jachens, R.C., Griscom, Andrew, and Roberts, C.W., 1995a, Distribution of Cenozoic deposits in the southern San Francisco Bay trough from gravity and magnetic anomalies [abs.]: American Association of Petroleum Geologists Bulletin, v. 79, no. 4, p. 588.

1995b, Regional extent of Great Valley basement west of the Great Valley, California: Implications for extensive tectonic wedging in the California Coast Ranges: Journal of Geophysical Research, v. 100, no. B7, p. 12769-12790.

Jachens, R.C., and Moring, B.C., 1990, Maps of the thickness of Cenozoic deposits and the isostatic residual gravity over basement for Nevada: U.S. Geological Survey Open-File Report 90-404, 15 p., scale 1:1,000,000, 2 sheets.

Jachens, R.C., and Roberts, C.W., 1993, Aeromagnetic map of the Palo Alto 1:100,000 scale quadrangle, California: U.S. Geological Survey Open-File Report 93-668, scale 1:100,000.

Jachens, R.C., Wentworth, C.M., and McLaughlin, R.J., 1998, Pre-San Andreas location of the Gualala block inferred from magnetic and gravity anomalies, in Elder, W.P., ed., Geology and tectonics of the Gualala block, northern California: Society of Economic Paleontologists and Mineralogists, Pacific Section Special Publication 84, p. 27-64.

Jachens, R.C., and Zoback, M.L., 1999, The San Andreas Fault in the San Francisco Bay region, California; structure and kinematics of a young plate boundary: International Geology Review, v. 41, 
no. 3, p. 191-205.

Jennings, C.W., and Strand, R.G., compilers, 1959, Geologic map of California, Santa Cruz sheet: San Francisco, California Division of Mines and Geology, scale 1:250,000.

Jones, D.L., Graymer, Russell, Wang, Chi, McEvilly, T.V., and Lomax, Anthony, 1994, Neogene transpressive evolution of the California Coast Ranges: Tectonics, v. 13, no. 3, p. 561-574.

Langel, R.A., 1992, International geomagnetic reference field; the sixth generation: Journal of Geomagnetism and Geoelectricity, v. 44, no. 9, p. 679-707.

Lienkaemper, J.J., 1992, Map of recently active traces of the Hayward Fault, Alameda and Contra Costa Counties, California: U.S. Geological Survey Miscellaneous Field Studies Map MF-2196, scale 1:24,000, 3 sheets.

Lienkaemper, J.J., Borchardt, Glenn, and Lisowski, Michael, 1991, Historic creep rate and potential for seismic slip along the Hayward Fault, California: Journal of Geophysical Research, v. 96, no. B11, p. 18261-18283.

Marlow, M.S., Jachens, R.C., Hart, P.E., Carlson, P.R., Anima, R.J., and Childs, J.R., 1999, Development of San Leandro synform and neotectonics of the San Francisco Bay block, California: Marine and Petroleum Geology, v. 16, no. 5, p. 431-442.

McCulloch, D.S., 1987, Regional geology and hydrocarbon potential of offshore central California, in Scholl, D.W., Grantz, Arthur, and Vedder, J.G., eds., Geology and resource potential of the continental margin of western North America and adjacent ocean basins-Beaufort Sea to Baja California: Houston, Tex., Circum-Pacific Council for Energy and Mineral Resources, p. 353-401.

McCulloch, D.S., and Chapman, R.H., 1977, Maps showing residual magnetic intensity maps along the California coast, lat 37 degrees $30 \mathrm{~N}$ to lat 34 degrees $30 \mathrm{~N}$ : U.S. Geological Survey Open-File Report 77-79, scale 1:125,000, 14 sheets.

Meltzer, A.S., Levander, A.R., and Mooney, W.D., 1987, Upper crustal structure, Livermore Valley and vicinity, California Coast Ranges: Seismological Society of America Bulletin, v. 77, no. 5, p. 1655-1673.

Miller-Hoare, M.L., and Liou, J.G., 1980, Gabbroic with associated cumulate mafic and ultramafic rocks - a probable ophiolitic slice-near Stevens Creek canyon, California: Eos (American Geophysical Union Transactions), v. 61, no. 46, supp., p. 1154-1155.

Morton, D.M., and Matti, J.C., 1993, Extension and contraction within an evolving divergent strike-slip fault complex; the San Andreas and San Jacinto Fault zones at their convergence in southern California, in Powell, R.E., Weldon, R.J., II, and Matti, J.C., eds., The San Andreas fault system; displacement, palinspastic reconstruction, and geologic evolution: Geological Society of America Memoir 178, p. 217-230.

Page, B.M., 1990, Evolution and complexities of the transform system in California, U.S.A.: Annales Tectonicae, v. 4, no. 2, p. 53-69. 1992, Tectonic setting of the San Francisco Bay region, in Borchardt, Glenn, Hirschfield, S.E., Lienkaemper, J.J., McClellan, Patrick, Williams, P.L., and Wong, I.G., eds., Proceedings of the second conference on earthquake hazards in the eastern San Francisco Bay area: California Division of Mines and Geology Special Publication 113, p. 1-7.

Pampeyan, E.H., 1994, Geologic map of the Montara Mountain and San Mateo 7 1/2 quadrangles, San Mateo County, California: U.S. Geological Survey Miscellaneous Investigations Series Map I-2390, scale 1:24,000.

Parsons, Tom, and Zoback, M.L., 1997, Three-dimensional upper crustal velocity structure beneath San Francisco Peninsula, California: Journal of Geophysical Research, v. 102, no. B3, p. 5473-5490.

Roberts, C.W., 1991, Principal facts for more than 700 new gravity stations in the San Francisco North and San Francisco South quadrangles, California: U.S. Geological Survey Open-File Report 91-103, 29 p.

Roberts, C.W., and Jachens, R.C., 1993, Isostatic residual gravity map of the San Francisco Bay area, California: U.S. Geological Survey Geophysical Investigations Map GP-1006, scale 1: 286,500.

Smith, M.B., 1964, Map showing distribution and configuration of basement rocks in California: U.S. Geological Survey Oil and Gas Investigations Map 0M-215, scale 1:500,000, 2 sheets.

Smith, Neal, 1992, Gravity interpretation of San Pablo Bay and vicinity, in Wright, T.L., ed., Field trip guide to Late Cenozoic geology in the north bay region: Northern California Geological Society Guidebook, p. 71-80.

Stanley, R.G., Jachens, R.C., Kvenvolden, K.A., Hostettler, F.D., Magoon, L.B., and Lillis, P.G., 1996, Evidence for an oil-bearing sedimentary basin of probable Miocene age beneath "Silicon Valley," California: American Association of Petroleum Geologists-Society of Economic Paleontologists and Mineralogists Annual Meeting Abstracts, v. 5, p. 133-134.

U.S. Geological Survey, 1992, Aeromagnetic map of Livermore and vicinity, California: U.S. Geological Survey Open-File Report 92-531, scale 1:250,000.

1996, Aeromagnetic map of the central part of the San Francisco Bay region, California: U.S. Geological Survey Open File Report 96-530, scale 1:100,000.

-1997a, Aeromagnetic map of Santa Rosa and vicinity on parts of the Santa Rosa and San Francisco 1 degree by 2 degree quadrangles, California: U.S. Geological Survey Open-File 97-468, scale 1:250,000.

1997b, Investigation of the San Bruno Fault near the proposed extension of the Bay Area Rapid Transit line from Colma to San Francisco International Airport, San Mateo County, California: U.S. Geological Survey Open-File Report 97-429, 73 p.

Wagner, D.L., and Bortugno, E.J., 1982, Geologic map of the Santa Rosa quadrangle, California: California Division of Mines and Geology Regional Geologic Map Series Map 2A, scale 1: 250,000 .

Wagner, D.L., Bortugno, E.J., and McJunkin, R.D., 1991, Geologic map of the San Francisco-San Jose quadrangle, California: California Division of Mines and Geology, Regional Geologic Map Series Map 5A, scale 1:250,000.

Wentworth, C.M., 1997, General distribution of geologic materials in the San Francisco Bay region, California; a digital map database: U.S. Geological Survey Open-File Report 97-744, scale 1:125,000 [URL http://geopubs.wr.usgs.gov/docs/wrgis/of97.html].

Working Group on California Earthquake Probabilities, 1999, Earthquake probabilities in the San Francisco Bay region: 2000 to 2030 — a summary of findings: U.S. Geological Survey Open File Report 99-517, 60 p.

Wright, T.L., and Smith, Neal, 1992, Right step from the Hayward fault to the Rodgers Creek fault beneath San Pablo Bay, in Borchardt, Glenn, Hirschfeld, S.E., Lienkaemper, J.J., McClellan, Patrick, Williams, P.L., and Wong, I.G., eds. Proceedings of the second conference on earthquake hazards in the eastern San Francisco Bay area: California Division of Mines and Geology Special Publication 113, p. 407-417. 
Zoback, M.L., Jachens, R.C., and Olson, J.A., 1999, Abrupt alongstrike change in tectonic style; San Andreas Fault zone, San Francisco Peninsula: Journal of Geophysical Research, v. 104, no. B5, p. 10719-10742.

Zoback, M.L., Olson, J.A., and Jachens, R.C., 1995, Seismicity and basement structure beneath south San Francisco Bay, California, in Sangines, E.M., Anderson, D.W., and Buising, A.V., eds., Recent geologic studies in the San Francisco Bay area: Society of Economic Paleontologists and Mineralogists, Pacific Section Special Publication 76, p. 31-46. 



\title{
Marine Seismic-Reflection Data Acquired in the San Francisco Bay Region, 1991-97
}

\author{
By Patrick E. Hart, Jonathan R. Childs, Tom Parsons, Ray W. Sliter, Dennis M. Mann, and Jill \\ McCarthy
}

\section{CONTENTS}

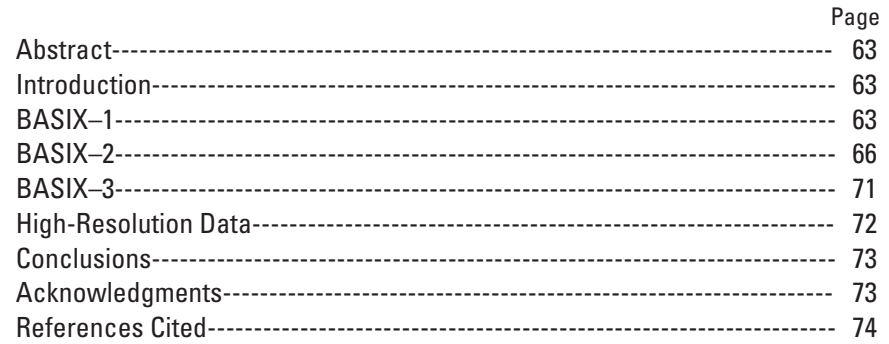

\section{Abstract}

Between 1991 and 1997, the U.S. Geological Survey conducted seismic-reflection studies of earthquake faults in the San Francisco Bay region. The goal of these studies was to investigate the positions and structure of the region's strike-slip faults, from shallow subsurface depths down through the entire crust, using various seismic-reflection techniques with overlapping resolution and depths of penetration. The deep-crustal and midcrustal geometry of the San Andreas and Hayward Faults was the focus of the threephase Bay Area Seismic Imaging eXperiment (BASIX) run in 1991, 1995, and 1997, which utilized large airgun arrays and widely distributed hydrophone receivers to obtain seismic-reflection images of these faults to $22-\mathrm{km}$ depth. A combination of higher-resolution seismic-reflection methods were used to study the shallow crust. A small airgun multichannel system was used to acquire seismic-reflection profiles with 1 to $2 \mathrm{~km}$ of penetration for detailed fault and shallow-structure studies. Very high resolution images of approximately the shallowest $25 \mathrm{~m}$ of the subsurface were collected along many of the multichannel tracklines, using a surface-towed, electromechanical ("boomer") source and a vertically oriented transducer array. All seismic data were digitally recorded, processed, and archived. Positional data were acquired by using the Global Positioning System in either nondifferential (early 1990s) or differential (mid-1990s and late 1990s) mode.

\section{Introduction}

From the early 1970s through 1990, the U.S. Geological Survey (USGS) routinely collected marine multichannel seis- mic-reflection data for use in regional geologic-framework studies. Most of this work was conventional, two-dimensional marine profiling, using a $2.4-\mathrm{km}$ multichannel hydrophone streamer and an array of 5 or 10 airguns totaling more than $32 \mathrm{~L}$ in volume. Since 1991, however, the focus of USGS marine research has shifted to shallow-water studies relevant to coastal processes, shallow aquifers, and geologic hazards. These programmatic changes necessitated the development of equipment and methods more suitable to shallow-water operation and near-surface targets, including new high-resolution systems and novel uses of conventional seismic-reflection systems. In the San Francisco Bay region, long segments of the San Andreas and related earthquake faults lie submerged beneath shallow coastal and inland waters. Beginning in 1991, the USGS conducted a series of marine seismic-reflection studies, using new systems and methods designed to image the region's geologic structures and fault geometry, as summarized in table 1 .

\section{BASIX-1}

The first Bay Area Seismic Imaging eXperiment (BASIX-1) was the first attempt to use marine seismic-reflection profiling to define the deep-crustal structure and fault geometry of the San Francisco Bay region. This experiment, which was designed to investigate a model proposed by Furlong and others (1989) that the network of major regional earthquake faults are structurally linked by a horizontal fault beneath San Francisco Bay, was conducted in September 1991 by the USGS in collaboration with the University of California, Berkeley, Stanford University, Penn State University, and Lawrence Berkeley Laboratory (McCarthy and Hart, 1993).

Although options for a large-scale seismic-reflection study in the San Francisco Bay region are severely restricted by dense urban development, the bays and delta that dissect the region provide accessible pathways that cross the major faults. These inland waters were used for BASIX-1 and the followup experiments in 1995 and 1997, BASIX-2 and BASIX-3, respectively. The research vessel S.P. Lee was used as the main platform for BASIX-1 data acquisition. A 12-airgun 96-L source array and a 120-channel digital seismic recording system were installed on the S.P. Lee. Because heavy ship traffic, shallow water, and rapidly changing tidal currents combined to make the use of a 
Table 1.-Summary of marine seismic-reflection data collected in the San Francisco Bay region, 1991-97.

$\begin{array}{ll}\begin{array}{l}\text { Date } \\ \text { Cruise ID }\end{array} & \text { Vessel } \\ \text { Sept. 1991 } & \text { S.P. Lee } \\ \text { L1-91-NC } & \\ \text { BASIX-1 } & \end{array}$

$\begin{array}{ll}\text { Sept. 1991 } & \text { S.P. Lee } \\ \text { L1-91-NC } & \\ \text { BASIX-1 } & \\ & \\ \text { Apr. 1995 } & \text { Robert Gray } \\ \text { G1-95-SF } & \\ \text { BASIX-2 } & \end{array}$

Sept. 1997

M1-97-SF

McGaw and

BASIX-3
Data Description

60-120-channel data; radio telemetered from single hydrophones buoyed at 100-200-m intervals along shot tracklines; 50-m shot interval; 12-gun 96-L airgun array; sourcereceiver offsets, $\max 20 \mathrm{~km}$; 16-s record length; 4-ms sample interval.

Single-channel vertical incidence records of the BASIX-1 airgun shots acquired with a towed 50-m hydrophone streamer. 5-s record length; 4-ms sample interval.

48-channel stationary streamer laid directly on the bay floor. 12-gun 96-L airgun array; $\sim 200 \mathrm{~m}$ shot int. Radio trigger link. Sourcereceiver offsets, $\max 20 \mathrm{~km}$; 16 -s record length; 4-ms sample interval

48-channel stationary streamer laid directly on the bay floor. 12-gun 96-L airgun array; $\sim 200 \mathrm{~m}$ shot interval. Radio-trigger link. Source-receiver offsets, $\max 20 \mathrm{~km}$; 16-s record length; 4-ms sample interval.
Comments

Stacked profiles and common-receiver gathers from San Francisco, San Pablo, and Suisun Bays, the Sacramento River delta, and $10 \mathrm{~km}$ out the Golden Gate. Low signal-to-noise ratio. Good upper-crustal structural imaging in eastern part of delta. Deep (6-10 s) reflectivity observed in central San Francisco Bay. Map: figure 1; data example: figures $2-4$.

Profiles acquired along most of the BASIX- 1 shot tracklines. Much less noise than in buoyedhydrophone data. Map: figure 1.

Three streamer deployments in central and southern San Francisco Bay designed to better define the deep reflectivity observed on BASIX-1 data and to test the bottom cable recording technique. Records show drastic reduction in noise relative to BASIX-1. Map: figure 5; data example: figure 6 .

Five streamer deployments made to extend the BASIX-2 data into San Pablo and Suisun Bays and to provide data acquired with the receiver array perpendicular to the San Andreas and Hayward Faults. Map: figure 5; data example: fig. 6 .

High-resolution data availableat URL http://geopubs.wr.usgs.gov/open-file/of00-494/

\begin{tabular}{|c|c|c|}
\hline $\begin{array}{l}\text { July } 1993 \\
\text { J8-93-SF }\end{array}$ & David Johnston & $\begin{array}{l}\text { airguns; } 50-200-\mathrm{Hz} \text { bandwidth; 6-12-fold, } \\
\text { with 3.12-m common-depth-point interval; } \\
\text { 1-2-s record length; 2-ms sample interval. }\end{array}$ \\
\hline $\begin{array}{l}\text { May } 1994 \\
\text { J2-94-SF }\end{array}$ & David Johnston & $\begin{array}{l}\text { 24-channel 150-m-long streamer; two } 0.65-\mathrm{L} \\
\text { airguns; } 50-200-\mathrm{Hz} \text { bandwidth; 6-12-fold, } \\
\text { with 3.12-m common-depth-point interval; } 2 \\
\text { s record length; 2-ms sample interval. }\end{array}$ \\
\hline $\begin{array}{l}\text { May } 1994 \\
\text { J2-94-SF }\end{array}$ & David Johnston & $\begin{array}{l}\text { Surface-towed sled system; single channel; } \\
\text { "boomer" source; inline cone receiver array; } \\
\sim 1,000-4,000-\mathrm{Hz} \text { bandwidth; } 200-\mathrm{ms} \text { record } \\
\text { length; } 0.0625-\mathrm{ms} \text { sample interval ( } 16 \mathrm{kHz}) \text {. }\end{array}$ \\
\hline
\end{tabular}

June 1995 G2-95-SF

Robert Gray Robert Gray

24-channel 150-m-long streamer; two 0.65-L airguns; 50-200-Hz bandwidth; 6-12-fold, with 3.12-m common-depth-point interval; 2$\mathrm{s}$ record length; 2-ms sample interval.

Mar. 1997

David Johnston

J4-97-SF 24-channel 240-m-long streamer; 0.57./0.57L dual-chamber airgun; 50-200-Hz bandwidth; 6-12-fold, with 5.0-m commondepth-point interval; 2-s record length; 2-ms sample interval.
Nine good-quality multichannel seismic profiles in southern San Francisco Bay imaging the San Leandro Basin to $1 \mathrm{~km}$ depth. Map: figure 8 .

Data acquired in four areas: southern San Francisco Bay, San Pablo Bay, Sacramento delta near the town of Pittsburg, and a single east-west profile out the Golden Gate. All good quality except San Pablo lines. Map: figure 8; data example: figure 9.

Very high resolution profiles acquired concurrently with most of the 1994 multichannel seismic profiles except the Golden Gate line. Good quality with $25-\mathrm{m}$ penetration, except San Pablo data, which are obscured by shallow gas. Owing to recording problem, data have low dynamic range. Map: figure 8; data example: figure 10 .

Grid of high-quality multichannel profiles outside Golden Gate imaging San Andreas and San Gregorio Fault zones to $>1-\mathrm{km}$ depth. A few fairquality profiles in central San Francisco Bay and the Sacramento River delta. Map: figure 8.

A single southern San Francisco Bay profile across the San Leandro Basin acquired to test improvements made to the high-resolution multichannel seismic system. Map: figure 8; data example: figure 11 . 
conventional kilometers-long towed hydrophone streamer unfeasible, individual floating hydrophones with radio telemetry units were used as receivers. These receivers were anchored at 100- to 200-m intervals adjacent to the ship tracklines to record airgun blasts (fig. 1) and transmit the data back to the shipboard recording system. Each day of the experiment, 60 to 120 receivers were deployed by using several small boats. The airguns were fired at night along the receiver array and off end to distances of approximately $20 \mathrm{~km}$. Over a 2-week period, 1,030 receiver stations were occupied, recording a total of 11,634 airgun blasts at a 50$\mathrm{m}$ shot spacing. Telemetrically received data were recorded at a 4-ms sample interval to a 16-s record length. Receiver deployments began at the east limit of the experiment, near the town of Rio Vista, and progressed daily to the west, through Suisun Bay, San Pablo Bay, southward through San Francisco Bay and westward $10 \mathrm{~km}$ beyond the Golden
Gate. Airgun tracklines were constrained to the relatively deeper $(>8 \mathrm{~m}$ ) water of the dredged shipping channels.

Data quality varies significantly along the individual BASIX-1 tracklines (fig. 2). Noise from tidal currents and strong winds dominates most of the far-offset data. Noise bursts, presumably from the hydrophones jostling in the choppy water, are common. Additional degradation of the far-offset data could be due to transmission noise in the radio signal from the hydrophone receivers to the recording ship. As a result, extensive editing of the data was necessary. After eliminating the noisiest data traces, a custom automatic noise-burst editor was applied, followed by conventional seismic-reflection processing steps. Data were gained, bandpass-filtered at 14 to $44 \mathrm{~Hz}$, and sorted to common-midpoint gathers; then, normal moveout velocities were picked and applied. Residual statics were calculated and applied, and the data were stacked at an average of 65 -fold. A 50-m single-

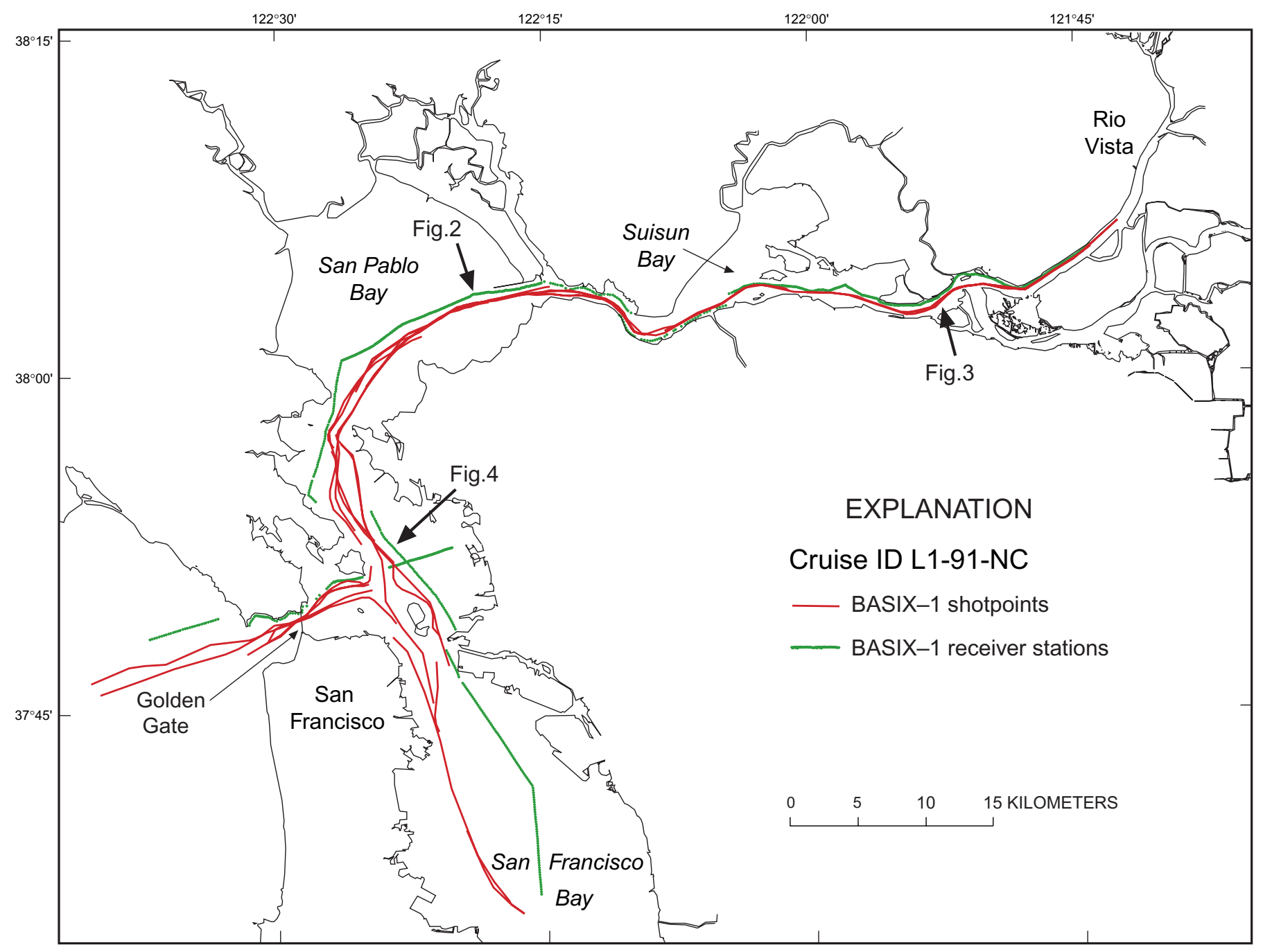

Figure 1.-Gulf of the Farallones and San Francisco Bay region, Calif., showing locations of major faults and tracklines of high-resolution multichannel seismic-reflection records acquired for this study. Shaded area, general area of the San Gregorio Basin as defined here; hachured area, the Bodega Basin of McCulloch (1987, 1989). Rectangle denotes area of figure 6. 
channel streamer was towed behind the S.P. Lee along most of the airgun tracklines to record vertical-incidence data to 5-s two-way traveltime. These profiles are much less noisy and provide better upper-crustal images than the stacked buoyedhydrophone data.

Few laterally continuous reflections are evident in the BASIX-1 data. However, on one $20-\mathrm{km}$ section at the east edge of the study area (fig. 1), a 4-s-two-way-traveltime $(10-12 \mathrm{~km})$ zone of coherent, continuous reflections can be clearly seen (fig 3). These data help define the structure of the Kirby Hills Fault (see Parsons and others, this volume). The only other area with continuous high-amplitude reflections is central San Francisco Bay, where a zone of horizontal reflections between 6- and 10-s two-way traveltime are observed on both the stacked profile and the receiver gathers. A representative receiver gather from central San Francisco Bay is shown in figure 4. The highamplitude reflections at 6- to 7-s two-way traveltime were interpreted by Brocher and others (1994) to originate at 18- to $21-\mathrm{km}$ depth on a horizontal detachment fault linking the San Andreas and Hayward Faults. This interpretation is supported by the observation that the zone of reflections between 6 and $10 \mathrm{~s}$ is visible only on receiver gathers between these two faults and so is unlikely to result from a regional deep-crustal reflector. BASIX-1 airgun data were also recorded on an array of land seismometer stations (Brocher and Moses, 1993) and ocean-bottom seismometers (Holbrook and others, 1996) deployed throughout the region, which show a similar distribution of possible deepcrustal and midcrustal reflectivity. However, the low signalto-noise ratio of many of the marine data makes it difficult to map the lateral extent of the reflectivity with certainty, using only the data from BASIX-1.

\section{BASIX-2}

A subsequent field program was proposed in 1995 to attempt to solve the noise problems encountered during BASIX-1 by using bottom-cable hydrophone receivers.

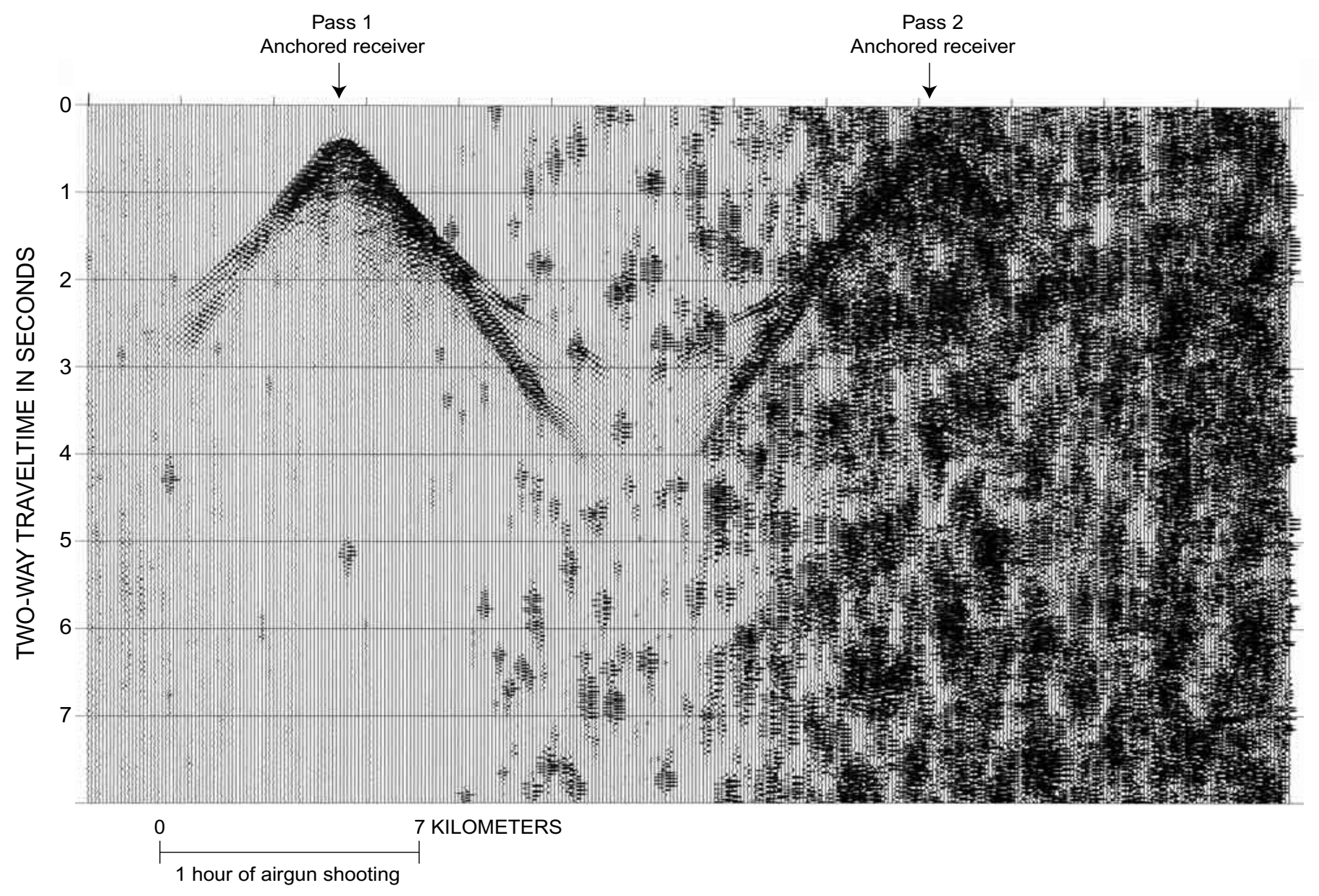

Figure 2.-Part of a single common-receiver gather from San Pablo Bay (see fig. 1 for location) recorded during 5 hours of airgun shooting during BASIX-1. No amplitude scaling has been applied to illustrate noise problems. Airgun ship made two passes by anchored hydrophone receiver. During second pass, noise from tidal currents and surface waves increased to the point where high-amplitude noise bursts completely dominate record. 
Deploying long arrays of hydrophones directly on the bay floor could enhance the signal-to-noise ratio of the deepcrustal reflection data in several ways. Hydrophones enclosed within a flexible cable lying in contact with the soft muddy bottom of the bay would not be as strongly affected by strong tidal currents and choppy waters as were the floating hydrophones used in 1991. In addition, linear arrays of hydrophones would be used for each recorded channel, diminishing random noise in favor of coherent-reflection energy arriving vertically from below. Finally, the stationary-receiver spread would be wired directly to the recording system, eliminating noise introduced by radio telemetry.

BASIX-2, which was conducted by the USGS in April 1995, was planned to be a relatively small pilot study of the bottom-cable recording technique that, if successful, would lead to a much larger program. The field-operations budget was thus too small to allow the work to be contracted to a geophysical-data-acquisition company or to lease the specialized equipment needed for bottom-cable recording. USGS personnel and equipment had to be used as much as pos- sible. The USGS owns a 2.4-km-long oil-filled hydrophone streamer designed to be towed behind a recording ship during conventional open-ocean seismic profiling. This streamer was modified for use as a 48-channel bottom cable by taping $2,4000.45-\mathrm{kg}$ lead weights at $1-\mathrm{m}$ intervals along its length. The weighted streamer and its storage reel was mounted on a 9- by 18-m leased barge, along with the multichannel recording system in a portable van. A 12-airgun array, deployment gantry, air compressor, and shot controller were installed on a second 9 - by $21-\mathrm{m}$ barge.

Three sites were chosen in central and southern San Francisco Bay for deployment of the weighted streamer (fig. 5). These sites overlapped all the hydrophone-station locations from BASIX-1 that recorded deep reflectivity. Operational considerations also influenced the locations of the deployment sites. To minimize risk of damage to the streamer during deployment or recovery, existing side-scan-sonar data were reviewed to ensure that the sites were flat and that no debris or rocky outcrops existed along each 2.4-km-long deployment line. Because each deployment location was to be

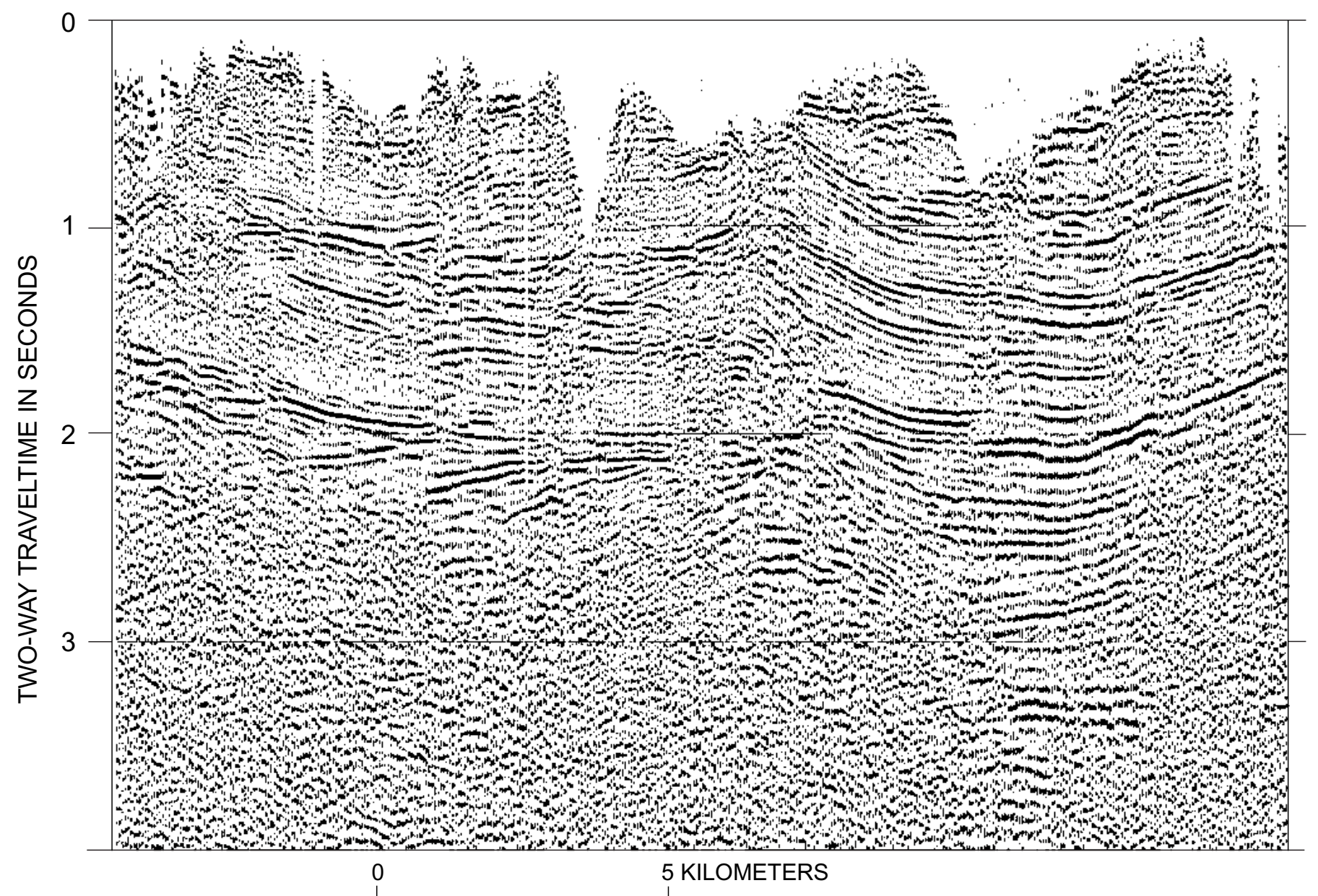

Figure 3.-Approximately 65 -fold stacked section of BASIX-1 data from west to east across the Kirby Hills Fault (see fig. 1 for location). Extensive noise editing that was applied before stacking has caused gaps visible in upper $1 \mathrm{~s}$ of record. 


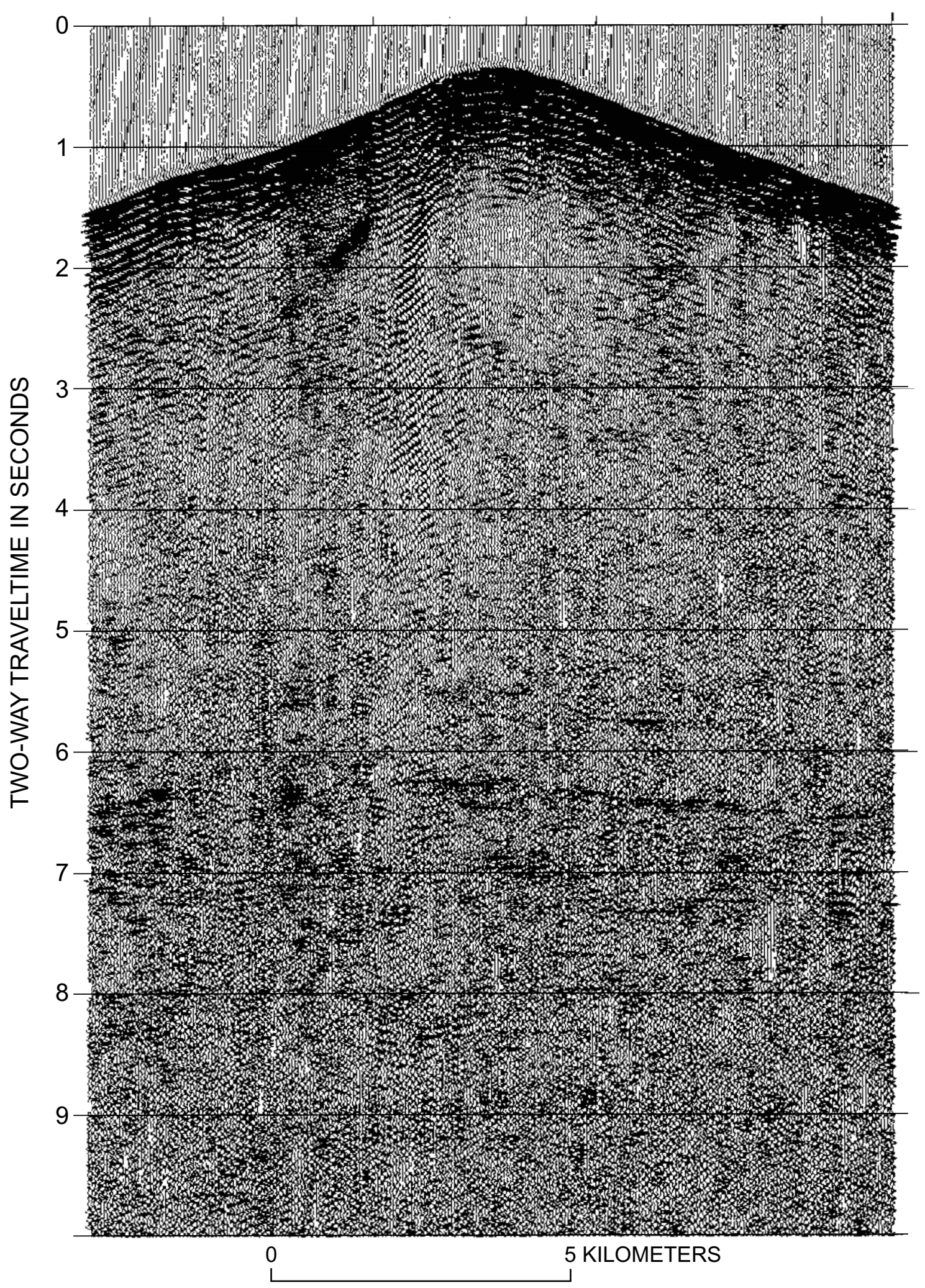

Figure 4.-Common-receiver gather from central San Francisco Bay (see fig. 1 for location) recorded during BASIX-1. Although this record has a low signal-to-noise, it shows a zone of coherent horizontal reflectivity between 6- and 8-s two-way traveltime. One major goal of BASIX-2 and BASIX-3 was to determine origin of this reflectivity. 
occupied for 1 to 2 days, the deployment lines were chosen to be parallel to tidal currents so as to reduce the possibility that the streamer might roll a significant distance if pushed perpendicularly by a strong current. The lines were in water depths greater than about $5 \mathrm{~m}$ to allow vessel access during deployment and recovery, and the shipping channel was avoided in case the streamer might float up off the bottom in the turbulence of a passing ship and be damaged.

The field operation for BASIX-2 was complex and fairly awkward. The procedure using equipment mounted on barges was the least expensive way to test bottom-cable recording in San Francisco Bay and was not intended to be a prototype for future work. The motor vessel Robert Gray was contracted to move the barges as needed for data acquisition, and to house all personnel during the experiment. The Robert Gray towed the recording barge along the deployment lines as the streamer was rolled off its reel and laid onto the bay bottom in a straight line; the recording barge was then anchored at the end of the streamer. Airgun shooting was accomplished by the Robert Gray towing the shooting barge past the stationary streamer and to about $20 \mathrm{~km}$ beyond the ends of the deployment lines as the airguns were fired at a 90-s (approx $200 \mathrm{~m}$ ) interval. A radio-trigger link synchronized the gun firing with the data recording. A total of 1,241 shots were recorded at the three deployment sites during 8 days of shooting.

BASIX-2 data quality is much higher than that of BASIX-1. High-amplitude reflections are conspicuous between 6- and 10-s two-way traveltime on shot records from each of the deployments (fig. 6). The BASIX-2 data suggest a highly reflective lower crust beneath San Francisco Bay,

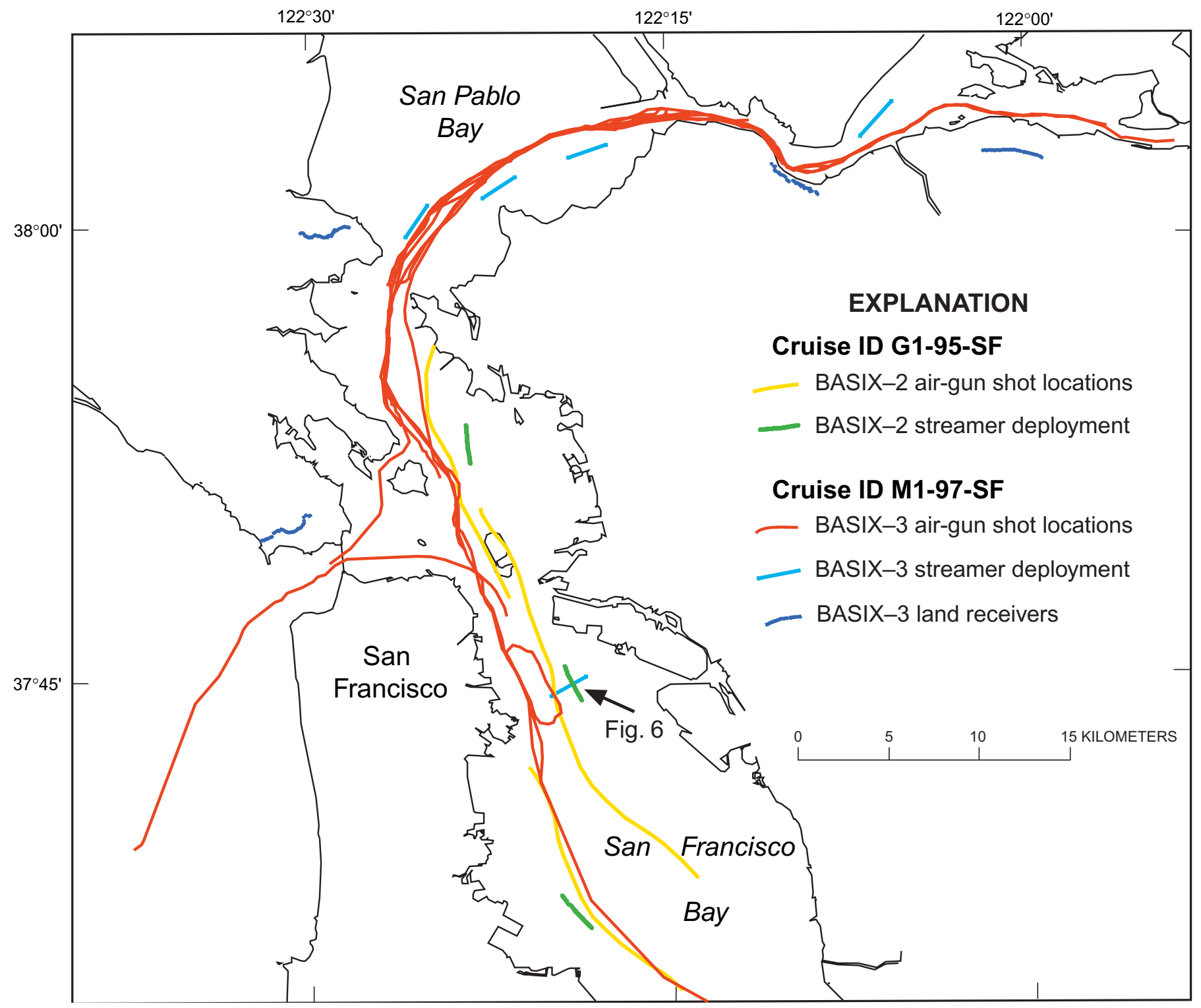

Figure 5.-San Francisco Bay region, showing locations of BASIX-2 (1995) and BASIX-3 (1997) airgun tracklines and hydrophone-streamer deployments, BASIX-3 onland geophone-receiver stations, and data example from figure 6. 


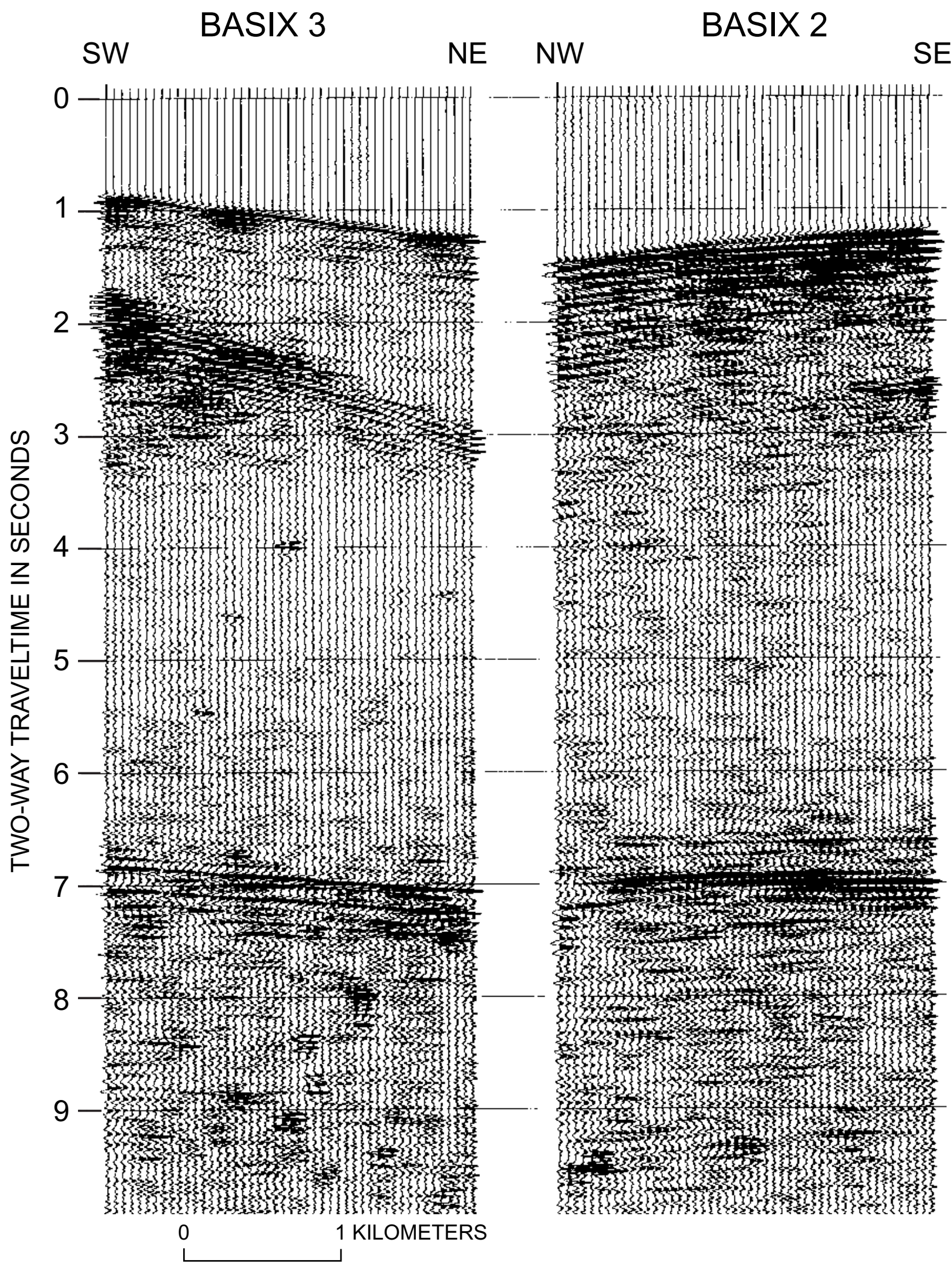

Figure 6.-Single-shot gathers from BASIX-2 and BASIX-3, showing records from airgun shots at similar locations (fig. 5). Orientation of hydrophone streamer for BASIX-3 record is perpendicular to that of BASIX-2 record. Difference between the two records in moveout of reflection event at 7-s two-way traveltime has been analyzed to determine that reflection originates from steeply dipping San Andreas Fault plane. 
in support of the model of a detachment-fault connection between the San Andreas and Hayward Faults. However, this interpretation is inconsistent with data acquired on the San Francisco peninsula in 1995 (Parsons, 1998), when large chemical-explosive sources were recorded on a spread of land seismometers deployed orthogonal to the San Andreas Fault. Those data showed conspicuous reflections at 12- to 14-s twoway traveltime but not at 6- to 10-s two-way traveltime, as seen on the BASIX-2 data. Parsons (1998) concluded that the reflections on land came from a $70^{\circ}$-SW.-dipping Hayward Fault between 18- and 24-km depth. A similar out-of-plane origin for the BASIX-2 reflections was considered, but the acquisition geometry of BASIX-2 did not allow distinction between horizontal and dipping fault-plane reflectors because the deployment lines and shooting tracklines nearly paralleled the region's major faults (Parsons and Hart, 1999; see Parsons and others, this volume).

\section{BASIX-3}

BASIX-3, which was completed in September 1997, used the same airgun source array and weighted hydrophone streamer as BASIX-2, although the field operation was modified to increase efficiency and allow better access to new deployment lines. Two ships, instead of barges, were contracted to carry and deploy the equipment. The streamer reel and recording van were put on the research vessel McGaw, and the airgun system was installed on the motor vessel Auriga (fig. 7). A small tugboat was used to help maneuver the $M c G a w$ during streamer deployment and recovery and to help set the four-point anchoring system that held the McGaw in place during acquisition.

Five streamer-deployment lines were occupied (fig. 5), and a total of 2,751 airgun shots were recorded during 10 days of shooting. The southernmost deployment was just south of the San Francisco-Oakland Bay Bridge at a right angle to one of the 1995 BASIX-2 lines, to determine the orientation of the deep reflection events observed in the BASIX-2 data by comparing the arrival times across these two orthogonal spreads (fig. 6). Deployments were also made in San Pablo Bay and Suisun Bay to provide data east of and crossing the Hayward Fault. Analysis of the entire BASIX-2 and BASIX-3 data sets indicates that most, if not all, of the high-amplitude reflectivity at $>6$-s two-way traveltime

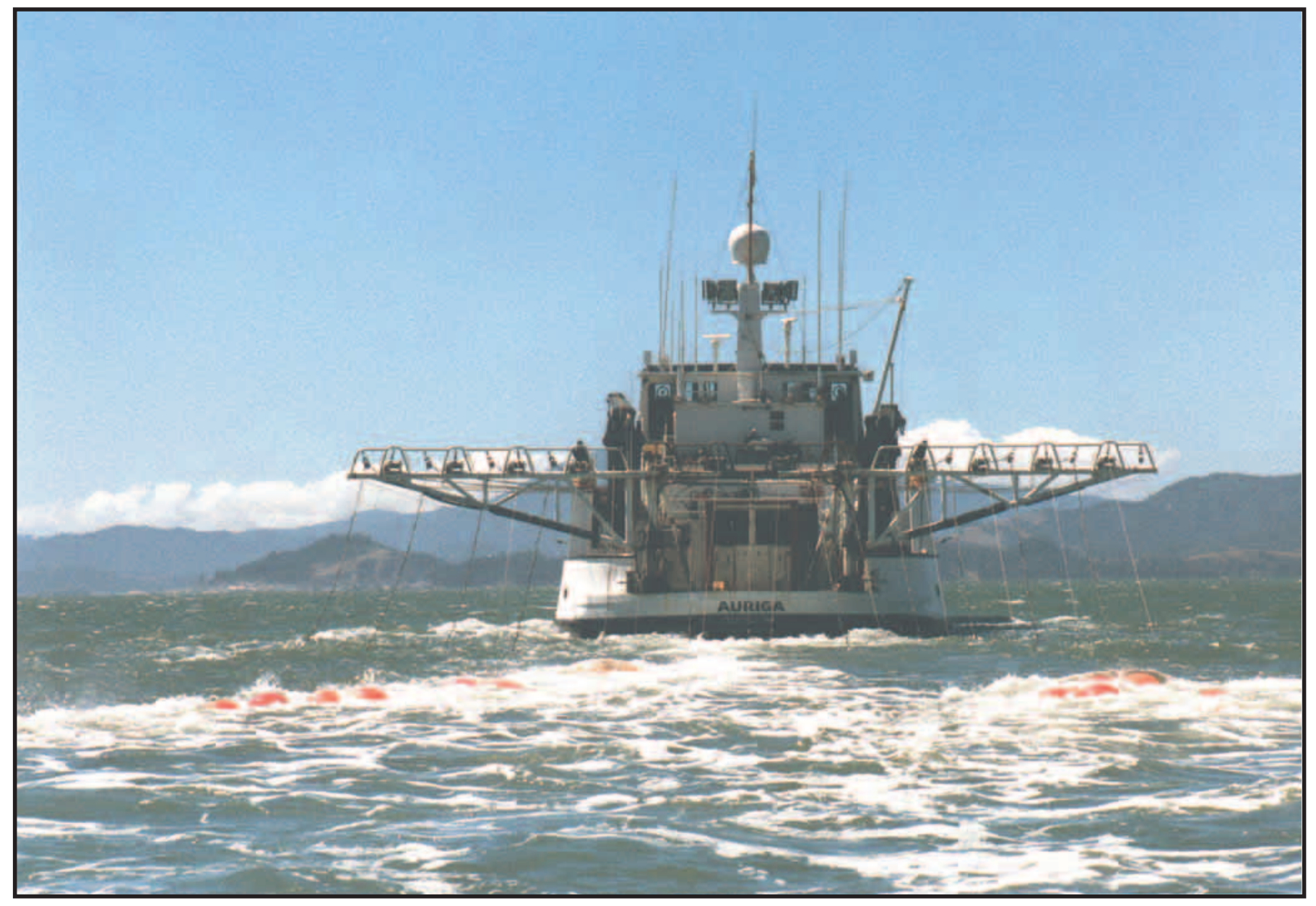

Figure 7.-Motor vessel Auriga, with 12-airgun source array, working in San Pablo Bay (see figs. 1, 5) during BASIX-3. 
results from steeply dipping reflectors interpreted to be fault planes (Parsons and Hart, 1999; see Parsons and others, this volume). The San Andreas and Hayward Faults are interpreted to be vertical to about 10 - to 12-km depth, then to dip toward each other at $60^{\circ}$ and $70^{\circ}$, respectively, beneath San Francisco Bay to the base of the crust. The fault planes cannot be mapped with the BASIX data below the base of the crust at about $25-\mathrm{km}$ depth.

\section{High-Resolution Data}

Work began in 1993 on a multichannel seismic system capable of imaging geologic structures to 1- to 2-km depth with a spatial resolution of 5 to $10 \mathrm{~m}$ in relatively shallow water environments (Childs and others, 2000). The main components of this system were a small airgun source, a short 24-channel streamer, and a compact PC-based digital recording instrument. The initial streamer was of solid-core construction with "thin film" cylindrical hydrophones of polyvinylidene fluoride plastic, which is characterized by high sensitivity and a broadband $(5-5,000 \mathrm{~Hz})$ frequency response. The streamer was $150 \mathrm{~m}$ long, with a 6.25 -m group interval and one hydrophone per channel. The source was a pair of 0.65-L airguns with "wave shape" kits installed in their chambers to suppress the bubble pulse. Navigation software developed by the USGS provided trackline following and position logging. Positioning was accomplished with a single Global Positioning System receiver with an absolute position accuracy of approximately $\pm 30 \mathrm{~m}$. Relative positions, from fix to fix, were accurate to within a few meters.

In July 1993, this system was installed on the USGS research vessel David Johnston for field trials in southern San Francisco Bay. The major difficulty encountered during the field trials was proper ballasting of the streamer to allow it to "fly" just below the water surface but not contact the bay floor when working in water as shallow as $2 \mathrm{~m}$. Then, nine seismic-reflection profiles were recorded (cruise J8-93-SF, fig. 8). The shot-firing interval for these lines was either 6.25 or $12.5 \mathrm{~m}$. Factors limiting the firing interval were air-compressor capacity and the shot-processing time required by the recording system. At speeds below $1.8 \mathrm{~m} / \mathrm{s}$, the $6.25-\mathrm{m}$ fire interval could be maintained; higher speeds (generally tidally controlled) necessitated the longer shot-firing interval. Resulting common-midpoint data were either 12- or 6-fold, with a 3.125-m common-midpoint interval. Data were recorded at a 1-ms sample interval to a 2 -s record length. The data-processing sequence used to create stacked profiles from the field data is SEG-Y (Barry and others, 1974) input and resampling to 2 $\mathrm{ms}$, trace edit, geometry assignment, bandpass filter (50-200 $\mathrm{Hz}$ ), automatic gain control (100-ms window), water-bottom mute, frequency-wavenumber filter $(50-200 \mathrm{~Hz}, \pm 2,400$ $\mathrm{m} / \mathrm{s}$ ), spiking deconvolution, common-midpoint sort, stacking-velocity analysis, normal-moveout correction, stack, and SEG-Y output.

Data quality of the 1993 tests was high, allowing imaging of structure deeper than $1 \mathrm{~km}$ in places. On the basis of this success, in May 1994, detailed surveys using the research vessel David Johnston were run over southern San Francisco Bay near San Bruno Shoal (Marlow and others, 1998), over the Kirby Hills Fault where it crosses the western part of the Sacramento River delta (see Parsons and others, this volume), and over the Hayward-to-Rodgers Creek Fault stepover in San Pablo Bay. A subsequent cruise was conducted in June 1995, using the motor vessel Robert Gray, over the offshore extension of the San Andreas Fault system west of the Golden Gate (fig. 8; table1; see Bruns and others, this volume). All data were processed using a sequence similar to that listed above. Differential GPS navigation used during the 1995 cruise improved absolute positional accuracy to approximately $\pm 10 \mathrm{~m}$.

In 1994, very high resolution reflection profiles were acquired concurrently with the airgun data. The instrument used to acquire these profiles consisted of a source and a receiver mounted together on a 2-m-long catamaran sled towed behind and to the side of the survey vessel. The source was a wideband (500-4,500 Hz) electrodynamic "boomer" that generated a single positive-pressure transient of as much as approximately $218 \mathrm{~dB}$ referenced to $1 \mu \mathrm{Pa}$ at $1 \mathrm{~m}$; the receiver was a line-in-cone hydrophone array oriented to maximize vertical-incidence reflected energy. Data were recorded digitally at 16-kHz sampling rate to a record length of $200 \mathrm{~ms}$, at a repetition rate of 2 to 4 "pings" per second. Low power levels from the analog-signal conditioner resulted in recorded data with a relatively low dynamic range $(<30 \mathrm{~dB})$; however, a vertical resolution of $>50 \mathrm{~cm}$ to a subbottom depth of $\sim 25 \mathrm{~m}$ and a lateral resolution of $\sim 1 \mathrm{~m}$ were achieved.

Part of a multichannel seismic profile acquired in 1994 in the Sacramento River delta crossing the Kirby Hills Fault Zone is shown in figures 9 and 10. The steeply dipping nearsurface sedimentary deposits are imaged at better than 10 times the multichannel seismic resolution by the very high resolution data. This combination of data-acquisition systems allows interpretations of the uppermost 1 or $2 \mathrm{~km}$ of crust to be tied to the shallowest subsurface. These data have been used in fault investigations of the Kirby Hills Fault zone (see Parsons and others, this volume) and southern San Francisco Bay (Marlow and others, 1996).

In March 1997, a single seismic profile was recorded in southern San Francisco Bay during tests of changes made to reflection profiling system to improve the penetration and data signal-to-noise ratio. A new 240-m solid-core hydrophone streamer and a dual-chamber generator-injector airgun were used. The streamer was of the same type as used previously but featured a 10-m group interval (240-m overall active length) and three hydrophones per channel. The airgun consists of a 0.57-L "injector" chamber timed to discharge a short time (typically, 20-30 ms) after the 0.57-L "generator" chamber so as to suppress the bubble pulse and create an optimal signal. This gun was fired as frequently as the air compressor would allow, typically at 10- to 12-s intervals. Stack fold therefore ranged from 4 to 12 , depending on the vessel speed. A migrated version of this profile is shown in figure 11 to demonstrate the data quality and resolution that are achievable with this system in shallow water. 


\section{Conclusions}

Modeling and analysis of the BASIX data sets is continuing to refine the interpretation of the crustal structure in the San Francisco Bay region. Refraction data from arrays of land seismometers deployed during BASIX-3, and data from the eastern streamer deployments of BASIX-3, have not yet been studied in detail. Although much work remains to be completed, results from BASIX have given the best picture yet of the deeply buried segments of the San Francisco Bay region's earthquake fault system.

The USGS high-resolution multichannel seismic and very high resolution systems have proved capable of acquiring high-quality seismic-reflection profiles in the shallow water of San Francisco Bay. These data combine to provide a continuous image of subsurface geologic structure and fault geometry that ties 5- to 10-m resolution and 1- to 2-km penetration with less than 1-m resolution in the uppermost few tens of meters.

The data described here are all available for download from the USGS Web site at URL http://walrus.wr.usgs.gov/ reports/. Because of recent regulatory changes pertaining to the use of airgun sources within San Francisco Bay region waters (Childs and others, 1999), additional surveys of the type described here will probably not be undertaken.

\section{Acknowledgments}

The success of the USGS marine seismic programs in the San Francisco Bay region during the 1990s is largely attributable to the technicians, engineers, and staff at the USGS marine facility in Redwood City, Calif., whose work before and during the often-difficult field operations directly

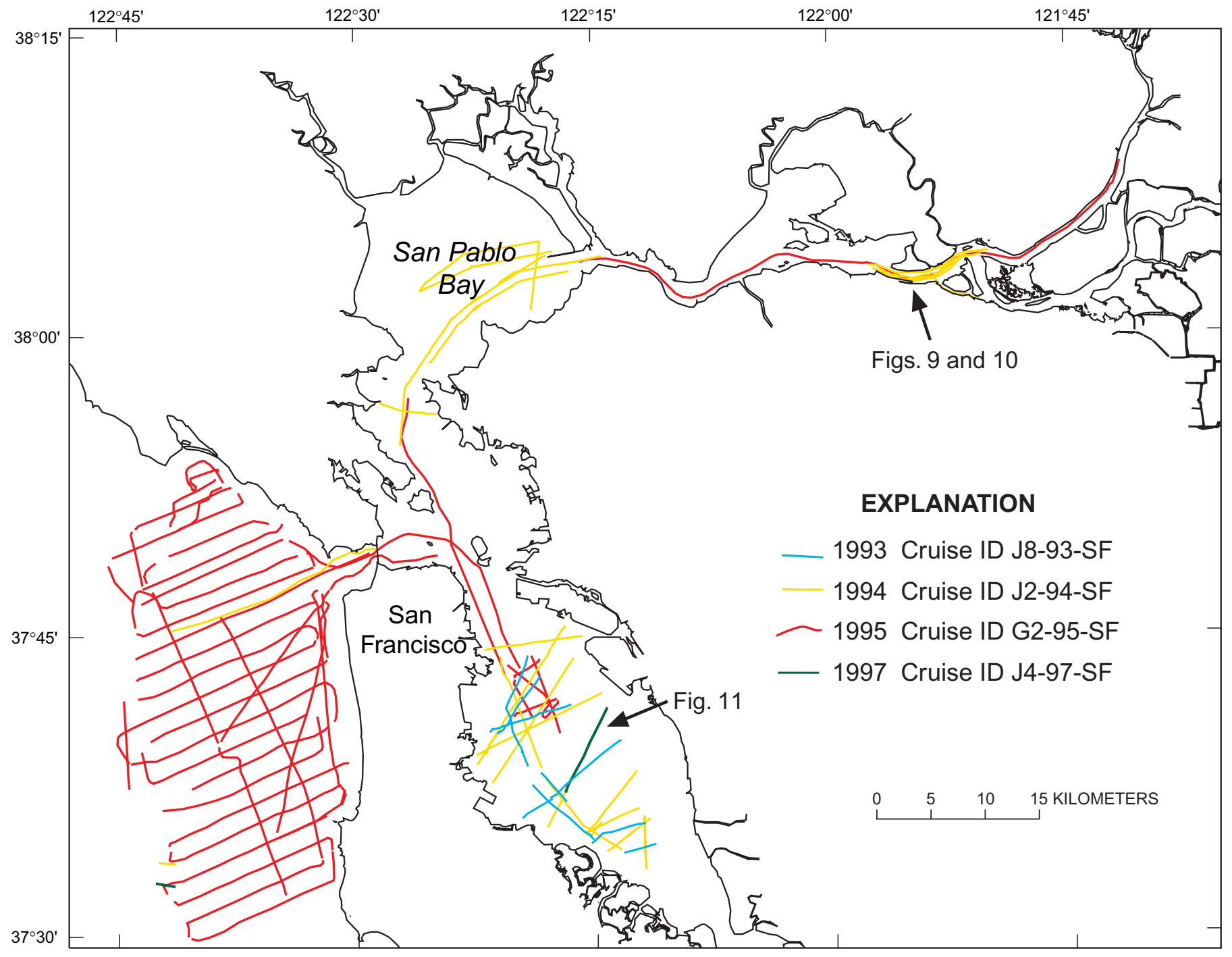

Figure 8.-San Francisco Bay region, showing locations of tracklines for four high-resolution marine seismic-reflection surveys completed from 1993 to 1997 and data examples in figures 9 through 11. 
resulted in new data-acquisition capabilities and a comprehensive regional data set collected with minimal time lost to technical problems. In particular, we thank Steve Wallace, Kevin O'Toole, Hal Williams, Walt Olson, Dave Hogg, Larry Kooker, Bill Robinson, Mike Boyle, Fred Payne, Sue Hunt, Gerry O'Brien, and Gordon Smith, the master of the research vessel David Johnston. We are grateful to Diane Minasian for her work in preparing all the maps and figures for this chapter.

\section{References Cited}

Barry, K.M., Cavers, D.A., and Kneale, C.W., 1975, Recommended standards for digital tape formats: Geophysics, v. 40, no. 2, p. 344-352.

Brocher, T.M., McCarthy, Jill., Hart, P.E., Holbrook, W.S., Furlong, K.P., McEvilly, T.V., Hole, J.A., and Klemperer, S.L., 1994, Seismic evidence for a possible lower-crustal detachment beneath San Francisco Bay, California: Science, v. 265, no. 5177, p. 1436-1439.

Brocher, T.M., and Moses, M.J., 1993, Onshore-offshore wide-angle seismic recordings of the San Francisco Bay Area seismic imaging experiment (BASIX); the five-day recorder data: U.S. Geological Survey Open-File Report 93-276, 89 p.

Childs, J.R., Hart, P.E., Sliter, R.W., Bruns, T.R., and Marlow, M.S., 2000, High-resolution marine seismic reflection data from the San Francisco Bay area; 1993-1997: U.S. Geological Survey Open-File Report 00-494 [URL: http://geopubs.wr.usgs.gov/ open-file/of00-494/].

Childs, J.R., Normark, W.R., and Fisher, M.A., 1999, Permit application and approval chronology for a small airgun survey offshore southern California, June 1999: U.S. Geological Survey OpenFile Report 99-572 [URL: http://geopubs.wr.usgs.gov/open-file/ of $99-572 /]$

Furlong, K.P., Hugo, W.D., and Zandt, George, 1989, Geometry and evolution of the San Andreas fault zone in northern California: Journal of Geophysical Research, v. 94, no. B3, p. 3100-3110.

Holbrook, W.S., Brocher, T.M., ten Brink, U.S., and Hole, J.A., 1996, Crustal structure of a transform plate boundary, San Francisco Bay and the central California continental margin: Journal of Geophysical Research, v. 101, no. B10, p. 2231122334.

Marlow, M.S., Hart, P.E., Carlson, P.R., Childs, J.R., Mann, D.M., Anima, R.J., and Kayen, R.E., 1996, Misinterpretation of lateral acoustic variations on high-resolution seismic reflection profiles as fault offsets of Holocene bay mud beneath the

W

$E$

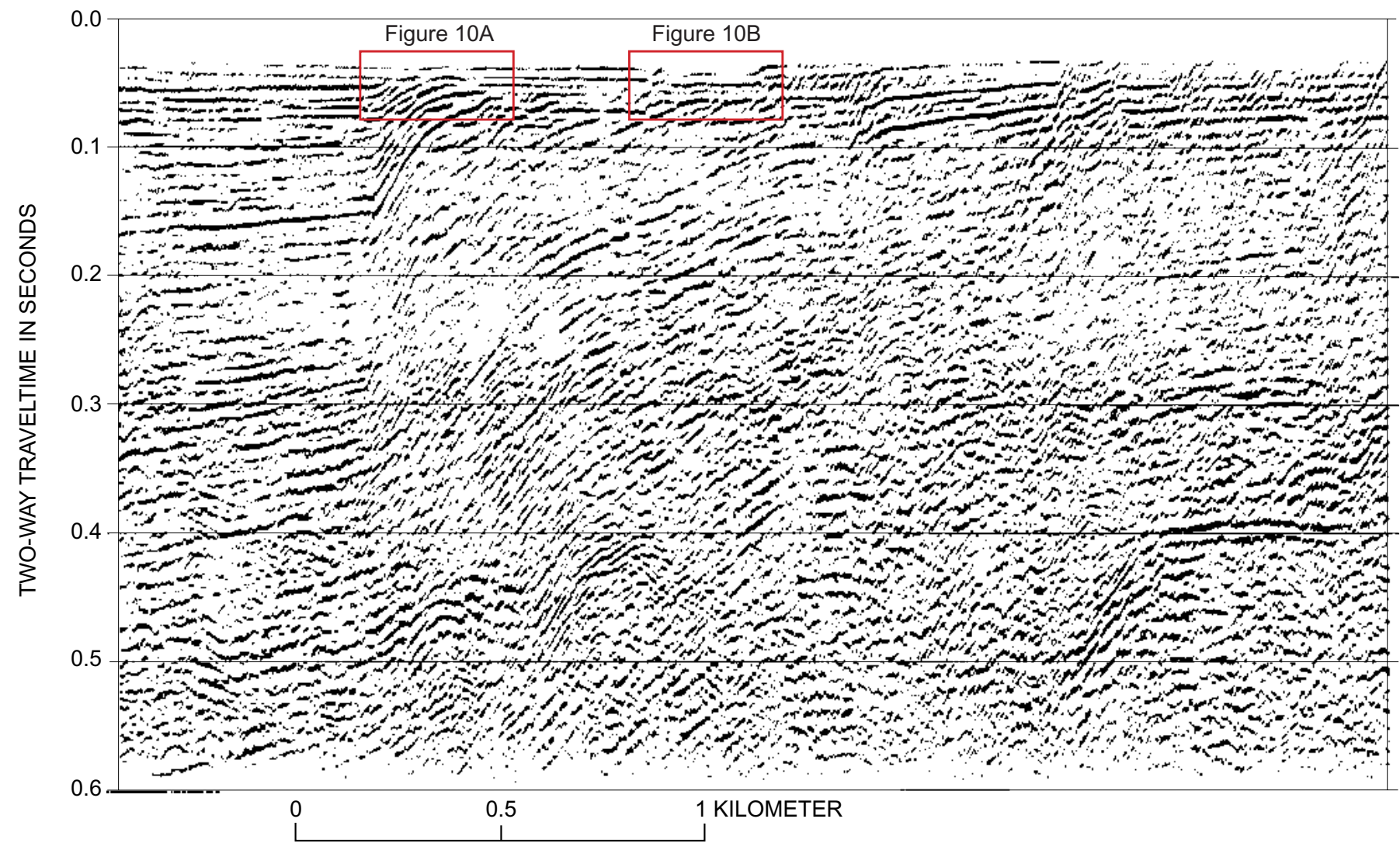

Figure 9.-Section of a high-resolution multichannel seismic profile acquired in the Sacramento River delta crossing the Kirby Hills Fault zone (see fig. 8 for location), showing approximately $500 \mathrm{~m}$ of penetration. Two rectangular boxes indicate coverage of coincident very high resolution data examples in figure 10. 


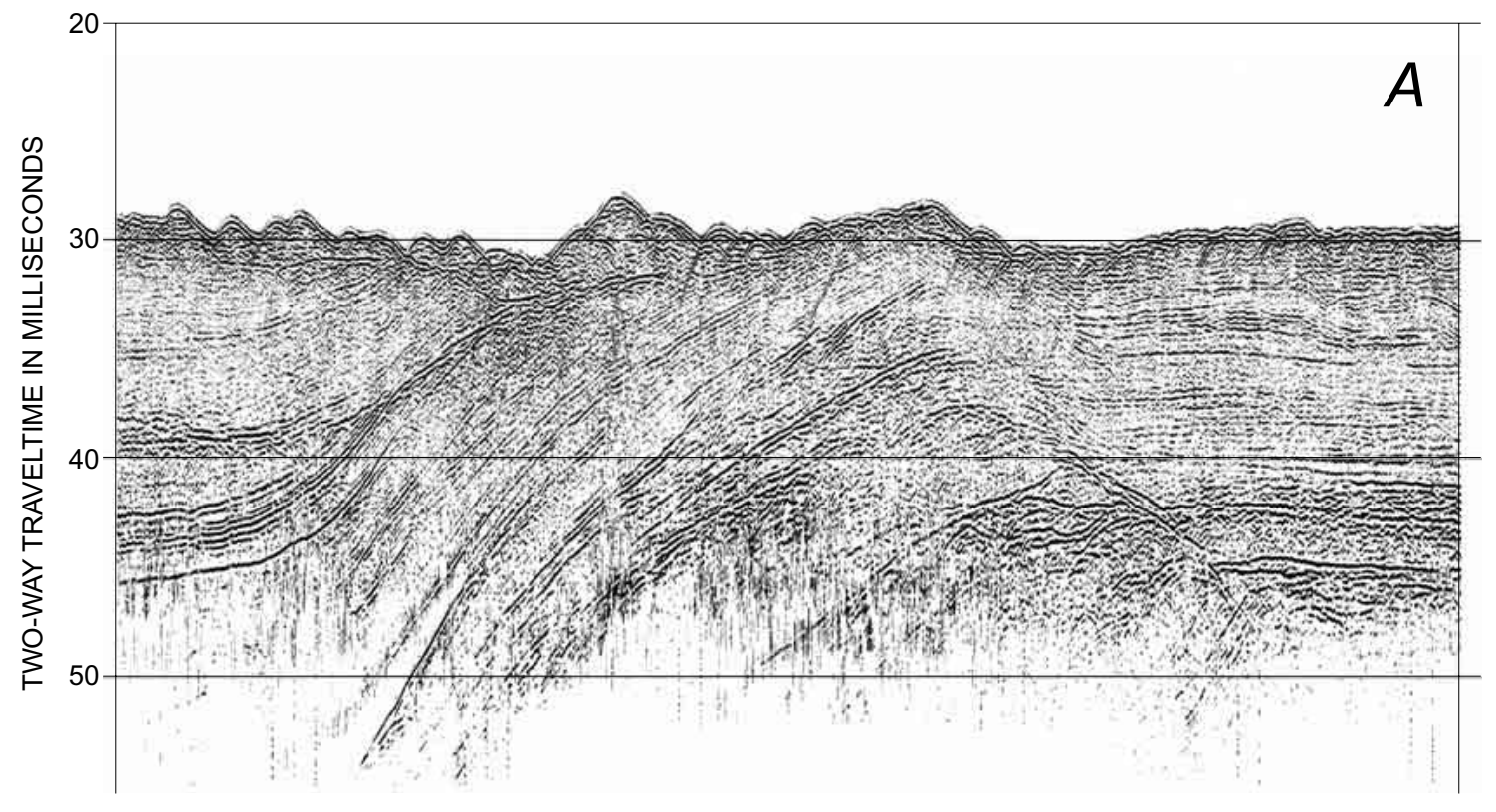

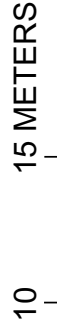

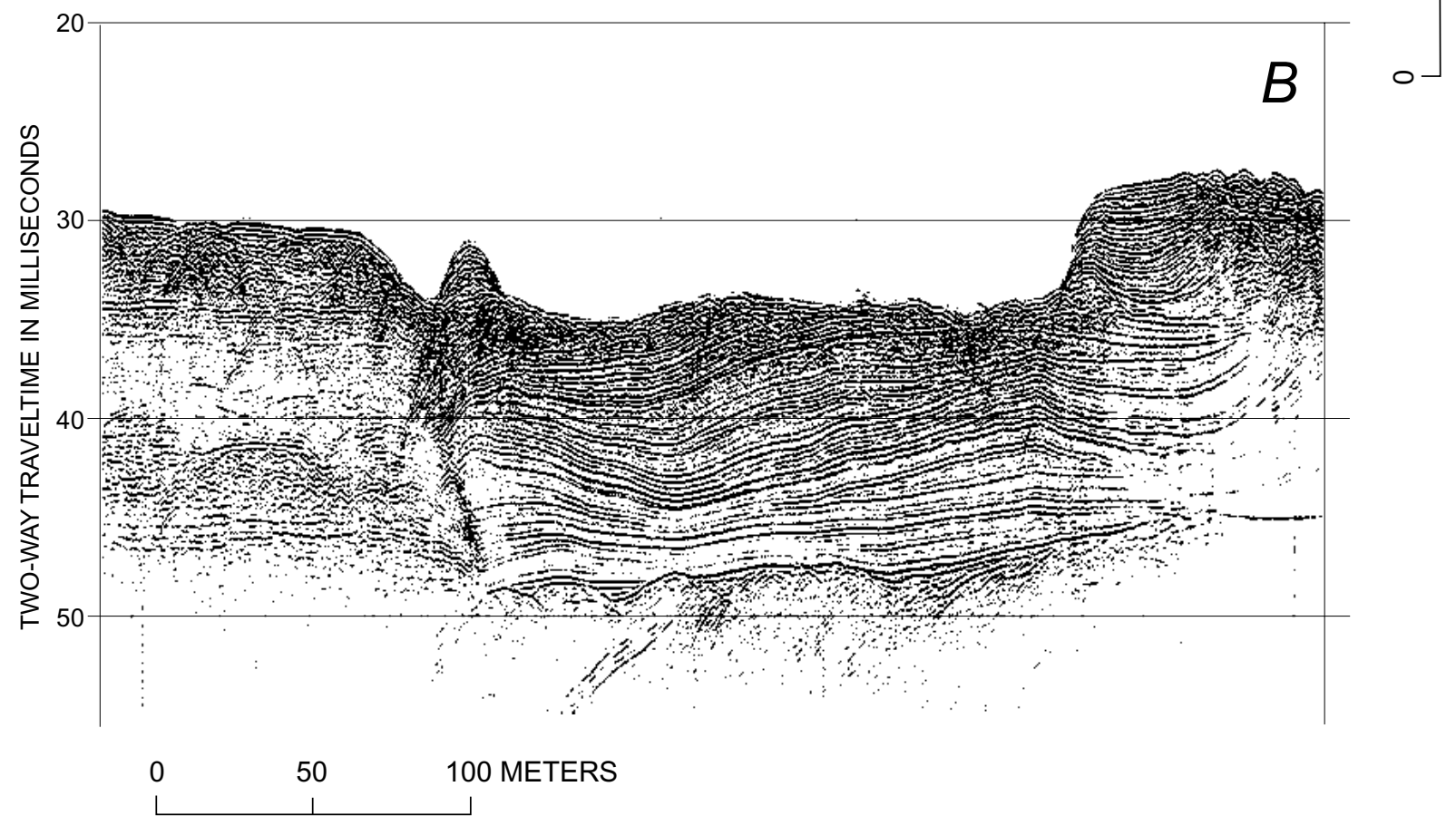

Figure 10.-Two sections of a very high resolution seismic reflection profile acquired in 20 to $25 \mathrm{~m}$ of water in the Sacramento River delta near the Kirby Hills Fault (see fig. 8 for location), showing a "zoomed in" image of two zones $(A, B)$ outlined in figure 9. These data, which have more than $20 \mathrm{~m}$ of subbottom imaging with approximately $30 \mathrm{~cm}$ of vertical resolution, allow interpretations to be extended to shallowest subsurface in much greater detail than is possible with multichannel seismic data alone. 
southern part of San Francisco Bay, California: Marine and Petroleum Geology, v. 13, no. 3, p. 341-348.

Marlow, M.S., Jachens, R.S., Hart, P.E., Carlson, P.R., Anima, R.J., and Childs, J.R, 1998, Development of San Leandro synform and neotectonics of the San Francisco Bay Block, California: Marine and Petroleum Geology, v. 16, no. 5, p. 431-442.

McCarthy, Jill, and Hart, P.E., 1993, Data report for the 1991 Bay Area seismic imaging experiment (BASIX): U.S. Geological Survey
Open-File Report, 93-301, 26 p.

Parsons, Tom, 1998, Seismic-reflection evidence that the Hayward fault extends into the lower crust of the San Francisco Bay area, California: Seismological Society of America Bulletin, v. 88 , no. 5, p. 1212-1223.

Parsons, Tom, and Hart, P.E., 1999, Dipping San Andreas and Hayward faults revealed beneath San Francisco Bay, California: Geology, v. 27, no. 9, p. 839-842.

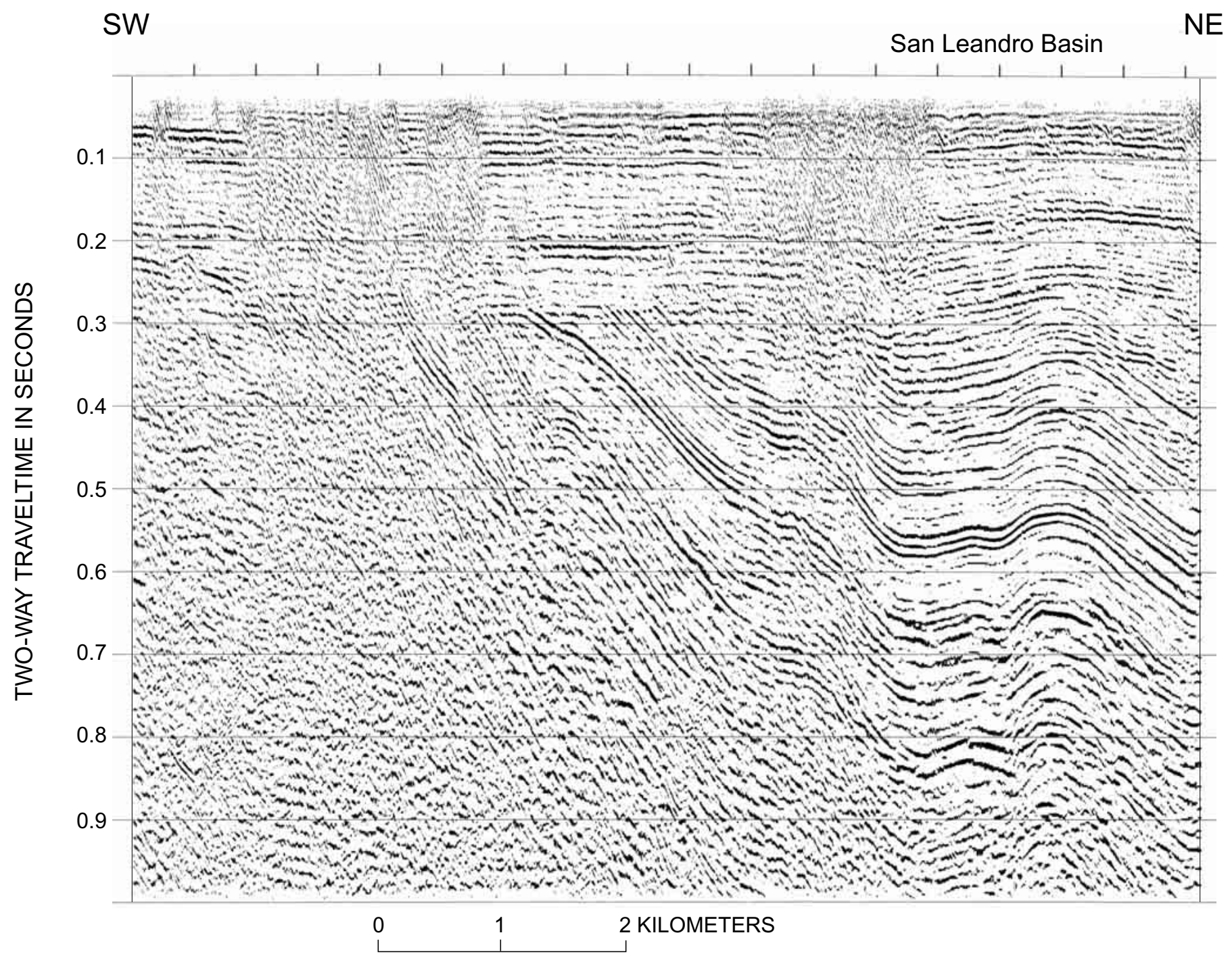

Figure 11. Migrated multichannel seismic-reflection profile acquired in southern San Francisco Bay (see fig. 8 for location). This airgun line shows approximately $1 \mathrm{~km}$ of penetration into folded sedimentary deposits of the San Leandro Basin. 


\title{
Structure of the Submerged San Andreas and San Gregorio Fault Zones in the Gulf of the Farallones off San Francisco, California, from High-Resolution Seismic-Reflection Data
}

\author{
By Terry R. Bruns, Alan K. Cooper, Paul R. Carlson, and David S. McCulloch
}

\section{CONTENTS}

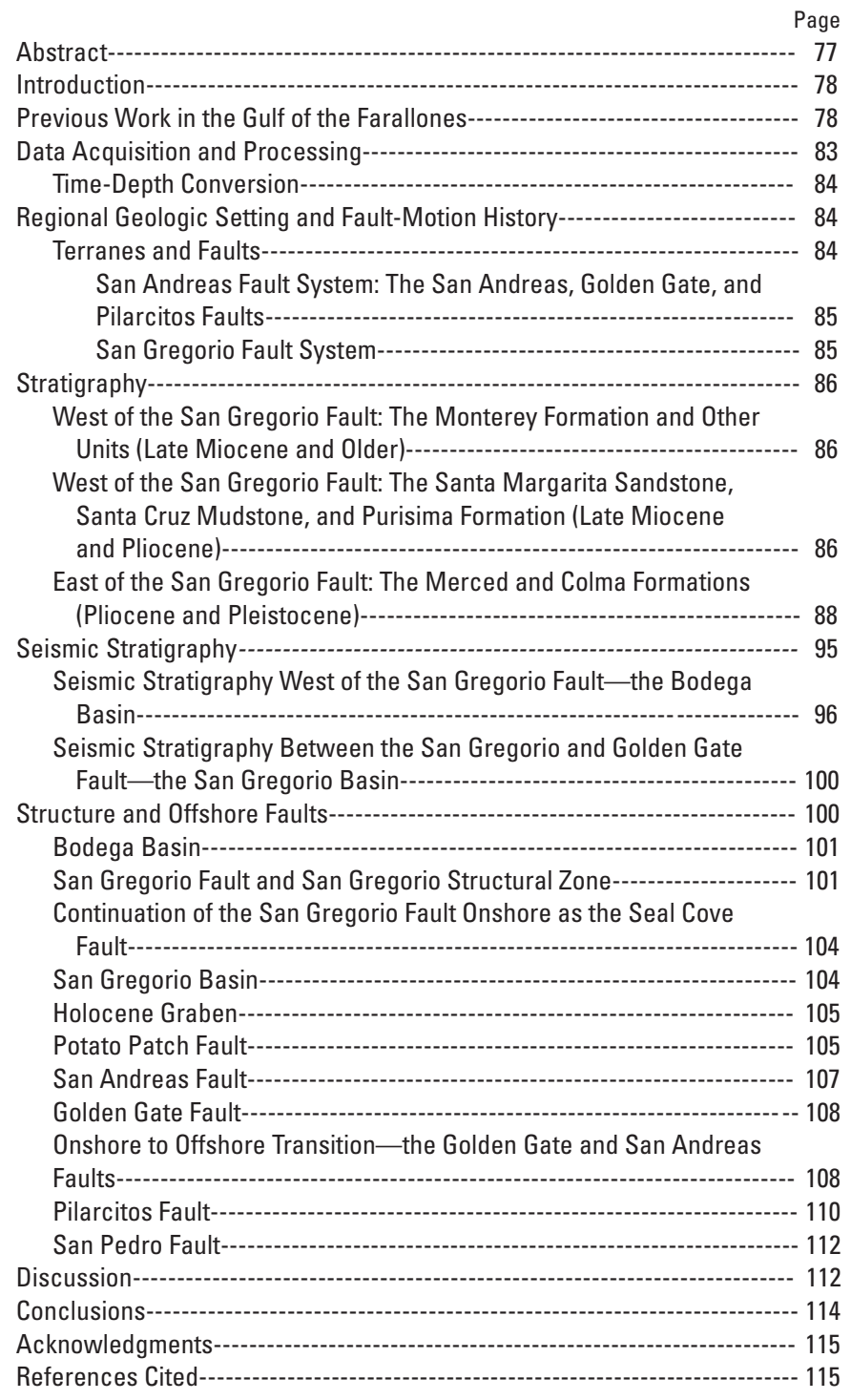

\section{Abstract}

The San Andreas and San Gregorio Fault zones are major strike-slip-fault systems that form part of the active plate boundary between the Pacific and North American Plates. The San Gregorio Fault is offshore for most of its length, whereas the San Andreas Fault extends offshore near Daly City south of San Francisco. On the basis of magnetic and seismicity data, motion on the San Andreas Fault has been interpreted to step over to another fault, the Golden Gate Fault, that lies 3 $\mathrm{km}$ to the east of the San Andreas Fault and also goes offshore near San Francisco. All three faults merge and come onshore again at Bolinas Lagoon. Although the overall trend of these faults is clear, the details of what has occurred offshore on these faults is not. Therefore, we acquired about $550 \mathrm{~km}$ of high-resolution seismic-reflection data in the Gulf of the Farallones to image these faults between Point Montara and Bolinas Lagoon. Seismic lines were acquired on about a 2-km line spacing, and the seismic-reflection data imaged approximately the uppermost $1.5 \mathrm{~km}$ of the sedimentary sequence in the offshore sedimentary basins.

Our interpretation of the seismic-reflection data identifies the following major features.

1. The Golden Gate, San Andreas, and San Gregorio Faults all have recognizable continuations across the Gulf of the Farallones. The Potato Patch Fault branches eastward off the San Gregorio Fault and continues northward as another fault with significant, but unknown, offset, possibly merging with the San Andreas Fault south of Bolinas. The San Gregorio structural zone, an area of major thrust-fault deformation west of the San Gregorio Fault, also continues across the Gulf of the Farallones and widens from about 2 to more than $8 \mathrm{~km}$ from south to north. All of these features are undergoing modern uplift onto the Point Reyes peninsula.

2. The San Gregorio Fault separates two major offshore sedimentary basins: the San Gregorio Basin, which lies between the Golden Gate/San Andreas Faults and the San Gregorio Fault; and the Bodega Basin, which lies west of the San Gregorio Fault. Maximum sedimentary thickness in the San Gregorio Basin is poorly defined but probably approaches $2 \mathrm{~km}$ overlying Franciscan and Salinian basement rocks. The age of the basin fill is unknown but could be similar to that of strata in the onshore Merced Formation, which are younger than about 1.8 Ma. We cannot directly correlate strata in the San Gregorio Basin with the 
Merced Formation because a structural discontinuity may separate the two sequences. In the Bodega Basin, more than $800 \mathrm{~m}$ of Late Miocene and younger (less than approx $6 \mathrm{Ma}$ ) strata overlies the Monterey Formation and older rocks.

3. Although strike-slip motion on the San Andreas Fault appears to step northeastward to the Golden Gate Fault in the area from Daly City to the Golden Gate, the offshore continuation of the San Andreas Fault has served as a locus for subsidence. The fault generally underlies the depocenter of the San Gregorio Basin. The Potato Patch Fault, which lies between the San Andreas and San Gregorio Faults, forms the edge of a structural high in the basin. Both the San Andreas and Potato Patch Faults are at least partly normal faults along which basement rocks have undergone differential subsidence during basin formation. The faults could have a strike-slip component, but we cannot determine how much from the seismic-reflection data. In the northern parts of the basin, strata appear to cross the faults with virtually no disruption.

4. The San Gregorio Fault has a long transform history. North of Pacifica, however, the fault has converted to a normal fault along which the San Gregorio Basin has subsided. The transform motion on the San Gregorio Fault appears to step over to the Golden Gate Fault through the San Gregorio Basin.

5. The underlying mechanism creating the San Gregorio Basin seems to be the combined stepover of motion on the San Andreas and San Gregorio Faults onto the Golden Gate Fault, leading to the creation of a transtensional strike-slip stepover basin-the San Gregorio Basin. A simple model with this assumption places the region of maximum subsidence of a stepover basin beneath the deepest part of the San Gregorio Basin. Although the stepover model may be adequate to explain the overall formation of the basin, the details of how motion is transferred are unclear. Deformation on the basin faults north of Lake Merced seems to be mainly normal faulting. The Potato Patch Fault, however, probably has a component of strike-slip motion and serves as a transfer fault for motion from the San Gregorio Fault to the Golden Gate Fault.

6. Finally, the San Andreas Fault broke on the Point Reyes peninsula and at Bolinas Lagoon during the great 1906 San Francisco earthquake, yet the observed offshore structure indicates that this fault was not an active transform fault during much of the formation of the San Gregorio Basin. The offshore section of the fault could now be in a transitional stage intermediate between a transtensional right stepover and a more throughgoing transform fault.

\section{Introduction}

A series of major strike-slip faults transect central California and form part of the active plate boundary between the Pacific and North American Plates (fig. 1). The best known of these faults is the San Andreas Fault, which crosses the San Francisco peninsula and extends offshore south of San
Francisco. The less well known San Gregorio Fault lies west of the San Andreas Fault, mostly offshore; in the Gulf of the Farallones region, the fault zone lies onshore only on the headland north of Half Moon Bay (fig. 1). A third fault, the Pilarcitos Fault, which could have accommodated most San Andreas Fault system displacement sometime before about $3 \mathrm{Ma}$, lies between the San Andreas and San Gregorio Faults and trends offshore just north of Point San Pedro. All these faults, except the Pilarcitos Fault, cross the Gulf of the Farallones and come onshore at Bolinas Lagoon on the Point Reyes peninsula. These faults also separate the Continental Shelf into two basic structural domains-the Bodega Basin, which lies west of the fault, and the San Gregorio Basin (named herein), which lies to the east (Cooper, 1973; McCulloch, 1987, 1989).

To delineate the near-surface structure and fault history of the Gulf of the Farallones, we conducted a high-resolution seismic-reflection survey in the region in June 1995 (figs. 1-3). High-resolution aeromagnetic data (Jachens and Zoback, 1999; see Jachens and others, this volume) provide additional information on fault locations at depths greater than observable in the seismic-reflection data (fig. 4). With this data base, we use the seismic-reflection data to (1) map the offshore traces of the San Andreas and San Gregorio Fault systems and associated structures; (2) compare the mapped fault locations with other data sets, including aeromagnetic data; and (3) develop a better understanding of the fault history and kinematics of the San Andreas/San Gregorio Fault systems.

\section{Previous Work in the Gulf of the Farallones}

Previous seismic-reflection studies in the Gulf of the Farallones region were published by Cooper (1973) and McCulloch (1987, 1989). Cooper delineated the general structure of the Continental Shelf west of San Francisco. He defined the Farallon platform as lying beneath the Gulf of the Farallones west of the San Gregorio Fault (fig. 1), where as much as $3.5 \mathrm{~km}$ of sedimentary rocks overlies granitic basement rocks. The Golden Gate platform lies east of the fault, with more than $1 \mathrm{~km}$ of strata overlying basement. Cooper also outlined a structural graben between the San Gregorio Fault and the San Andreas Fault (figs. 1, 3). His seismicreflection data penetrated to as much as 1.8-s two-way traveltime (approx 1.7-2 km deep) in areas adjacent to Point Reyes, but much less than that to the south. He traced the San Andreas, Pilarcitos, and San Gregorio Faults (his Seal Cove Fault; see Glenn, 1959) across the Gulf of the Farallones to Bolinas Lagoon.

McCulloch $(1987,1989)$ described the Cenozoic geologic history of the California continental margin. Using all available single-channel and multichannel seismic-reflection data, as well as gravity and aeromagnetic data, he outlined the major structural elements off central California and determined offset in basement rocks. McCulloch (1987, 1989) had more seismic-reflection data that crossed the San 
Gregorio and San Andreas Fault zones than Cooper (1973) had. Thus, McCulloch's $(1987,1989)$ locations of the faults differ somewhat from Cooper's; whereas Cooper took the Seal Cove strand of the San Gregorio Fault as the major strand, McCulloch $(1987,1989)$ interpreted a wide fault zone, with the Seal Cove Fault forming the east boundary.
McCulloch $(1987,1989)$ was able to map part of the Golden Gate Fault offshore. He also used aeromagnetic data to delineate faults, most of which show up in much more detail in recently acquired aeromagnetic data (Jachens and Zoback, 1999; Zoback and others, 1999; see Jachens and others, this volume). The details of fault interactions remained unclear,

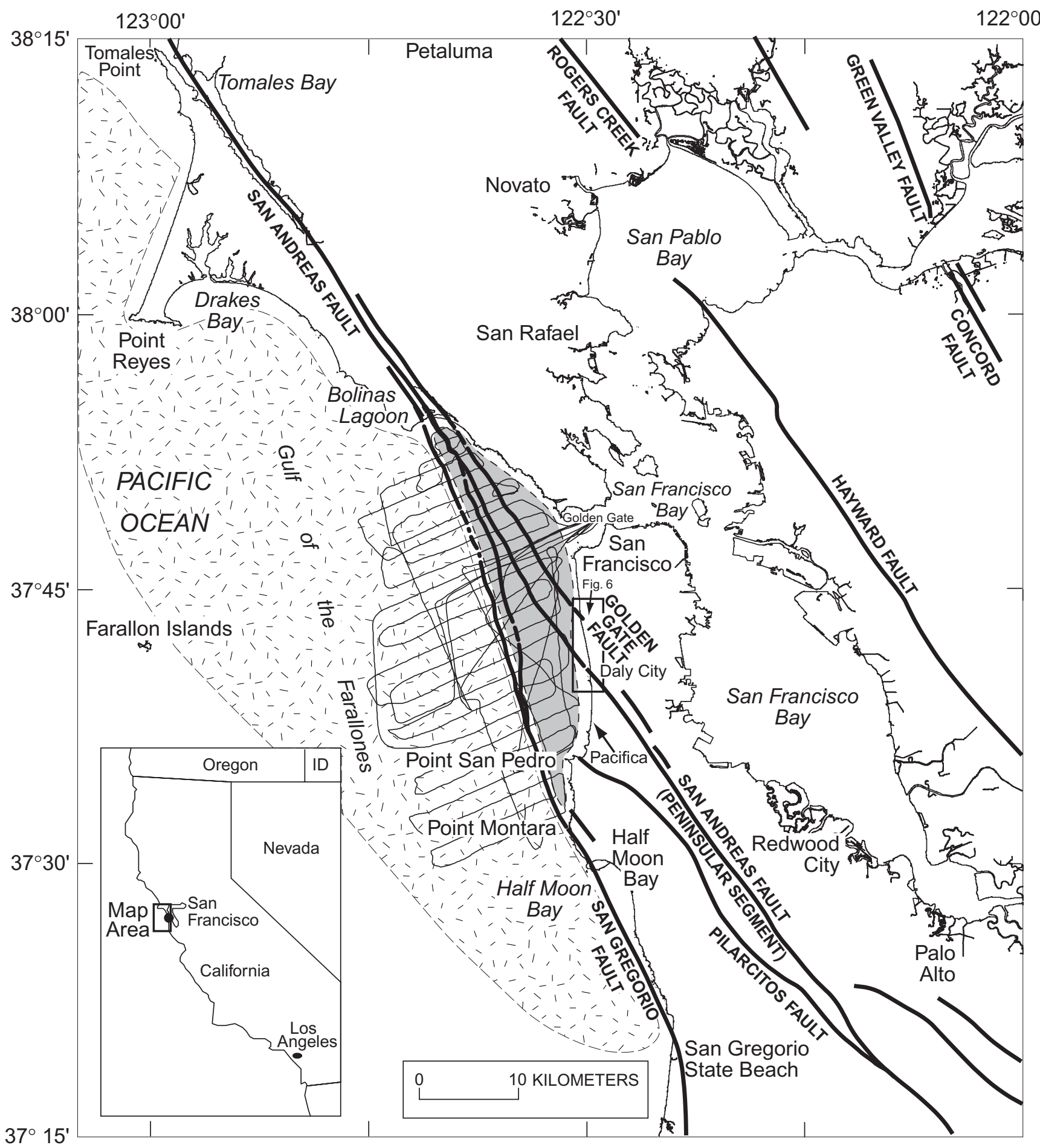

Figure 1.-Gulf of the Farallones and San Francisco Bay region, Calif., showing locations of major faults and tracklines of high-resolution multichannel seismic-reflection records acquired for this study. Shaded area, general area of the San Gregorio Basin as defined here; hachured area, the Bodega Basin of McCulloch $(1987,1989)$. Rectangle denotes area of figure 6. 


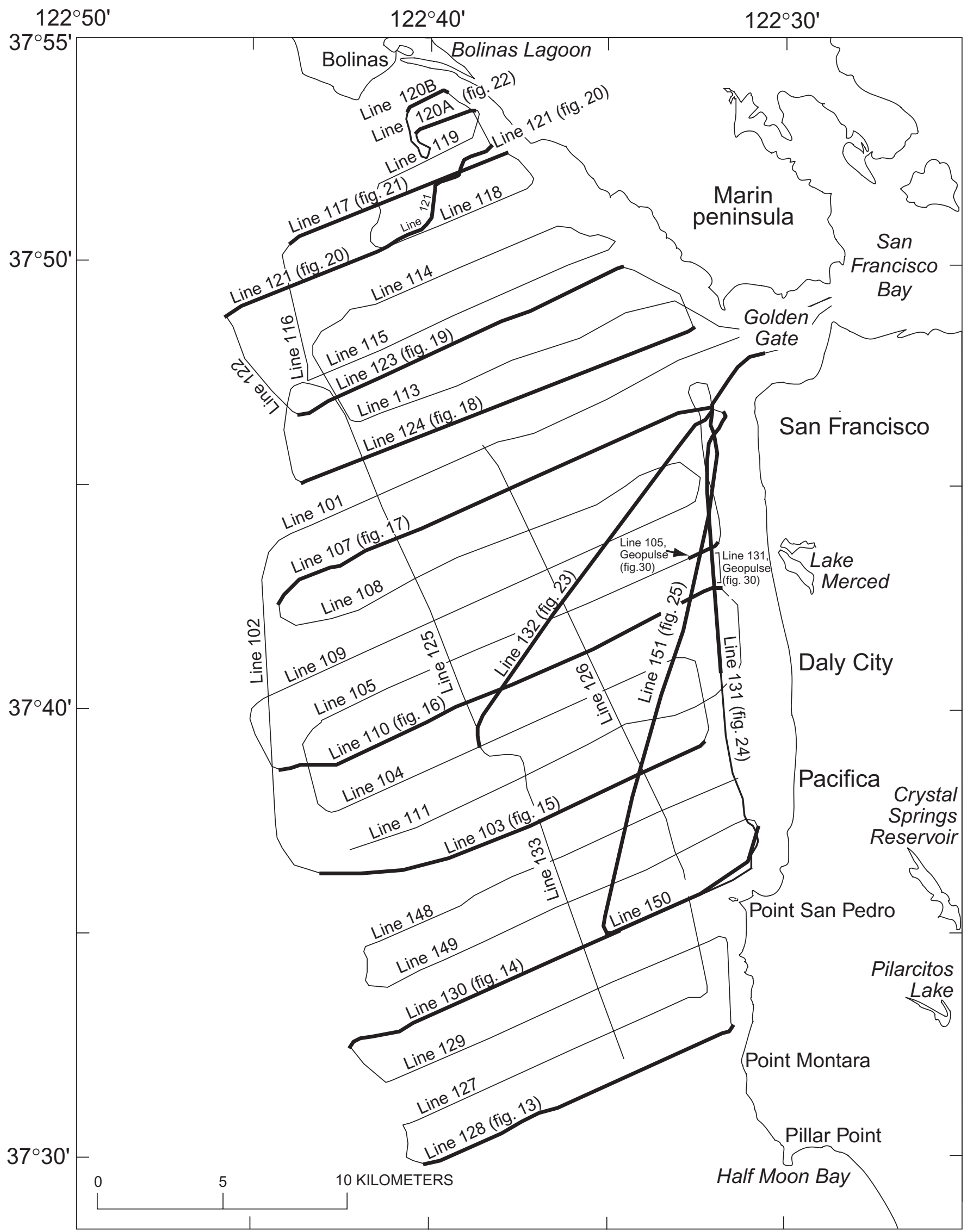

Figure 2.-Gulf of the Farallones and San Francisco Bay region, Calif., showing locations of tracklines of high-resolution multichannel seismicreflection data; data for bold tracklines are plotted in figures 13 through 25. 


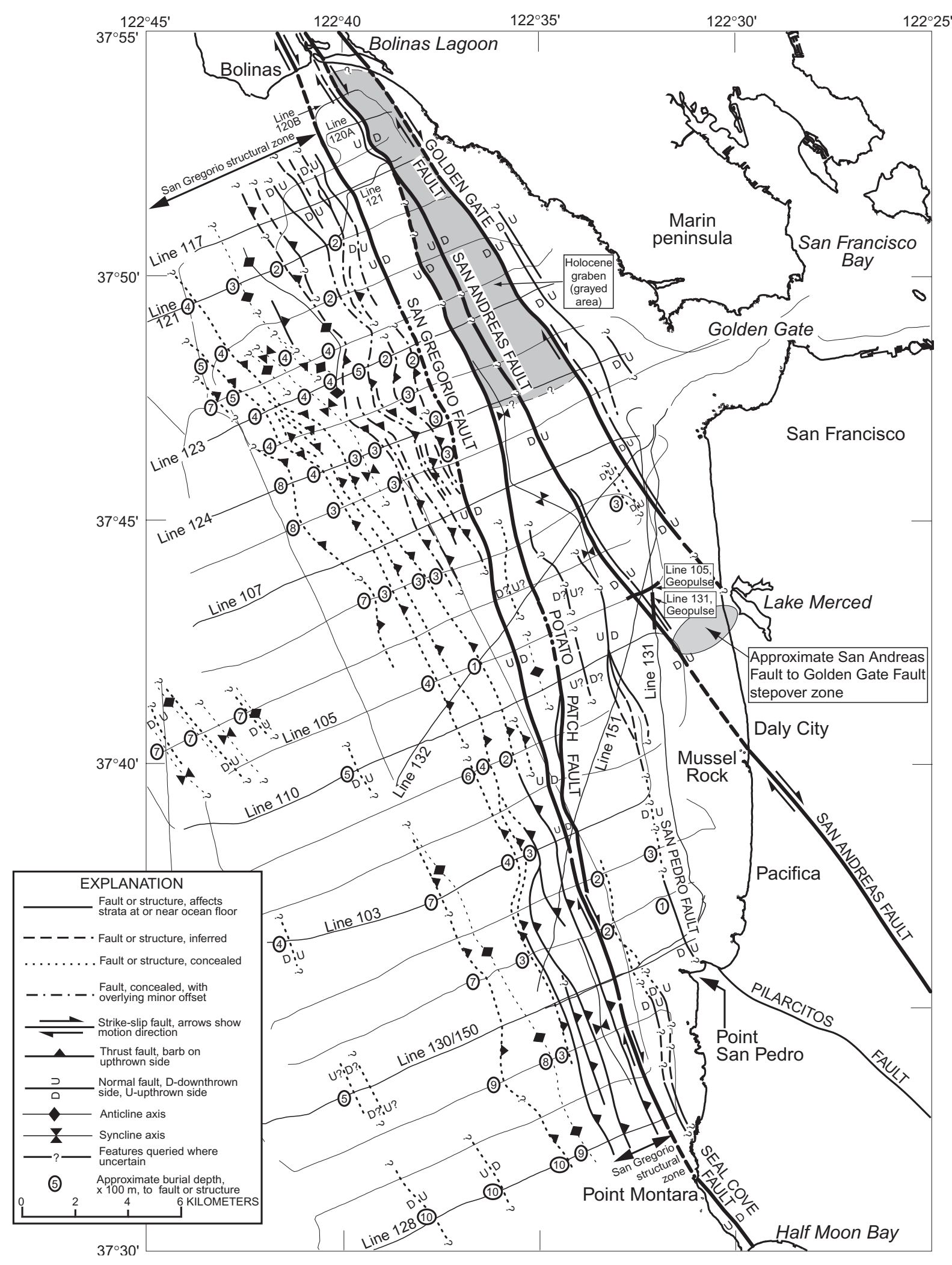

Figure 3.-Gulf of the Farallones and San Francisco Bay region, Calif., showing the offshore San Gregorio, San Andreas, Golden Gate, and related faults west of San Francisco and the Golden Gate. Labeled tracklines are shown in figures 13 through 25 . The Bodega Basin lies west of the San Gregorio Fault, and the San Gregorio Basin lies between the San Gregorio and San AndreasGolden Gate Faults. A Holocene graben (shaded area) lies between the Golden Gate and Bolinas. Shaded oval shows region where motion on the San Andreas Fault is interpreted to stepover to the Golden Gate Fault in the vicinity of Lake Merced. Motion on the San Gregorio Fault most likely steps over to the Golden Gate Fault along the Potato Patch Fault but possibly also along the San Pedro Fault, both of which would then be strike-slip transfer faults. 


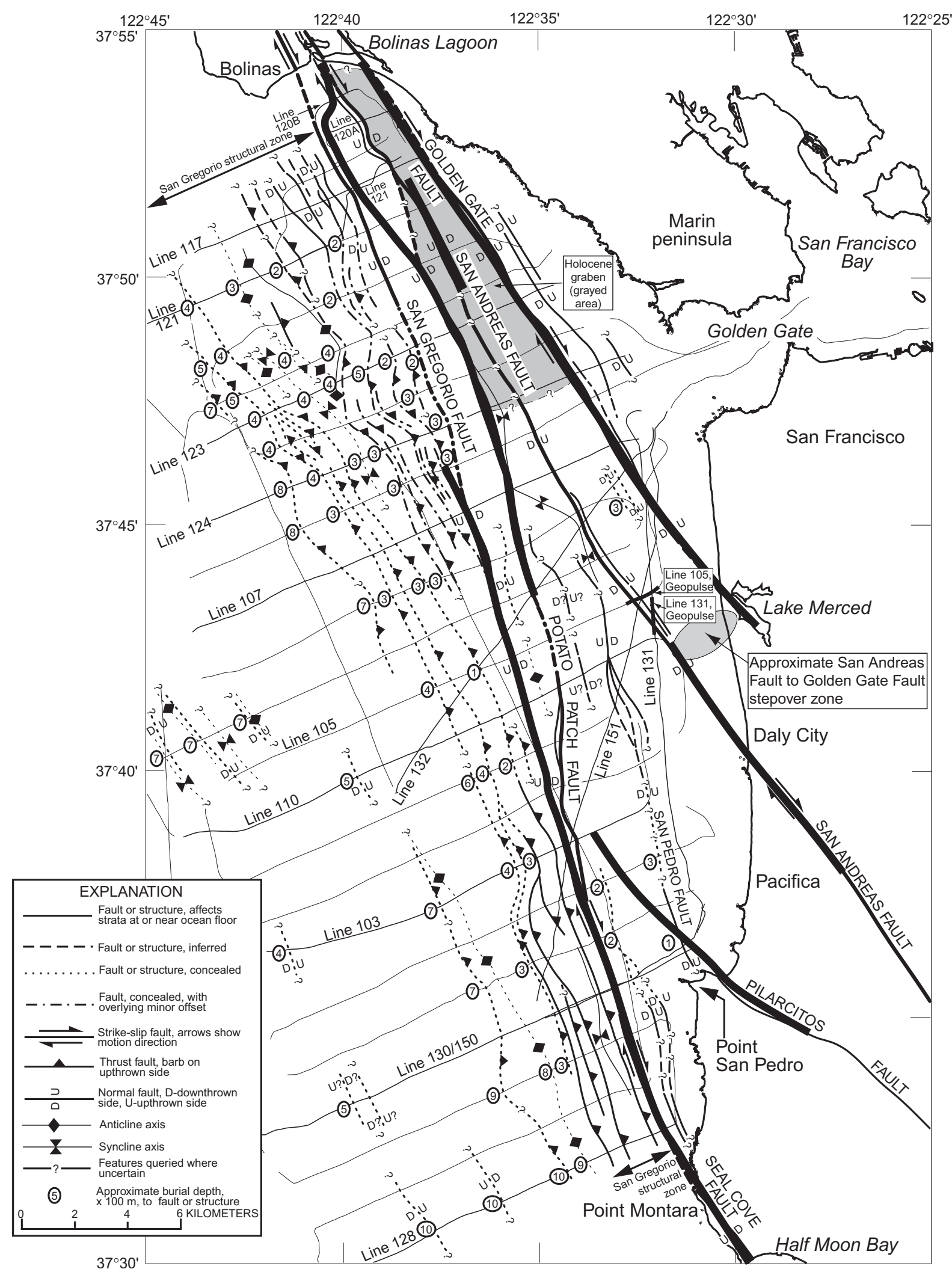

Figure 4.-Gulf of the Farallones and San Francisco Bay region, Calif., showing locations of basement faults (heavy lines) as interpreted from aeromagnetic data by Jachens and others (1999) and Jachens and others (this volume). Faults interpreted from seismic-reflection data show high correlation with magnetically located southern section of the San Gregorio Fault, northern section of the Potato Patch Fault, and the Golden Gate Fault; the Pilarcitos Fault is not evident in seismic-reflection data. 
however, because of an absence of high-quality deep- to medium-penetration seismic-reflection data east of the San Gregorio Fault.

A fold-and-thrust belt lies west of the San Gregorio Fault (fig. 3). Cooper (1973) termed this belt the "Eastern Marginal High," but McCulloch $(1987,1989)$ incorporated it into the San Gregorio Fault zone. We follow McCulloch's (1987, 1989) suggestion because our interpretations indicate that the belt is tectonically linked to the San Gregorio Fault. Thus, we refer to it as the "San Gregorio structural zone" and discuss it along with the San Gregorio Fault system below.

Jachens and Zoback (1999), Zoback and others (1999), and Jachens and others (this volume) interpret high-resolution aeromagnetic data over the Gulf of the Farallones to show faulting in the magnetic basement rocks (fig. 4; see Jachens and others, this volume). They show that a long, linear magnetic anomaly associated with the Seal Cove Fault (onshore) and San Gregorio Fault (offshore) trends northwest to a position slightly southwest of the Golden Gate, where the fault is interpreted to end (fig. 4). Northward, basement fault offset is then on an east-stepping separate arcuate fault, partly corresponding to our Potato Patch Fault, that trends back onshore at Bolinas Lagoon. Aeromagnetic data indicate that the Pilarcitos Fault trends offshore for about $8 \mathrm{~km}$ before either merging with or being truncated by the San Gregorio

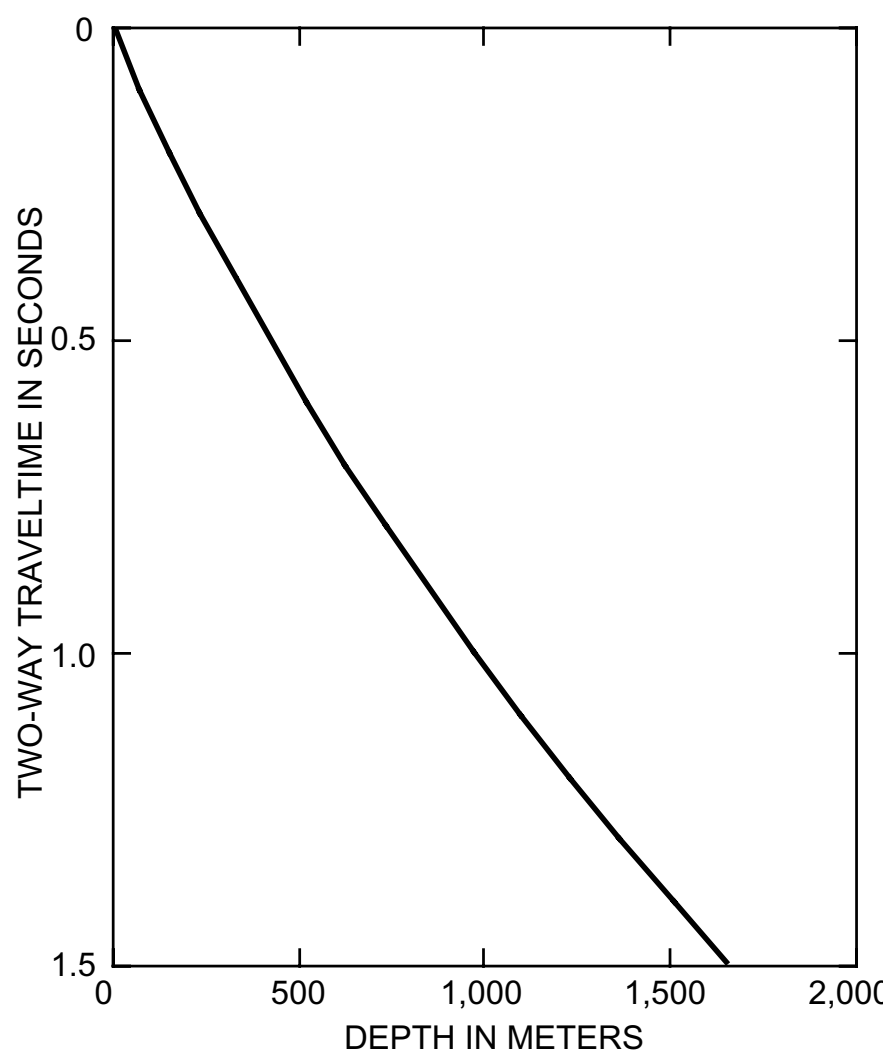

Figure 5.-Curve for converting two-way seismic-reflection time (in seconds) to approximate depth (in meters) in high-resolution seismicreflection data presented here.
Fault. The Peninsular segment of the San Andreas Fault continues offshore for about $6 \mathrm{~km}$, where it is interpreted to stepover to the Golden Gate Fault, which is outlined by a conspicuous magnetic lineament that trends northwest from Lake Merced (fig. 4). These data show a continuity of the faults and fault zones present within offset magnetic basement units, but not the structure or stratigraphy in the uppermost 1 to $2 \mathrm{~km}$ of sedimentary strata associated with the faults.

Using the earlier work by Cooper (1973) and McCulloch (1987, 1989), the aeromagnetic interpretation, and local earthquake seismicity, Zoback and others (1999) interpreted a change from compressional to extensional deformation on the Peninsular segment of the San Andreas Fault. Source studies of small seismic events beneath the Gulf of the Farallones showed normal faulting, associated with extensional deformation, instead of the compressional events that might be associated with strike-slip or thrust faults. Jachens and Zoback (1999), Zoback and others (1999), and Jachens and others (this volume) then proposed a 3-km northeastward jump of fault motion from the San Andreas Fault to the Golden Gate Fault (a right step), and Zoback and others (1999) suggested that this right stepover created the extensional tectonic regime. The stepover leads to the formation of an extensional strike-slip basin containing thick deposits of the Pliocene and Pleistocene Merced Formation, a suggestion made earlier by Hengesh and Wakabayashi (1995) on the basis of their reconstruction of offset on the San Andreas Fault system and the geologic history of the Merced Formation.

\section{Data Acquisition and Processing}

In June 1995, we collected about $550 \mathrm{~km}$ of high-resolution seismic-reflection data across the submerged sections of the San Gregorio and San Andreas Fault systems in the Gulf of the Farallones between Point Montara and Bolinas Lagoon (figs. 1-3; Bruns and others, 1995, 1996). The data were acquired along an approximately $2-\mathrm{km}$ north-south line spacing from nearshore to about $16 \mathrm{~km}$ offshore and west of the San Gregorio Fault, into the Bodega Basin (figs. 1-3). Tielines between the east-west lines were acquired in the Bodega Basin, nearshore, and elsewhere as opportunity allowed during field acquisition. This seismic survey was designed to systematically examine the fault systems with adequate spatial resolution to correlate fault traces across the offshore area. The seismic-reflection data show sedimentary bedding and structure to about $1.5-\mathrm{km}$ depth; the small acoustic power of the seismic source seldom penetrated farther.

We collected the data with a 24-channel recording system, a 150-m-long streamer, and two 0.65-L (40 in $\left.{ }^{3}\right)$ airguns fired at $12.5-\mathrm{m}$ intervals. The data were digitally recorded, and navigated with a Global Positioning System navigation program called YoNav, developed by the U.S. Geological Survey (Gann, 1992). We processed the digital airgun data through a standard set of programs on a DISCO 
processing system including velocity correction of commondepth-point gathers, deconvolution, stacking, muting, automatic gain control, filtering at 50 to $160 \mathrm{~Hz}$, and migration.

In a few areas, single-channel high-resolution seismicreflection profiles were acquired with a Geopulse system, a frequency range of 2,000 to $4,000 \mathrm{~Hz}$, and penetration of a few tens of meters. Owing to weather conditions, we were unable to acquire these data over all the multichannel tracks. Two of these high-resolution tracklines are shown in figure 2 .

\section{Time-Depth Conversion}

Seismic data are plotted in two-way traveltime, and seismic horizons must be converted to depth to interpret the geology. We do not have good velocity information for the section imaged in the high-resolution seismic-reflection data. Stacking velocities from the multichannel high-resolution data indicated that a good approximation to the velocity structure was obtained by increasing interval velocities from 1,500 to $2,400 \mathrm{~m} / \mathrm{s}$ between 0.0 - to 1.0 -s two-way traveltime; we then assumed that interval velocities would be about $3,500 \mathrm{~m} / \mathrm{s}$ by 2.0-s two-way traveltime. We used these interval velocities to construct a curve for converting time information on the seismic sections into depths (fig. 5). A substantially lower velocity model (that is, interval velocities of $2,000 \mathrm{~m} / \mathrm{s}$ at 1.0 s two-way traveltime and $3,000 \mathrm{~m} / \mathrm{s}$ at 2.0 -s two-way traveltime) would result in an approximately 10-percent decrease in calculated depths.

About a quarter of the acquired seismic lines are shown here with interpretations. All of the lines are available in uninterpreted digital formats on a CD-ROM (Childs and others, 2000).

\section{Regional Geologic Setting and Fault- Motion History}

\section{Terranes and Faults}

The San Gregorio and San Andreas Fault systems divide the Continental Shelf into three tectonostratigraphic terranes - the Salinia terrane, the Pilarcitos block, and the Franciscan Complex, composed of several Franciscan terranes (see McCulloch, 1987, 1989).

The Salinia terrane lies west of the San Andreas and San Gregorio Faults throughout most of central California, and west of the Pilarcitos Fault on the San Francisco peninsula. Substantial separation has occurred within the terrane along the San Gregorio Fault (McCulloch, 1987, 1989). The basement of the Salinia terrane is composed of Mesozoic and older metamorphic rocks intruded by Cretaceous granitic plutons. Overlying the crystalline basement is a sequence of sedimentary rocks that range in age from Paleocene to Holocene. These sedimentary rocks underlie the Bodega Basin between the San Gregorio Fault and the Farallon Ridge structural high near the edge of the Continental Shelf (McCulloch, 1987, 1989).

The Franciscan terrane, which is composed of late Mesozoic to Tertiary rocks, underlies the onshore area immediately east of the Pilarcitos and San Andreas Faults. The Franciscan rocks in this area consist predominantly of melange that includes graywacke, serpentinite, chert, and blocks of blueschist in a penetratively sheared argillite matrix (for example, Ross, 1978; Brabb and Pampeyan, 1983; Blake, 1984; Brabb and others, 1998; Page, 1992; McCulloch, 1987, 1989). The basement units offshore are overlain by a substantial thickness of sedimentary rocks of the San Gregorio Basin, and onshore by the Merced Formation.

Throughout most of central California, the San Andreas Fault separates the Salinia terrane on the west from the Franciscan terrane. On the San Francisco peninsula, however, the Pilarcitos Fault separates these two terranes, and the San Andreas Fault lies entirely within the Franciscan terrane (Brabb and Pampeyan, 1983). Both the Pilarcitos and San Andreas Faults are steeply to vertically dipping features that extend to an upper-crustal depth of at least $10 \mathrm{~km}$ (Parsons and Zoback, 1997). The Pilarcitos block, which lies between the active San Andreas and San Gregorio Faults, consists of basement rocks of the Salinia and Franciscan terranes, now amalgamated together along the Pilarcitos Fault. McLaughlin and others (1996) and Parsons and Zoback (1997) concluded that the Pilarcitos Fault took up motion on the San Andreas Fault system before the Quaternary and probably before about $3 \mathrm{Ma}$.

The terms "San Andreas Fault system" and "San Gregorio Fault system" describe multiple faults on which motion has occurred. The Continental Shelf off San Francisco is cut by at least seven subsidiary faults that are segments of these fault systems (fig. 3). All of these subsidiary faults except the Pilarcitos Fault affect the basin fill in either the Bodega or San Gregorio Basin.

1. The Golden Gate strand of the San Andreas Fault trends offshore from Lake Merced in the northern part of the San Francisco peninsula (figs. 1, 3). Herein, we refer to this fault as the "Golden Gate Fault."

2. The Peninsular segment of the San Andreas Fault extends offshore at Mussel Rock in Daly City (figs. 1, 3). Herein, this segment is routinely referred to both onshore and offshore as the "San Andreas Fault."

3. The Pilarcitos Fault, which lies between the San Andreas and San Gregorio Faults, is a now-inactive fault that separates basement terranes with markedly different rock types (figs. 1, 3).

4. The herein-named San Pedro Fault trends north from near where the Pilarcitos Fault goes offshore, but does not follow the magnetically determined offshore trace of the Pilarcitos Fault (figs. 3, 4). Instead, the San Pedro Fault cuts across the magnetic trends and lies between the San Andreas and Potato Patch Faults. This fault's affiliation, if any, with either the San Gregorio or San Andreas Fault system is unclear.

5. The Potato Patch Fault (after McCulloch, 1987, 1989) lies between the offshore San Andreas Fault and the San Gregorio Fault. We interpret this fault to originate at depth 
from the San Gregorio Fault system at its south end; at its north end, it may merge with the San Andreas Fault south of Bolinas (figs. 1, 3).

6. The San Gregorio Fault system lies offshore as a major structural boundary between Half Moon Bay and Bolinas (figs. 1, 3), and extends onshore into the Seal Cove Fault near Half Moon Bay (R.C. Jachens, written commun., 2001).

7. The San Gregorio structural zone comprises the series of thrust faults lying west of the San Gregorio Fault (fig. 3). These faults probably merge with the San Gregorio Fault at depth.

\section{San Andreas Fault System: The San Andreas, Golden Gate, and Pilarcitos Faults}

The San Andreas Fault extends from the Gulf of California to northern California as a major strike-slip fault. About $100 \mathrm{~km}$ southwest of the San Francisco peninsula, the nearly linear Central California segment of the fault bifurcates, with the western strand forming the Peninsular segment of the San Andreas Fault along the San Francisco peninsula and the eastern strand forming the Hayward-Calaveras Fault system east of San Francisco Bay. Together, these two strands currently account for about $32 \mathrm{~mm} / \mathrm{yr}$ of plate motion, or approximately 85 percent of the total plate motion west of the Sierra Nevada (Working Group on Northern California Earthquake Probabilities, 1999). The Peninsular segment of the San Andreas Fault trends offshore near Daly City south of San Francisco (fig. 3). The offshore trend was mapped by Cooper (1973) and McCulloch $(1987,1989)$, though not with certainty because of the sparse data base.

The Golden Gate Fault trends offshore from Lake Merced (figs. 3, 4). The fault, which was partly mapped by McCulloch $(1987,1989)$, is better shown by the aeromagnetic data of Jachens and Zoback (1999) and Jachens and others (this volume). Jachens and Zoback (1999), Zoback and others (1999), and Jachens and others (this volume) use fault geometry, seismicity patterns, aeromagnetic data, and seismic-reflection studies to infer an approximately $3-\mathrm{km}$ right step from the Peninsular segment of the San Andreas Fault onto the Golden Gate Fault. Zoback and others (1999) interpreted that this right step has led to the formation of an extensional strike-slip pullapart basin which is represented onshore by the now-uplifted Merced Formation (see next section; Clifton and Hunter, 1987, 1991).

The Pilarcitos Fault lies between the San Andreas and San Gregorio Faults, is present onshore north of Half Moon Bay, and trends offshore near Point San Pedro (figs. 3, 4). Jachens and others (1999 and this volume) use aeromagnetic data to outline the fault for 7 to $8 \mathrm{~km}$ offshore to where the fault bends northward to lie near, merge with, or be truncated by the San Gregorio Fault (fig. 4). The onshore Pilarcitos Fault has been inactive during the Holocene (Bortugno and others, 1992) and is currently aseismic (Zoback and others, 1999). The fault has been interpreted as an abandoned strikeslip section of the Pacific-North American Plate boundary.
It probably accommodated most displacement on the San Andreas Fault system before the Quaternary (McLaughlin and others, 1996; Parsons and Zoback, 1997). Parsons and Zoback (1997) argued that it became inactive by about $3 \mathrm{Ma}$. Estimates of offset along the Pilarcitos Fault based on offset rock units or geophysical anomalies range from 120 to more than $250 \mathrm{~km}$ before abandonment (Griscom and Jachens, 1990; Page, 1990, 1992; McLaughlin and others, 1996; Parsons and Zoback, 1997). Alternatively, Wakabayashi (1999) postulated that offset must have been less than $7 \mathrm{~km}$, on the basis of local geologic interpretations. The time of cessation of motion on the fault is poorly constrained, and is tied mainly to the beginning of deposition of the Merced Formation during the Pliocene and early Pleistocene.

The current slip rate on the San Andreas Fault in the Golden Gate/San Francisco peninsula area is estimated at 17 to $24 \mathrm{~mm} / \mathrm{yr}$ (Working Group on Northern California Earthquake Probabilities, 1999). The slip rate increases north of Bolinas because of added slip from the merging San Gregorio Fault system (Niemi and Hall, 1992; Noller and others, 1993). On the basis of the offset of geologic basement units and associated magnetic anomalies, Jachens and others (1999 and this volume) argue that the total offset on the Peninsular segment of the San Andreas Fault is tightly constrained to about $22 \mathrm{~km}$. However, Wakabayashi (1999) believed that offset could be as much as $36 \mathrm{~km}$. Thus, at present estimated slip rates of 17 to $24 \mathrm{~mm} / \mathrm{yr}$, the current trace of the fault has been active for about the past 1 to $2 \mathrm{~m}$.y. This is an age similar to the initiation of deposition of the basal Merced Formation at about 1.6-1.2 Ma, although the timing is poorly constrained (Clifton and Hunter, 1987, 1991; Hengesh and Wakabayashi, 1995). The similar ages suggest a possible link between the onset of basin growth and the initiation of faulting on the Peninsular segment of the San Andreas Fault.

\section{San Gregorio Fault System}

The San Gregorio Fault zone is part of a system of strike-slip faults that includes the Hosgri and Sur Faults, which extend from Point Arguello north of Santa Barbara to Monterey Bay, and the San Gregorio Fault zone, which extends from Monterey Bay to Bolinas (McCulloch, 1987, 1989). The San Gregorio Fault system lies mostly offshore, with the easternmost faults extending onshore only between Point Año Nuevo (south of study area) and San Gregorio State Beach (fig. 1) and between Pillar Point and Point Montara, where it is also referred to as the "Seal Cove Fault" (figs. 1-3).

The San Gregorio Fault may have become active by about the middle Miocene, and has accumulated at least 150 km of offset since then (Clark and others, 1984; Simpson and others, 1997; Jachens and others, 1999). Onshore trenching studies have shown a slip rate of about 6 to $8 \mathrm{~mm} / \mathrm{yr}$ on the Seal Cove Fault (Simpson and others, 1997; Lettis, 1999), and regional geologic correlations give a similar slip rate of about 6 mm/yr (Clark, 1999; Sedlock, 1999; Weber and others, 1999). Hengesh and Wakabayashi (1995) and Wakabayashi 
and Hengesh (1995) estimated slip rates of $5 \mathrm{~mm} / \mathrm{yr}$ averaged over the past 2 m.y. Clark $(1998,1999)$ discussed geologic correlations indicating that about 50 to $60 \mathrm{~km}$ of the total displacement occurred from 10 to $8 \mathrm{Ma}, 81 \mathrm{~km}$ from 8 to $3 \mathrm{Ma}$, and $19 \mathrm{~km}$ from 3 to $0 \mathrm{Ma}$. This last offset gives an average slip rate of $6 \mathrm{~mm} / \mathrm{yr}$ for the past $3 \mathrm{~m} . \mathrm{y}$.

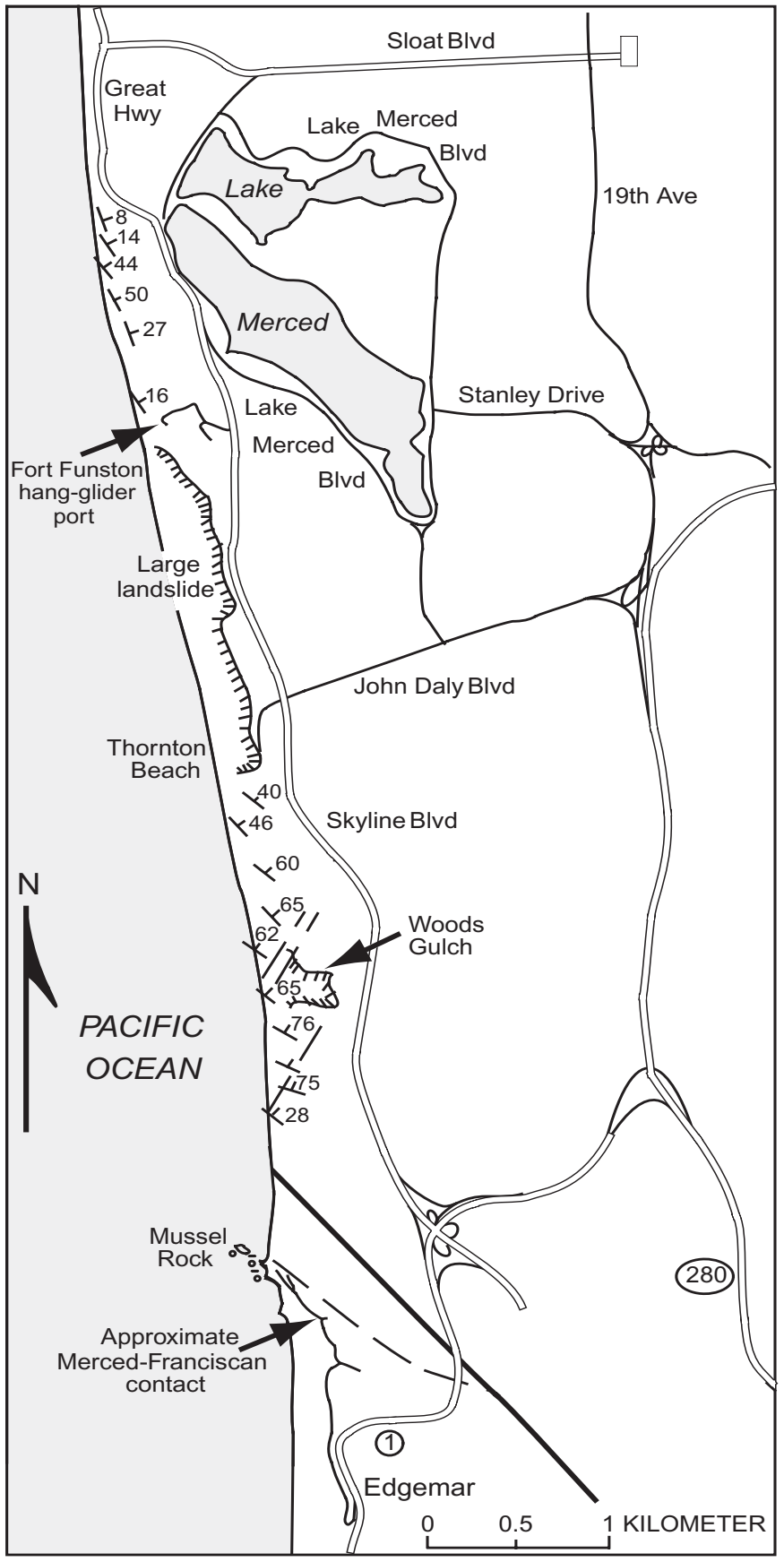

Figure 6.-Coastal area south of San Francisco (fig. 1), showing geologic features of the Merced Formation in seacliff exposures. From Clifton and Hunter (1987, 1991).

\section{Stratigraphy}

\section{West of the San Gregorio Fault: The Monterey Formation and Other Units (Late Miocene and Older)}

Basement rocks west of the San Gregorio Fault in the study area (fig. 1) are composed of granitic rocks of the Salinia terrane (McCulloch, 1987). Overlying basement is a transgressive succession of sedimentary rocks composed of conglomerate and sandstone of the Paleocene Point Reyes Conglomerate, overlain by the Miocene Laird Sandstone and the deep-water siliceous Miocene Monterey Formation (McCulloch, 1987; Clark and others, 1991; Clark and Brabb, 1997). The rocks were uplifted, deformed, and erosionally truncated early in the Late Miocene. The resulting erosional unconformity, which truncated folded strata of the Monterey Formation on the Point Reyes peninsula (Clark and others, 1991; Clark and Brabb, 1997), is identified in the offshore as a gently eastward sloping erosional surface in the Bodega Basin that is truncated at the San Gregorio Fault (see next section).

\section{West of the San Gregorio Fault: The Santa Margarita Sandstone, Santa Cruz Mudstone, and Purisima Formation (Late Miocene and Pliocene)}

The Miocene Santa Margarita Sandstone and Santa Cruz Mudstone and the Miocene and Pliocene Purisima Formation are extensively exposed in the Santa Cruz Mountains, and these formation names have been applied to correlative units on the Point Reyes peninsula (Clark and others, 1984; Clark and Brabb, 1997). The units lie entirely east of the San Gregorio Fault in the Santa Cruz Mountains, and west of the fault at Point Reyes. Offshore units in the Bodega Basin west of the San Gregorio Fault, which have been sampled in boreholes (Hoskins and Griffiths, 1971; McCulloch, 1987), are correlated with the strata on the Point Reyes peninsula and into the offshore area surveyed by seismic-reflection data.

Development of the Late Miocene unconformity at the top of the Monterey Formation was followed by subsidence and deposition of as much as $3 \mathrm{~km}$ of Late Miocene and Pliocene marine claystone and siltstone. The strata thin westward across the basin and, locally, adjacent to the San Gregorio Fault, where thinning and onlap in the San Gregorio structural zone reveal a deformation history along the fault. The late Miocene Santa Margarita Sandstone on the Point Reyes peninsula is a thin (max $50 \mathrm{~m}$ thick) glauconitic sandstone overlying the Monterey Formation with angular unconformity. The thick overlying Santa Cruz Mudstone is sandy and glauconitic where it conformably overlies the Santa Margarita Sandstone, and grades upward into mudstone. The Santa Cruz Mudstone is as much as 2,000 m thick in the Bolinas area and thins northward to pinch out north 

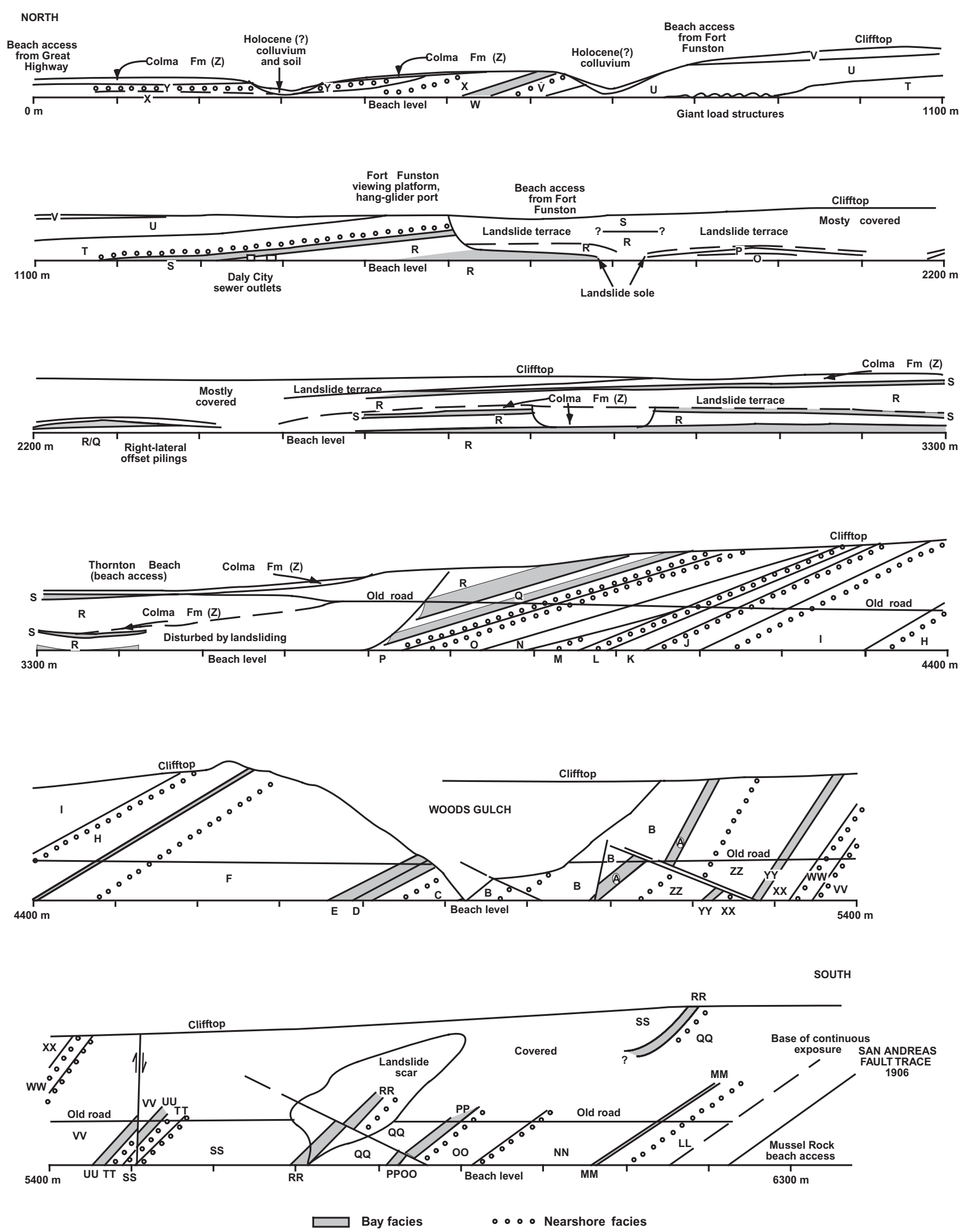

Figure 7.-Generalized cross sections of exposures of the Merced and Colma Formations in seacliffs between Lake Merced and Mussel Rock on the San Francisco peninsula. South end of section is approximately $500 \mathrm{~m}$ north of Mussel Rock (fig. 6). Letters denote sequences and lithologic units of Clifton and Hunter $(1987,1991)$. Sections tie together end to end from northernmost (top) to southernmost (bottom). Scale in meters; no vertical exaggeration. 
of Drakes Bay. The Purisima Formation, which is the uppermost shallow-marine phase of basin filling, is as much as 490 $\mathrm{m}$ thick onshore (Clark and others, 1991; Clark and Brabb, 1997). Offshore, McCulloch $(1987,1989)$ interpreted the local upper Miocene and younger section to be more than 2 $\mathrm{km}$ thick near the Point Reyes peninsula. The upper Miocene and younger section ranges from 800 to $1,100 \mathrm{~m}$ in thickness (north-to-south maximum thickness) on McCulloch's (1987) interpreted seismic lines in the Golden Gate area.

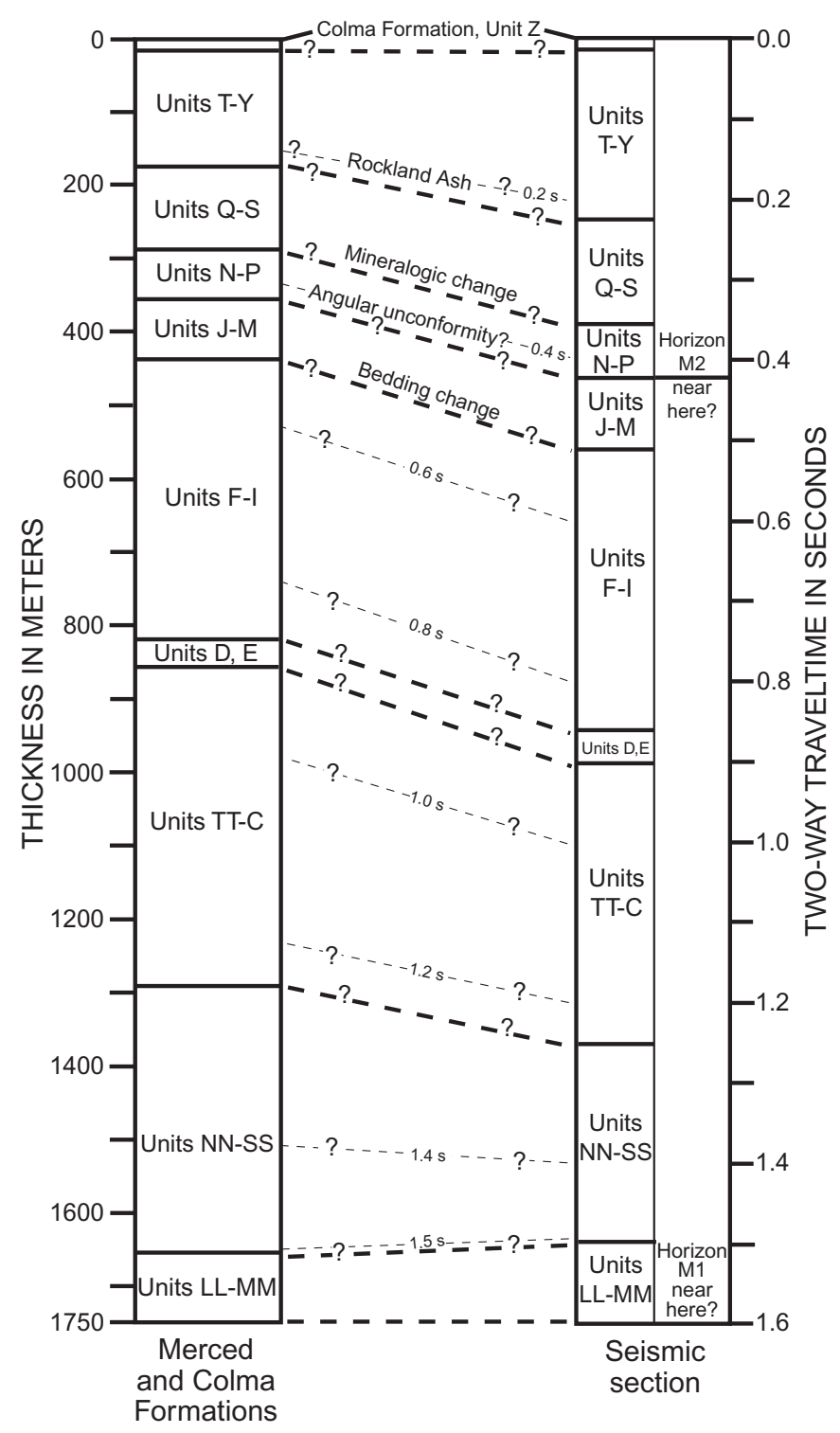

Figure 8.-Unit designations for the Merced and Colma Formations, and comments on significant features within formations (from Clifton and Hunter, 1987, 1991). A possible correlation to seismic-reflection records in the San Gregorio Basin is also shown but is uncertain. Conversion of seismic-reflection time to depth is from figure 5 .

\section{East of the San Gregorio Fault: The Merced and Colma Formations (Pliocene and Pleistocene)}

The Merced Formation is a poorly dated Pliocene(?) and Pleistocene sequence of marine to eolian gravel, sandstone, and siltstone. The Merced Formation is overlain by a thin (less than $10 \mathrm{~m}$ thick), sandy nonmarine unit, the Pleistocene Colma Formation, which is probably about 75 to $135 \mathrm{ka}$ old (fig. 6; Hall, 1966; Clifton and Hunter, 1987, 1991). The Merced Formation crops out in two localities. The type section on the northern San Francisco peninsula lies east of the San Andreas Fault and is exposed in seacliffs extending from Mussel Rock 6 km northward to near Lake Merced (figs. 6, 7; Hall, 1966; Clifton and Hunter, 1987, 1991). The section is as much as $1,750 \mathrm{~m}$ thick and less than $2.5 \mathrm{~km}$ wide. These strata extend southward along the San Andreas Fault for about $19 \mathrm{~km}$. A thinner, narrower section is exposed west of the San Andreas Fault at Bolinas, where it is as much as 100 to $150 \mathrm{~m}$ thick and $2 \mathrm{~km}$ wide, lies at elevations of as much as $130 \mathrm{~m}$, and extends northward from the lagoon for about $15 \mathrm{~km}$ (Galloway, 1977; Clark and Brabb, 1997). The type section was described in considerable detail by Clifton and Hunter (1987, 1991), whose description forms the basis for the following discussion. The stratigraphic section at Bolinas has not been studied in similar detail.

On the San Francisco peninsula, the Merced Formation consists of sedimentary sequences that require a shallowing open-ocean, wave-dominated depositional environment. Complete sequences begin with a marine-shelf siltstone and progress upward from shelf sand through nearshore, foreshore, shore, and backshore units and, in some sequences, through eolian, fluvial, and marsh units. Shelf facies predominate in the lower $1,300 \mathrm{~m}$ of the sequence, and nonmarine facies in the upper $300 \mathrm{~m}$. The change corresponds to a conspicuous mineralogic change (see below) that occurs at $290 \mathrm{~m}$ below the top of the section. These sequences indicate alternating transgressions and regressions of the sea, reflecting a combination of eustatic changes in sea level, fluctuations in sediment supply, and continuing tectonic subsidence. The cycles appear generally similar in scale and duration to known Pleistocene glacioeustatic sea-level fluctuations (Clifton and others, 1988).

Merced strata lie in a homoclinal succession with a northeasterly strike (figs. 6, 7). Dips commonly exceed $50^{\circ}$ in the lower third of the unit. In the upper two-thirds of the unit, dips are less than $20^{\circ}$ except near Lake Merced, where the range is $40^{\circ}-50^{\circ}$ across a short stratigraphic interval. The stratigraphic succession is broken only by small faults across which strata can be readily correlated. The great thickness of very shallow marine deposits indicates rapid subsidence during deposition. These strata have been subsequently uplifted, tilted, and truncated into their present outcrop position at elevations of as much as $200 \mathrm{~m}$. The most recent deformation occurred after deposition of the Colma Formation, which rests with angular unconformity on deformed strata of the Merced Formation and is, in turn, gently tilted northward in seacliff exposures. 


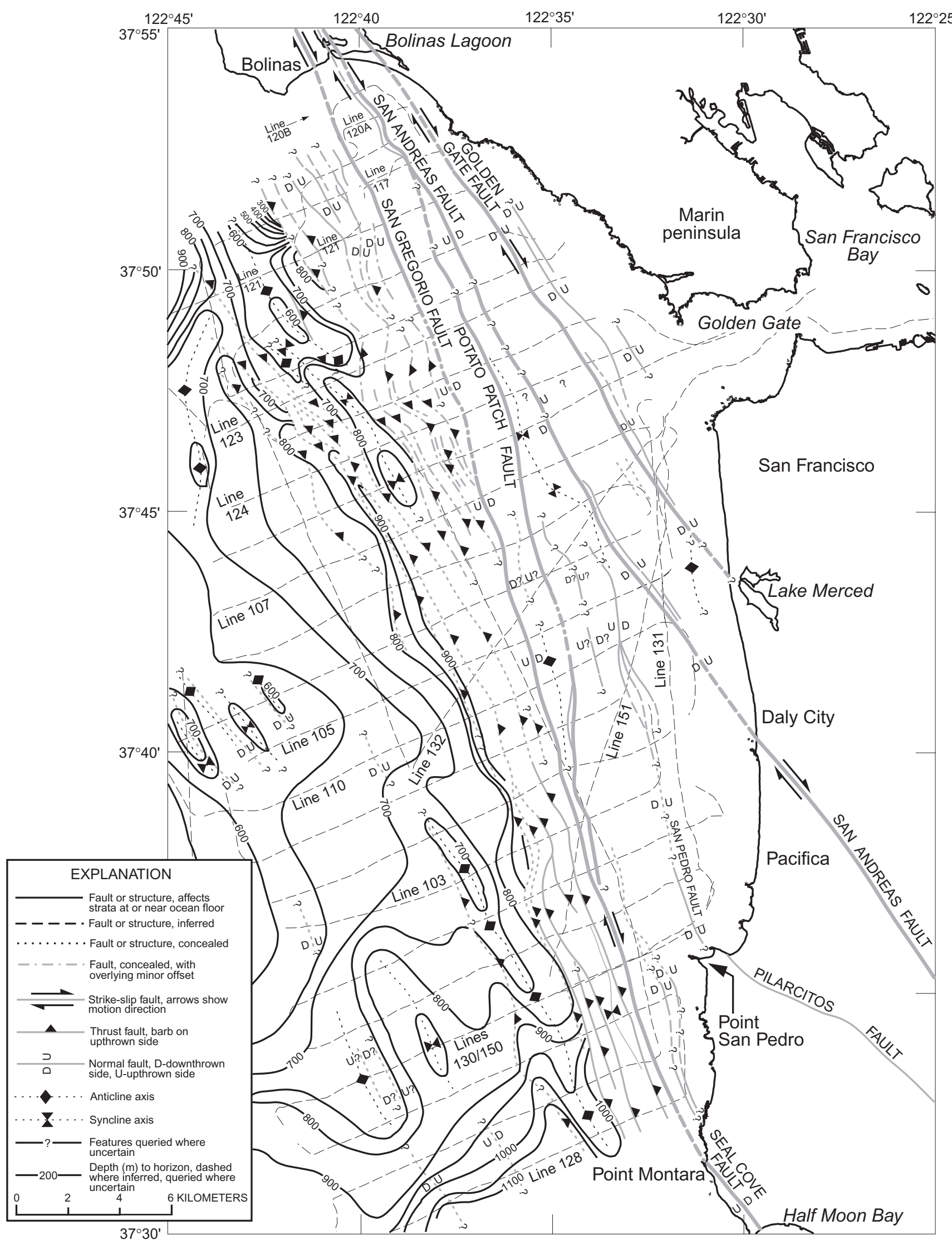

Figure 9.-Gulf of the Farallones and San Francisco Bay region, Calif., showing contours of depth to seismic horizon A (approximate top of the Monterey Formation) in the Bodega Basin west of the San Gregorio Fault. Contours in meters; contour interval, $50 \mathrm{~m}$. Contoured horizon is shown on interpreted seismic sections in figures 13 through 25. 


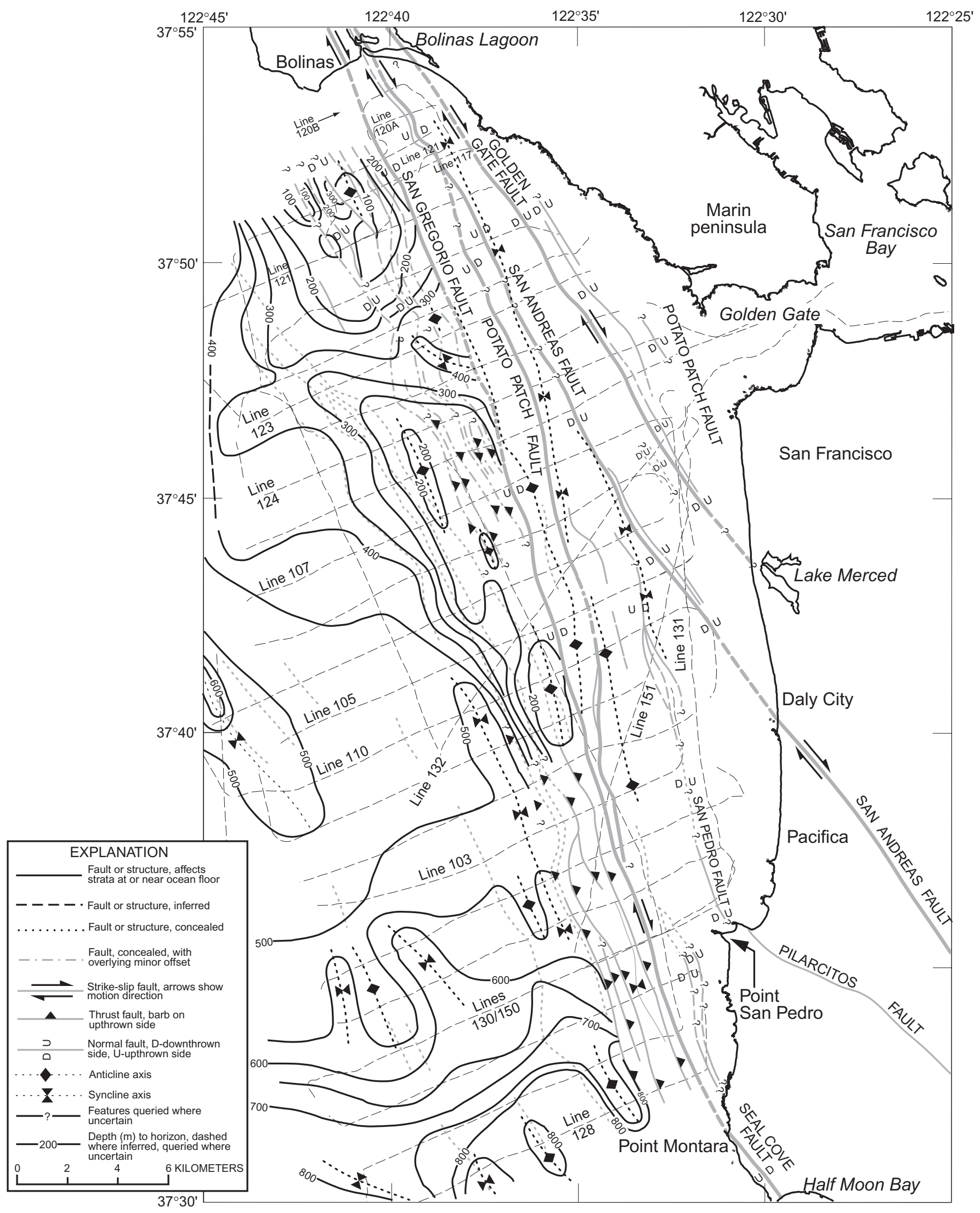

Figure 10.-Gulf of the Farallones and San Francisco Bay region, Calif., showing contours of depth to seismic horizon C in the Bodega Basin west of the San Gregorio Fault. Contours in meters; contour interval, $50 \mathrm{~m}$. Contoured horizon is shown on interpreted seismic sections in figures 13 through 25 . 


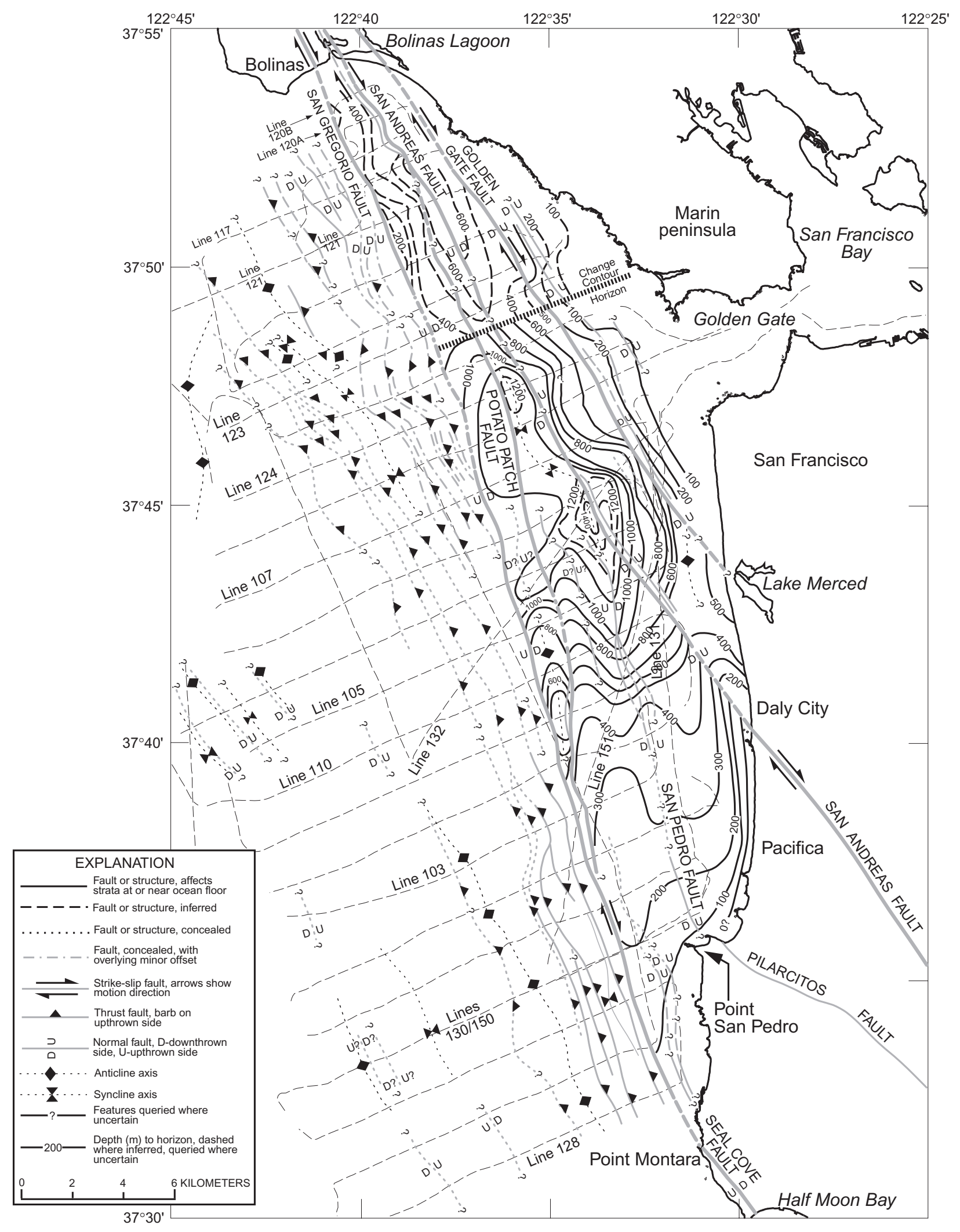

Figure 11.-Gulf of the Farallones and San Francisco Bay region, Calif., showing contours of depth to seismic horizon M1 in the San Gregorio Basin east of the San Gregorio Fault. Horizon is at approximate base of strata in shallowest parts of the San Gregorio Basin but is in lower part of strata in deepest parts of basin, where acoustic energy was insufficient to penetrate to base of sedimentary section. Horizon thus gives a minimum thickness of strata in the San Gregorio Basin. Contours in meters; contour interval, 100 m. Contoured horizon is shown on interpreted seismic sections in figures 13 through 25. 


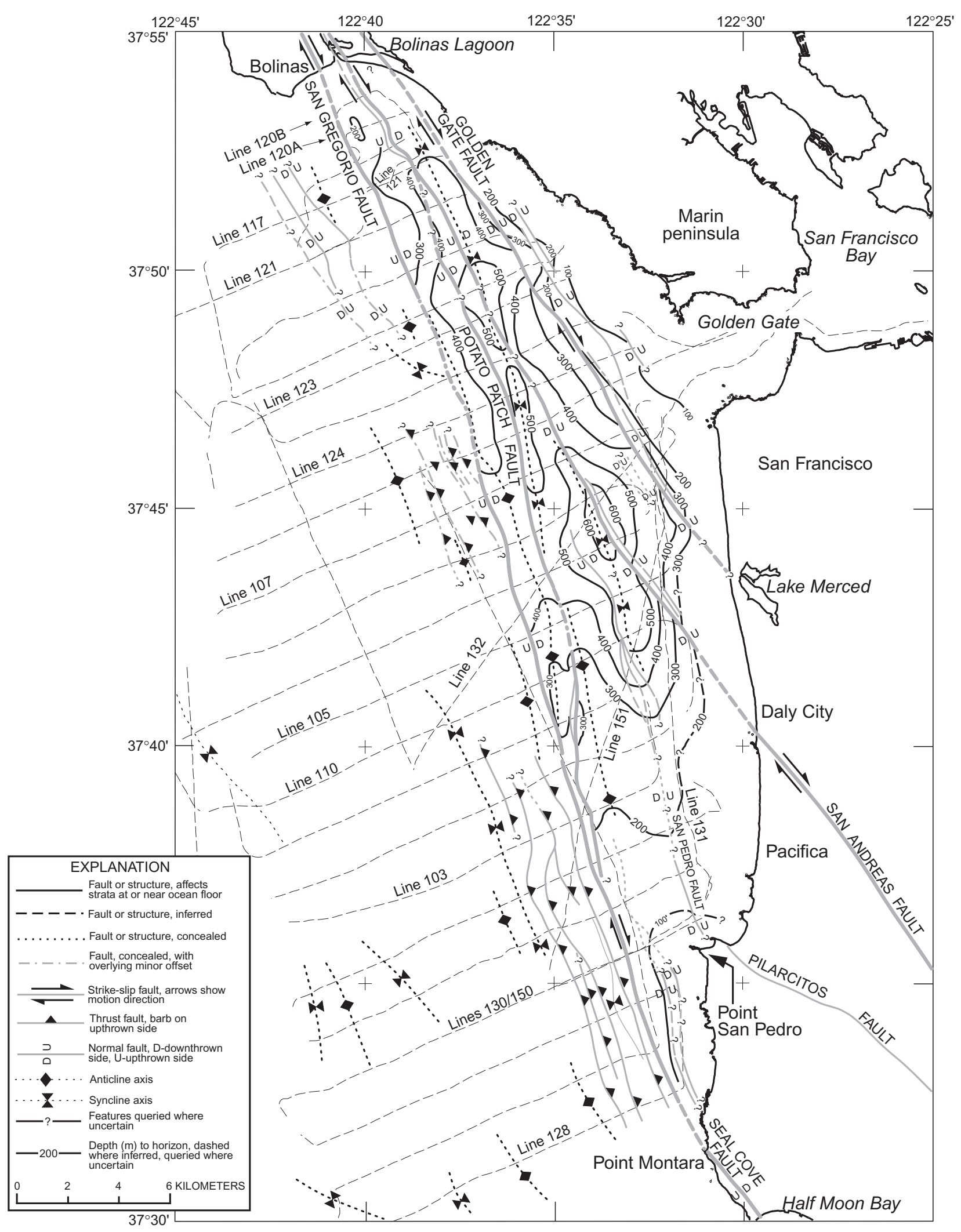

Figure 12.-Gulf of the Farallones and San Francisco Bay region, Calif., showing contours of depth to seismic horizon M2 in the San Gregorio Basin, east of the San Gregorio Fault. Seismic horizon is within strata of the San Gregorio Basin, possibly at approximate level of a bedding change or angular unconformity in the onshore Merced Formation identified by Clifton and Hunter (1987, 1991). In offshore basin, this horizon marks time when significant folding of strata in the San Gregorio Basin began over the Potato Patch Fault. Contours in meters; contour interval, $100 \mathrm{~m}$. Contoured horizon is shown on interpreted seismic sections in figures 13 through 25. 
The Merced Formation has been assigned a late Pliocene and Pleistocene age (Clifton and Hunter, 1987, 1991; Lajoie, 1996; Clark and Brabb, 1997), but age data for the units are meager. A mineralogic change $290 \mathrm{~m}$ below the top of the section reflects a change in provenance at about $0.62 \mathrm{Ma}$ from local sources dominated by the Franciscan Complex to sources dominated by rocks of the Sacramento-San Joaquin River drainage basin (Hall, 1966; Clifton and Hunter, 1991). The Rockland ash bed at $175 \mathrm{~m}$ from the top of the section (fig. 7) has been dated at $400 \mathrm{ka}$ (Sarna-Wojcicki and others,

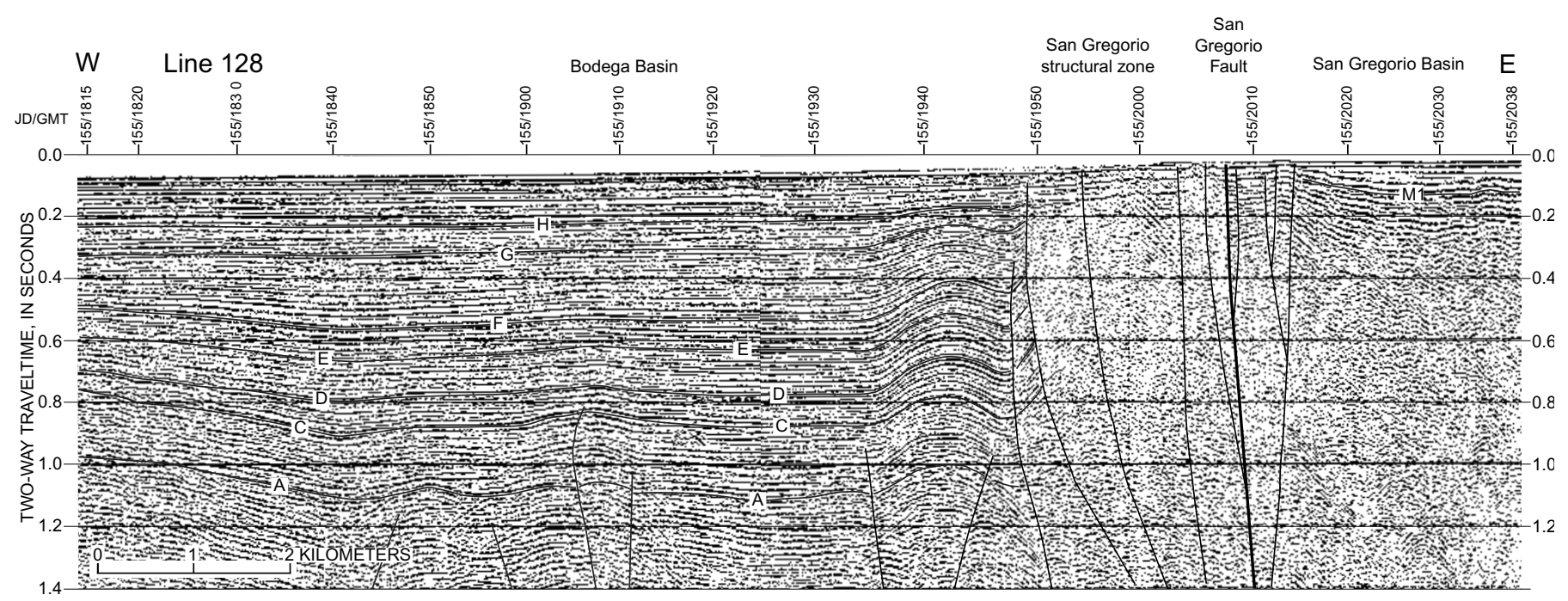

Figure 13.- Seismic line 128 off Point Montara at south end of study area (figs. 2, 3, 9-12). Seismic horizon A in the Bodega Basin is approximately at top of the Monterey Formation; rocks above unconformity correspond to the Late Miocene and younger onshore Santa Margarita Sandstone, Santa Cruz Mudstone, and Purisima Formation (Cooper, 1973; McCulloch, 1987, 1989). Horizons B through $G$ are local to regional unconformities but cannot be directly tied to onshore sequences. Line shows truncation of units below horizon $\mathrm{A}$ at unconformity that characterizes horizon $\mathrm{A}$, and narrow (less than $2 \mathrm{~km}$ wide) deformational region associated with the San Gregorio structural zone.

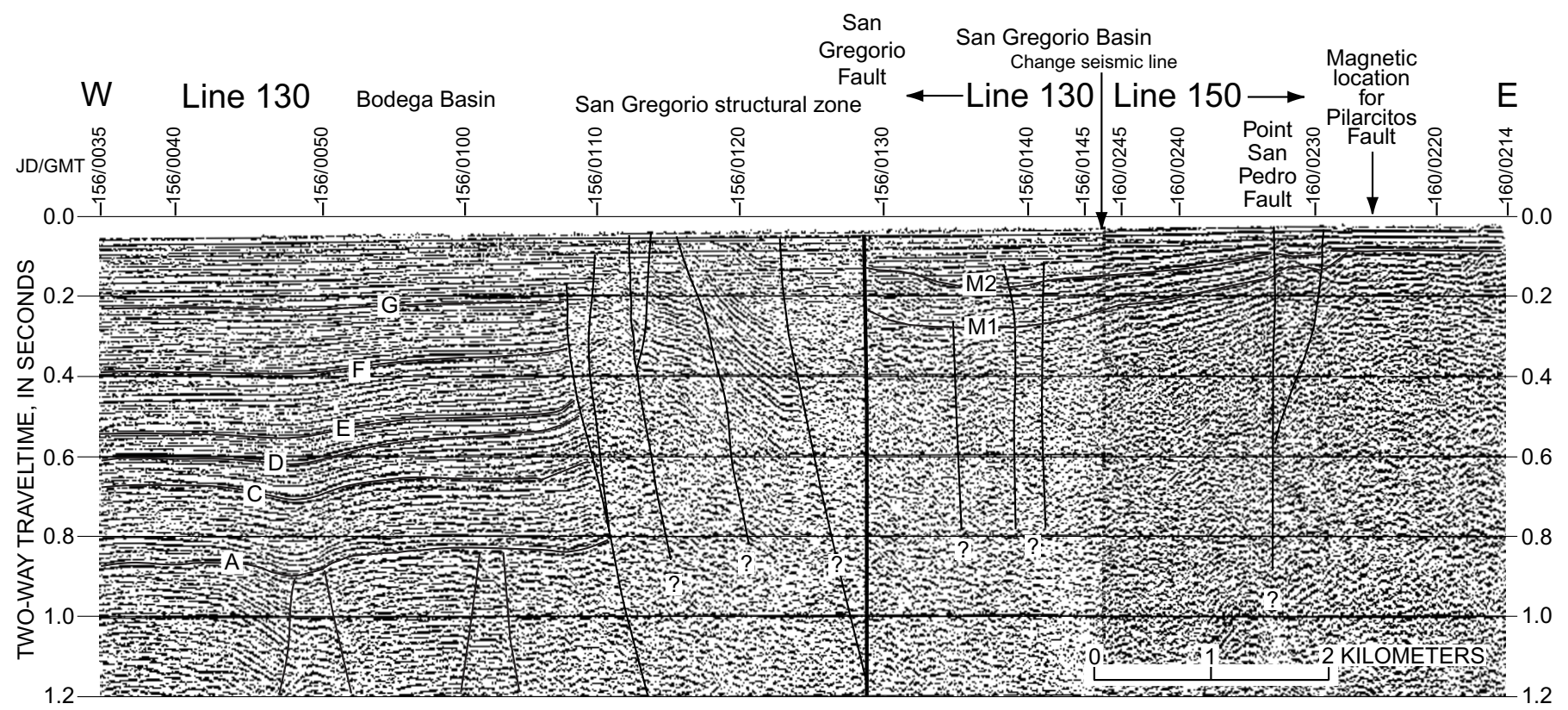

Figure 14.-Seismic line 130/150 off Point San Pedro (figs. 2, 3, 9-12). Same horizons in the Bodega Basin as in figure 13. In the San Gregorio Basin, between the San Andreas and San Gregorio Faults, horizon M1 is acoustic basement on flanks of basin, but acoustic basement cannot be seen in deepest parts of basin, and horizon M1 indicates a minimum mapped sediment thickness. Horizon M2 is an unconformity within basin. Age of strata in the San Gregorio Basin is unknown but is inferred to be younger than about $3 \mathrm{Ma}$. The San Gregorio structural zone is still narrow. Location of offshore extension of the Pilarcitos Fault is based on aeromagnetic data; seismic-reflection records do not show a fault. A nearby fault, the Point San Pedro Fault, seems to be independent of the Pilarcitos Fault. 


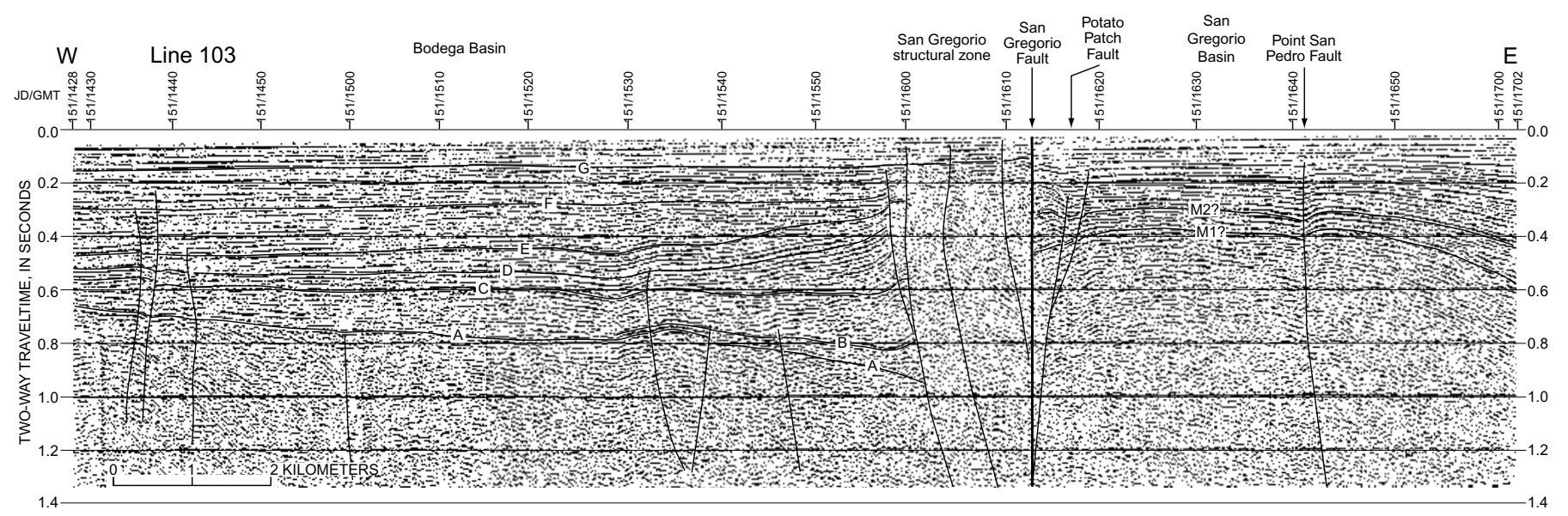

Figure 15.- Seismic line 103 west of Pacifica/Daly City, Calif. (figs. 2, 3, 9-12). Fault just east of the San Gregorio Fault is mapped here as beginning of the Potato Patch Fault. Small offset associated with the Point San Pedro Fault is also visible at east end of line. Strata overlying basement in the San Gregorio Basin here are about 400 to $500 \mathrm{~m}$ thick (approx 0.4-0.5-s two-way traveltime; see fig. 5). West of the San Gregorio Fault, horizon $B$ appears for first time, and unit between horizons A and B thickens northward. Thickening of strata into the San Gregorio structural zone to horizon $D$ is apparent; above that horizon, units thin into structural zone, indicating that uplift in structural zone started after horizon $D$ time. Same seismic-horizon annotations as in figures 13 and 14.

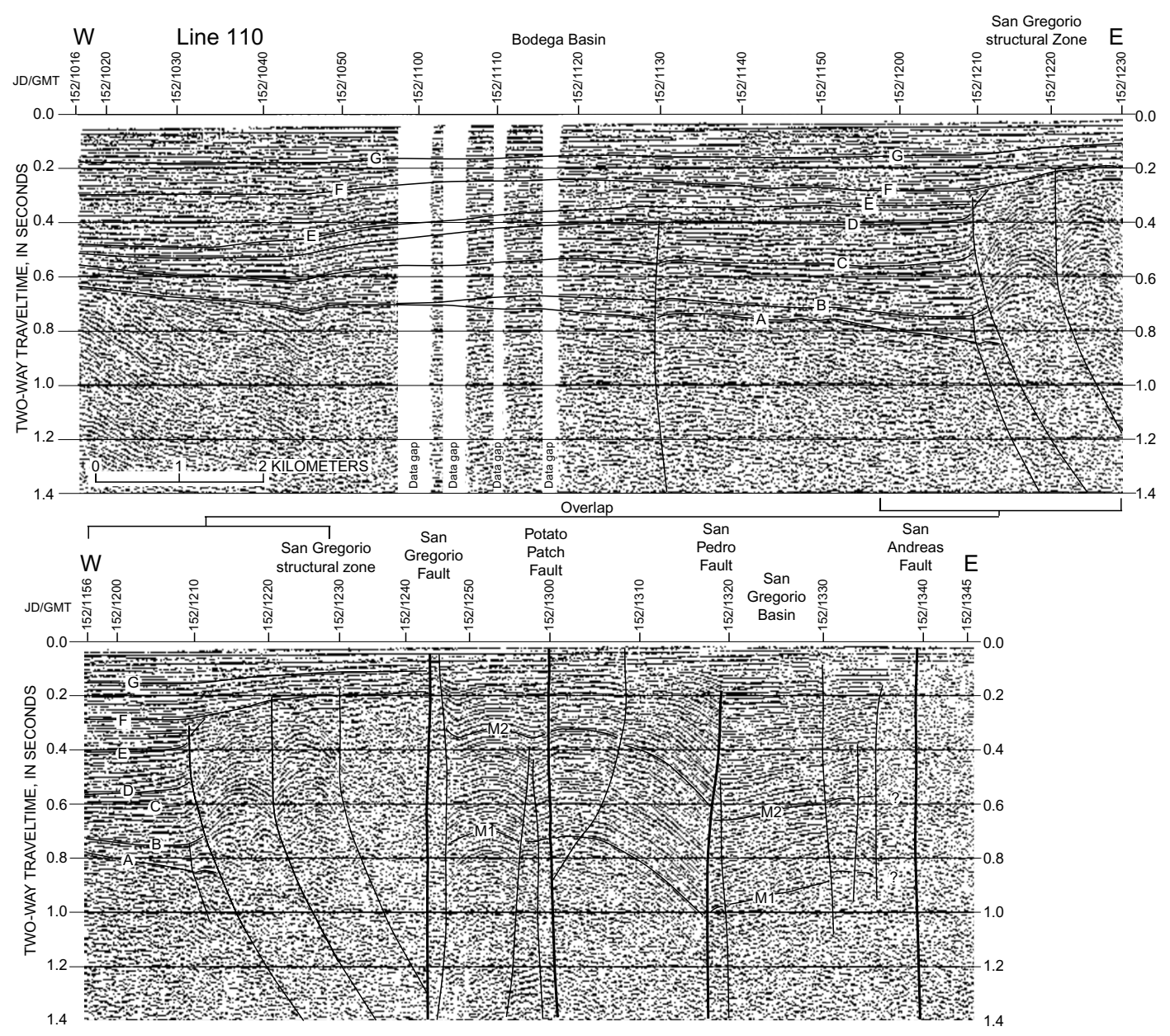

Figure 16.-Seismic line 110 (figs. 2, 3, 9-12), off Lake Merced. The San Gregorio structural zone has widened to 3 $\mathrm{km}$ and is covered by about $200 \mathrm{~m}$ of relatively flat lying sediment. Strata in the San Gregorio Basin have thickened significantly relative to strata on seismic line 103 to south. Anticline has developed west of the San Pedro Fault. Horizon M2 here marks initiation of growth on anticline; strata below horizon M2 thicken seaward, whereas strata above horizon thin onto growing structure. 
1985), although more recent dating suggests an earlier age of 600 to $610 \mathrm{ka}$ (Lanphere and others, 1999), indicating that further study is needed.

We assume that the Merced and Colma Formations are at least partly correlative with sedimentary strata in the offshore San Gregorio Basin. However, we lack seismic-reflection data that directly tie the Merced Formation to the offshore strata, and the age and timing of deposition could differ substantially, as discussed below.

\section{Seismic Stratigraphy}

We divide the offshore seismic stratigraphy into two fundamentally different sequences at the San Gregorio Fault, on the basis of our interpreted correlations with onshore strata. West of the San Gregorio Fault (figs. 1, 3), we correlate the offshore sedimentary section with units that crop out on the Point Reyes peninsula. Between the San Gregorio Fault and the San Andreas/Golden Gate Faults (figs. 1, 3), the seismic

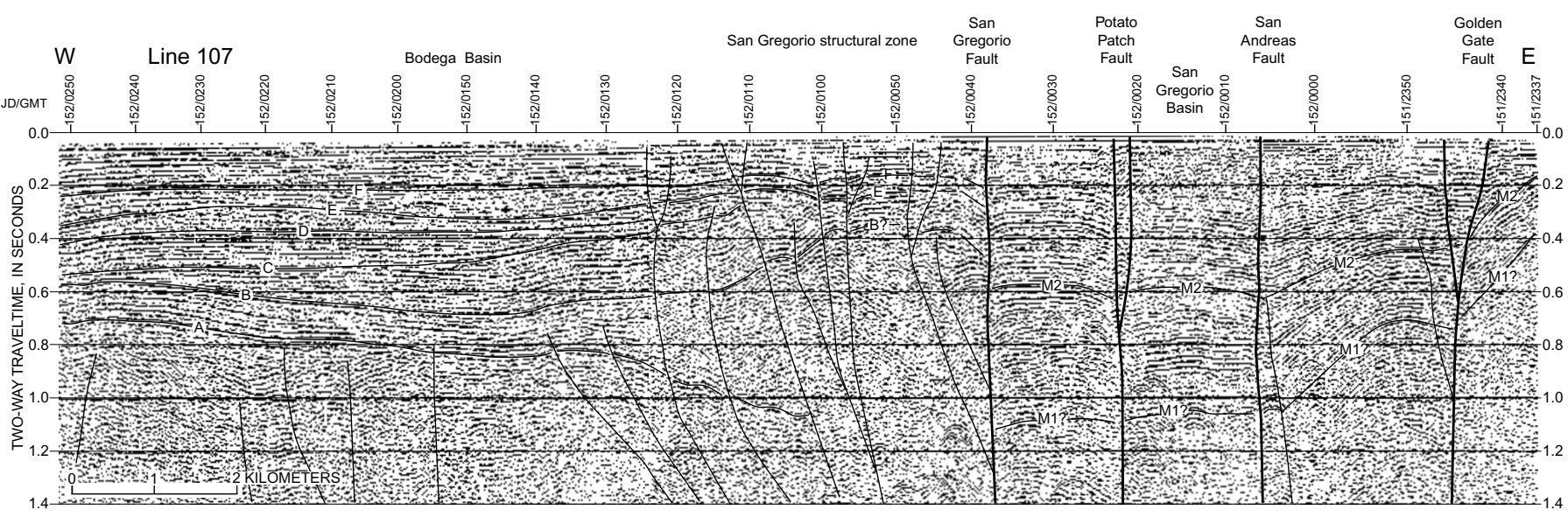

Figure 17.- Seismic line 107 just southwest of the Golden Gate (figs. 2, 3, 9-12). The San Gregorio structural zone has widened to more than 4 km, and strata between horizons A and B in the Bodega Basin have thickened substantially relative to same features on lines to south. Similarly, strata in the San Gregorio Basin have significantly thickened relative to strata visible on seismic line 103. Horizon M1 is almost certainly not at base of sedimentary section in the San Gregorio Basin; section probably approaches $2 \mathrm{~km}$ thickness for basin fill estimated from seismic-refraction data (or greater than 1.5-s two-way traveltime on a seismic line; see fig. 5). Same seismic-horizon annotations as in figures 13 and 14.

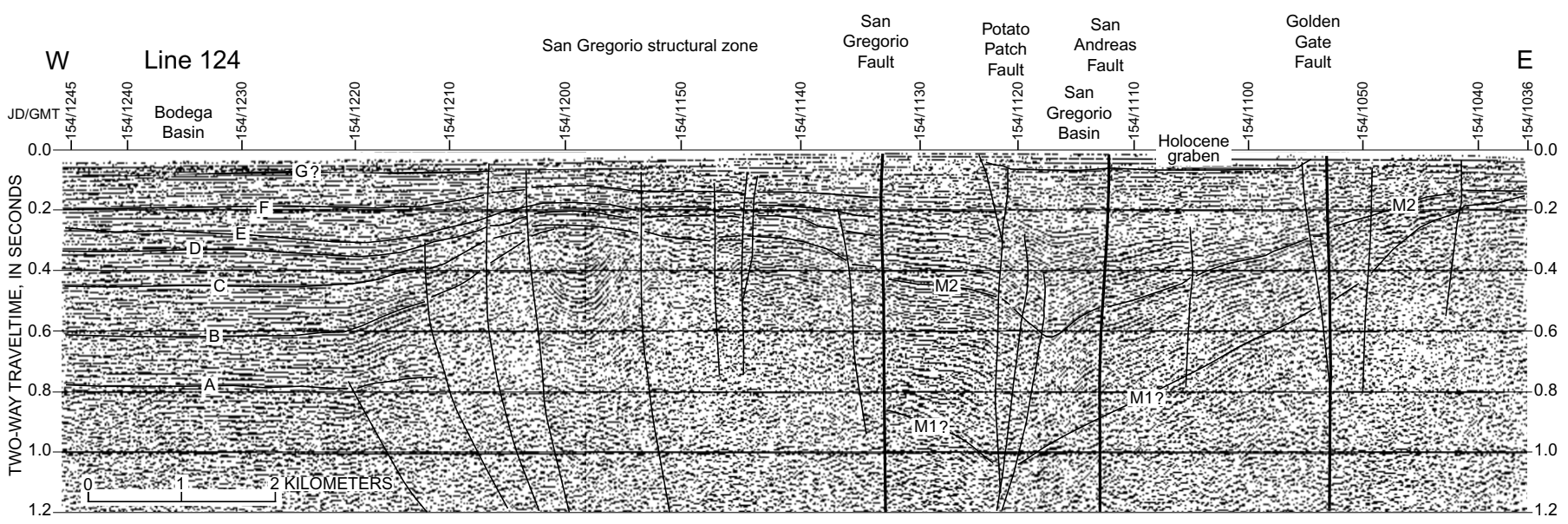

Figure 18.- Seismic line 124 west of the Golden Gate (figs. 2, 3, 9-12). The San Gregorio structural zone has widened to more than 6 km, and a marked unconformity is apparent over top of structures at about 0.2- to 0.3-s two-way traveltime. Especially obvious is truncated syncline below JD/GMT 154/1200. The San Gregorio, Potato Patch, and San Andreas Faults are not characterized by clearly broken, discontinuous, or terminating seismic reflectors and so are poorly defined. Faults are herein considered to be mainly active as normal faults in this part of basin, with subsidence creating the San Gregorio Basin. Faults would thus not be throughgoing major transform faults. Instead, most or all transform motion has probably transferred over to the Golden Gate Fault. Same seismic-horizon annotations as in figures 13 and 14. 
sequence is probably composed of units that are at least partly, if not entirely, equivalent to the onshore Merced and Colma Formations (fig. 8). We have mapped horizons in the seismic-reflection data to show the stratigraphy and structure of the basins (figs. 9-12), and we show these horizons on the interpreted seismic data (figs. 13-25).

\section{Seismic Stratigraphy West of the San Gregorio Fault-the Bodega Basin}

In the seismic-reflection data west of the San Gregorio Fault, we map an unconformity, here designated horizon A (figs. 13-25). Rocks below horizon A have been at least

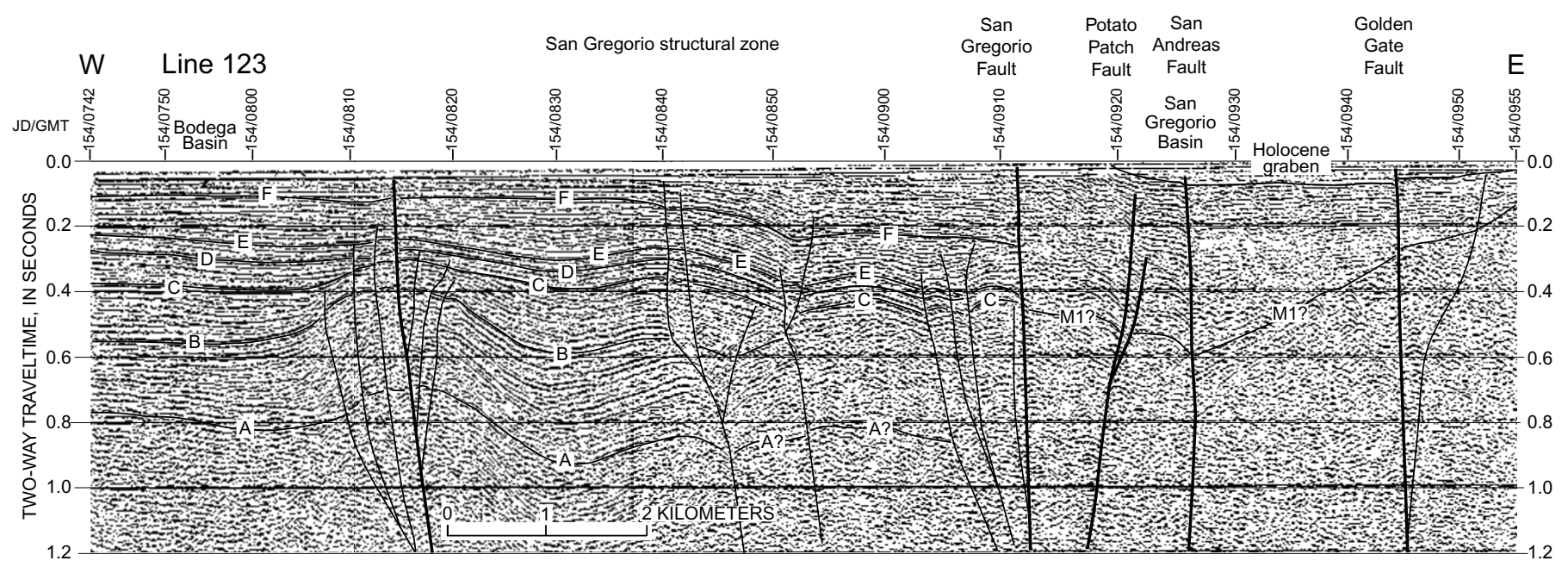

Figure 19.-Seismic line 123 northwest of the Golden Gate (figs. 2, 3, 9-12). The San Gregorio structural zone is now almost $8 \mathrm{~km}$ wide and is buried beneath from 0.3- to 0.4-s two-way traveltime of relatively undeformed strata. A Holocene graben is apparent at east end of line between the Potato Patch/San Andreas Faults and the Golden Gate Fault. The San Gregorio, Potato Patch, and San Andreas Faults are not characterized by clearly broken, discontinuous, or terminating seismic reflectors and so are poorly defined. Faults are herein considered to be mainly active as normal faults in this part of basin, with subsidence creating the San Gregorio Basin. Faults would thus not be throughgoing major transform faults. Instead, most or all transform motion has probably transferred over to the Golden Gate Fault. Same seismic-horizon annotations as in figures 13 and 14.

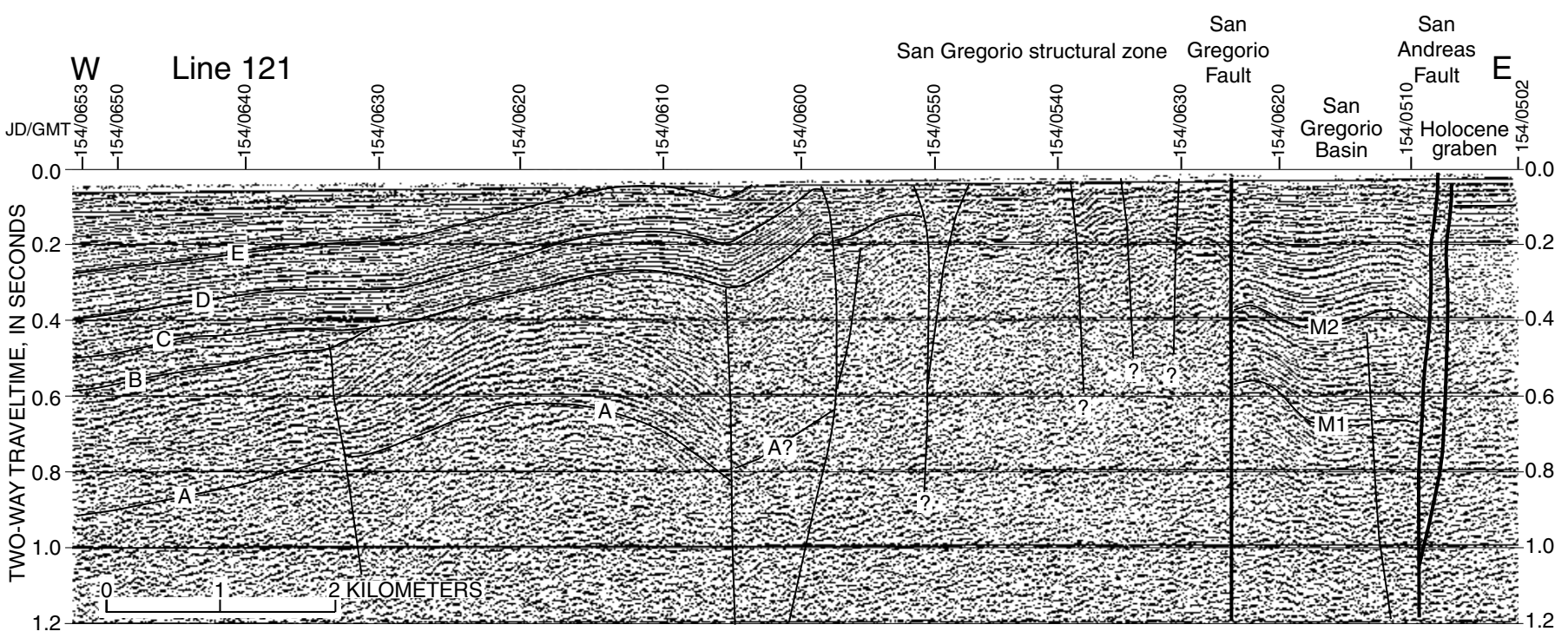

Figure 20.-Seismic line 121 about $5 \mathrm{~km}$ south of Bolinas Lagoon (figs. 2, 3, 9-12). Uplift begins to affect northern part of study area (fig. 1) as offshore section is uplifted onto the onshore Point Reyes peninsula. The San Gregorio and San Andreas Faults are much more distinctive than on lines farther to south (figs. 18, 19); fault traces are well defined by discontinuous or terminating seismic reflectors. Seismic horizons M1 and M2 are not definitively tied to lines farther to south and are projected on the basis of seismic reflections. Same seismic-horizon annotations as in figures 13 and 14. 


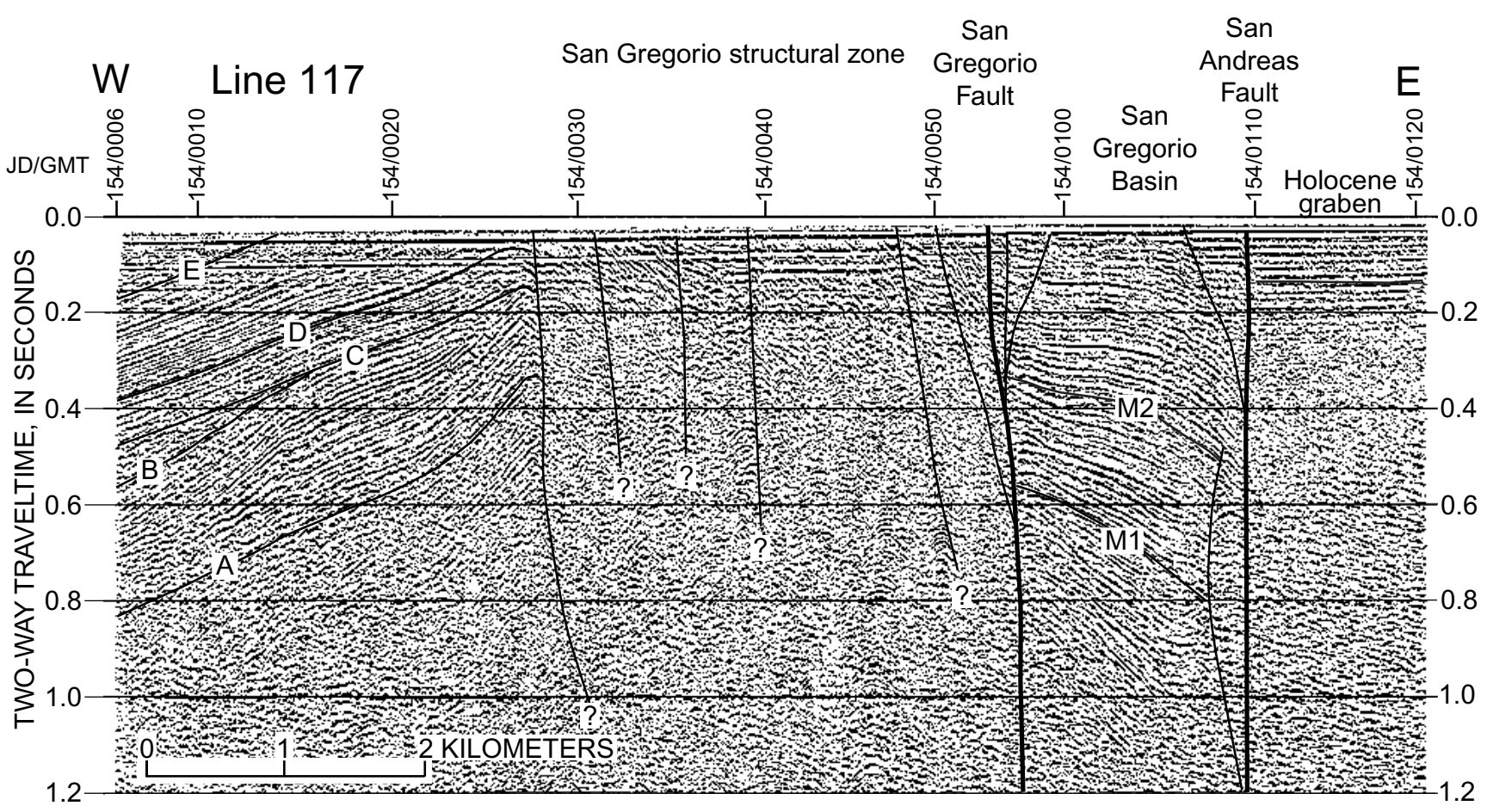

Figure 21.-Seismic line 117 about 5 km south of Bolinas Lagoon (figs. 2, 3, 9-12). Section of line east of the San Gregorio Fault partly overlaps seismic line 121 (see fig. 20). Line shows continuing uplift of section onto the Point Reyes peninsula, as well as well-defined San Gregorio and San Andreas Faults. Seismic horizons M1 and M2 are not tied to lines farther to south, and are projected on the basis of seismic reflections. Same seismic-horizon annotations as in figures 13 and 14.
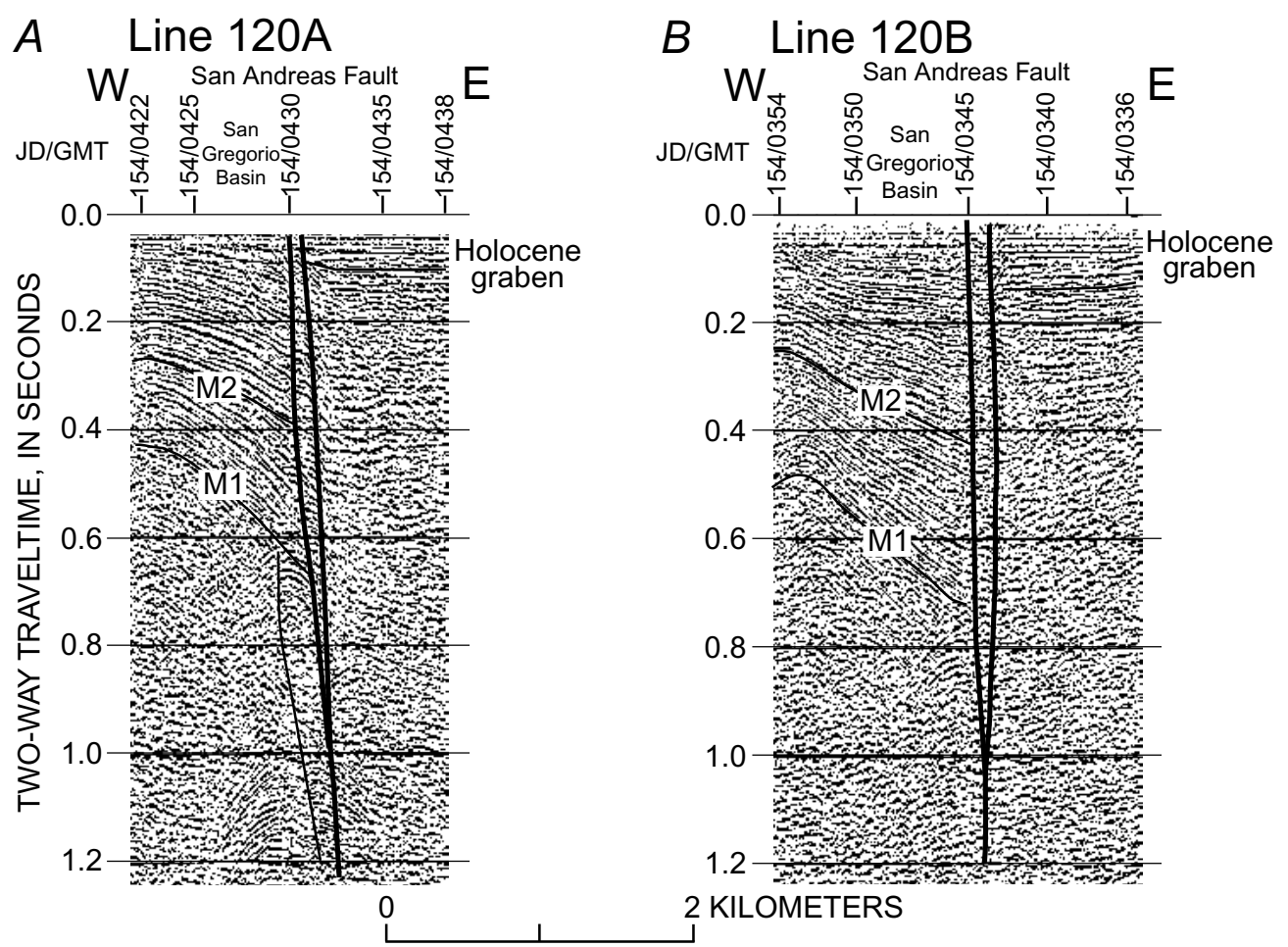

Figure 22.-Seismic lines $120 \mathrm{~A}(A)$ and $120 \mathrm{~B}(B), 2$ and $3 \mathrm{~km}$, respectively, south of Bolinas Lagoon (figs. 2, 3, 9-12), which are closest lines we were able to acquire near lagoon. The San Andreas Fault is well defined as a dual strand on both lines, yet horizons could be easily carried across fault-for example, note seismic reflection associated with horizon $\mathrm{M} 2$, suggesting only a small offset on fault. As on seismic lines 121 (fig. 20) and 117 (fig. 21), seismic horizons M1 and M2 are not tied to lines farther to south and are projected on the basis of seismic reflections. Same seismic-horizon annotations as in figures 13 and 14. 
locally deformed and are eroded and truncated at horizon A. Deformation is most apparent at the west end of the seismic lines (for example, seismic line 110, figs. 16; seismic line 107, fig. 17), where dipping beds are clearly truncated at about 0.65- to 0.70-s two-way traveltime. Near the San Gregorio structural zone, units are largely conformable across horizon A. The onshore Monterey Formation is similarly separated from overlying Late Miocene and younger formations by an unconformity. Following Cooper (1973) and McCulloch (1987, 1989), we correlate horizon A with the top of the Monterey Formation. Units above the unconformity, then, are age equivalent to the onshore Santa Margarita Sandstone, the Santa Cruz Mudstone, the Purisima Formation, and the Merced Formation.

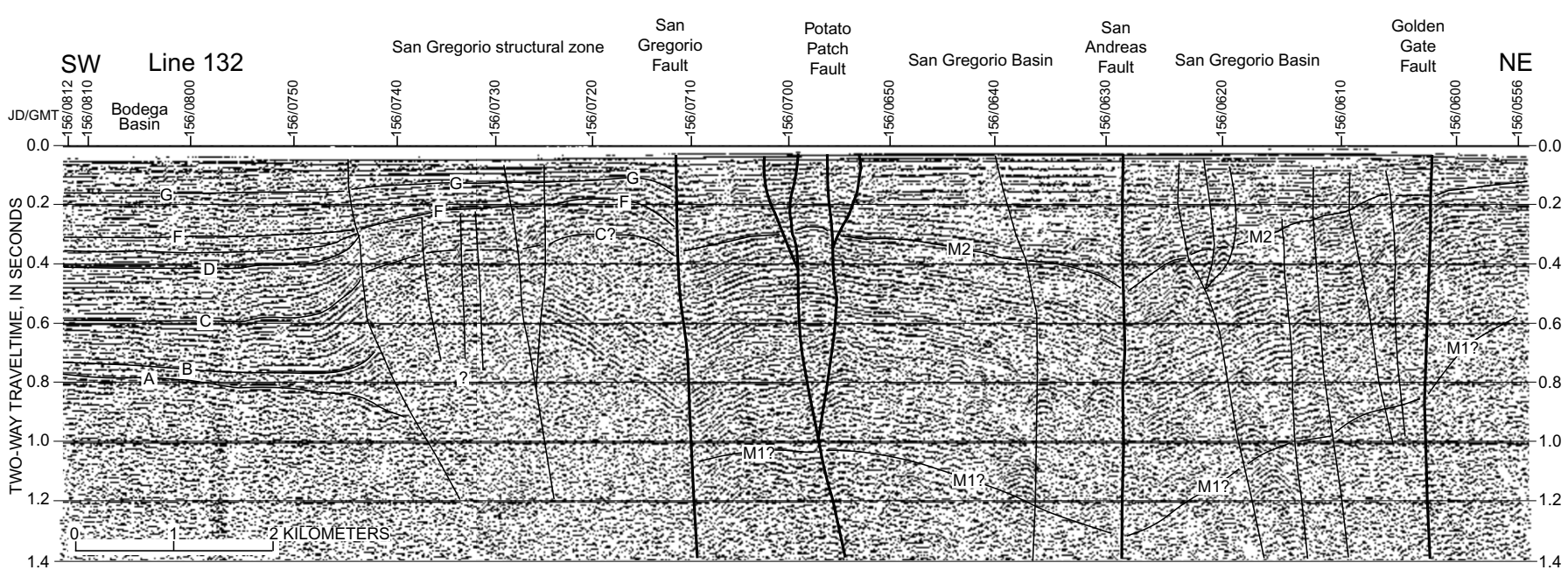

Figure 23.- Seismic line 132 southwest of the Golden Gate (figs. 2, 3, 9-12). Line shows maximum thickness of the San Gregorio Basin that is visible on seismic-reflection records, and serves as a partial tieline to several other lines that allow mapping of seismic horizons M1 and M2 in central part of the San Gregorio Basin. Line is plotted from southwest (on left) to northeast (on right) so that tectonic features can be easily compared to features on west-trending seismic lines. Same seismic-horizon annotations as in figures 13 and 14.

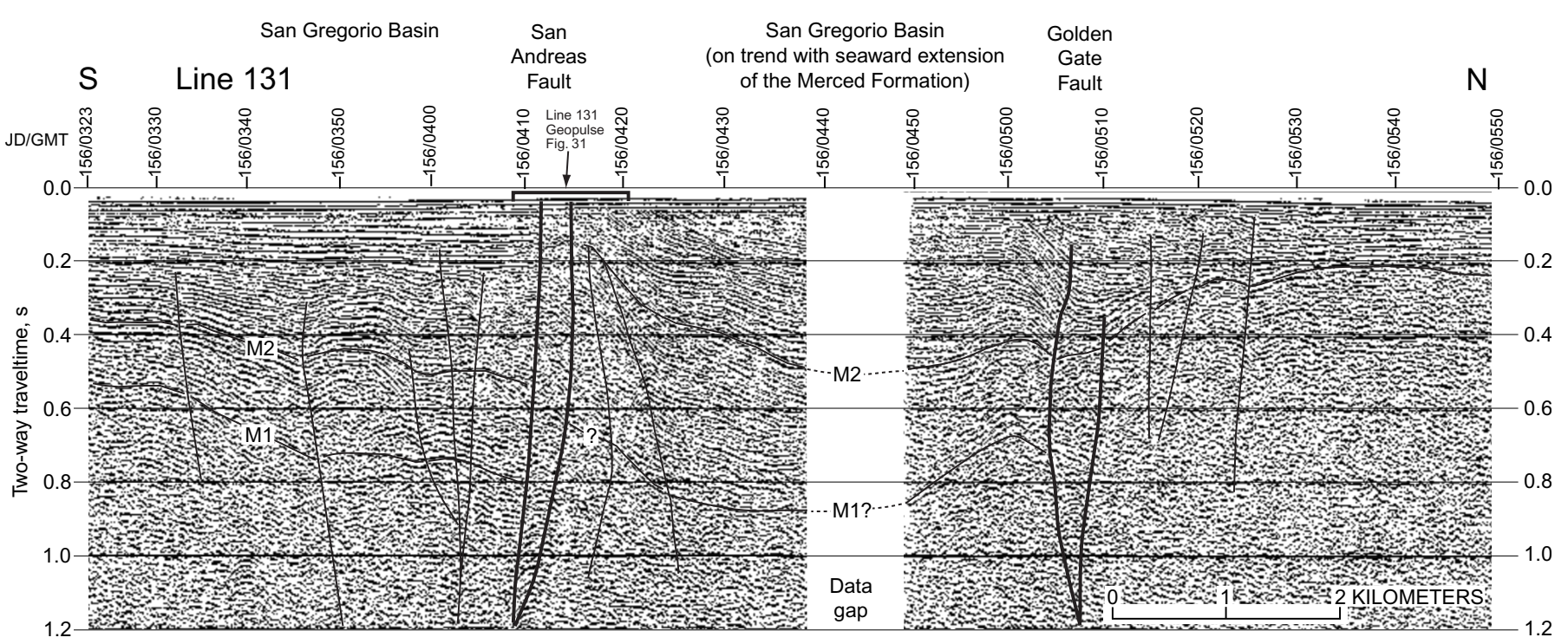

Figure 24.-Seismic line 131 across the Golden Gate and San Andreas Faults (figs. 2, 3, 9-12), at closest approach to land on this cruise. Section visible on seismic-reflection record is nearly identical to that visible onshore in seacliffs, with north-dipping beds near the San Andreas Fault, relatively flat lying beds between the two faults, and a monocline over the Golden Gate Fault. Major difference is that onshore dips are at least $30^{\circ}$ steeper than those on this nearby offshore line ( $3 \mathrm{~km}$ away). We believe that this substantial uplift within a very short distance is caused by rotation and uplift of section between the San Andreas and Golden Gate Faults (see figs. 27, 28). Line is plotted from south (on left) to north (on right) so that tectonic features can be easily compared to features on west-trending seismic lines. Direction of line is reversed in figure 28 for comparison with onshore stratigraphic section of Clifton and Hunter (1987, 1991). Same seismic-horizon annotations as in figures 13 and 14. 
Numerous local and regional unconformities, shown here as horizons B through G (figs. 15, 16, 18, 23), are present within the offshore section. We cannot correlate these unconformities to unconformities within onshore sections. On the basis of correlations with McCulloch's $(1987,1989)$ interpretations, the strata above horizon $\mathrm{C}$ are approximately Late Pliocene and younger and probably correspond to the upper part of the Purisima Formation and, at least in age, partly to the Merced Formation. We also cannot correlate any of these seismic horizons with those in the San Gregorio Basin because we are unable to unequivocally trace seismic reflectors across the San Gregorio Fault. Independent stratigraphic or age control is needed to make such a correlation.

Structure-contour maps constructed on horizons A and $\mathrm{C}$ show the configuration of strata in the Bodega Basin (figs. 9,10 ). Both horizons can be mapped with a high degree of confidence throughout the basin because seismic reflectors are continuous and good tielines exist.
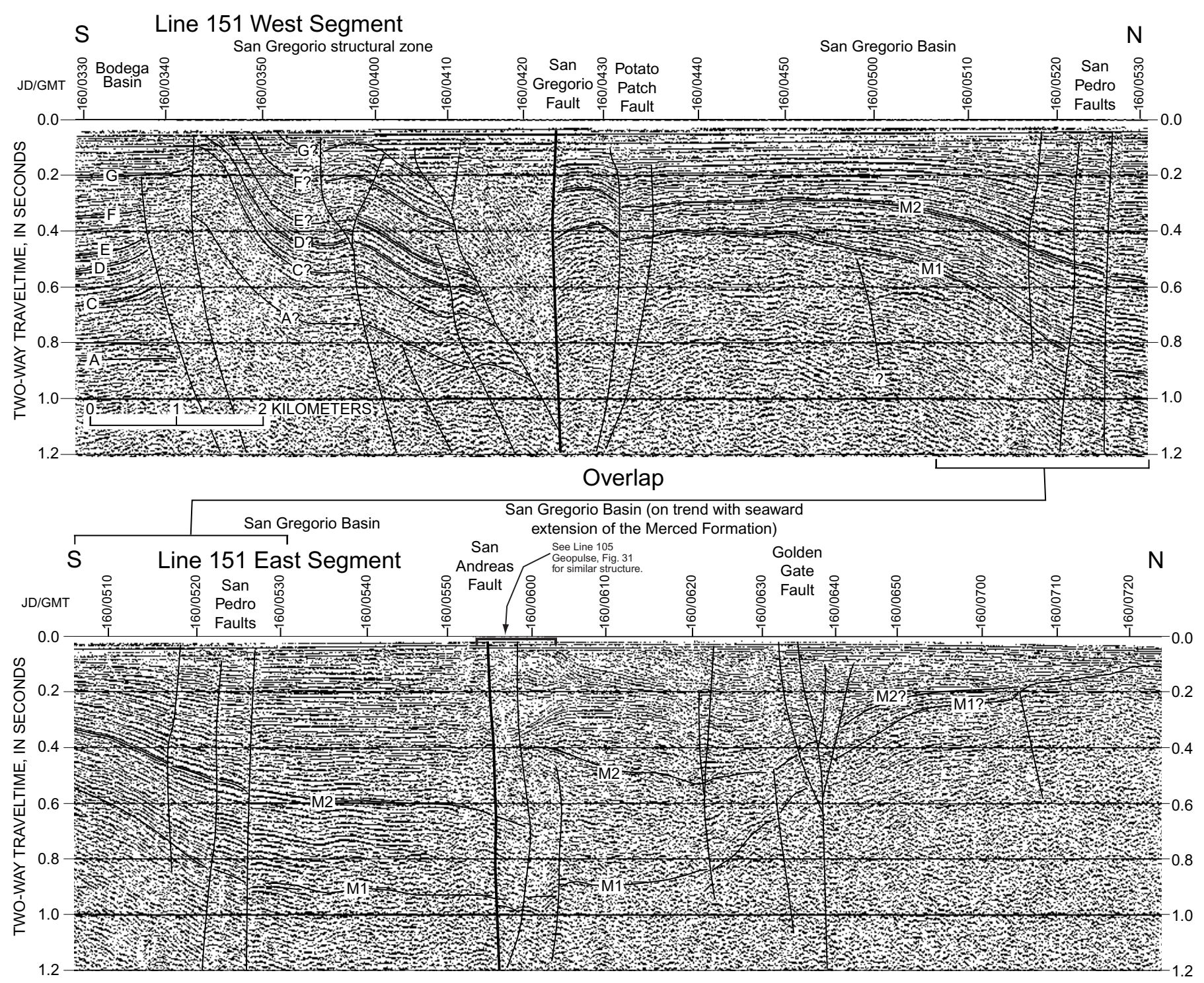

Figure 25.- Seismic line 151 south of the Golden Gate (figs. 2, 3, 9-12). Line is a tieline that allows mapping of seismic horizons through south end of seismic grid. Seismic section spreads out appearance of structures in the San Gregorio structural zone because it crosses structural zone at an angle of about $45^{\circ}$. Faults in structural zone are clearly thrust faults, probably rooted in the San Gregorio Fault. Structure between the Golden Gate and San Andreas Faults is similar to that visible on seismic line 131 (see figs. 24, 27). Line is plotted from south (on left) to north (on right) so that tectonic features can be easily compared to features on west-trending seismic lines. Same seismic-horizon annotations as in figures 13 and 14. 


\section{Seismic Stratigraphy Between the San Gregorio and Golden Gate Faults-the San Gregorio Basin}

In the seismic-reflection data east of the San Gregorio Fault, a sedimentary section at least 1,300 to $1,500 \mathrm{~m}$ thick (figs. 13-25; approx 1.3-1.4-s two-way traveltime in the seismic-reflection data) is imaged in the fault-controlled San Gregorio Basin. The seismic-reflection data show relatively continuous seismic reflections south of seismic line 107 (fig. 2), and tielines between the east-west seismic lines allow a high degree of confidence in correlations from line to line. North of seismic line 107 (fig. 2), however, no tielines are available, and our interpreted correlations are based on matching the acoustic characteristics of the seismic reflections from line to line-an inexact process. Thus, our confidence in the position of the mapped horizon is low. From seismic line 114 northward (fig. 2), seismic reflectors become less continuous to discontinuous and chaotic, no tielines exist, individual horizons are uncorrelatable between lines, and structure contours are based solely on the general form of the basin (formline contours). We changed contour horizons here because no continuous reflections are present below about 0.5 -s two-way traveltime. Thus, the structure contours north of seismic line 114 serve only as a guide to basin form.

We mapped a seismic horizon, M1, at or near the base of strata in the San Gregorio Basin; the resulting structure contours (fig. 11) show the depth to that horizon below sea level. In the contoured area, water depths range from less than $10 \mathrm{~m}$ to about $30 \mathrm{~m}$; the contoured horizon depth is therefore close to being an isopach map of strata in the San Gregorio Basin. In the shallow parts of the basin, the acoustic basement is a strong reflector. In the deep parts of the basin, below about 1,000- to 1,200-m depth, horizon M1 is not well defined, the contoured depth to the base of the strata is a minimum thickness, and basin strata could be substantially thicker.

We also mapped a second seismic horizon, M2, throughout the basin (fig. 12). This horizon, which is an unconformity throughout at least the central part of the basin (see seismic line 110, fig. 16), divides strata that thicken seaward into the San Gregorio Fault from strata that thin onto growing folds over the Potato Patch Fault and across the San Andreas Fault extension. The horizon thus dates the beginning of vertical deformation on both of these fault strands.

We do not know the age of strata in the San Gregorio Basin. We cannot directly tie the onshore outcrops of the Merced Formation to the offshore strata shown in the seismic-reflection data, because the offshore strata have not been sampled or dated, and we have no seismic tieline between onshore and offshore. If the Merced Formation was deposited in a stepover basin that formed between the San Andreas and Golden Gate Faults, as suggested by Hengish and Wakabayashi (1995), Zoback and others (1999), Jachens and Zoback (1999), and Jachens and others (this volume), then a fundamental tectonic discontinuity could be present between the onshore and offshore sections, possibly causing markedly different subsidence rates on either side of the discontinuity or leading to markedly different depositional settings. Therefore, we cannot straightforwardly assume that the strata of the Merced Formation and the San Gregorio Basin are equivalent.

We can, however, consider two possible end-member correlations. First, the slip rate on the San Gregorio Fault is about a third of the slip rate on the San Andreas Fault. If the Merced Formation and San Gregorio Basin strata were both deposited in transtensional strike-slip stepover basins (Jachens and Zoback, 1999; Zoback and others, 1999; Jachens and others, this volume), then presumably deposition would be about 3 times as rapid in the Merced Basin (opening at the San Andreas Fault slip rate) as in the San Gregorio Basin (opening at the San Gregorio fault rate). Thicknesses onshore would be about 3 times greater than coeval thicknesses offshore. Thus, the approximately $2 \mathrm{~km}$ of sediment in the San Gregorio Basin could have taken much longer to accumulate than the sediment in the Merced Basin, and could be substantially older.

For the second end member, our favored interpretation, we make a straightforward correlation of San Gregorio Basin strata with the Merced Formation, assuming that basin formation for both sets of strata started when motion on the Pilarcitos Fault stopped, and that onshore and offshore strata are equivalent. In figure 8 , we show the simplified onshore section on the left (from Clifton and Hunter, 1987, 1991) and its conversion to two-way traveltime on the right. Then, in the thickest parts of the San Gregorio Basin, we assume that the onshore section provides an approximate correlation with the offshore section. The potentially useful part of this correlation is that horizon M2 in the seismic lines nearest shore (seismic line 131, fig. 24; seismic line 151, fig. 25 ) lies at a depth of about 0.4- to 0.5-s two-way traveltime and approximately corresponds to the angular unconformity and nearby bedding change (change from thick regressive-bedded sequences to thin sequences) observed in the onshore section. Thus, the unconformity visible in the basin could correspond to a time of changing depositional style recorded in the onshore section as well.

\section{Structure and Offshore Faults}

On the basis of previous work (Cooper, 1973; McCulloch, 1987, 1989) and new seismic-reflection data, the San Gregorio Fault separates the Bodega Basin to the west from the San Gregorio Basin to the east (figs. 1, 3). The two basins are affected by six active structural elements: the San Gregorio structural zone, the San Gregorio Fault, the Potato Patch Fault, the San Pedro Fault, the San Andreas Fault, and the Golden Gate Fault (fig. 3). The Pilarcitos Fault does not deform strata in the San Gregorio Basin above acoustic-basement horizon M1 and has not been an active tectonic feature during the formation of the San Gregorio Basin. 


\section{Bodega Basin}

The Bodega Basin lies between the edge of the Continental Shelf and the San Gregorio Fault (figs. 1, 3, 9, 10; McCulloch, 1987, 1989). Rocks below horizon A have been deformed and truncated at the horizon (see figs. 13-17); structures in the pre-early Miocene rocks were mapped by McCulloch (1987, 1989).

Rocks above horizon A are little deformed west of the San Gregorio structural zone. Some doming occurs in these rocks over structural highs in the older rocks (figs. 13-15). Some relatively young deformation occurs off Point Montara and Point San Pedro just seaward of the San Gregorio Fault (figs. 13, 14), and minor faulting extends upward from older, buried structures, particularly in strata that overlie the most deeply buried parts of the San Gregorio structural zone (figs. 14-19).

Strata in the Bodega Basin above horizon A range in thickness from about $900 \mathrm{~m}$ near Bolinas to about 1,100 m at the south end of the study area (fig. 9). The strata thin to less than $600 \mathrm{~m}$ westward in the seismic-reflection data and continue to thin westward of our data set until they truncate against the Farallon Ridge at the edge of the Continental Shelf (see McCulloch, 1987, 1989). Within the post-horizon A

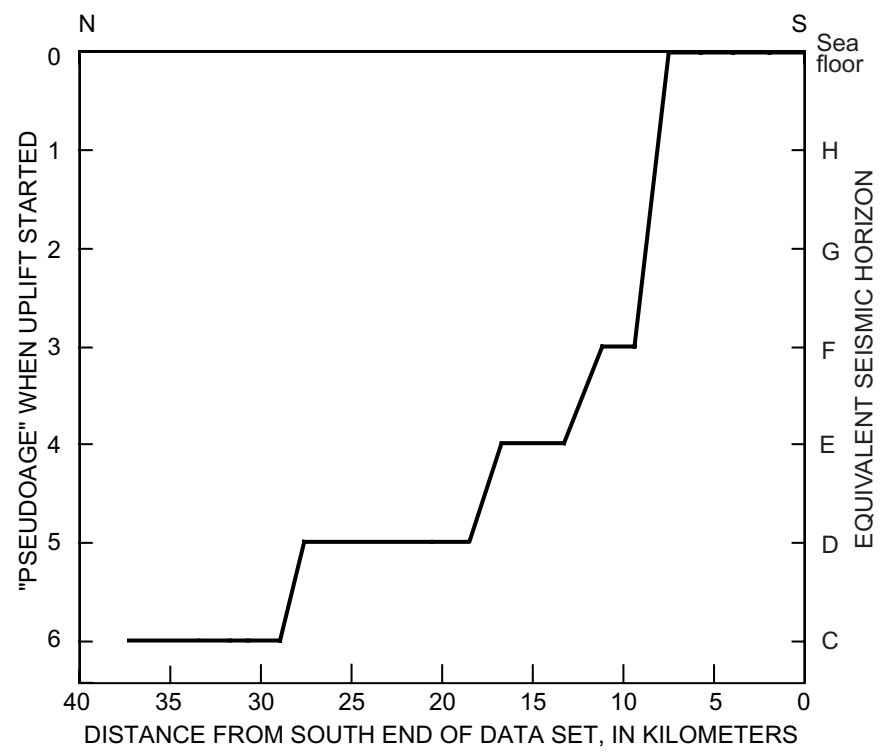

Figure 26.-Relative age of deformation of strata above horizon $A$ in the San Gregorio structural zone versus distance from south end of study area near Point Montara (fig. 1), showing increasing age of deformation with offset. True age of strata above horizon $A$ is unknown, but mapped seismic horizons can be used to give a "pseudoage" based on relative age of horizon. In this case, each horizon is assigned a number 0 (sea floor) to 8 (horizon A) from youngest to oldest, and that number is plotted against distance along the San Gregorio Fault from south end of study area (figs. 2, 3). Uplift at a horizon starts when thinning begins between that horizon and overlying horizon. Plot simply shows increasing age of deformation with offset. sequence, strata between horizons $\mathrm{A}$ and B thicken northward from 200 to $250 \mathrm{~m}$ on the south to 400 to $450 \mathrm{~m}$ on the north. In contrast, strata between horizon B and the sea floor thin northward from more than $800 \mathrm{~m}$ on the south to $350 \mathrm{~m}$ on the north (figs. 13-25). Clearly, the depocenter for the basin shifted southward beginning at about horizon B time.

Onshore, on the Point Reyes peninsula, the total thickness of units above the Monterey Formation is estimated at as much as 2,500 m (Galloway, 1977; Clark and others, 1984, 1991), with about 2,000 m of Santa Cruz Mudstone and 500 $\mathrm{m}$ of Purisima Formation. Nowhere offshore south of Bolinas do we see so great a thickness of units above horizon A. Adjacent to and north of Point Reyes, Cooper (1973) and McCulloch (1987, 1989) showed offshore sedimentary deposits more than $2 \mathrm{~km}$ thick above the Monterey Formation, in general agreement with what is observed on the Point Reyes peninsula. They also showed sediment thicknesses in the Golden Gate area similar to what we see. Thus, units above horizon A thicken substantially northward and westward towards Point Reyes. Much of this thickening could occur between horizons $\mathrm{A}$ and $\mathrm{B}$, as a continuation of the northward-increasing thickness observed in the seismic-reflection data near Bolinas.

\section{San Gregorio Fault and San Gregorio Structural Zone}

The San Gregorio Fault (fig. 3) is clearly a major tectonic boundary across the Gulf of the Farallones, as indicated by major differences across the fault in inferred basement-rock types, based on seismic-reflection and aeromagnetic data. Throughout its length across the Gulf of the Farallones, the San Gregorio Fault separates Early Eocene and younger strata in the Bodega Basin on the west from mildly deformed Late Pliocene(?) and Pleistocene rocks in the San Gregorio Basin on the east. The San Gregorio structural zone, which consists of the thrust-faulted strata on the west side of the San Gregorio Fault, is about $2 \mathrm{~km}$ wide near Point Montara and widens northward to at least $8 \mathrm{~km}$ near Bolinas.

In the Gulf of the Farallones region, the San Gregorio Fault can be divided into three segments with slightly different characteristics and direction. The first segment, from Point Montara to just south of the Golden Gate, from lat $37^{\circ} 33^{\prime}$ to about $37^{\circ} 46^{\prime}$ N. (figs. 1, 3; from seismic line 128 northward to seismic line 107 , figs. $2,13-17$ ), trends about N. $17^{\circ} \mathrm{W}$. and is a clearly defined, major break in the seismic-reflection data throughout the sedimentary section. At the south end of this first segment, the fault and associated structural zone crop out at the sea floor. To the north, a cover of flat-lying to gently dipping strata, as much as $300 \mathrm{~m}$ thick, overlaps the structural zone and appears to continue across the San Gregorio Fault with only minor vertical offset. Strike-slip offset, if any, cannot be determined from the available data. Throughout this segment of the fault, aeromagnetic data (fig. 4) also show a sharply defined fault (Jachens and Zoback, 1999; see Jachens and others, this volume), and the locations of the fault based on seismic-reflection and aeromagnetic data 
virtually coincide. In the seismic-reflection data, the fault is vertical in the uppermost $1.5 \mathrm{~km}$ of crust, and the aeromagnetic data indicate that it continues to be near-vertical down to magnetic basement.

The second segment, the next $6 \mathrm{~km}$, of the San Gregorio Fault, from about lat $37^{\circ} 45^{\prime}$ to $37^{\circ} 48^{\prime} \mathrm{N}$. (figs. 1, 3; from seismic line 101 northward to seismic line 123, figs. 2, 18, 19), also trends N. $17^{\circ} \mathrm{W}$., but displacement across the fault in shallow parts of the seismic-reflection data is less distinct than to the south, and here from 300 to $500 \mathrm{~m}$ of strata overlap the San Gregorio structural zone with only minor faulting. Along this second segment, the aeromagnetic data (fig. 4) do not show a basement break corresponding to the mapped trace in the seismic-reflection data but, instead, show a basement fault that is stepped eastward about $2 \mathrm{~km}$, beneath the mapped position of the Potato Patch Fault. The aeromagnetic data also track the Potato Patch Fault for about 3 to $4 \mathrm{~km}$ both northward and southward of this segment of the San Gregorio Fault. Within this area, the adjacent San Gregorio structural zone begins to markedly widen, from 3 to more than $5 \mathrm{~km}$.

The third segment of the San Gregorio Fault, from about lat $37^{\circ} 48^{\prime} \mathrm{N}$. to Bolinas (fig. 1), trends about N. $22^{\circ}$ W. (fig. 3; from seismic line 123 northward to seismic line 119 , figs. 2, 19-21), slightly more westerly than the segment to the south. The fault is well defined by seismic reflections that are truncated at the fault at all levels. The aeromagnetic data, again, do not track a basement fault lying vertically below this third segment of the San Gregorio Fault but, instead, partly track the Potato Patch Fault and partly lie between the mapped traces of the two faults. The main fault trace as mapped in the seismic-reflection data could dip east to join the magnetically mapped basement fault or the Potato Patch Fault; alternatively, the fault at depth could extend westward into nonmagnetic rocks below the San Gregorio structural zone. The structural zone continues to widen, to more than $8 \mathrm{~km}$, and becomes more deeply buried, to more than $500 \mathrm{~m}$.

Numerous thrust faults are present along each of the seismic lines crossing the San Gregorio structural zone. We have attempted to correlate these faults from line to line, but the structure changes rapidly in short intervals within the structural zone, and even with a 2-km line spacing, we are not confident that faults are correctly correlated between seismic lines. In figure 3, the faults are interpreted as long strands that trend subparallel to the San Gregorio Fault.

Within the San Gregorio structural zone, structures are tightly folded in the southern, narrow part of the zone but become much broader and less tightly folded northward. The thrust faults and amount of offset on these faults are well illustrated on seismic line 151 (fig. 25), which crosses the structural zone at an oblique angle at the south end of the study area (fig. 3), where the structural zone is about $2 \mathrm{~km}$ wide. On this line, seismic reflectors are correlated across the fault on the basis of acoustic characteristics. If the correlations are correct, we estimate that almost $700 \mathrm{~m}$ of uplift has occurred at the initial thrust fault (at JD/GMT 160/0340, fig. 25). Seismic lines 130/150 (fig. 14) and 103 (fig. 15) are near seismic line 151 and cross perpendicular to the structural zone, showing the tight folding that characterizes the south end of the structural zone.

The broadened San Gregorio structural zone to the north is illustrated on seismic lines 124 (fig. 18) and 123 (fig. 19), where a syncline is bracketed by thrust faults. On these lines, the deformation zone is almost $7 \mathrm{~km}$ wide. We cannot determine the amount of uplift across the faults because we cannot correlate seismic reflectors across the faults with any assurance, but the deformed section has clearly been uplifted and eroded, and subsequently has subsided and been covered by largely undeformed strata during its post-Miocene geologic history.

Near Bolinas, the entire sedimentary section in the Bodega Basin has been uplifted onto the Point Reyes peninsula, and this uplift is superposed on the buried structural zone, which now gets exhumed. In the seismic-reflection data, this uplift is first visible north of seismic line 123 (figs. 3,19 ) as a doming west of the San Gregorio Fault over the San Gregorio structure zone. By seismic line 121 (figs. 3, 20), substantial uplift has occurred, forming a broad anticline. The intensity of folding increases northward on seismic lines 117 (fig. 21) and 120A and 120B (fig. 22). Mapped seismic horizons indicate that this uplift begins at least after horizon $\mathrm{E}$ time and, possibly, after horizon $\mathrm{F}$ time, as shown by the absence of thinning between horizons $\mathrm{C}, \mathrm{E}$, and $\mathrm{F}$ on seismic line 121 (fig. 20). Thus, the uplift is very young and is an active, ongoing process.

The structures in the San Gregorio structural zone show a northward progression in both age and depth of burial; the northern structures are significantly older than those at the south end of the structural zone, and are gradually buried beneath thicker strata than those to the south. This progression is shown by numerous unconformities within the structural zone where seismic reflections show pronounced thickening and thinning between unconformities. In the lower part of the section above horizon A, strata thicken into the fault zone. Thinning onto the structures indicates when structural growth began, and deposition of relatively undeformed strata over the structures indicates when uplift ceased. At the south end of the data set, structures deform strata at the sea floor (for example, seismic lines 128, 130/150, and 151; figs. $13,14,25)$. Northward, however, structures are buried under increasingly thick undeformed strata (see seismic lines 103, $110,132,107,124,123$, from south to north, figs. 2, 3, 15-19, 23). In any one locality, however, initial basin subsidence and deposition are followed by thrust-fault uplift, and these uplifted strata, in turn, begin to subside once again.

The sequential formation of structures, from young on the south to old and deeply buried on the north, can be partly quantified by plotting a pseudoage of the time when uplift began versus distance northward along the San Gregorio Fault zone (fig. 26). Horizons A through $\mathrm{H}$ and the sea floor are numbered from 8 to 0 to serve as a proxy for age (thus, pseudoage), with " 8 " assigned to horizon A and " 0 " assigned to the sea floor. Initiation of uplift is then assigned the pseudoage when the seismic horizons switch from thickening into the fault zone to thinning over the growing structures. The 
plot of this pseudoage against distance northward along the fault (fig. 26; distance $0 \mathrm{~km}$ is on the San Gregorio Fault on seismic line 128 at the south end of the data set) shows a clear trend of earliest structural growth to the north (strata thin between horizons $\mathrm{C}$ and $\mathrm{D}$, indicating that structural growth began after horizon $\mathrm{C}$ time) and latest structural growth at the south (structures still actively deforming the sea floor).

The structural zone appears to be an inherited feature that developed south of Half Moon Bay, and subsequently rides passively northward. We believe that these structures
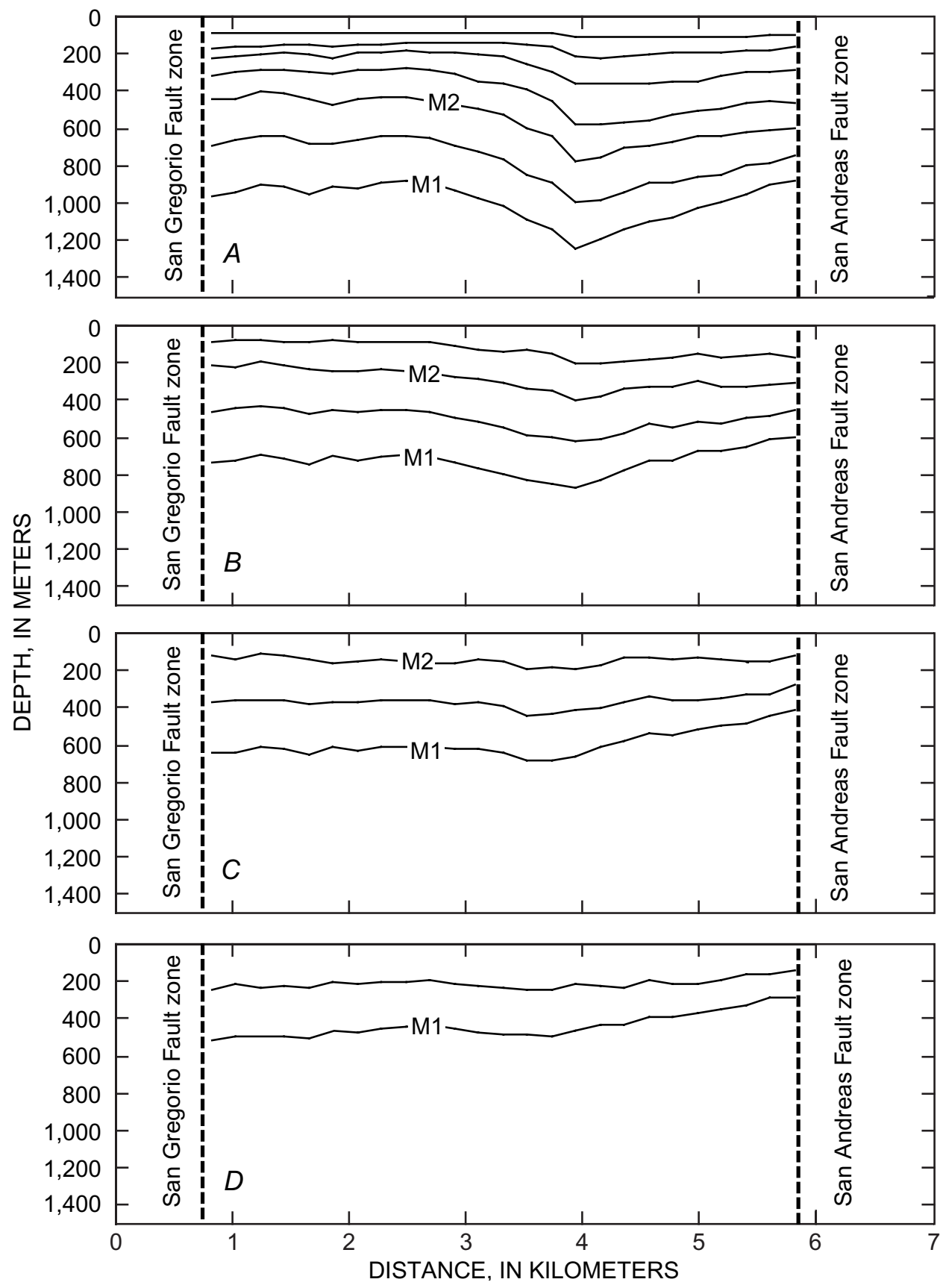

Figure 27.-Seismic horizons from seismic line 110 (fig. 16) between the San Gregorio and San Andreas Faults. $A$, Depth to seismic horizons, based on time-depth-conversion curve in figure 5. Vertical exaggeration, about 1.6 to 1 . $B$, Reconstructed horizons after flattening on second layer. $C$, Reconstructed horizons after flattening on fourth layer. $D$, Reconstruction after flattening on horizon M2. Reconstructed horizons show that structural growth visible on seismic-reflection record did not begin until after horizon $\mathrm{M} 2$ time. 
have formed in a transpressional strike-slip setting on the San Gregorio Fault south of Half Moon Bay. North of Half Moon Bay, the structures enter a transtensional tectonic environment and begin to subside.

\section{Continuation of the San Gregorio Fault Onshore as the Seal Cove Fault}

The relation of the San Gregorio Fault at the south end of the study area to the onshore Seal Cove Fault (figs. 1, 3, 4) is not defined by the seismic-reflection data. The offshore fault closely approaches the trace of the Seal Cove Fault but could either attach to the Seal Cove Fault or continue as a separate fault just offshore. A pronounced magnetic anomaly, however, continues from the mapped trace of the offshore San Gregorio Fault through the Seal Cove Fault (R.C. Jachens, written commun., 2001). Thus, almost certainly, the main trace of the San Gregorio Fault as mapped here also continues to join the onshore Seal Cove Fault, and faults of the San Gregorio structural zone cut offshore rocks west of the Seal Cove Fault.

Other unnamed minor faults lie just east of the main trace of the San Gregorio Fault (fig. 3). These faults have multiple strands (at least two mapped) just offshore but merge into a single strand northward. The fault mainly affects basement units but also causes small offsets and minor structures within overlying strata in the San Gregorio Basin (for example, seismic line 128, fig. 13; seismic lines 130/150, fig. 14). We interpret that this fault continues about $10 \mathrm{~km}$ to the north of Seal Cove, mainly as a concealed fault. This offshore fault trends onshore to either join or lie just east of the Seal Cove Fault. In the seismic-reflection data, we interpret the fault to be a small eastward splay off the San Gregorio Fault.

\section{San Gregorio Basin}

The boundaries of the San Gregorio Basin are controlled by the San Gregorio Fault on the west and by the San Andreas and Golden Gate Faults on the east (figs 3, 11, 12). Between these two faults, a triangular basin contains strata more than $1.5 \mathrm{~km}$ thick. The basin begins near Point San Pedro, widens to about $8 \mathrm{~km}$ near where the Golden Gate Fault trends onshore west of Lake Merced, narrows northward to about 6 $\mathrm{km}$ throughout much of the central part of the basin off the Golden Gate, and further narrows to about $3 \mathrm{~km}$ near Bolinas (figs. 3, 11, 12).

Strata in the San Gregorio Basin are cut or folded by four major faults, including, from west to east, the Potato Patch Fault (after McCulloch, 1987, 1989), the here informally named San Pedro Fault, the offshore San Andreas Fault (which is the offshore extension of the onshore Peninsular segment of the San Andreas Fault), and the Golden Gate Fault (fig. 3). The Pilarcitos Fault, a major onshore tectonic boundary, does not significantly disrupt sedimentary rocks above the seismic acoustic basement offshore.

The form of the San Gregorio Basin is shown by structure contours on horizons M1 and M2 (figs. 11, 12). From south to north, the depositional axis of the San Gregorio Basin lies along the San Pedro Fault, then shifts to the San Andreas Fault off the Golden Gate and continues mostly along the San Andreas Fault to Bolinas Lagoon. The thickest part of the San Gregorio Basin, between the San Andreas and Golden Gate Faults, trends onshore into the Merced Formation. Unlike onshore, however, where little or no Merced Formation is present west of the San Andreas Fault, strata in the San Gregorio Basin maintain a more or less constant thickness across the San Andreas Fault and extend to the San Gregorio Fault. Offshore, basin strata dip west; in contrast, onshore strata dip northeast, indicating that the onshore Merced Formation must lie on the east limb of an anticline which lies beneath or immediately offshore from the present shoreline.

At the south end of the basin, a shallow basement horizon extends northward from Point San Pedro (fig. 11). In this shallow basement region, little or no deformation is observed in basin strata above horizon M1 over the magnetically located Pilarcitos Fault. Minor deformation, however, is present over the San Pedro Fault over this shallow basement region (figs. 14, 15).

For about $10 \mathrm{~km}$ northward of Point San Pedro, the sedimentary section gradually thickens from less than 100 to about $500 \mathrm{~m}\left(\mathrm{dip}\right.$, approx $\left.2^{\circ}-3^{\circ}\right)$. Then, the dip of the basement surface steepens northward, and basin sediment thicknesses increase rapidly to more than $1,400 \mathrm{~m}$ over a northward distance of about $5 \mathrm{~km}$ (average dip, approx $10^{\circ}$ ). This thick section continues in the basin axis northward for at least another 15 , possibly $20, \mathrm{~km}$ to near Bolinas (fig. 11). The maximum offshore sediment thickness could approach $2,000 \mathrm{~m}$, as suggested by interpretations of seismic-refraction data (Hole and others, 1993; Holbrook and others, 1996; Tom Parsons, oral commun., 2001); we have insufficient acoustic-energy penetration to see this thickness on the seismicreflection data. On east-west seismic-line crossings, strata in the San Gregorio Basin extend at least $2 \mathrm{~km}$ eastward of the Golden Gate Fault, where they range from 0 to $300 \mathrm{~m}$ in thickness in the Golden Gate area. To the north, basin rocks are uplifted onto the Point Reyes peninsula and may correlate with the 150-m-thick Merced Formation mapped onshore.

Structural relief in the San Gregorio Basin has resulted from differential subsidence of basement rocks. A major structural high underlies the central part of the basin west of Lake Merced between the San Gregorio and Potato Patch Faults (seismic line 110, fig. 16) and between the San Gregorio and San Andreas Faults (seismic line 132, fig. 23). The structure bends steeply upward from the San Pedro Fault west of Lake Merced (fig. 11). This structure could have resulted from compressional deformation, an interpretation that seems unlikely in a basin where the general tectonic regime is one of rapid subsidence. The structural high corresponds to a negative magnetic anomaly associated with basement rocks of the Salinia terrane, and the adjacent structural low correlates with a high, positive magnetic anomaly, characteristic of basement rocks of the Franciscan terrane. The deformation history of basin strata (as discussed below) indicates that the structural 
high resulted from differential subsidence within the developing basin - that is, the Salinia block beneath the high has stayed relatively high, and the adjacent Franciscan block has subsided.

The structural high dies out northward, and west and north of the Golden Gate, a somewhat simpler basin architecture prevails (figs. 11, 12), as strata dip into the basin and truncate against the San Gregorio Fault (seismic line 107, fig. 17). Farther north, strata rise slightly from a basin axis just east of the Potato Patch Fault into the San Gregorio Fault (seismic lines 123, 124, figs. 18, 19). In the 10-km stretch south of Bolinas, dips between the San Gregorio and San Andreas Faults steepen northward, reaching a maximum dip of about $12^{\circ}-14^{\circ}$ E. on seismic lines nearest Bolinas.

The seismic stratigraphy indicates that the San Gregorio Basin initially formed as a half-graben, with subsidence occurring along the San Gregorio Fault during deposition of the lower two-thirds of the basin fill. Formation of the faults and the structural high within the basin was relatively late in the basin history. Horizon M2 divides strata that thicken westward into the basin from strata that thin westward over a developing structure, a relation best seen on seismic line 110 (fig. 16). In figure 27, we converted seismic horizons on seismic line 110 to depth, then sequentially flattened each depth-converted horizon. The reconstructed section before horizon M2 time (fig. 27D) shows that the strata below horizon M2 are relatively flat lying and thicken from east to west into the San Gregorio Basin. Only after horizon M2 time does significant vertical deformation begin along any of the major basin-cutting faults - the Potato Patch, San Pedro, or San Andreas Fault. During deposition of about the upper third of the strata in the San Gregorio Basin, part of the basin basement continued to subside, while another part of the basement stayed high, producing the structural high at the south end of the basin (seismic line 110, fig. 16). Thus, horizon M2 marks the time of initiation of basin deformation. Only during deposition of the upper third of the basin strata did the faults become a significant factor in basin development. The surprising conclusion is that about two-thirds of the sedimentary section in the San Gregorio Basin was deposited before the Potato Patch, San Pedro, or San Andreas Fault actively began to deform the strata.

\section{Holocene Graben}

A small active graben is present in the north third of the San Gregorio Basin, beginning at about seismic line 124 and continuing to Bolinas Lagoon (fig. 3). The maximum sediment thickness in the graben is about $100 \mathrm{~m}$ on seismic line 123 (fig. 19). On seismic line 124 (fig. 18), the graben is a broad low, without well-defined east or west boundaries; but on seismic lines 123 and 121 (figs. 19, 20), the faults forming the west boundary are well defined. On seismic lines 124 through 115 (fig. 3), the bounding fault on the west is the Potato Patch Fault. From there northward to Bolinas Lagoon on seismic lines 114 through 121 (fig. 3), the Potato Patch merges with the San Andreas Fault, which is the bounding fault. The Golden Gate Fault forms the east boundary.

Cooper (1973) and McCulloch $(1987,1989)$ assumed that this graben formed during the Holocene, because sealevel rise would presumably have eroded an older feature. Cooper also noted, and we concur, that the material filling the graben is acoustically transparent and probably consists of fine sand or mud. The unit probably represents shallow-water Holocene shelf deposits.

The presence of the graben indicates that the faults cutting the San Gregorio basin are still active-although the graben only shows vertical motion and does not give information on possible horizontal offset. Although the Holocene graben shows unequivocal ongoing subsidence between the San Gregorio-Potato Patch-San Andreas-Golden Gate Faults, uplift of young strata is occurring onto Point Reyes immediately to the west across the San Gregorio Fault and adjacent to the subsiding graben (for example, seismic line 121, fig. 20; seismic line 117, fig. 21). Thus, similar to the area near Daly City, both uplift and subsidence are occurring within a very short distance.

\section{Potato Patch Fault}

The Potato Patch Fault is a curvilinear fault that runs diagonally between the San Gregorio and San Andreas Faults (fig. 3), branching off the San Gregorio Fault on the south and joining the San Andreas Fault on the north. The Potato Patch Fault starts just south of the seismic-line 103/151 intersection (fig. 3, approximately at lat $37^{\circ} 37^{\prime} \mathrm{N}$., long $122^{\circ} 35^{\prime} \mathrm{W}$.), then trends north (figs. 15-17, 25). The fault lies along the east side of the magnetic high associated with the San Gregorio Fault on the south end (fig. 4) and trends along a separate conspicuous magnetic-anomaly boundary for the rest of its length. On the basis of the aeromagnetic data (fig. 4), Jachens and Zoback (1999) and Jachens and others (this volume) interpret the fault as continuing almost to Bolinas (fig. 2). On the seismic-reflection records, the shallow fault either dies out near lat $37^{\circ} 50^{\prime} \mathrm{N}$., south of seismic lines 121 (fig. 20) and 117 (fig. 21), or merges with the San Andreas Fault.

The southern segment of the Potato Patch Fault deforms strata in the San Gregorio Basin adjacent to a structural high, where the anticlinal high lies west of the fault, and double fault strands form a small graben along and east of the fault (seismic line 110, fig. 16). The amount of deformation decreases northward to only minor apparent offset by seismic line 107 (fig. 17). The north end of the Potato Patch Fault forms the west boundary of the Holocene graben on seismic lines from 124 northward to 114 (figs. 3, 18, 19); from seismic line 114 northward, the Potato Patch fault has died out or merged with the San Andreas Fault.

The Potato Patch Fault is currently active, as shown by deformation of the shallowest strata on the southern reaches of the fault and by the active graben margin formed by the fault in the northern reaches. As shown earlier, however, the fault was active in only a minor way during deposition of the 

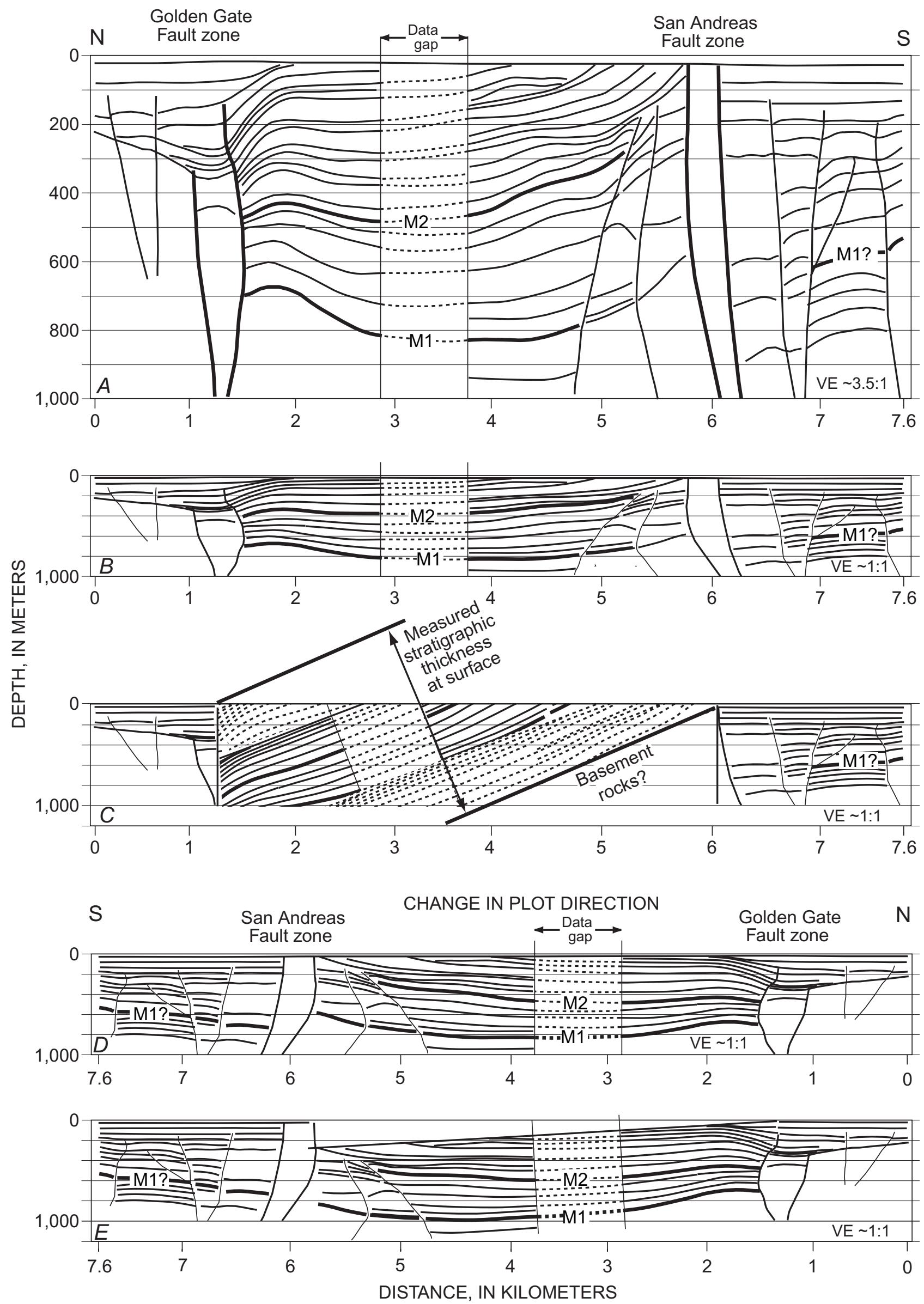
lower two-thirds of the basin strata (fig. 27). In the seismicreflection data, defined motion is dip slip, with the east side dropping down relative to the west side. Along the southern seismic lines crossing the fault, the Potato Patch Fault can be interpreted as a normal fault arising from the San Gregorio Fault. The data are not definitive, however, because the fault is mostly imaged as vertical in the upper 1- to 1.5-s two-way traveltime of data, and so alternative interpretations include that the fault could arise as a normal fault splay of the San Andreas Fault, or as a vertical fault caused by differential settling of basement blocks within the San Gregorio Basin. In any of these cases, the fault markedly affects the basement rocks. Seismic-reflection data with deeper penetration are needed to fully resolve the roots of the fault.

We cannot unequivocally determine whether a component of strike-slip motion exists on the Potato Patch Fault, although we would strongly expect such motion on a fault that ties two major strike-slip faults. We observe two possible indications of transfer motion along the Potato Patch Fault. First the south end of the Potato Patch Fault is located adjacent to the area where undeformed or mildly deformed sediment begins to cover the San Gregorio Fault, possibly because transform motion moves from the San Gregorio Fault to the Potato Patch Fault. Second, the structural low west of the Potato Patch Fault could be offset about $4 \mathrm{~km}$ north from the deepest part of the San Gregorio basin. We suggest, but cannot prove, that motion on the San Gregorio Fault transfers to the Potato Patch Fault, which then transfers the motion to the San Andreas Fault in the vicinity of Bolinas.

\section{San Andreas Fault}

The offshore extension of the San Andreas Fault begins where its Peninsular segment trends offshore at Mussel Rock (fig. 3). For about $12 \mathrm{~km}$, from lat $37^{\circ} 40^{\prime}$ to $37^{\circ} 45^{\prime} \mathrm{N}$. off San Francisco, the fault trends about N. $34^{\circ} \mathrm{W}$., then changes trend slightly to N. $30^{\circ} \mathrm{W}$. for the $20-\mathrm{km}$ stretch from lat $37^{\circ} 45^{\prime}$ to $37^{\circ} 55^{\prime} \mathrm{N}$. at Bolinas (fig. 2). Overall, it trends about N. $32^{\circ} \mathrm{W}$., slightly more northerly than the average trend of N. $36^{\circ} \mathrm{W}$. along the onshore Peninsular segment. For $5 \mathrm{~km}$ offshore of Mussel Rock, the fault trends along the northeast edge of a magnetic high (fig. 4). Jachens and Zoback (1999) and Jachens and others (this volume) interpret that the fault is active only in this first 5-km offshore stretch. From there northward, the aeromagnetic data do not require faulting of basement rocks anywhere along the San Andreas Fault except along a short (approx $4 \mathrm{~km}$ long) segment near seismic line 121 (fig. 4), but, instead, show block-bounding basement faulting along the Golden Gate Fault (fig. 4). Jachens and Zoback (1999) and Jachens and others (this volume) use these data, along with earthquake-epicenter information, to interpret a 3-km stepover in transform motion from the San Andreas to the Golden Gate Fault.

Seismic-reflection data across the San Andreas Fault off Lake Merced show a complex fault system. Nearshore, the fault has multiple splays (at least three; see figs. 11, 12; seismic line 151, fig. 25), and strata between the splays appear to dip steeply and be highly contorted. Strata east of the fault dip about $14^{\circ} \mathrm{N}$. in the shallow section (see seismic lines 131, 151, figs. 24, 25, 28, 29), but on seismic line 151 (fig. 25), strata slightly deeper in the section dip south, forming a triangular bedding configuration (at GMT 160/0400, figs. 25, 29). This configuration could have resulted from a combination of early deposition and infilling into a narrow depositional low (channel or fault valley?), followed by uplift and tilting of the section between the Golden Gate and San Andreas Faults (as discussed below). Immediately west of the San Andreas Fault, strata are relatively undeformed.

The San Andreas Fault continues northward as a significant fault that deforms strata in the San Gregorio Basin. Basement subsidence along the fault is indicated by the coincident basin depocenter (fig 11), and near Bolinas, the San Andreas Fault is, with the Potato Patch Fault, a significant element in the formation of the Holocene graben. As with the Potato Patch Fault, however, the San Andreas Fault has disrupted beds crossing the fault only during or after deposition of the upper third of strata in the San Gregorio Basin (fig. 27). Structure contours and seismic reflectors can be carried across the fault with little or no displacement. On the basis of structural contours, the basin axis is little affected by the fault, although the deepest part of the basin may be slightly offset northward. Thus, only minor horizontal offset appears to have occurred within the San Gregorio basin along the presumed

Figure 28.-Cross sections across the Golden Gate and San Andreas Fault zones. A, Cross section along part of seismic line 131 (figs. 2, 3, 24), plotted north to south, in opposite direction from seismic line in figure 24, to better correlate with onshore stratigraphic section. Seismic-reflections are converted to approximate depth based in time-depth-conversion curve in figure 5 . Vertical exaggeration, about 3.5 to 1 . This line, which is closest to the Merced Formation exposed in seacliff, shows same structural features seen onshore, including monocline over the Golden Gate Fault and steepening dips near the San Andreas Fault. Major difference is that onshore dips of $25^{\circ}$ to greater than $50^{\circ}$ are significantly steeper than offshore dips, which are a maximum of about $10^{\circ}-20^{\circ}$. B, Same cross section as in figure $28 A$, reduced to true scale and simplified (some horizons removed). C, Cross section between the Golden Gate and San Andreas Faults, tilted up $20^{\circ}$ along a hingeline at the Golden Gate Fault. Dips in resulting cross section range from $40^{\circ}$ near the Golden Gate Fault to $25^{\circ}-30^{\circ}$ near the San Andreas Fault. This section more closely matches dips in the onshore Merced Formation, although onshore dips are still steeper (see fig. 6). $D$, Same cross section as in figure $28 B$, plotted south to north to match seismic line shown in figure 24, and to match direction of seismic line 151 in figures 25 and 29 . E, Segment in figure $28 D$ between the Golden Gate and San Andreas Faults flattened by rotating about $3^{\circ}$ downward along the San Andreas Fault, with a hingeline at the Golden Gate Fault. Reconstruction shows that about $250 \mathrm{~m}$ of uplift has occurred along the San Andreas Fault since deposition of horizon M1. 
San Andreas strike-slip fault. We interpret this observation to mean that, in the basin, the San Andreas Fault may have been active as a strike-slip fault for only a short time. Any significant strike-slip motion along the onshore Peninsular segment of the San Andreas Fault appears to have been transferred elsewhere, presumably onto the Golden Gate Fault, during early San Gregorio Basin deposition.

\section{Golden Gate Fault}

The Golden Gate Fault extends offshore from Lake Merced and trends about N. $33^{\circ}$ W. to Bolinas Lagoon (fig. 3 ). On the seismic lines that cross the fault just south of the Golden Gate (see seismic line 107, fig. 17), shallow basement rocks on the east are downdropped into the basin on the west, and overlying sedimentary rocks are deformed into a faulted monocline, similar to that seen onshore across the extension of the fault toward Lake Merced (fig. 7; Clifton and Hunter, 1987, 1991). North of seismic line 124, off the Marin Headlands, the fault is less clearly defined, relatively flat lying strata in the San Gregorio Basin are slightly offset by the fault, and the basement dips seaward (seismic lines 124, 123, figs. 18, 19). In these areas, little evidence exists for dip-slip motion, and so we infer that motion is mainly strike slip. The fault is characterized throughout its length by a coincident linear magnetic anomaly arising from the basement rocks (fig. 4; Jachens and Zoback, 1999; see Jachens and others, this volume).

\section{Onshore to Offshore Transition-the Golden Gate and San Andreas Faults}

The dominant tectonic mechanism forming the San Gregorio Basin is subsidence. Yet, within a very small distance
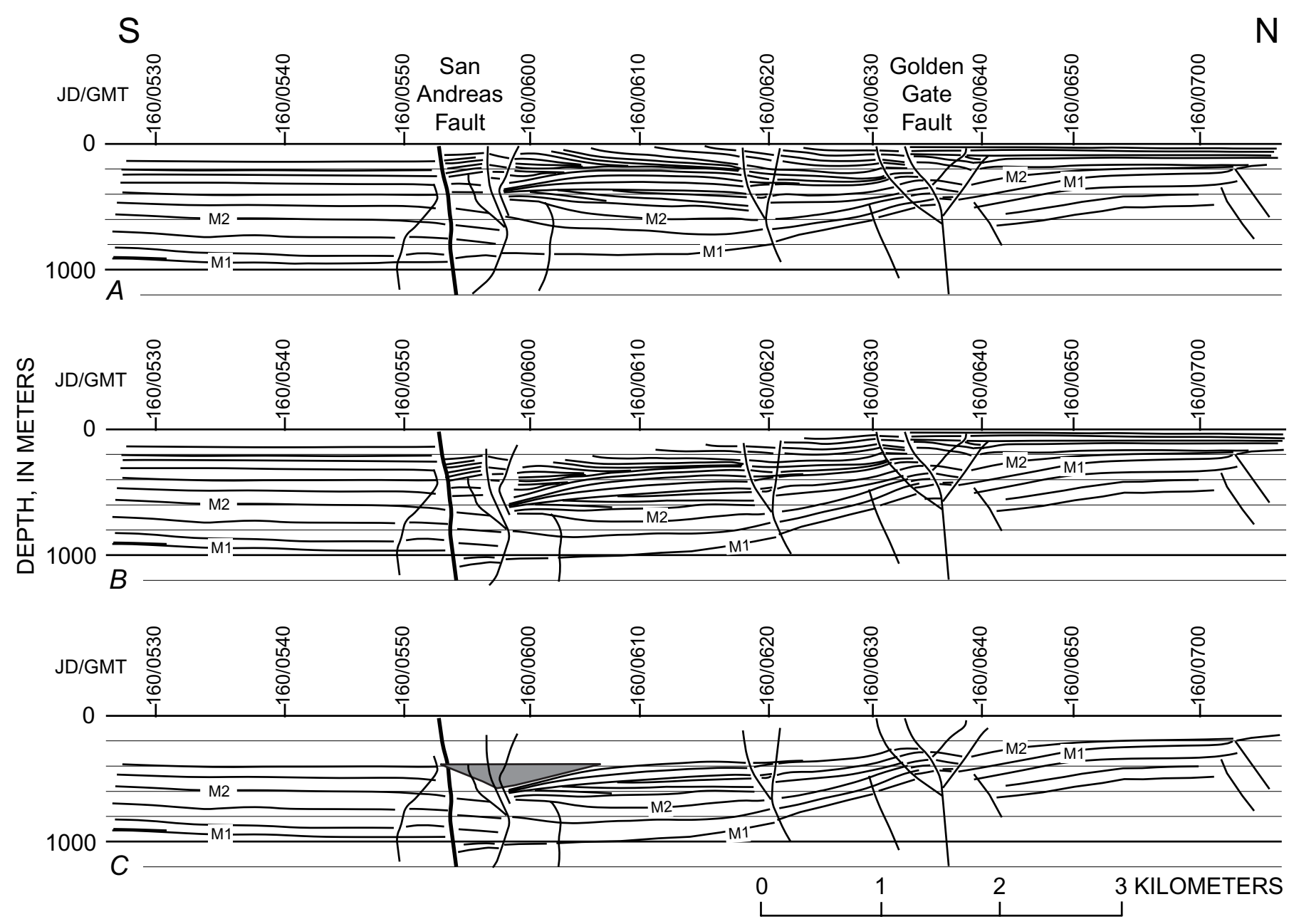

Figure 29.-Cross section along part of seismic line 151 across the Golden Gate and San Andreas Fault zones (see figs. 2, 3, 25). $A$, Cross section with two-way traveltime converted to depth by time-depth-conversion curve in figure 5 . Approximately true scale. $B$, Same cross section with upper-sequence beds flattened by rotating with a hingeline at the Golden Gate Fault and rotating downward about $200 \mathrm{~m}$ along the San Andreas Fault. $C$, Same cross section with flattened upper beds removed. Dipping beds at the San Andreas Fault have appearance of a channel or valley with about $200 \mathrm{~m}$ of relief (shaded triangular area) that was subsequently filled in and covered by about $400 \mathrm{~m}$ of flat-lying strata. Resulting cross section is now being uplifted along the San Andreas Fault as a popup structure. 
along the San Andreas and Golden Gate Faults, marked compressional deformation occurs locally. The Merced and Colma Formations have undergone recent extensive uplift, but within 3 to $4 \mathrm{~km}$ offshore, strata in the adjacent San Gregorio Basin are relatively undeformed and subsiding.

The seismic lines nearest shore show part of how this rapid change occurs. Three seismic lines approach within about $3 \mathrm{~km}$ of the onshore section (seismic lines 105/106 through a $90^{\circ}$ bend, seismic line 131 , and seismic line 151 , figs. 2, 3, 24, 25). These lines cross the faults offshore about $4 \mathrm{~km}$ north along the Golden Gate Fault and about $6 \mathrm{~km}$ north along the San Andreas Fault (figs. 2, 3). Two of these seismic lines $(131,151)$ are shown as depth sections at $1: 1$ scale in figures 28 and 29.

Onshore, as mapped in the coastal cliffs, the Merced Formation is deformed into a gentle monocline just south of the Golden Gate Fault (figs. 6, 7; Clifton and Hunter, 1987, 1991). All dips are northeastward, in contrast to westward dips offshore. Strata in the Merced Formation dip $8^{\circ}-14^{\circ}$ east of the Golden Gate Fault (north end of exposed section). Dips steepen to more than $50^{\circ}$ in the monocline off
Lake Merced, and then the section flattens to relatively gentle dips on the west side of the Golden Gate Fault (south of the fault in the coastal cliffs), finally steepening to $40^{\circ}-70^{\circ}$ on the east side of the San Andreas Fault (north of the fault in the coastal cliffs). No unequivocal Merced Formation rocks are exposed onshore south of the San Andreas Fault (that is, on the west side of the fault), according to Clifton and Hunter $(1987,1991)$. All dips are northeastward, and the monocline indicates relative east-side-down deformation across the Golden Gate Fault.

Offshore, the observed structure in the three closest seismic lines (figs. 2, 3, 28, 29) is similar to that in the onshore section. As onshore, a monocline is present just south of the Golden Gate Fault, indicating relative eastside-down deformation. Strata adjacent to the San Andreas Fault are tilted upward. Along each of these lines, a small anticlinal structure is present below a depth of about 0.2- to 0.3 -s two-way traveltime on the west side of and adjacent to the Golden Gate Fault. Along seismic line 151 (fig. 25), gentle doming is present in the youngest section adjacent to the San Andreas Fault. In contrast to onshore, however, the

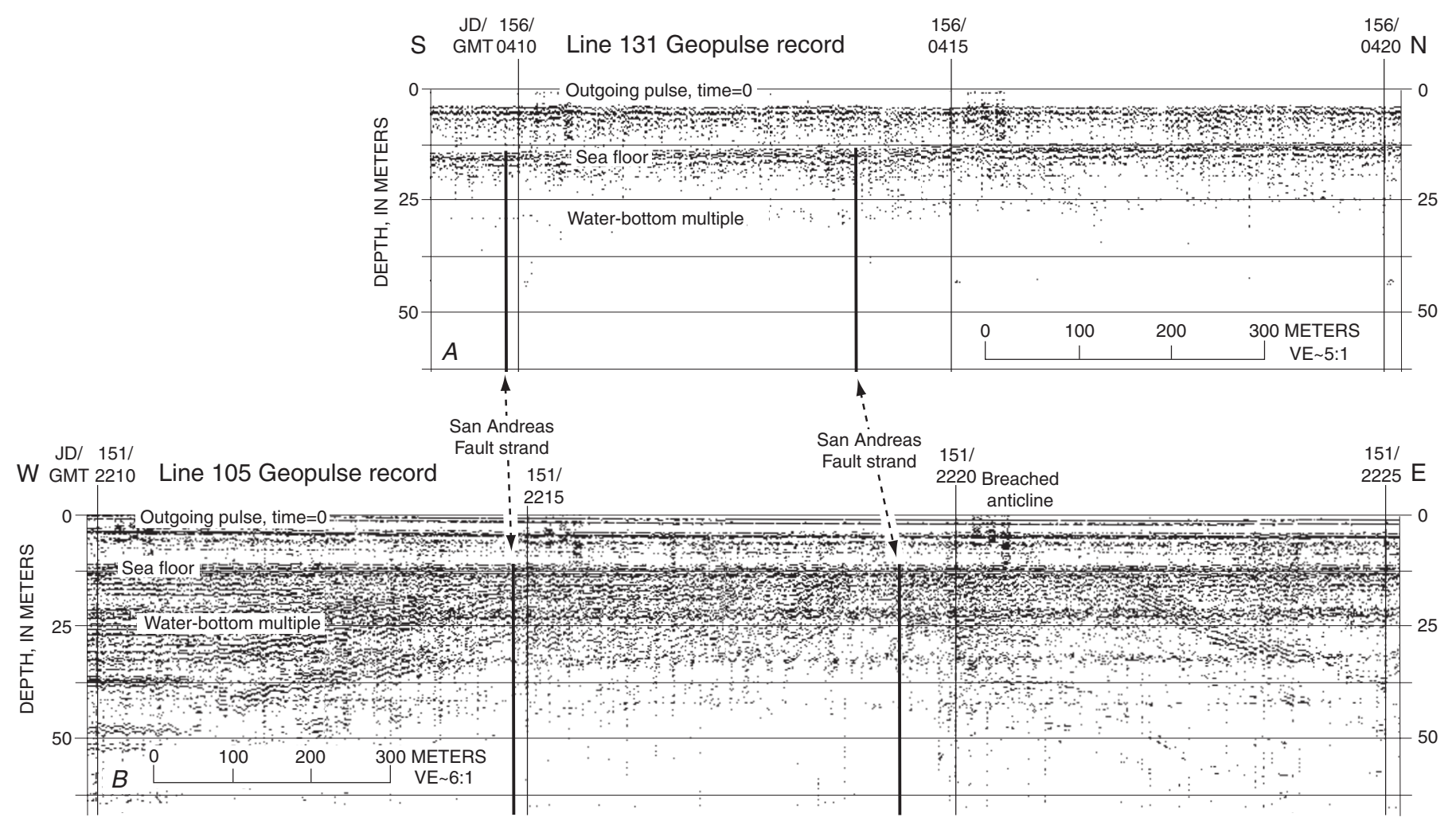

Figure 30.- Single-channel Geopulse profiles across nearshore part of the San Andreas Fault (see figs. 2, 3 for location). A, Part of Geopulse profile 131 (location shown on seismic line 131, fig. 24), showing strata dipping about $7^{\circ} \mathrm{N}$. just north of the San Andreas Fault. These dipping beds outcrop at sea floor, but neither faulting nor outcropping beds have an offset at sea floor. $B$, Part of profile 105, showing a young anticline just north of the San Andreas Fault, breached at sea floor. Again, neither faulting nor deformed beds disrupt sea floor. Profile crosses the San Andreas Fault in same place as seismic line 151 (fig. 25). On both profiles 131 and 105, even youngest beds are somewhat deformed, indicating ongoing compressional deformation. Absence of offset at sea floor is probably due to erosion of friable beds by intense current and wave action. 
steepest dips are all less than about $15^{\circ}$, as opposed to dips of $50^{\circ}-75^{\circ}$ onshore. Also, the dips are westward rather than eastward, indicating that an anticline is present between the shoreline and the seismic lines (fig. 11). The configuration of strata along the San Andreas Fault also is decidedly unusual, especially on seismic line 151 (figs. 25, 29), where downdipping, flat, and updipping reflectors overlie each other near the fault.

On Geopulse high-resolution seismic-reflection profiles through this area (fig. 30), faulting and compressional deformation extend to but do not disrupt the sea floor. On a single-channel Geopulse high-resolution profile along part of seismic line 131 (fig. 30A), strata dip north away from the eastern strand of the San Andreas Fault. Geopulse data along part of seismic line 105 (fig. 30B) show at least two fault strands, with an anticline present below the sea floor east of the fault. Deformation is clearly young and ongoing because even the youngest beds are tilted into the fault (for example, between JD/GMT 151/2215 and 151/2220). The absence of sea-floor offset is probably due to rapid erosion by currents and waves of unconsolidated to highly friable strata, similar to the strata immediately onshore in the Merced Formation.

By about $6 \mathrm{~km}$ north from shore along both the San Andreas and Golden Gate Fault strands, the structure changes markedly. Along seismic line 132 (fig. 23), dips are uniformly westward into the San Gregorio Basin, and the convoluted bedding observed on seismic line 151 (figs. 25, 29) along the San Andreas Fault has given way to strata that dip into the fault at a relatively gentle angle. Clearly, the tectonic regime is also now one of subsidence, rather than the uplift that characterizes the onshore Merced Formation and the strata shown on the nearshore lines.

A detailed look at the nearshore lines shows that the most likely cause of the observed deformation is rapid onshore and nearshore uplift along the San Andreas Fault, with a hingeline at the Golden Gate Fault. This uplift is most visible along seismic line 131 (figs. 24, 28). The San Andreas Fault cuts strata of the San Gregorio Basin, which are uplifted and truncated at the sea floor just north of the San Andreas Fault and then dip about $7^{\circ}$ N. for $2 \mathrm{~km}$. The strata flatten through the next $2 \mathrm{~km}$, then dip $14^{\circ}$ into the monocline over the next 500 to $1,000 \mathrm{~m}$. In figure 28 , the seismic-reflection data along seismic line 131 (fig. 28A) are converted to depth, with no vertical exaggeration (fig. 28B), so that a simple rotation can then give dips similar to those measured onshore in the Merced Formation (fig. 28C). If the section is rotated with a hingeline at the Golden Gate Fault and with upward motion on the San Andreas Fault, then dips can approach those seen onshore. For example, in figure $28 \mathrm{C}$, rotation by $20^{\circ}$ leads to dips of about $35^{\circ}$ in the tilted section. This uplift is recent, because virtually all units below 0.1-s two-way traveltime (less than 75-m depth) in the seismic-reflection data thicken into the fault zones, rather than thin, as would happen once uplift started.

The dipping beds near the San Andreas Fault can be restored to a generally horizontal position by simply rotating the uppermost section downward along the San Andreas
Fault, again with a hingeline on the Golden Gate Fault (figs. $28 D, 28 E$ ). The amount of rotation needed is then a measure of uplift along the fault. On this seismic line, the total amount of uplift along the San Andreas Fault is about $250 \mathrm{~m}$, and is clearly more for the deeper beds.

The geometry of the strata along seismic line 151 leads to the same conclusion of rotation and may explain the triangular configuration of strata on the north side of the fault (fig. 29). Here, the upper $300 \mathrm{~m}$ of strata (0.4 s) shows the deepest beds dipping about $7^{\circ}-10^{\circ}$ down, then merging upward with a generally flat lying reflector, overlain in turn by reflectors dipping about $7^{\circ}-10^{\circ}$ up. On this line, subsidence or depositional fill of a channel can explain the downdipping seismic reflectors. Downward rotation of the section along the San Andreas Fault by about $200 \mathrm{~m}$ flattens the uppermost reflectors (fig. 29B). If we then strip away the upper reflectors, we find that the downdipping reflectors form a channel or topographic low with about $200 \mathrm{~m}$ of relief (fig. 29C). If this topographic low is filled, followed by deposition and uplift, we obtain the reflection geometry of the strata observed in the seismic-reflection data. Thus, our interpretation is that along seismic line 151 (and seismic lines 105/106, which have a similar configuration), a topographic low was filled and then covered by about $400 \mathrm{~m}$ of strata, and the resulting package was uplifted and everted by rotation along the San Andreas Fault.

Another difference in the structure between onshore and offshore is that an anticline must be present nearshore. Rotation of the sedimentary section between the San Andreas and Golden Gate Faults can create the onshore structure seen in the cliff face, but both the cliff face and the seismic lines are close to being plungelines along an antiform that must be present nearshore. We were unable to acquire seismic lines near enough to shore to cross the axis of the presumed structure, and northward along the faults, the anticline may be absent because the deformation dies out.

Tilting and uplift may explain the onshore structure, but do not explain how the dominant subsidence of the San Gregorio basin observed elsewhere can convert to uplift in such a local domain. However, in the same area where motion along the San Andreas Fault steps over to the Golden Gate Fault, the tectonic pattern changes from subsidence to uplift and tilting. The section between the two faults is being squeezed upward by convergence between the two faults caused by different trends in the faults or by differing strengths of basement rocks on either side of the faults, as discussed below.

\section{Pilarcitos Fault}

Jachens and Zoback (1999) interpreted aeromagnetic data to indicate that the onshore Pilarcitos Fault continues on a trend of about N. $50^{\circ} \mathrm{W}$. into the offshore basement and may merge with the San Gregorio Fault (fig. 4). No deformation is observed in 300- to 400-m-thick strata in the San Gregorio Basin that overlie the magnetically determined trace of the 


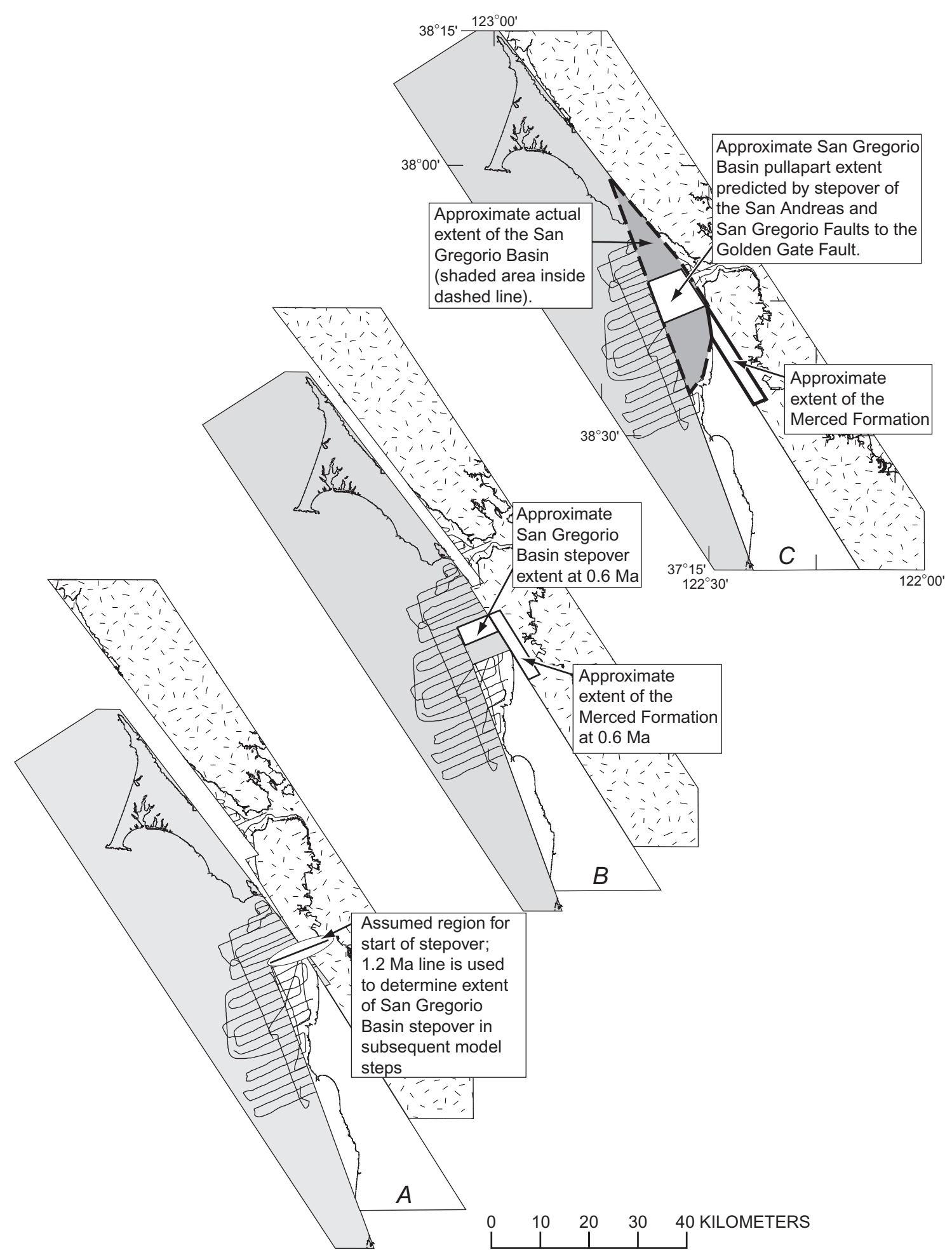

Figure 31.-Model for formation of the San Gregorio Basin as a transtensional strike-slip stepover basin, with all offset on the San Gregorio and San Andreas Faults transferring to the Golden Gate Fault. $A$, Initial position of the Pacific Plate, Pilarcitos block, and North American Plate at $1.2 \mathrm{Ma}$. Positions shown assume maximum offset of $22 \mathrm{~km}$ on the San Andreas Fault and an average slip rate of $18 \mathrm{~mm} / \mathrm{yr}$, giving an age of $1.2 \mathrm{Ma}$ when this offset started, and assume an average slip rate of about $6 \mathrm{~mm} / \mathrm{yr}$ on the San Gregorio Fault, giving about $8 \mathrm{~km}$ of offset over $1.2 \mathrm{Ma}$. $B$, Approximate position of blocks at $0.6 \mathrm{Ma}$. By that time, an 11-km-long, narrow pullapart basin has formed because of offset along the San Andreas Fault, and a 4-km-wide basin has formed as a result of motion along the San Gregorio Fault. $C$, Present, with a 22-km-long basin developed as a result of motion on the San Andreas Fault, and an 8-km-long basin as a result of San Gregorio motion. Area with maximum pullapart is in central part of the actual San Gregorio Basin; rest of basin's extent could be due to subsidence along north and south ends of pullapart basin. 
Pilarcitos Fault. These strata are in the upper part of the basin, indicating no substantial deformation along the Pilarcitos Fault trend during at least the late stage of basin deposition. We cannot prove that the fault has been inactive throughout the entire time the San Gregorio basin has formed, although we believe that this interpretation is likely on the basis of the absence of deformation anywhere along the magnetically defined offshore extension of the fault.

\section{San Pedro Fault}

A minor fault that cuts strata in the San Gregorio Basin begins near Point San Pedro and trends N. $15^{\circ}$ W. (fig. 3). In the seismic-reflection data, the fault has caused a slight vertical offset in strata just north of Point San Pedro (seismic lines 130/150, fig. 14), and deformation over the fault has created a small anticlinal structure a little farther north (seismic line 103, fig. 15). The fault extends into a major fold and fault at the base of the structural high in the western part of the San Gregorio Basin off Lake Merced (seismic line 110, fig. 16). Thus, at least locally, the fault controls basement-rock deformation, uplifting the horst-block anticline on the west and downdropping basement on the east beneath the basin depocenter. We herein informally name this fault the "San Pedro Fault." We cannot uniquely correlate this fault with an onshore fault. The San Pedro Fault cuts across the magnetically defined basement trends and is far from the magnetically mapped or inferred trace of the offshore Pilarcitos Fault (Jachens and Zoback, 1999; see Jachens and others, this volume), and so we do not believe that the San Pedro Fault is the offshore continuation of the Pilarcitos Fault.

\section{Discussion}

Previous studies (Hengesh and Wakabayashi, 1995; Wakabayashi and Hengesh, 1995, Jachens and Zoback, 1999; Zoback and others, 1999; see Jachens and others, this volume) concluded that strike-slip motion transfers from the San Andreas Fault to the Golden Gate Fault just offshore of Lake Merced and that this stepover led to the deposition of the Merced Formation along the San Francisco peninsula. These studies relied heavily on the observed eastward step of the San Andreas Fault rupture in the 1906 San Francisco earthquake from the Peninsular segment of the fault to the trace at Bolinas Lagoon, on magnetic anomalies that outline faults in basement units, and on the distribution of the onshore Merced Formation. So far, the stepover has been defined as occurring between the Peninsular segment of the San Andreas Fault and the Golden Gate Fault. With the additional details shown here in the structure of the San Gregorio Basin, we believe that a stepover also occurs as a result of the rapid transfer of motion from the San Gregorio Fault to the Golden Gate Fault.

The San Gregorio Basin formed by subsidence of basement rocks in an area bounded by the Golden Gate and San Gregorio Faults. Major basin subsidence began southwest of
Lake Merced, starting where the basement of the San Gregorio Basin dips steeply north. South of this area, a gently undulating basement subsides from sea level to about 500-m depth. North of this line, the basement drops into the 1,400$\mathrm{m}$-deep basin depocenter. The ending point of the basin is approximately defined by an east-west line about $10 \mathrm{~km}$ south of Bolinas Lagoon, where the basin depocenter ends and basin strata rapidly begin to rise toward Bolinas (figs. 1, 2). This north boundary is significantly less well known, because the quality of the seismic information is not as good in this part of the San Gregorio Basin as it is to the south. Between these two boundaries, the deepest part of the subsiding basin is about 15 to $18 \mathrm{~km}$ long and narrows northward from about 7.5 to about $5 \mathrm{~km}$ wide.

This part of the San Gregorio Basin began to develop as a half-graben hinged at the Golden Gate Fault, with maximum subsidence along the San Gregorio Fault. During deposition of the lower two-thirds of the section (pre-horizon M2), the basin maintained this half-graben architecture. Only minor vertical deformation is observed in the strata deposited during this initial depositional period, on the basis of depth reconstructions of the seismic-reflection data. Significant horizontal offset, particularly on the San Andreas Fault, does not seem likely but is not completely precluded, on the basis of the general continuity of seismic reflections across the fault in most of the San Gregorio Basin and on the absence of offset of basin contours along the fault. During deposition of the upper third of the section (post-horizon M2), differential subsidence of basement rocks began along the Potato Patch and offshore San Andreas Faults, which led to the formation of horst-and-graben structure within the basin. These faults may have initiated as strike-slip transfer faults that also began to step motion from the San Gregorio Fault over to the Golden Gate Fault.

The subsidence history of the San Gregorio Basin includes subsidence along and over all the major faults that bound or cut the basin. North of the area where the basin basement begins to dip steeply north, the San Gregorio structural zone begins to get buried. Even the San Gregorio Fault is covered by sediment that seems continuous across the fault. Presumably, if the San Gregorio Fault were still an active transform fault with from 4 to $10 \mathrm{~mm} / \mathrm{yr}$ of slip, it would remain a fundamental tectonic boundary with significant offset extending to the sea floor, as is visible on the southernmost seismic lines. Instead, the entire northern reach of the fault seems to be covered by only moderately disrupted sediment, and is mainly affected by subsidence.

Our interpretation is that the San Gregorio Basin formed as a result of a transtensional right stepover of motion from the San Gregorio Fault onto the Golden Gate Fault. The stepover may be accommodated by motion on the Potato Patch, San Andreas, and San Pedro Faults acting as strike-slip transfer faults. Motion on the San Gregorio Fault is rather slow; if this motion were partitioned onto the other faults, we might be unable to detect strike-slip motion from the basin structure but would see them as major areas of vertical deformation and subsidence. Other studies have concluded that a stepover 
occurs near Lake Merced (fig. 2), with motion transferring from the San Andreas to the Golden Gate Fault (Hengesh and Wakabayashi, 1995; Wakabayashi and Hengesh, 1995, Jachens and Zoback, 1999; Zoback and others, 1999; see Jachens and others, this volume), and so the concept is not original here; we extend this concept only to include motion on the San Gregorio Fault.

We can consider a relatively simple model (fig. 31) to gain insight into how the San Gregorio Basin and Merced Formation might have developed as a result of motions on both the San Andreas and San Gregorio Faults. Although the model does not explain the details of basin structure, it does show how movement of terranes along the fault has created the space needed for basin formation as pullapart basins. Variables for this model include fault-motion rates, the onshore extent of the San Gregorio Basin, and offset on the San Andreas Fault.

Initial deposition of the Merced Formation, opening of the San Gregorio Basin, initiation of motion on the Peninsular segment of the San Andreas Fault, and cessation of motion on the Pilarcitos Fault all began since about $3 \mathrm{Ma}$ and could have begun approximately contemporaneously. The timing of all these events is poorly constrained. Offset on the Peninsular segment is about $22 \mathrm{~km}$, based on correlating magnetic anomalies and source bodies across the fault (Jachens and Zoback, 1999; see Jachens and others, this volume). Suggested present-day offset rates range from 16 to $24 \mathrm{~mm} / \mathrm{yr}$ (Hall and others, 1999; Jachens and Zoback, 1999; Zoback and others, 1999; see Jachens and others, this volume), giving a date of from $2 \mathrm{Ma}$ to about $1 \mathrm{Ma}$ for offset along the Peninsular segment. Long-term slip rates of about 7 to $12 \mathrm{~mm} / \mathrm{yr}$ have been suggested by geologic studies (for example, Taylor and others, 1980) and could make offset as old as about 3 Ma. The age of the Merced Formation is poorly constrained from fossil dating but is most likely not much older than late Pliocene(?), about 1.8 m.y., and possibly younger (Clifton and Hunter, 1987, 1991). Subsidence of the San Gregorio Basin and motion on the Peninsular segment of the San Andreas Fault probably started no earlier than after the abandonment of the Pilarcitos Fault, inferred to be about 3 Ma by Parsons and Zoback (1997). Basin formation is presumably post-Pilarcitos motion and so is not affected by the Pilarcitos Fault.

For our model, we make the following assumptions. 1. Total offset on the Peninsular segment of the San Andreas Fault is $22 \mathrm{~km}$ (Jachens and Zoback, 1999; see Jachens and others, this volume). We arbitrarily chose a slip rate of $18 \mathrm{~mm} / \mathrm{yr}$ for the San Andreas Fault, within the range $16-24 \mathrm{~mm} / \mathrm{yr}$ discussed above, giving a period of $1.2 \mathrm{~m} . \mathrm{y}$. for the simple model with $22 \mathrm{~km}$ of total offset. A lower rate- that is, something close to the long-term slip rates of 7 to $12 \mathrm{~mm} / \mathrm{yr}$ - would give a period of from 1.8 to 3 m.y., possibly in better agreement with the abandonment of the Pilarcitos Fault and the oldest ages for the Merced Formation. Alternatively, we could use the 22-km offset and the estimated age of 1.8 m.y. for the Merced Formation to give a slip rate of about $12 \mathrm{~mm} / \mathrm{yr}$, similar to the long-term slip rate of 7 to $12 \mathrm{~mm} / \mathrm{yr}$. In any case, the main result of using different slip rates is to change the length of the stepover basin of the Merced Formation that formed between the Golden Gate and San Andreas Faults.

2. A reasonable slip rate for the San Gregorio Fault is 6 $\mathrm{mm} / \mathrm{yr}$ (Clark, 1998, 1999), which determines the alongstrike length of the modeled San Gregorio Basin caused by motion on the San Gregorio Fault. Again, as mentioned above, changes in slip rate and duration can lead to a longer or shorter basin. Slip rates could have been much higher when the Pilarcitos Fault was active and joined with the San Gregorio Basin, but here we are looking only at post-Pilarcitos motion.

3. The starting point for the stepover basin is at the south end of onshore outcrops of the Merced Formation. Variation in this starting position affects the final position of the modeled offshore depocenter of the San Gregorio Basin.

4. All motion on both the San Gregorio Fault and the Peninsular segment of the San Andreas Fault steps over to the Golden Gate Fault. This stepover occurs at the south end of the San Gregorio Basin, where the basement drops rapidly off into the basin depocenter (approximately corresponding to the area between the 400- and 1,000-m contour lines, fig. 11).

5. The San Gregorio Basin then forms as a transtensional right-stepping strike-slip basin as the margin segment north of the stepover is pulled northward with the Pacific Plate. Basin opening is at San Andreas Fault slip rates between the Golden Gate and San Andreas Faults, and at combined San Andreas and San Gregorio Fault slip rates west of the San Andreas Fault.

The model (fig. 31) shows two resulting basin segments defined by the faults. The first basin segment is a long, narrow basin of Merced Formation that forms between the San Andreas and Golden Gate Faults; the width of this basin is determined by the distance between the two faults, and its length is simply the total offset along the fault. The size and length of this narrow basin are nearly identical to what is actually observed onshore in the Merced Formation. The second basin segment is the San Gregorio Basin that forms between the San Gregorio and Golden Gate Faults; again, the width of this basin is determined by the distance between the faults, and its length, $8 \mathrm{~km}$, is determined by the total assumed offset along the San Gregorio Fault during the model period. This second basin segment closely matches the deepest part of the San Gregorio Basin. The shallow parts of the basin north and south of the modeled segment could be the subsiding basin margins. This simple model shows that motion on both the San Gregorio and San Andreas Faults is essential to correctly explain the actual extent of the San Gregorio and Merced Formations. The two basin segments result from motion on the San Gregorio Fault and the Peninsular segment of the San Andreas Faults stepping over to the Golden Gate Fault.

The simple model matches conditions necessary for deposition of the Merced Formation. The Merced Formation was adjacent to an open ocean during its deposition (Clifton and Hunter, 1987, 1991). In the model, the basin would 
always be open to the sea, because the uplifted (or uplifting) Point Reyes peninsula would always lie to the north of the developing basin. Also, the long, narrow finger of onshore Merced Formation would always be open to the ocean at its north end, as the basin grew northward with continuing motion along the San Andreas Fault. The Merced Formation could be deposited in a shingled basin (Sylvester, 1988), formed as the depositional area migrated northward with the pullapart line and left behind north-dipping strata. The Merced Formation can be used to test the pullapart model if sufficiently detailed age controls are obtainable, because the rocks at the south end of the basin should be older than those to the north. This relation is true where the stratigraphic sequence is observable in the sea cliffs, but should continue to be true at the south end of the Merced Formation.

Formation of the San Gregorio Basin has been accompanied by subsidence of the basement blocks beneath the basin and along the bounding faults, particularly the San Gregorio Fault. Earthquake seismicity (Zoback and others, 1999) and the structure of the San Gregorio Basin shown here clearly indicate that subsidence has been the dominant structural regime during basin formation. Motion on the San Gregorio Fault before the emergence of the stepover led to formation of the San Gregorio structural zone along the San Gregorio Fault; this structural zone is an inherited feature. The stepover onto the Golden Gate Fault would have isolated the block of material between the San Gregorio and Golden Gate Faults from transform motion on the faults to the south. This isolated block would be coupled to the Pacific Plate along the San Gregorio Fault and would move with the Pacific Plate with an eastern margin on the Golden Gate Fault (fig. 31). Decoupling of the block from transform motion would allow subsidence to occur both within this block and along and over the San Gregorio Fault and associated structural zone, thus leading to burial of the San Gregorio structural zone. Basically, everything north of the stepover line and west of the Golden Gate Fault lies in a subsiding tectonic environment.

Maximum subsidence in the center of the San Gregorio Basin is associated with the $8-\mathrm{km}$ pullapart necessary to accommodate the shift of motion from the San Gregorio Fault to the Golden Gate Fault. The basin itself, however, extends well beyond the central area—offshore contours show significant thicknesses of sediment extending about $15 \mathrm{~km}$ both northward and southward of the main basin depocenter (figs. $11,12)$. The total extension along the pullapart zone could be more than the $8 \mathrm{~km}$ shown in the simple model because slip rates were faster, because more time was available for motion to occur on the San Gregorio Fault, or because the basin began to form while the Pilarcitos Fault was still active. Alternatively, gentle subsidence of basement rocks occurred both north and south of the area of maximum subsidence in the stepover basin. In the San Gregorio Basin, at least, formation of the pullapart basin was accompanied by subsidence along the basin trend for distances both north and south of the pullapart zone of about twice the pullapart distance.

How is motion transferred to the Golden Gate Fault, and how does the pullapart basin begin and end? Obviously, the motion involved in stretching of the Earth's crust in a pullapart basin must be accommodated along active faults. Motion could be accommodated on a series of east-west normal faults that drop into the basin—but the few lines trending northsouth, though not particularly well located for seeing northsouth faults, do not show a series of such downdropping normal faults. More likely, fault motion was and is currently being taken up on the subsidiary faults that cross the basin and that may be acting as strike-slip transfer faults. We need more information on the age and offset on these faults to see the details of how motion is transferred from one side of the basin to the other.

A puzzle is the cause of the substantial uplift that has elevated rocks of the Merced Formation to more than 200 $\mathrm{m}$ above sea level onshore, with uplift occurring since deposition of the overlying Colma Formation. Offshore seismic data, in combination with the onshore structure of the Merced Formation in the seacliffs, indicate that the section between the Golden Gate and San Andreas Faults is being both uplifted and rotated upward on a hingeline on the Golden Gate Fault. Jachens and others (this volume) suggest that this uplift results from slight compression of the section between the converging San Andreas and Golden Gate Faults. Fault separation in the offshore area is about $3 \mathrm{~km}$, whereas onshore it decreases to $2 \mathrm{~km}$. Thus, material deposited between the faults is being sequentially squeezed from 3 to 2 $\mathrm{km}$ as the stepover between the San Andreas and Golden Gate Faults rolls northward.

This compression may also be due to the basement structure west of the San Andreas Fault. The uplift and compression are occurring in exactly the area occupied by the structurally high, coherent basement terrane that underlies the shallow basement rocks at the south end of the San Gregorio Basin. These coherent basement rocks are riding northward with the Pilarcitos block, possibly squeezing the Merced Formation to the east. Also, the San Andreas Fault dips about $70^{\circ}$ E. in this same area (see Jachens and others, this volume), and so the basement rocks would be slightly underthrusting the Merced Formation east of the San Andreas Fault. The combination of converging fault traces (as described by Jachens and others, this volume) and converging and underthrusting coherent basement terrane could lead to the observed uplift and tilting of the Merced Formation.

\section{Conclusions}

The San Andreas and San Gregorio Fault systems, far apart near Half Moon Bay, converge by Bolinas Lagoon. Within this zone lies the 2-km-deep San Gregorio Basin. The tectonic regime responsible for basin formation is a transtensional strike-slip stepover, in which motion from both the San Gregorio and San Andreas Faults steps eastward onto the Golden Gate Fault in the vicinity of Lake Merced. North of this stepover and west of the Golden Gate Fault, subsidence occurs in a pullapart basin, as the stepover zone moves passively northward with the Pacific Plate. Even as far north as 
Bolinas Lagoon, subsidence occurs between the major faults, creating a surface and near-surface graben from the Golden Gate to Bolinas Lagoon. Southward, however, between the San Andreas and Golden Gate Faults, local compressional deformation is squeezing up the onshore Merced Formation between the two faults, with maximum uplift along the San Andreas Fault and a hingeline on the Golden Gate Fault. At the north end of the fault system, adjacent to the active graben on the San Gregorio Basin block, rocks west of the San Gregorio Fault are being uplifted onto the Point Reyes peninsula, leading to significant compressional deformation.

Within this tectonic regime, the Golden Gate, San Andreas, and San Gregorio Faults all have recognizable fault continuations across the Gulf of the Farallones; but north of the stepover zone, both the San Andreas and San Gregorio Faults are characterized by normal faulting as basin blocks subside in the pullapart basin. The Potato Patch Fault branches eastward off the San Gregorio Fault and continues northward with significant, but unknown, offset. The San Gregorio structural zone, a zone of major thrust-fault deformation west of the San Gregorio Fault, also continues across the Gulf of the Farallones and widens from about 2 to more than $8 \mathrm{~km}$ from south to north; but this deformation is an inherited feature, originating to the south and now moving and subsiding with the Pacific Plate.

These active faults separate two major sedimentary basins: the San Gregorio Basin, which lies between the Golden Gate/San Andreas Faults and the San Gregorio Fault; and the Bodega Basin, which lies west of the San Gregorio Fault. Maximum sediment thickness in the San Gregorio Basin is poorly defined but probably approaches $2 \mathrm{~km}$ overlying basement rocks of the Franciscan and Salinia terranes. The basin most likely formed after motion on the Pilarcitos Fault ceased, or later than $3 \mathrm{Ma}$. The age of these strata could be similar to that of the onshore Merced Formation, also poorly dated but probably younger than about $1.8 \mathrm{~m}$.y. In the Bodega Basin, more than $800 \mathrm{~m}$ of Late Miocene and younger (less than about $6 \mathrm{Ma}$ ) strata overlies older sedimentary rocks (the Monterey Formation and older rocks).

North of about Pacifica (fig. 1), subsidence on the east side of the San Gregorio Fault is creating the San Gregorio Basin. The San Andreas Fault generally underlies the basin depocenter. The Potato Patch Fault, lying between the San Andreas and San Gregorio Faults, in part forms the edge of a structural high in the basin. These three faults are all at least partly normal faults along which basement rocks beneath the faults have undergone differential subsidence during basin formation. In the northern parts of the basin, strata appear to cross the fault virtually undisrupted. The Potato Patch, San Pedro, and San Andreas Faults could also be transfer faults, as strike-slip motion steps over from the San Gregorio to the Golden Gate Fault. Strike-slip motion could be small enough that we cannot interpret it in the available seismic-reflection data.

The stepover of motion on the San Gregorio Fault onto the Golden Gate Fault leads to the creation of a pullapart basin - the San Gregorio Basin. A simple model with this assumption places the maximum area of subsidence of the pullapart basin beneath the deepest part of the San Gregorio Basin.

\section{Acknowledgments}

This report greatly benefited from discussions, comments, and reviews by Michael Marlow, Robert Jachens, Ed Clifton, Robert McLaughlin, Joe Clark, and John Wakabayashi. We thank Larry Kooker, Pat Hart, Ray Sliter, Dennis Mann, Fred Payne, Hal Williams, and Stephen Bruns for their help in acquiring the data, and Dave Hogg, Mike Boyle, Kevin O'Toole, Walt Olson, Susan Hunt, John Gann, Jon Childs, and Stephen Wallace for the logistical support needed to run the cruise.

\section{References Cited}

Blake, M.C., Jr., 1984, Franciscan geology of northern California: Los Angeles, Society of Economic Paleontologists and Mineralogists, Pacific Section Field Trip Guidebook, v. 43, 254 p.

Bortugno, E.J., McJunkin, R.D., and Wagner, D.L., 1992, Map showing recency of faulting, San Francisco-San Jose quadrangle, California: California Division of Mines and Geology Regional Geologic Map Series Map 51, sheet 5, scale 1:250,000.

Brabb, E.E., Graymer, R.W., and Jones, D.L., 1998, Geology of the onshore part of San Mateo County, California; a digital database: U.S. Geological Survey Open-File Report 98-137, 9 p.

Brabb, E.E., and Pampeyan, E.H., compilers, 1983, Geologic map of San Mateo County, California: U.S. Geological Survey Miscellaneous Investigations Series Map I-1257-A, scale 1:62,500.

Bruns, T.R., Carlson, P.R., and Cooper, A.K., 1996, Structure of the submerged San Andreas and San Gregorio fault zones off San Francisco, CA, from high resolution seismic reflection data [abs.]: Eos (American Geophysical Union Transactions), v. 77, no. 46, supp., p. F742.

Bruns, T.R., Carlson, P.R., Mann, D.M., and Cooper, A.K., 1995, High resolution seismic reflection survey of the San Andreas Fault zone in the Gulf of the Farallones, offshore San Francisco, CA [abs.]: Eos (American Geophysical Union Transactions), v. 76, no. 46, supp., p. F397-F398.

Childs, J.R., Hart, P.E., Bruns, T.R., Marlow, M.S., and Sliter, Ray, 2000, High resolution marine seismic-reflection data from the San Francisco Bay area: U.S. Geological Survey Open-File Report 00-494 [URL: http://geopubs.wr.usgs.gov/open-file/of00-494/].

Clark, J.C., 1998, Neotectonics of the San Gregorio Fault zone; age dating controls on offset history and slip rates [abs.]: American Association of Petroleum Geologists Bulletin, v. 82, no. 5A, p. 844-845.

1999, San Gregorio Fault zone; progress and problems [abs.]: American Association of Petroleum Geologists Bulletin, v. 83, no. 4, p. 684.

Clark, J.C., and Brabb, E.E., 1997, Geology of the Point Reyes National Seashore and vicinity, Marin County, California; a digital database: U.S. Geological Survey Open-File Report 97-456, 8 p.

Clark, J.C., Brabb, E.E., Greene, H.G., and Ross, D.C., 1984, Geology of Point Reyes peninsula and implications for San Gregorio Fault history, in Crouch, J.K., and Bachman, S.B., eds., Tectonics and sedimentation along the California margin: Los Angeles, 
Society of Economic Paleontologists and Mineralogists,

Pacific Section Field Trip Guidebook, v. 38, p. 67-86.

Clark, J.C., Wahrhaftig, Clyde, and Brabb, E.E., 1991, San Francisco

to Point Reyes; both sides of the San Andreas Fault, in Sloan,

Doris, and Wagner, D.L., eds., 1991, Geologic excursions in

northern California; San Francisco to the Sierra Nevada: California Division of Mines and Geology Special Publication 109, p. 11-24.

Clifton, H.E., and Hunter, R.E., 1987, The Merced Formation and related beds; a mile-thick succession of late Cenozoic coastal and shelf deposits in the seacliffs of San Francisco, CA, in Hill, M.L., ed., Centennial field guide: Boulder, Colo., Geological Society of America, Cordilleran Section, v. 1, p. 257-262. 1991, Depositional and other features of the Merced Formation in sea cliff exposures south of San Francisco, CA, in Sloan, Doris, and Wagner, D.L., eds., 1991, Geologic excursions in northern California; San Francisco to the Sierra Nevada: California Division of Mines and Geology Special Publication 109, p. 35-44.

Clifton, H.E., Hunter, R.E., and Gardner, J.V., 1988, Analysis of eustatic, tectonic and sedimentologic influences on transgressive and regressive cycles in the late Cenozoic Merced Formation, San Francisco, California, in Paola, Chris, and Kleinspehn, K.L., eds., New Perspectives in Basin Analysis: New York, SpringerVerlag, p. 109-128.

Cooper, A.K., 1973, Structure of the continental shelf west of San Francisco, California: U.S. Geological Survey Open-File Report $1907,65 \mathrm{p}$.

Galloway, A.J., 1977, Geology of the Point Reyes peninsula, Marin County, California: California Division of Mines and Geology Bulletin 202, $72 \mathrm{p}$.

Gann, J.T., 1992, YoNav; your own integrated navigation system for DOS platforms: U.S. Geological Survey Open-File Report 92-565, $62 \mathrm{p}$.

Glen, William, 1959, Pliocene and lower Pleistocene of the western part of the San Francisco Peninsula: University of California Publications in Geological Science, v. 36, no. 2, p. 147-197.

Griscom, Andrew, and Jachens, R.C., 1990, Crustal and lithospheric structure from gravity and magnetic studies, chap. 9 of Wallace, R.E., ed., The San Andreas fault system, California: U.S. Geological Survey Professional Paper 1515, p. 239-259.

Hall, N.T., 1966, Late Cenozoic stratigraphy between Mussel Rock and Fleishhacker Zoo, San Francisco peninsula: California Division of Mines and Geology, Mineral Information Service, v. 19, no. 11, p. S22-S25.

Hall, N.T., Wright, R.H., and Clahan, K.B., 1999, Paleoseismic studies of the San Francisco Peninsula segment of the San Andreas fault zone near Woodside, California: Journal of Geophysical Research, v. 104, no. B10, p. 23215-23236.

Hengesh, J.V., and Wakabayashi, John, 1995, Dextral translation and progressive emergence of the Pleistocene Merced basin and implications for timing of initiation of the San Francisco peninsula segment of the San Andreas Fault, in Sangines, E.M., Andersen, D.W., and Buising, A.B., eds., Recent geologic studies in the San Francisco Bay Area: Society of Economic Paleontologists and Mineralogists, Pacific Section Field Trip Guidebook, v. 76, p. 47-53.

Holbrook, W.S., Brocher, T.M., ten Brink, U.S., and Hole, J.A., 1996, Crustal structure of a transform plate boundary; San Francisco Bay and the Central California continental margin: Journal of Geophysical Research, v. 101, no. B10, p. 22311-22334.

Hole, J.A., Holbrook, W.S., Klemperer, S.L., Ten Brink, U.S., and
Brocher, T.M., 1993, Crustal structure in the San Francisco Bay area from wide-angle seismic refraction data [abs.]: Eos (American Geophysical Union Transactions), v. 74, no. 43, supp., p. 445.

Hoskins, E.G., and Griffiths, J.R., 1971, Hydrocarbon potential of northern and central California offshore, in Future petroleum provinces of the United States; their geology and potential: American Association of Petroleum Geologists Memoir 15, v. 1, p. 212-228.

Jachens, R.C., Wentworth, C.M., and McLaughlin, R.J., 1999, Pre-San Andreas location of the Gualala block inferred from magnetic and gravity anomalies, in Elder, W.P., ed., 1998, Geology and tectonics of the Gualala Block, northern California: Society of Economic Paleontologists and Mineralogists, Pacific Section Field Trip Guidebook, v. 84, p. 27-64.

Jachens, R.C., and Zoback, M.L., 1999, The San Andreas Fault in the San Francisco Bay region, California; structure and kinematics of a young plate boundary: International Geology Review, v. 41, no. 3, p. 191-205.

Lanphere, M.A., Champion, D.E., Clynne, M.A., and Muffler, L.J.P., 1999, Revised age of the Rockland Tephra, Northern California; implications for climate and stratigraphic reconstructions in the western United States: Geology, v. 27, no. 2, p. 135-138.

Lettis, W.R., 1999, The San Gregorio/Hosgri fault system, California-an evaluation of the style and range of Quaternary deformation [abs.]: American Association of Petroleum Geologists Bulletin, v. 83, no. 4, p. 693-694.

McCulloch, D.S., 1987, Regional geology and hydrocarbon potential of offshore central California, in Scholl, D.W., Grantz, Arthur, and Vedder, J.G., Geology and resource potential of the continental margin of western North America and adjacent ocean basins-Beaufort Sea to Baja California (Earth Science Series, v. 6): Houston, Tex., Circum-Pacific Council for Energy and Mineral Resources, p. 353-401.

1989, Evolution of the offshore central California margin, in Winterer, E.L., Hussong, D.M., and Decker, R.W., eds., The eastern Pacific Ocean and Hawaii, v. 5 of The geology of North America: Boulder, Colo., Geological Society of America, p. 439-447.

McLaughlin, R.J., Sliter, W.V., Sorg, D.H., Russell, P.C., and SarnaWojcicki, A.M., 1996, Large-scale right-slip displacement on the East San Francisco Bay Region fault system, California; implications for location of late Miocene to Pliocene Pacific plate boundary: Tectonics, v. 15, no. 1, p. 1-18.

Niemi, T.M., and Hall, H.T., 1992, Late Holocene slip rate and recurrence of great earthquakes on the San Andreas Fault in northern California: Geology, v. 20, no. 3, p. 195-198.

Noller, J.S., Kelson, K.I., Lettis, W.R., Wickens, K.A., Simpson, G.D., Lightfoot, Kent, and Wake, T., 1993, Preliminary characterization of Holocene activity on the San Andreas Fault based on offset archaeologic sites, Ft. Ross State Historic Park, California: final technical report for U.S. Geological Survey, National Earthquake Hazard Reduction Program, $16 \mathrm{p}$.

Page, B.M., 1990, Evolution and complexities of the transform system in California, U.S.A.: Annales Tectonicae, v. 4, no. 2, p. 53-69. -1992, Tectonic setting of the San Francisco Bay Region [abs.], in Galehouse, J.S., ed., Conference on Earthquake Hazards in the Eastern San Francisco Bay Area, 2d, Hayward, Calif., 1992, Programs and Abstracts: California Division of Mines and Geology Special Publication 113, p. 53.

Parsons, T.E., and Zoback, M.L., 1997, Three-dimensional upper crustal velocity structure beneath San Francisco Peninsula, 
California: Journal of Geophysical Research, v. 102, no. B3, p. 5473-5490.

Ross, D.C., 1978, The Salinian Block; a Mesozoic granite orphan in the California Coast Range, in Howell, D.G., and McDougall, K.A., eds., Mesozoic paleogeography of the United States (Pacific Coast Paleogeographic Symposium 2): Los Angeles, Society of Economic Paleontologists and Mineralogists, Pacific Section, p. 509-522.

Sarna-Wojcicki, A.M., Meyer, C.E., Bowman, H.R., Hall, N.T., Russell, P.C., Woodward, J.J., and Slate, J.L., 1985, Correlation of the Rockland ash bed, a 400,000-year old stratigraphic marker in northern California and western Nevada, and implications for middle Pleistocene paleogeography of central California: Quaternary Research, v. 23, no. 2, p. 236-257.

Sedlock, R.L., 1999, The San Gregorio Fault zone; late Cenozoic dextral slip and slip rate, and southward linkage with the Sur, San Simeon, and Hosgri Faults [abs.]: American Association of Petroleum Geologists Bulletin, v. 83, no. 4, p. 701.

Simpson, G.D., Thompson, S.C., Noller, J.S., and Lettis, W.R., 1997, The northern San Gregorio Fault zone; evidence for the timing of late Holocene earthquakes near Seal Cove, California: Seismological Society of America Bulletin, v. 87, no. 5, p. 1158-1170.

Sylvester, A.G., 1988, Strike-slip faults: Geological Society of America Bulletin, v. 100, no. 11, p. 1666-1703.

Taylor, C.L., Cummings, J.C., and Ridley, A.P., 1980, Discontinuous en echelon faulting and ground warping, Portola Valley, California, in Streitz, Robert, and Sherburne, R.W., eds., Studies of the San Andreas fault zone in northern California: California Division of Mines and Geology Special Report 140, p. 59-70.

Wakabayashi, John, 1999, Distribution of displacement on and evolution of a young transform fault system; the northern San Andreas Fault system, California: Tectonics, v. 18, no. 6, p. 1245-1274.

Wakabayashi, John, and Hengesh, J.V., 1995, Distribution of late Cenozoic displacement on the San Andreas fault system, northern California, in Sangines, E.M., Andersen, D.W., and Buising, A.B., eds., Recent geologic studies in the San Francisco Bay Area: Society of Economic Paleontologists and Mineralogists, Pacific Section Field Trip Guidebook, v. 76, p. 19-29.

Weber, G.E., Nolan, J.M., and Zinn, E.N., 1999, Late Quaternary slip across the San Gregorio Fault zone, San Mateo County, California; estimates from marine terrace offsets [abs.]: American Association of Petroleum Geologists Bulletin, v. 83, no. 4, p. 705.

Working Group on California Earthquake Probabilities, 1999, Earthquake probabilities in the San Francisco Bay region: 2000 to 2030 — a summary of findings: U.S. Geological Survey OpenFile Report 99-517, 60 p.

Zoback, M.L., Jachens, R.C., and Olson, J.A., 1999, Abrupt alongstrike change in tectonic style; San Andreas Fault zone, San Francisco Peninsula: Journal of Geophysical Research, v. 104, no. B5, p. 10719-10742. 



\title{
A Review of Faults and Crustal Structure in the San Francisco Bay Area as Revealed by Seismic Studies: 1991-97
}

\author{
By Tom Parsons, Jill McCarthy, Patrick E. Hart, John A. Hole, Jon Childs, David H. Oppenheimer, \\ and Mary Lou Zoback
}

\section{CONTENTS}

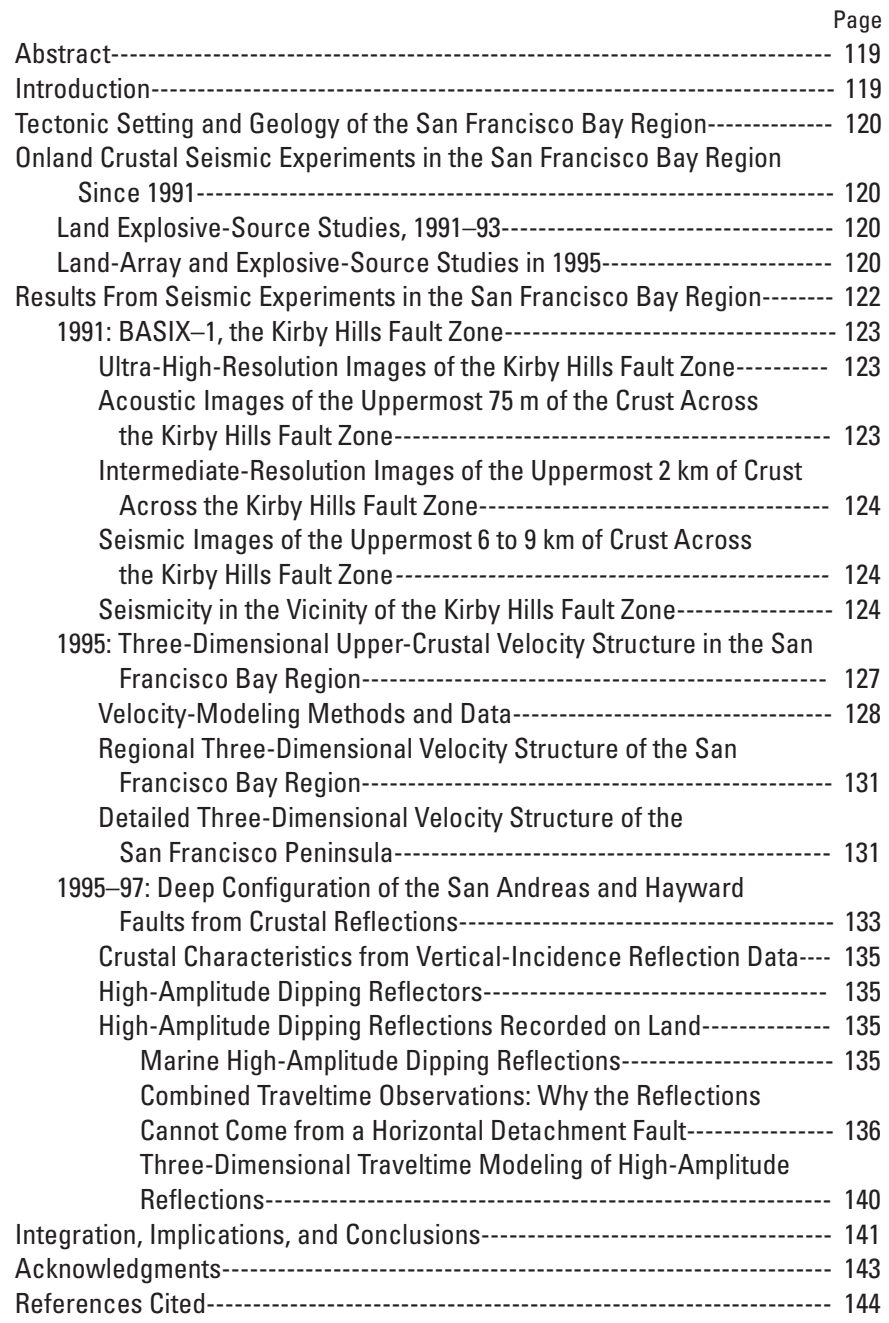

\section{Abstract}

This report summarizes and integrates the results from various seismic experiments conducted in the San Francisco Bay region. Three marine deep seismic-reflection surveys, two local-earthquake tomography studies, and multiple, focused high-resolution seismic-reflection experiments were aimed at resolving the structure of the strike-slip faults in the Pacific-North American Plate boundary zone. The primary conclusion from these studies is that the major strike-slip faults in the bay region cut through the entire crust at high angles $\left(60^{\circ}-80^{\circ}\right)$. This conclusion implies that horizontal shear in the midcrust or lower crust plays a minimal role in accommodating the right-lateral strain that was proposed in several tectonic models. Among the major faults in the San Francisco Bay region, throughgoing faults identified by marine data are the Kirby Hills Fault in the eastern San Francisco Bay region (dipping $\sim 80^{\circ} \mathrm{NE}$. in the lower crust), the Hayward Fault (dipping $\sim 70^{\circ} \mathrm{SW}$. in the lower crust), and the San Andreas Fault (dipping $\sim 60^{\circ} \mathrm{NE}$. in the lower crust). Strong lateral seismic-velocity contrasts across major rightlateral strike-slip faults are revealed by a three-dimensional tomography model in much of the upper crust to midcrust of the San Francisco Bay region. These cross fault velocity contrasts affect determinations of earthquake focal mechanisms, hypocenter locations, and simulated strong ground motion because seismic energy can be refracted laterally along such velocity boundaries. Localized tomography on the San Francisco peninsula indicates that the Pilarcitos Fault, paralleling the San Andreas Fault, is high angle and thus probably not an active thrust fault, as has been proposed. Most high-amplitude reflections in the lower crust are now recognized as reflecting from the dipping Hayward and San Andreas Faults. When these dipping reflections are accounted for, the remaining reflective texture of the lower crust is weak and highly discontinuous.

\section{Introduction}

Between 1991 and 1998, the U.S. Geological Survey (USGS) operated a project designed to augment earthquakehazard studies in urban central California by focusing on earthquake sources and ground response at submerged and coastal sites. This report summarizes efforts within this project to identify and map fault structures by using seismic techniques. When the project was initiated, there was vigorous debate whether the major right-lateral faults connected to a low-angle detachment fault below seismogenic depths. Various proposals suggested that this low-angle detachment fault linked strain between the vertical strike-slip faults. Thus, 
much of the initial focus of active-source marine seismic-data acquisition was aimed at resolving deep crustal structure. As the project matured, the goals of the USGS moved somewhat away from basic science toward more applied studies, and seismic projects began to be directed at shallow structure and specific faults. Here, we summarize and integrate most of the results from active- and passive-source seismic studies in the San Francisco Bay area conducted by, or in association with, the USGS and summarize what was learned about some of the major fault zones and associated crustal structures. Additional studies were conducted on the Golden Gate platform by Bruns and others (this volume), and Hart and others (this volume) discuss all the marine seismic data acquisition in the San Francisco Bay area by the USGS between 1991 and 1998.

\section{Tectonic Setting and Geology of the San Francisco Bay Region}

The San Francisco Bay region occupies a broad part of the San Andreas Fault system; the San Andreas Fault splays from a single fault just south of the region into several segments that cross east and west of the bay. A complex pattern of bending strike-slip faults and related accommodating thrust and normal faults is arrayed across the bay region; many of these faults pose a significant seismic hazard as evidenced by the $M=7.11989$ Loma Prieta, $M=7.71906$ San Francisco (Thatcher, 1975), and M 6.8 1868 Hayward (Bakun, 1999) earthquakes. Right-lateral shear takes place on several subparallel strike-slip faults (fig. 1), such as the San Andreas, Hayward, and Calaveras Faults, which together accommodate about $4 \mathrm{~cm} / \mathrm{yr}$ of relative motion between the Pacific and North American Plates (for example, DeMets and others, 1990; Lisowski and others, 1991; Kelson and others, 1992). The San Andreas Fault on the San Francisco peninsula is a relatively young feature that initiated about 3.3-1.3 Ma and has undergone $\sim 23 \mathrm{~km}$ of right-lateral offset (Cummings, 1968; Addicott, 1969; Taylor and others, 1980; Hall, 1984, Hall and Wright, 1993; Hall and others, 1996). Faults east of San Francisco Bay (that is, the Calaveras and Hayward Faults) have cumulatively accommodated as much as 160 to $170 \mathrm{~km}$ of right-lateral strain (for example, McLaughlin and others, 1996)

Like much of coastal California, the San Francisco Bay region is underlain primarily by the Late Mesozoic/Early Tertiary Franciscan Complex of accreted origin, an assemblage that contains fragments of oceanic crust, pelagic sedimentary rocks, and continental sandstone and shale mixed together in a melange in some places and occurring as coherent units in others (Page, 1992). These rocks were emplaced during the long-term phase of oblique to head-on subduction that occurred along the California margin, and many were subsequently translated along the coast during oblique subduction and when strike-slip motion supplanted subduction during Tertiary time (Blake, 1984). In general, Cretaceous granite of the Salinia terrane is exposed west of the San Andreas Fault (fig. 1; see Ross, 1978), although the Pilarcitos Fault marks that boundary on the San Francisco peninsula.
Regionally, earthquakes are observed at $\sim 0$ - to $15-\mathrm{km}$ depth (Hill and others, 1990), and their distribution indicates that the major strike-slip faults are near vertical in the seismogenic crust. Beneath about 15- to 20-km depth, the major strike-slip faults of the San Francisco Bay region may strain aseismically (Olson and Lindh, 1985; Dewey and others, 1989; Hill and others, 1990; Lisowski and others, 1991; Olson and Zoback, 1992). The absence of earthquake hypocenters beneath that depth has left many unresolved questions about the relations among the steeply dipping right-lateral transform faults that make up the San Andreas Fault zone in the San Francisco Bay region (fig. 1) within the ductile regime. Various tectonic models for plate interactions in the bay region (for example, Furlong and others, 1989; Furlong, 1993; Page and Brocher, 1993; Brocher and others, 1994; Jones and others, 1994; Bohannon and Parsons, 1995) suggest that horizontal shear in the deep crust drives or, at least, accommodates the strain expressed at the surface. Many researchers have proposed that a low-angle detachment fault between 15and 20-km depth could link slip between the San Andreas and Hayward Faults (fig. 2; see Furlong, 1993; Brocher and others, 1994; Bürgmann, 1997).

\section{Onland Crustal Seismic Experiments in the San Francisco Bay Region Since 1991}

We briefly summarize seismic-data acquisition conducted on land since 1991. Marine acquisition, including the Bay Area Seismic Imaging eXperiment (BASIX) studies, during this period is discussed by Hart and others (this volume).

\section{Land Explosive-Source Studies, 1991-93}

In 1991 and 1993, chemical explosions were detonated along the San Andreas, Calaveras, and Hayward Faults to study the rupture zone of the $M=7.11989$ Loma Prieta, Calif., earthquake and to measure seismic travelpaths through the crust (Catchings and Kohler, 1996). Six explosive sources and about 200 recorders were used to construct a velocity model of the crust along the San Francisco peninsula. Key observations were that the crust thins significantly from about $30 \mathrm{~km}$ near Loma Prieta to about $22 \mathrm{~km}$ beneath San Francisco and that earthquake shaking in San Francisco caused by the 1989 earthquake may have been augmented by reflected energy from the Moho (Catchings and Kohler, 1996).

\section{Land-Array and Explosive-Source Studies in 1995}

Beginning in January 1995, 31 Reftek seismographs were installed in an array spanning the San Francisco peninsula and the San Andreas and Pilarcitos Faults (fig. 3; see Parsons and Zoback, 1997; Parsons, 1998). The instruments were spaced 
about 1 to $3 \mathrm{~km}$ apart in any given direction and recorded continuously for 6 months. Most of the 23 seismometers were short-period $(4.5 \mathrm{~Hz})$ three-component sensors, 7 were intermediate-period $(1 \mathrm{~Hz})$ three-component sensors, and 1 was a downhole broadband sensor. These instruments each recorded an average of 105 local earthquakes $(M=1.0-3.0)$ from January through July 1995. In April 1995, marine airgun sources were recorded (for a complete description of the marine experiments, see Hart and others, this volume). In June 1995, 11 chemical explosions $(125-500 \mathrm{~kg})$ were detonated inside and outside the network (fig. 3). The explosive sources were recorded both on the 31 Reftek seismographs and on 183 Seismic Group Recorders (SGRs) that were deployed along a southwest-to-northeast line across the Pilarcitos and San Andreas Faults (fig. 3). The SGRs were deployed at 50-m spacing in a fixed array that recorded 7 inline shots spaced between 1 and $5 \mathrm{~km}$ apart and 4 fanshots located 5 to $20 \mathrm{~km}$ both north and south of the recording profile. The closely spaced SGRs enabled us to generate a higher resolution twodimensional velocity model of the uppermost $2 \mathrm{~km}$ of crust across the Pilarcitos Fault and to observe high-amplitude reflections from deep in the crust.

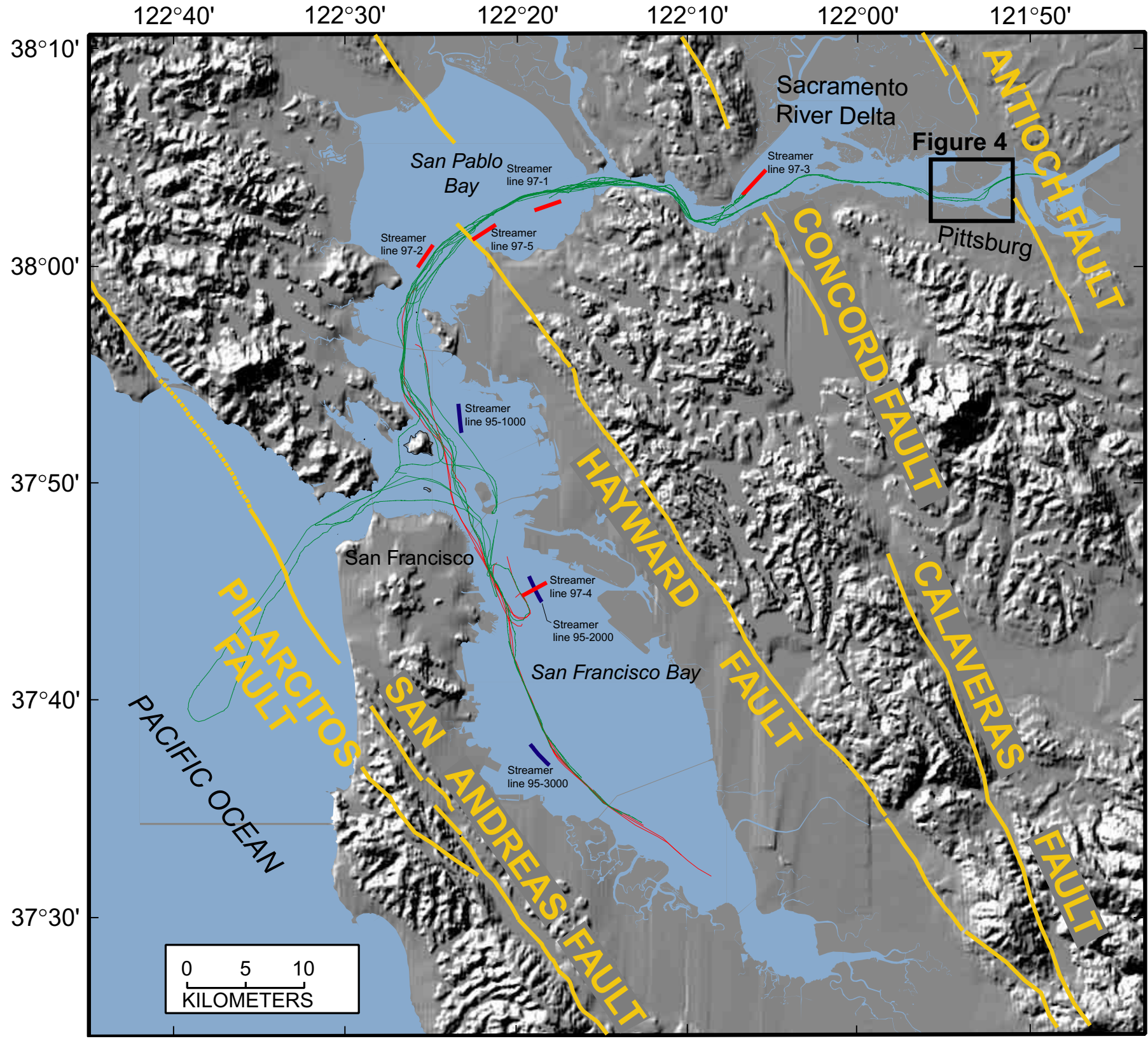

Figure 1.-San Francisco Bay region, showing locations of major faults and seismic-reflection profiles. Large airgun sources were deployed along green lines, and receiver cables as shown by short red and blue lines. In addition, many higher-resolution seismic-reflection profiles were gathered throughout the region. 


\section{Results from Seismic Experiments in the San Francisco Bay Region}

Here, we summarize our enhanced view into the crust of the San Francisco Bay region as provided by several imaging techniques. We present previously unpublished studies and expanded discussion, integration, and support of some published results. Much of the investigation and imaging was concentrated on active faults, either on their structure in the seismogenic zone ( $3-15-\mathrm{km}$ depth) or on their relations and connectivity in the lower crust beneath seismogenic depths. Some higher-resolution, shallower data were acquired for previously unknown or poorly known faults. We present the studies and principal results in chronological order, followed by a discussion and integration of the results.
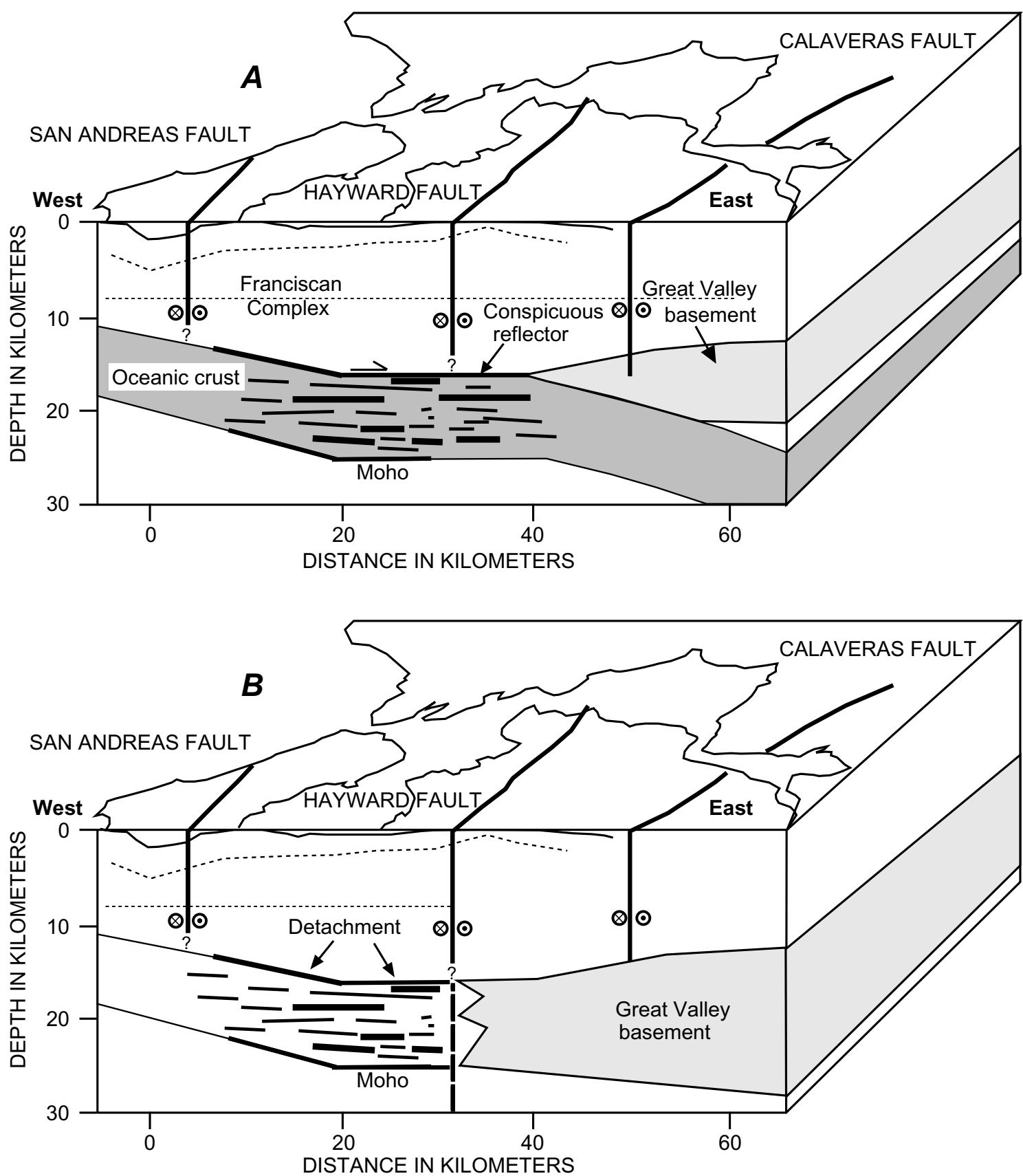

Figure 2.-Block diagrams of the San Francisco Bay region (fig. 1), illustrating two candidate models for deep configuration of bay-region faults. Either faults $(A)$ persist to midcrustal depths where, at base of seismicity, they terminate into a low-angle or detachment fault (for example Furlong and others, 1989; Furlong, 1993; Page and Brocher, 1993; Brocher and others, 1994; Jones and others, 1994); or (B) they cut through whole crust. 


\section{1: BASIX-1, the Kirby Hills Fault Zone}

Marine seismic-reflection data acquisition in San Francisco Bay poses severe challenges because of the shallow water depth, strong currents, and heavy shipping traffic. Not all of these problems were overcome during the first experiment in 1991, and data quality was poor in many places. However, east of San Francisco Bay in the Sacramento River delta (fig. 1), good-quality data were acquired and processed that confirmed the existence of the Kirby Hills Fault zone, which, along with the Antioch Fault, represents the easternmost segment of the San Andreas Fault system at the latitude of the Sacramento River. This feature is a reactivated struc-

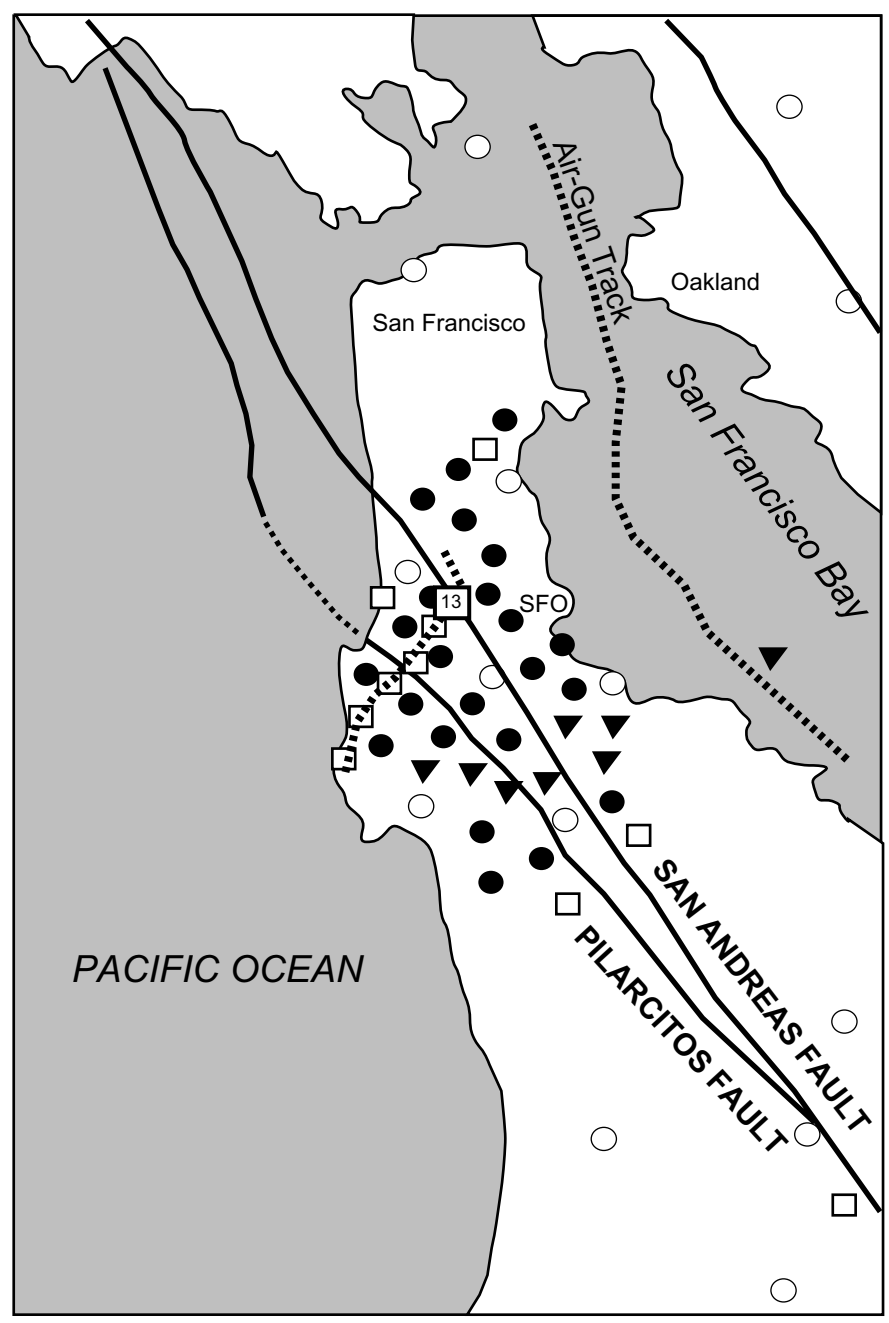

Figure 3.-Sketch map of the San Francisco Bay region (fig. 1), showing location of land-based San Francisco peninsula seismic experiment. Dots and triangles, stations in temporary (6 month) seismic network; circles, permanent stations in the Northern California Seismic Network (Calnet). Dashed line in San Francisco Bay denotes approximate trackline for airgun shots recorded by Calnet (see fig. 1). Squares, chemical-explosive shotpoints (box labeled "13" is gather shown in fig. 13); dashed line on peninsula, high-resolution refraction and deep reflection profile. ture that began its history as a normal fault during the Eocene (Krug and others, 1992; McKevett, 1992). Presently, the Kirby Hills Fault zone is a strike-slip fault dipping $80^{\circ}-85^{\circ} \mathrm{E}$. The fault is seismically active and is characterized by some of the deepest earthquakes recorded south of the Mendocino triple junction in northern California (Hill and others, 1990).

Various acoustic tools have been used to image the subsurface geometry of faults at different depths in the Earth's crust. A tradeoff exists between subsurface resolution and depth of source penetration, with lower-resolution but more powerful sources reaching deeper into the crust. When shallow and intermediate-depth acoustic images are combined with the information derived from deep earthquake activity, the position of the Kirby Hills Fault can be mapped down to the base of the crust. Such control is rare and provides important constraints on the physical properties and structural architecture of the midcrust and lower crust underlying the California Coast Ranges. Here, we present acoustic images that collectively define the subsurface geometry of the Kirby Hills Fault zone near Pittsburg (figs. 1, 4) and document that this structure cuts the entire crust down to at least $28-\mathrm{km}$ depth.

\section{Ultra-High-Resolution Images of the Kirby Hills Fault Zone}

The ultra-high-resolution data provide images of deformed and folded sedimentary rocks in the uppermost 30 $\mathrm{m}$ of crust. Two windows from a single ultra-high-resolution profile within the 1-km-wide Kirby Hills fault zone are shown in figure 5 . The eastern ultra-high-resolution profile (fig. 5A) reveals a conspicuous unconformity (reflector B) in the shallow near-surface, approximately $15 \mathrm{~m}$ subbottom. Beneath this unconformity, strata dip approximately $5^{\circ}-10^{\circ}$ W., whereas above the discontinuity, channel-fill deposits are nearly flat lying.

To the west (fig. $5 B$ ), the unconformity is broadly warped and uplifted. The antiform breaches the surface near the confluence of the Sacramento and San Joaquin Rivers, just opposite the town of Pittsburg (figs. 1, 4). Deformation of the river floor confirms that the Kirby Hills Fault zone is an active feature.

\section{Acoustic Images of the Uppermost $75 \mathrm{~m}$ of the Crust Across the Kirby Hills Fault Zone}

In the vicinity of the Kirby Hills Fault zone, a highresolution source provides vivid images of the uppermost 75 $\mathrm{m}$ of crust. Two representative profiles are shown in figure 6 , each of which displays the same three principal features identified on the ultra-high-resolution profiles: (1) an upper series of flat-lying to gently dipping sedimentary strata, (2) a conspicuous angular unconformity, and (3) a deeper series of $5^{\circ}-10^{\circ}$-W.-dipping strata that terminates abruptly at the unconformity. On the high-resolution profiles, the upper sedimentary strata display a slight westward dip and onlap the underlying angular unconformity. The unconformity itself is warped and folded and occurs at 5- to 35-m depth. The 
undulation of the unconformity suggests ongoing deformation associated with the fault zone.

\section{Intermediate-Resolution Images of the Uppermost 2 $\mathrm{km}$ of Crust Across the Kirby Hills Fault Zone}

Small-airgun, multichannel seismic-reflection profiles were acquired to provide a deeper picture of the crustal structure across the deformation zone identified in the higherresolution profiles. Two of the six profiles acquired (fig. 7) provide high-quality images of the crustal structure in the uppermost $1 \mathrm{~km}$ of crust in the vicinity of Pittsburg (fig. 4). These two profiles document an abrupt deformational front, east of which reflections are abruptly folded in an eastwardvergent geometry. This folding extends to at least $600-\mathrm{m}$ depth, but no fault-plane reflections are evident. Without clear images of the fault plane, it is difficult to constrain the style of faulting, whether fault-bend folding or fault-propagation folding. East of the zone of folding, small-airgun, multichannel seismic-reflection profiles show a conspicuous reflection at 400 -m subbottom (reflector C, fig. 7). This event corresponds to a second, deeper unconformity, as discussed below. The data indicate folding and faulting that extends down to $4.5-\mathrm{km}$ depth. The conspicuous unconformity imaged at $\sim 0.4$-s two-way traveltime (reflector $\mathrm{C}$ ) is independent of the unconformity imaged by higher-resolution techniques.

\section{Seismic Images of the Uppermost 6 to $9 \mathrm{~km}$ of Crust Across the Kirby Hills Fault Zone}

A lower-frequency multichannel seismic-reflection profile complements the higher-resolution, shallower-penetration images and allows us to image the Kirby Hills Fault zone down to 6- to 9-km depths (fig. 8). The multichannel seismic source used to investigate the Kirby Hills Fault zone had a dominant frequency of 10 to $20 \mathrm{~Hz}$ and consisted of a 12-element, 13.8-MPa, 95.5-L tuned-airgun array towed from the

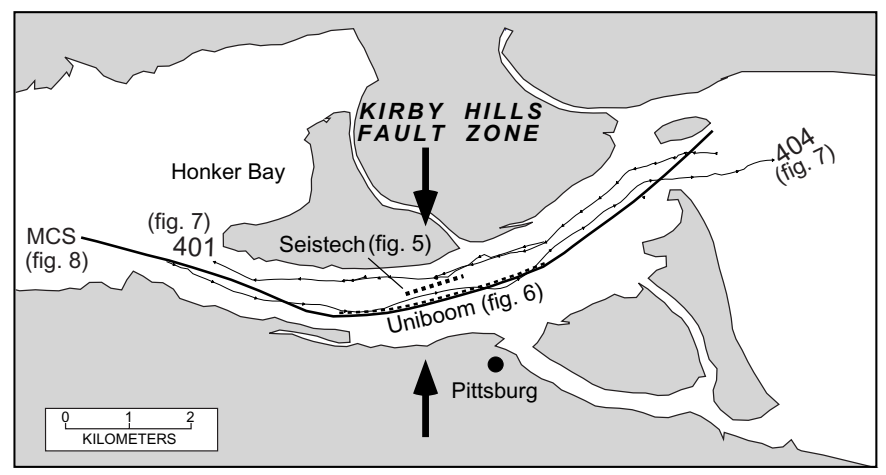

Figure 4.- Study area of the Kirby Hills Fault zone (see fig. 1 for location). Marine profiles of various resolutions shown in figures 5 through 8 were gathered along heavy black line. Fault zone is $\sim 1 \mathrm{~km}$ wide and is centered over arrows.
USGS research vessel S.P. Lee. The airguns were towed at an average water depth of $7.6 \mathrm{~m}$ and were fired at a $50-\mathrm{m}$ interval (see Hart and others, this volume).

A reflection at 1-s two-way traveltime is believed to correspond to the top of the Eocene Domengine Formation, as mapped by Krug and others (1992). Multichannel seismic images show upward warping and deformation within the fault zone in the uppermost 2 to $4 \mathrm{~km}$ of crust. These different data sets show a strong vertical alignment of deformation. Thus, even though the near-vertical fault is not imaged, the location of the fault can be construed by identifying the zone of folded and offset strata at ever-increasing depths in the crust. In the lower crust, earthquakes are used to constrain the location of the Kirby Hills Fault.

\section{Seismicity in the Vicinity of the Kirby Hills Fault Zone}

Faulting and deformation along the Kirby Hills Fault zone is associated with unusually deep seismicity, ranging from 15- to $28-\mathrm{km}$ depth (fig. 9), that is distributed across a 4-km-wide zone which coincides with, and extends eastward of, the deformation zone imaged in the upper crust. Together, these observations define a steeply dipping fault zone that extends from the near surface to the base of the crust.

The seismicity in the vicinity of the Kirby Hills Fault zone, as recorded by the USGS' Northern California Seismic Network (Calnet) since May 1974, is plotted in figure 9. South of lat $38^{\circ} 10^{\prime} \mathrm{N}$., the seismicity (cross secs. $A-A^{\prime}$, $B-B^{\prime}$, fig. 9) and focal mechanisms (fig. 10A) indicate that the fault dips from near vertical to $65^{\circ} \mathrm{NW}$. North of this latitude (cross sec. $C-C^{\prime}$, fig. 9), the seismicity and associated focal mechanisms indicate a complex pattern of strike-slip and reverse faulting (fig. 10A). Earthquakes are located within a layered velocity model developed by a joint hypocentervelocity inversion specifically for this area. The 544 (out of a total of 621) earthquakes plotted have horizontal and vertical uncertainties of 2.5 and $5.0 \mathrm{~km}$, respectively.

The deepest seismicity locates the Kirby Hills Fault at the base of the crust. These unusually deep earthquakes, which occur within a few kilometers of the Moho (for example, Holbrook and others, 1996) indicate that the fault is seismogenic throughout the crust. Such deep seismicity is highly unusual and suggests that the Kirby Hills Fault zone extends as a steeply dipping structure from the surface all the way to the base of the crust.

Representative focal mechanisms, determined from $P$ wave first-motion observations recorded by the Calnet, have also been analyzed (fig. 10A). All mechanisms have at least 40 first-motion observations. Motion is predominantly rightlateral strike slip on northwest-oriented faults, but thrust faulting also occurs on west-northwest-oriented planes north of the Sacramento River. The focal-mechanism studies are compatible with an $80^{\circ}$-E.-dipping fault plane (figs. 9, 10).

The earthquake activity near Pittsburg (figs. 1,4) extends $\sim 25 \mathrm{~km}$ northward and $\sim 5 \mathrm{~km}$ southward of the Sacramento 
River. To the north, the seismicity coincides with the mapped trace of the Kirby Hills Fault. To the south, it dies out near the north limit of the Kirker fault at the north edge of the Diablo Range. These results support the interpretation by Krug and others (1992), who proposed that the Kirby Hills and Kirker Faults are linked together in an $\sim 65$-km-long system of faults which they labeled the Kirby Hills Fault system. Thus, the Kirby Hills Fault system may be an important element in the ongoing crustal deformation in the eastern San Francisco Bay region.

Combining results from high-resolution seismic techniques with intermediate- and low-frequency sources, as well as with relocated earthquake hypocenters, allows us to image the entire Kirby Hills Fault zone through the crust (fig. $10 B)$. The high resolution data reveal a $1.0-\mathrm{km}$-wide zone of $3^{\circ}-5^{\circ}$-W.-dipping strata unconformably overlain by a 30 - to 40-m-thick package of westward-thickening prograding sedimentary rocks. The localization of these dipping strata and the conspicuous angular unconformity that separates them suggest a recent episode of tilting and erosion. The deeper seismic-reflection profiles show this zone of deformation extending downward to at least 6-km depth, on the basis of a series of reflector offsets in the upper 2- to 3-s two-way traveltime. Seismicity is distributed across a 4-km-wide belt that

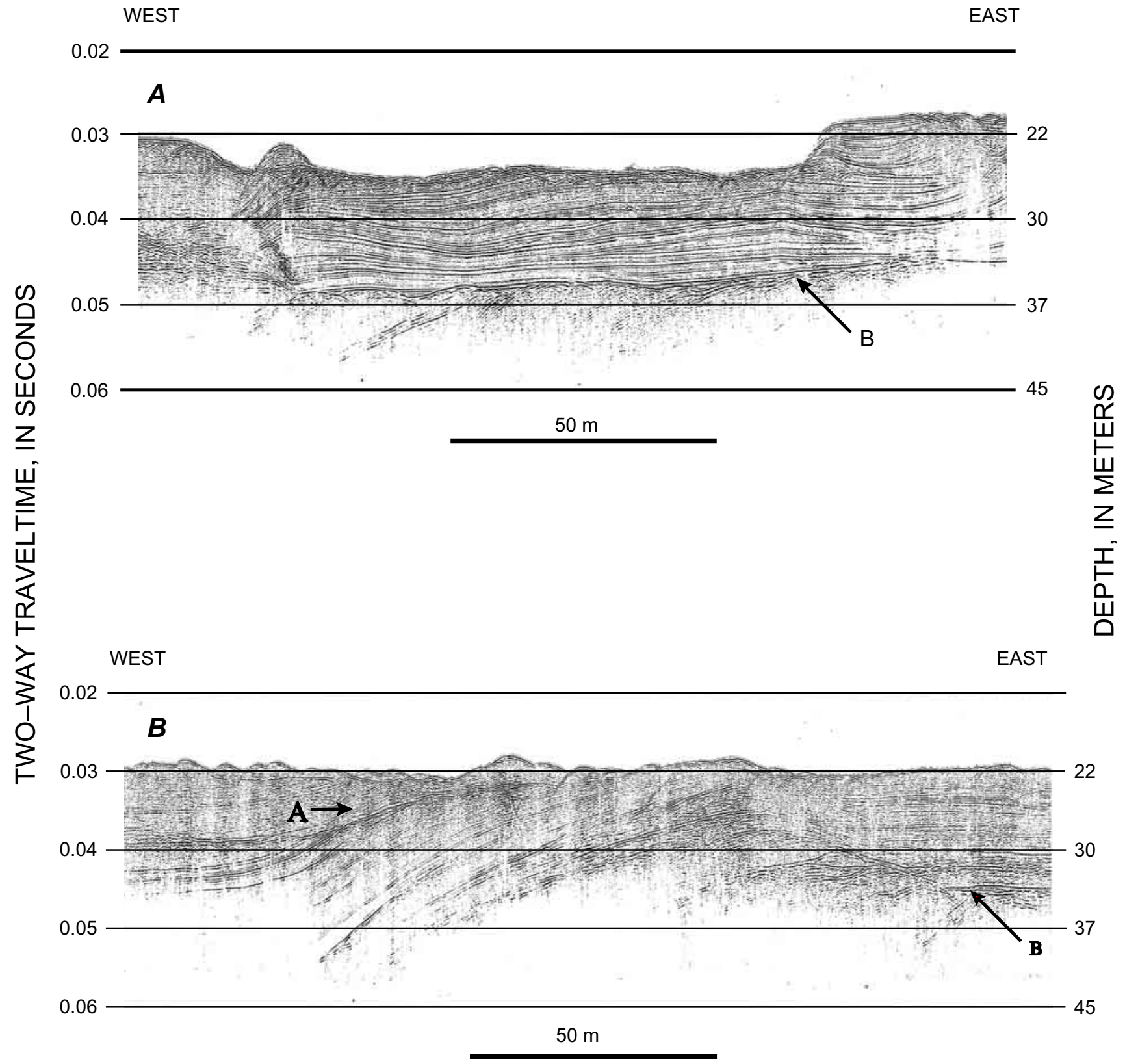

Figure 5.-Ultra-high-resolution seismic-reflection profiles gathered east $(A)$ and west $(B)$ of the Kirby Hills Fault zone (figs. 1, 4), showing significant deformation of youngest sedimentary rocks in fault zone. Approximately 200-m gap separates the two profiles, both of which fall within the 1-km-wide Kirby Hills Fault zone (fig. 4). Reflectors A and B are unconformities. 


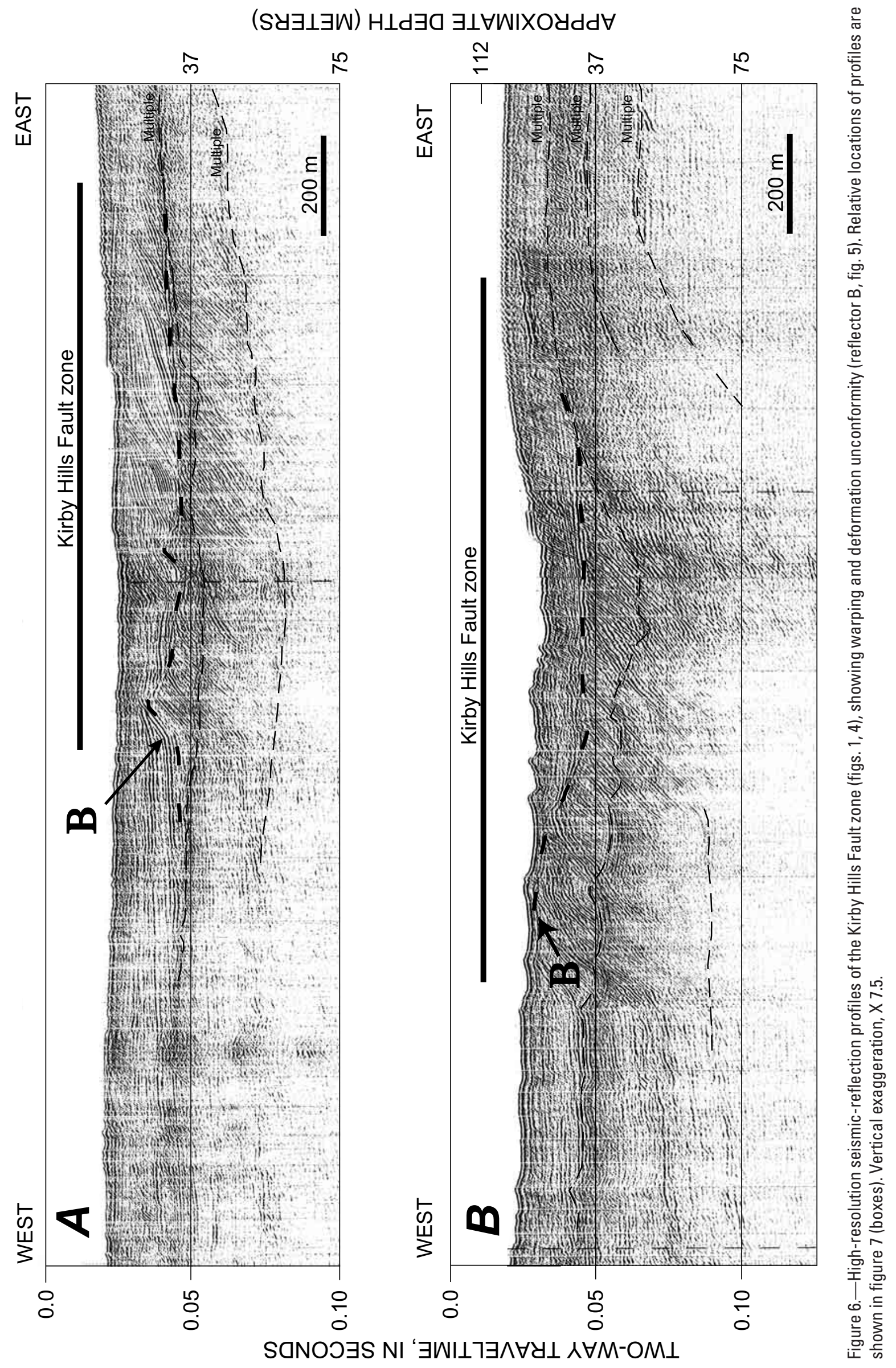


coincides with, and extends eastward of, the deformation zone imaged in the upper crust. Together, these observations define a near vertical or steeply $\left(>75^{\circ}-90^{\circ}\right)$ east-dipping fault zone that extends from the near surface down almost to the base of the crust. Focal mechanisms indicate predominantly strike-slip faulting.

\section{5: Three-Dimensional Upper-Crustal Veloc- ity Structure in the San Francisco Bay Region}

A three-dimensional seismic-velocity model of the San Francisco Bay region provides useful information for seis- mic hazard analysis: (1) a detailed three-dimensional model is needed to better predict strong ground motion during an earthquake because the travelpaths of seismic waves are governed by the velocity structure; (2) a three-dimensional velocity model allows proper analysis of crustal fault-plane reflections, (3) earthquake hypocenters can be better located, and focal mechanisms can be more accurately determined; and (4) subsurface fault zones can be mapped where insufficient microseismicity exists to identify them directly. We thus conducted inversions for the regional velocity structure, using earthquake and controlled seismic sources. Calnet has been recording earthquakes in the San Francisco Bay region since the 1960s. Over time, a vast catalog of quality earthquake

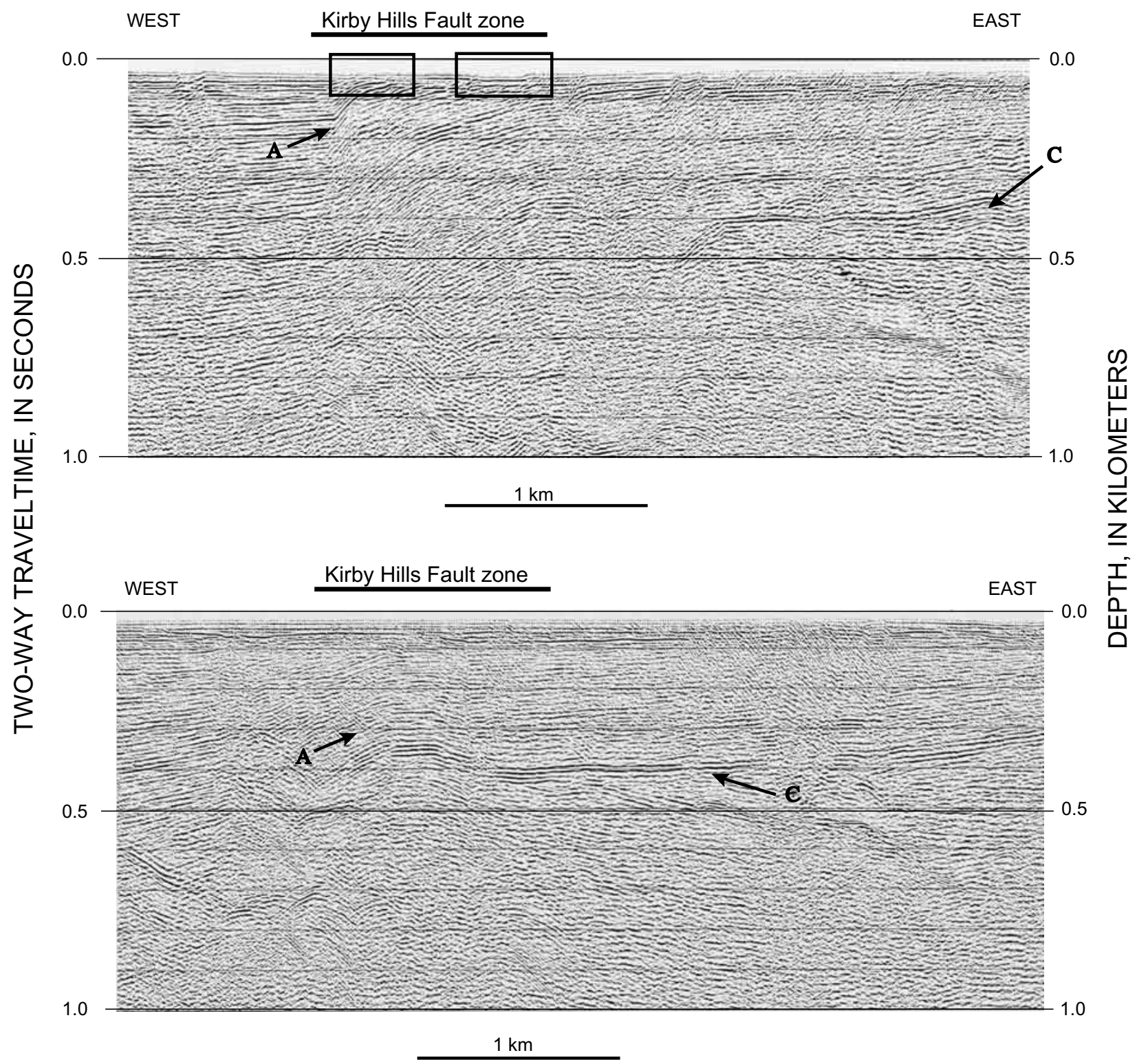

Figure 7.- Intermediate-resolution seismic-reflection profiles across the Kirby Hills Fault zone (figs. 1, 4), documenting an abrupt deformational front, east of which reflections are abruptly folded in an eastward-vergent geometry. Although this folding extends to at least $600-\mathrm{m}$ depth, no fault-plane reflections are evident. Without clear images of fault plane, it is difficult to constrain style of faulting, whether fault-bend folding or fault-propagation folding. Boxes show locations of high-resolution profiles in figure 6. 
arrival times has accumulated. We used this catalog in concert with the growing number of controlled sources recorded in and around San Francisco Bay to construct a three-dimensional model of the upper-crustal velocity structure of the bay region and, with the aid of a temporary local network, the detailed velocity structure of the northern part of the San Francisco peninsula.

\section{Velocity-Modeling Methods and Data}

We applied the three-dimensional tomographic technique of Hole (1992), modified to simultaneously invert for velocity, hypocenters, and origin times. This technique applies a finite-difference solution to the eikonal equation (Vidale, 1990; updated by Hole and Zelt, 1995) to calculate first-arrival times through a gridded slowness model. An iterative nonlinear inversion is performed as a simple backprojection along raypaths determined from the forward-modeling step.

We compiled traveltime picks from various sources for each receiver as a function of their three-dimensional source locations and inverted them for three-dimensional velocity structure. Four types of traveltime data were applied to our velocity modeling: (1) first-arrival times from local earthquakes on temporary networks, (2) first-arrival times from airgun blasts in San Francisco Bay, (3) first-arrival times from chemical-explosive sources detonated on land, and (4) traveltime picks from earthquake and controlled sources from the Calnet catalog and previous regional seismic experiments (Murphy and others, 1992; Brocher and Moses, 1993; McCarthy and Hart, 1993; Brocher and Pope, 1994; Kohler and Catchings, 1994; Holbrook and others, 1996).

Initial hypocenter locations and origin times of earthquakes were inputted as determined by Calnet. Starting models were discretized into grids of 1-km cells; we used small grid cells to ensure accurate calculation of raypaths along short source-receiver offsets. A spatial-smoothing filter was applied to the models between velocity and sourceparameter iterations. Early iterations were conducted that tested various one-dimensional starting models with very broad smoothing filters (max $100 \mathrm{~km}$ ), including only limited ranges of source-receiver offsets to solve the shallowest parts of the velocity model first. Subsequent iterations were conducted that included greater source-receiver offsets and progressively shorter smoothing filters.

The San Francisco Bay region is crossed by several major strike-slip faults that provided most of the seismicity we used to develop the velocity models presented here. These strike-slip faults also cause discontinuities in the velocity structure at seismogenic depths. The earthquakes used in this study were initially located with a one-dimensional veloc-

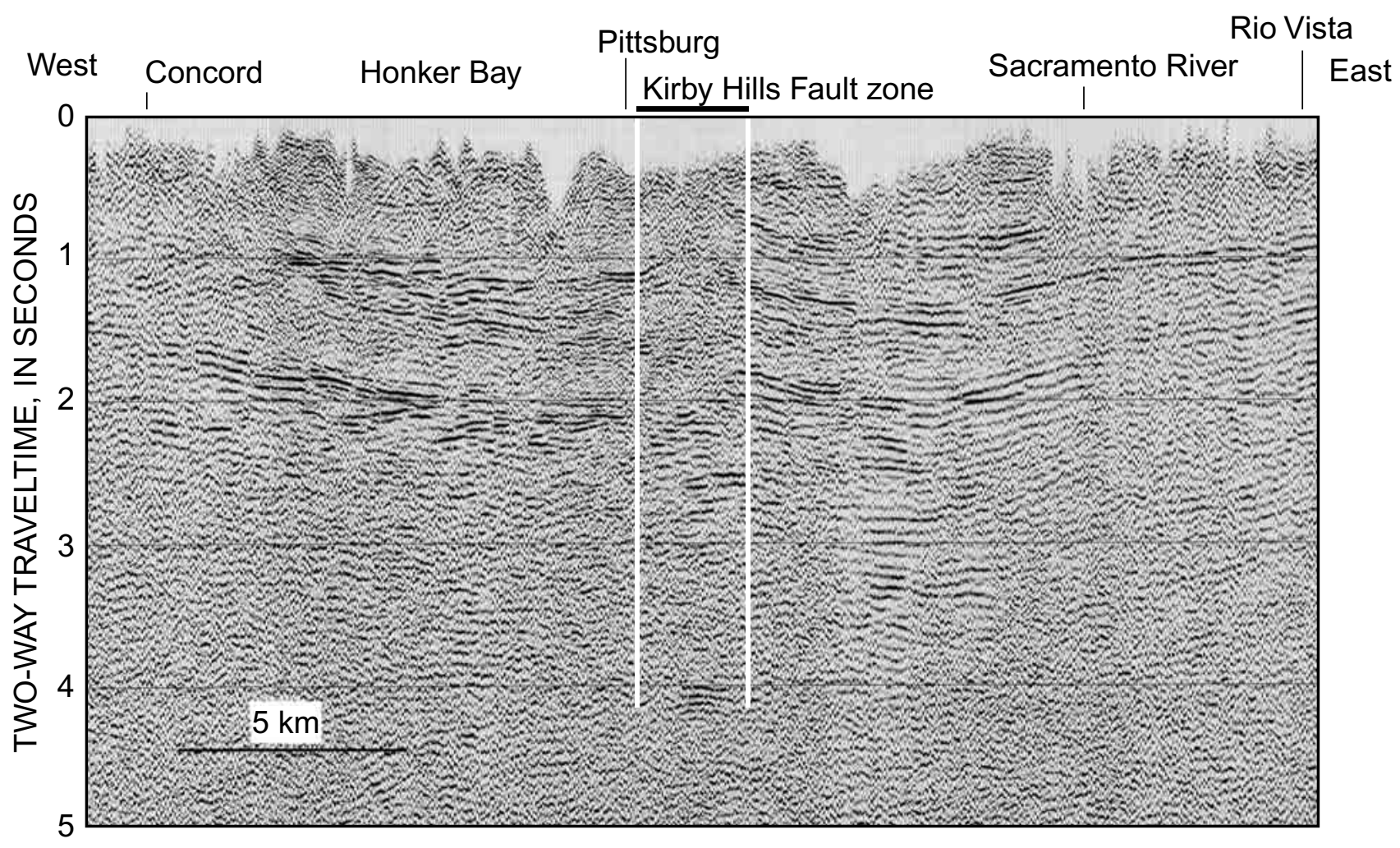

Figure 8.-Multichannel seismic-reflection profile across the Kirby Hills Fault zone (figs. 1, 4). Deformed rocks associated with fault zone are imaged from near surface to about 3-s two-way traveltime ( 6-9-km depth). Heavy black line, Kirby Hills Fault zone as mapped by higher-resolution methods. 

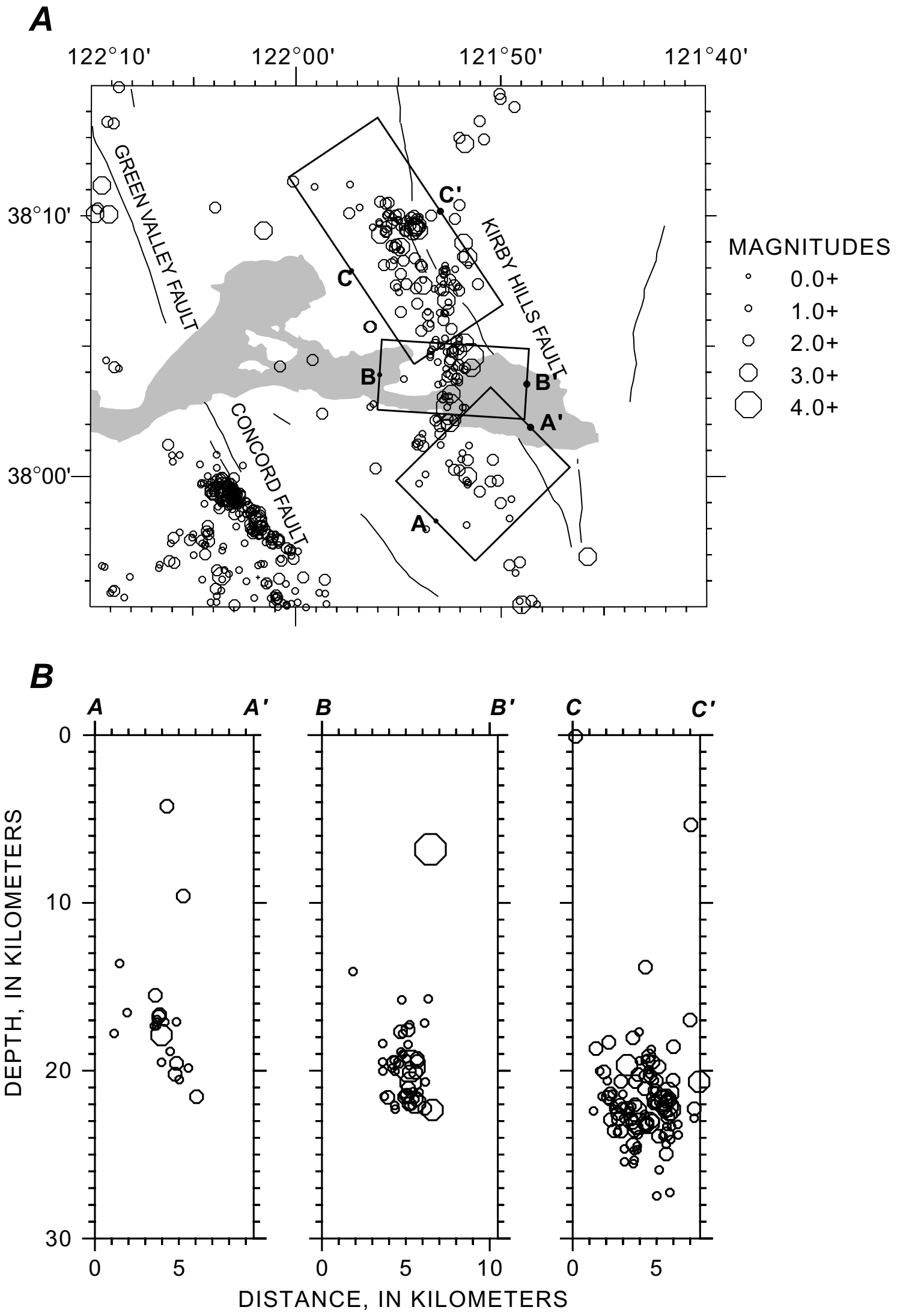

Figure 9.-Kirby Hills Fault zone (see figs. 1, 4 for location). $A$, linear trend of seismicity extending southward from where fault is mapped by marine investigations suggests that fault is $\sim 50 \mathrm{~km}$ long. $B$, Depth cross sections of hypocenters, illustrating deep seismicity associated with the Kirby Hills Fault zone that extends to base of crust. 

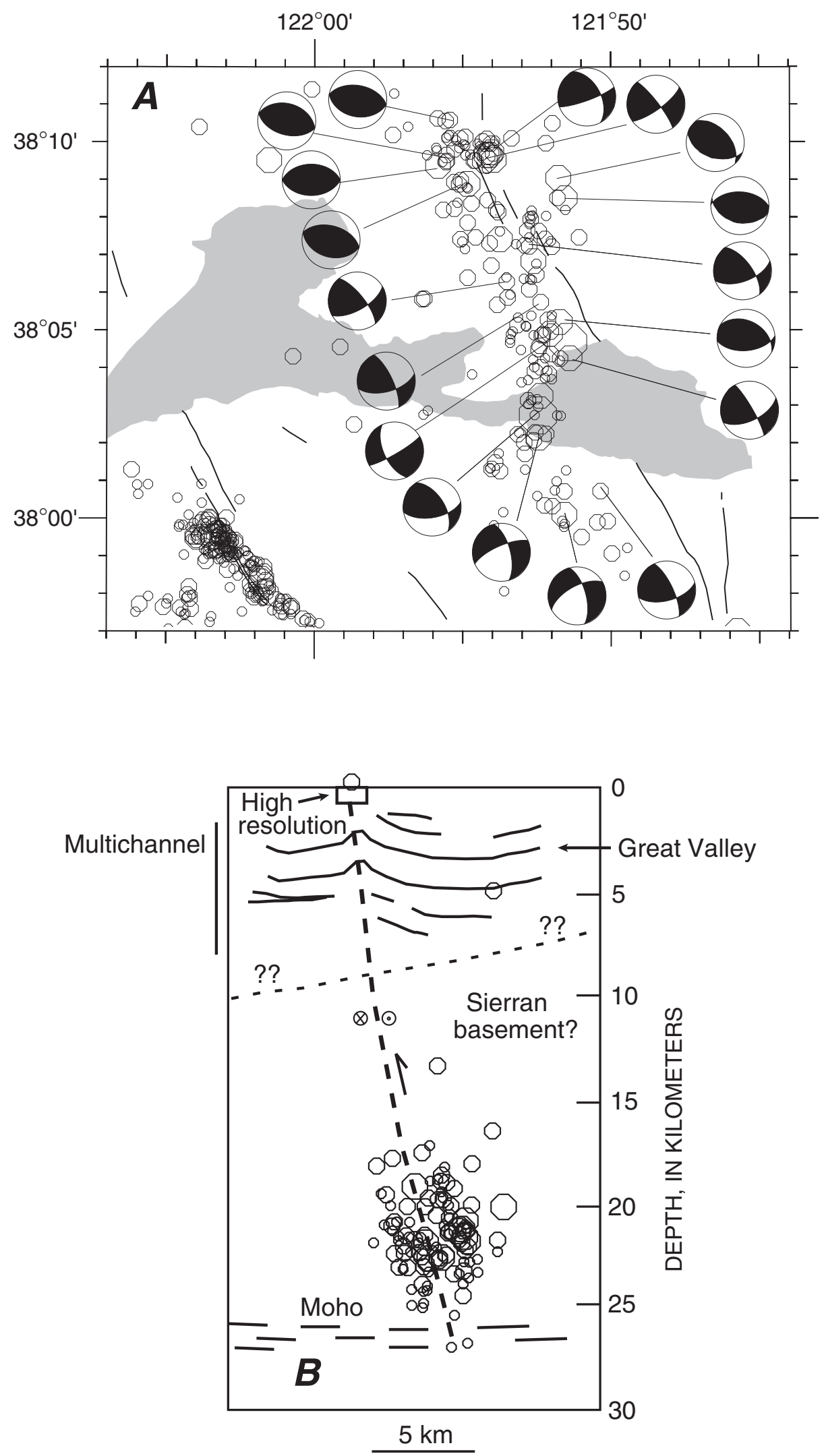

Figure 10.-Kirby Hills Fault zone (see figs. 1, 4 for location). $A$, Focal mechanisms of seismicity associated with zone. All mechanisms have at least 40 first-motion observations. Motion is predominantly right-lateral strike-slip on northwest-oriented faults, but thrust faulting also occurs on west-northwest-oriented planes north of the Sacramento River. $B$, Schematic interpretation of the Kirby Hills Fault zone based on various data constraints. 
ity model; thus, a degree of coupling between hypocenter location and the velocity structure derived from earthquake traveltimes is unavoidable and could cause significant errors in the resolved velocity models (Thurber, 1993). To reduce such errors, hypocenters and origin times were relocated with controlled source locations and times held fixed. The events were relocated between velocity iterations (mean relocation, $0.54 \mathrm{~km}$; see Hole, 1992, and Hole and others, 2000, for full details on the traveltime-inversion algorithm).

\section{Regional Three-Dimensional Velocity Structure of the San Francisco Bay Region}

Combined earthquake and controlled source traveltime data reveal a three-dimensional structural image of the seismogenic crust in the San Francisco Bay region from $~ 1-2-\mathrm{km}$ down to $18-\mathrm{km}$ depth (Parsons and Zoback, 1997; Hole and others, 2000). The three-dimensional velocity structure was inverted from 234,270 traveltime picks resulting from 7,742 earthquake arrivals recorded at 160 stations, and 2,874 controlled source-receiver pairs. We present a geologic interpretation of the seismic-velocity model below.

The model shows generally higher velocity west of the Hayward Fault at most depths (fig. 11). The Calaveras, Hayward, and Rodgers Creek Faults together show the strongest and most consistent correlation between surface fault trace and apparently offset rock bodies at depth. South of the Sacramento River delta, the Hayward and Calaveras Faults mark the boundary between higher-velocity Franciscan and lowervelocity Great Valley rocks. That boundary persists at depth to the base of model coverage at about 18-km depth (fig. 11). The consistent, well-developed velocity contrast across the Hayward and Calaveras Faults relative to the San Andreas Fault may result from their relatively larger cumulative offset (50-70 km versus 19-23 km; Cummings, 1968; McLaughlin and others, 1996).

In the uppermost $\sim 10 \mathrm{~km}$ of crust, high velocities are characteristic beneath San Francisco Bay between the Hayward and San Andreas Faults, which is interpreted as Franciscan basement (Hole and others, 2000). A local low-velocity anomaly beneath central San Francisco Bay (fig. 11) that correlates with the San Leandro Basin of Marlow and others (1999) seems to be no more than $4 \mathrm{~km}$ deep; another $\sim 5-\mathrm{km}$ thick basin underlies the Santa Clara Valley. East of the Calaveras Fault, sedimentary rocks of the Great Valley cause a low-velocity anomaly that persists to at least $12-\mathrm{km}$ depth.

Beneath $\sim 8-\mathrm{km}$ depth, a clear boundary emerges between higher-velocity Salinian rocks west of the San Andreas Fault and Franciscan rocks to the east (fig. 11). This boundary persists to at least the base of model coverage at 18-km depth and is especially pronounced north of the Loma Prieta rupture zone on the San Francisco peninsula. The Salinia-Franciscan terrane boundary is not apparent north of the Golden Gate.

North of the Sacramento River delta, high-velocity rocks appear to be offset east of the Rodgers Creek Fault (fig. 11). The surface geology is complex east of this fault, comprising slivers of the Franciscan terrane, Great Valley sequence, ultramafic rocks associated with the faulted terrane boundary, and Cenozoic volcanism. The seismic-station coverage is relatively sparse in this area, and the spatial resolution is larger than the geologic units, and so the model may be averaging the effects of shallow igneous rocks. Relatively high seismic velocity persists to at least $11-\mathrm{km}$ depth beneath the Sonoma Volcanic Field but not beneath The Geysers and the Clear Lake Volcanic Field farther north, similar to the less well resolved deep results of Stanley and others (1998).

The primary features of the upper-crustal structure of the San Francisco Bay region revealed by the three-dimensional tomography model are the strong lateral velocity contrasts across major right-lateral strike-slip faults. These contrasts indicate that the faults are high angle down to at least $\sim 15-\mathrm{km}$ depth into the crust. The strong crossfault velocity contrasts affect calculations of earthquake focal mechanisms, hypocenter locations, and strong-ground-motion simulations because seismic energy can be refracted laterally along such velocity boundaries. These effects are not accounted for in traditional one-dimensional model calculations.

\section{Detailed Three-Dimensional Velocity Structure of the San Francisco Peninsula}

The geology of the San Francisco Peninsula is dominated by the right-lateral San Andreas Fault. In most of central California, the San Andreas Fault bounds the Salinia and Franciscan terranes. On the San Francisco peninsula, however, the Salinia-Franciscan terrane boundary is marked by the subparallel Pilarcitos Fault west of the San Andreas Fault (figs. 3, 11; see Brabb and Pampeyan, 1983). On the surface, the San Andreas Fault on the San Francisco peninsula is contained entirely within the Franciscan Complex. At least two possible models for the arrangement of the SaliniaFranciscan terranes on the peninsula have been proposed: (1) the Pilarcitos Fault may be an east-dipping thrust fault that has emplaced Franciscan rocks over Salinian granites (fig. 12; see Wakabayashi and Moores, 1988), or (2) the Pilarcitos Fault may represent an old segment of the San Andreas Fault system that accommodated pre-Quaternary right-lateral slip, and so it is a high-angle structure (fig. 12; see Cummings, 1968; McLaughlin and others, 1996). The surface trace of the Pilarcitos Fault has a somewhat curved or scalloped appearance that makes it look more like a thrust fault than a strike-slip fault, and the fault trace is associated with east-dipping mylonite fabrics indicative of shortening (Wakabayashi and Moores, 1988). However, the relation, if any, between the mylonite and the Pilarcitos Fault remains unresolved.

A temporary seismograph network was deployed on the San Francisco peninsula during the first half of 1995 to use local earthquake and controlled-source traveltimes to create a detailed upper-crustal structural model of the San Andreas and associated faults. The goal of this study was to determine which of the two possible models for the arrangement of 

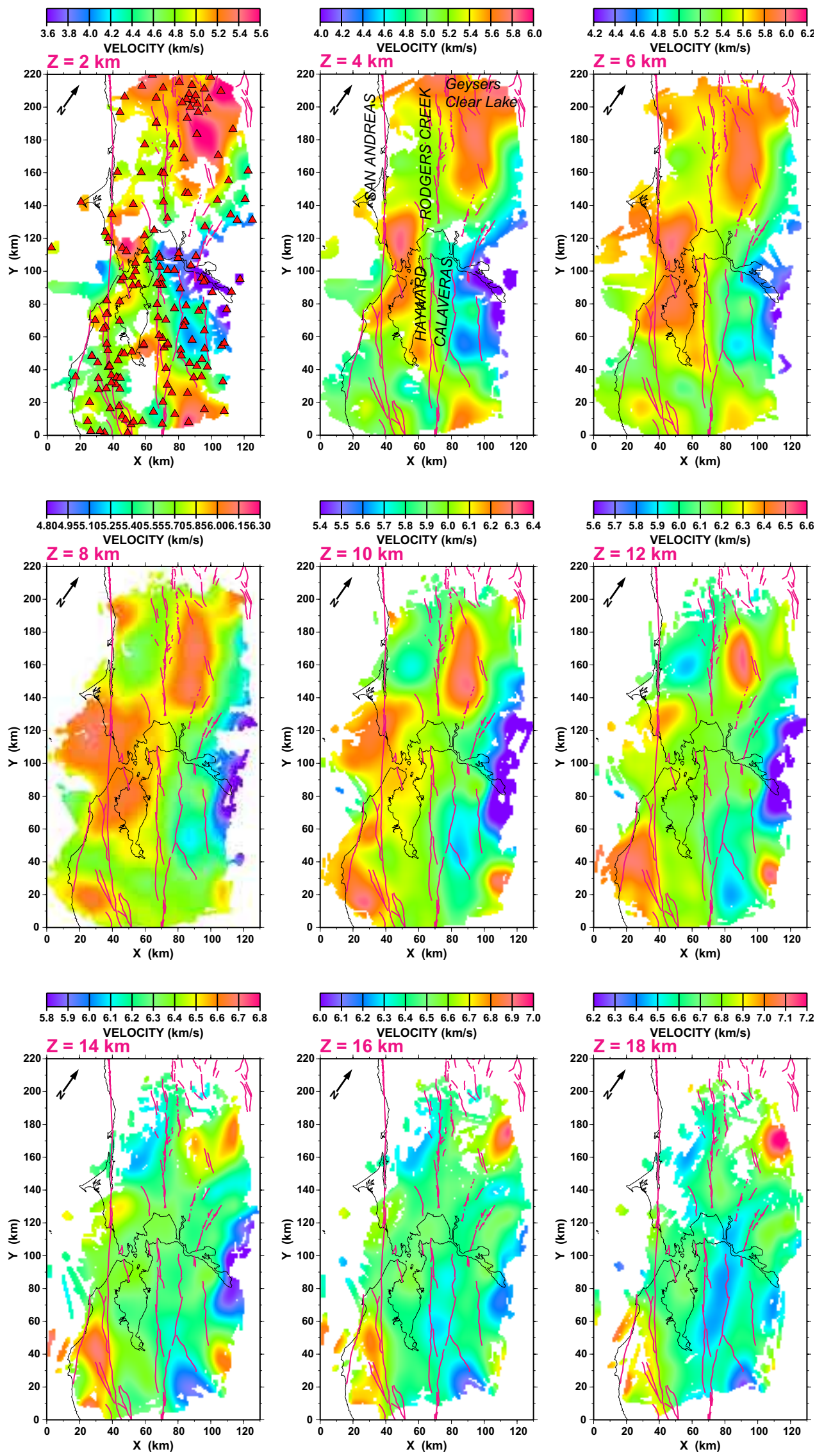

Figure 11.-Horizontal slices from a three-dimensional velocity model of the San Francisco Bay region taken at 2-km depth intervals. Colors represent variations in seismic velocity. 
the Salinia-Franciscan terranes on the peninsula is correct. The answer to this question is important because an active Pilarcitos thrust fault could imply far more hazard to nearby San Francisco and peninsula cities than an extinct proto-San Andreas segment.

To make the best use of the San Francisco peninsula array, the regional velocity model was used to calculate traveltimes from earthquake sources located outside of the network to the edges of a second, more detailed model. Our 1- to 3-km-spaced network allowed for a much shorter smoothing filter than did the 5- to 20-km-spaced Calnet. Thus, in effect, the distant earthquake sources were migrated to the edges of a more detailed model and treated like deep sources along the model faces; this technique somewhat resembles a teleseismic experiment, in that traveltime variations from distant sources were used to augment a local-array study. The uncertainties in source location and traveltime misfits of the regional velocity model may accumulate on long travelpaths and could cause errors in the traveltime calculations to the edges of the more detailed model. In practice, however, such uncertainties manifested primarily as small static-velocity shifts at depth in the resolution tests. The application of controlled sources from known locations acted to calibrate the velocity models. In combination with fixed sources, short $(2 \mathrm{~km})$ smoothing parameters and the close $(1-3 \mathrm{~km})$ station spacing prevented significant spatial shifting of velocity anomalies. Intentional static mislocation of earthquake sources in test models caused only minor changes in resolved velocity.

A three-dimensional velocity model limited to the San Francisco peninsula was constructed by shortening the final smoothing filter to $2 \mathrm{~km}$, in accordance with the 1- to $3-\mathrm{km}$ station spacing adopted for the temporary seismic network. The San Francisco peninsula model converged to an rootmean-square traveltime misfit of $245 \mathrm{~ms}$ after five iterations. Horizontal slices ( 20 by $20 \mathrm{~km}$ ) from the three-dimensional model volume are shown in figure 12 . At $3 \mathrm{~km}$ depth, the highest-velocity $(5.5 \mathrm{~km} / \mathrm{s})$ rocks appear to be confined between the downward vertical projection of surface traces of the San Andreas and Pilarcitos Faults and probably represent either a deeper expression of the Franciscan greenstone mapped at the surface, or a higher velocity unit underlying the Permanente terrane. Southwest of the Pilarcitos Fault, velocities are consistent with the large outcrop of Cretaceous granite (Montara Mountain Granite) that is part of the Salinian block (Brabb and Pampeyan, 1983).

Below 3- to 5-km depth, a downward vertical projection of the surface trace of the Pilarcitos Fault appears to mark a velocity transition from lower velocities $(5.5-6.0 \mathrm{~km} / \mathrm{s})$ to the southwest into higher velocities $(6.2-6.8 \mathrm{~km} / \mathrm{s})$ to the northeast (especially evident at 7-km depth, fig. 12). Our resolution tests indicate that below 6-km depth, velocity anomalies are resolvable only within $\sim 2 \mathrm{~km}$ of their true positions. Thus, this lateral velocity change could reasonably be attributed to either the San Andreas or Pilarcitos Fault. Below 7-km depth are hints of structures that could be bounded by downward vertical projections of the Pilarcitos and San Andreas Faults, but coverage at these depths is limited, and such correlations are only tentative. More typical Franciscan velocities of $\sim 6.0$ to $6.2 \mathrm{~km} / \mathrm{s}$ are observed at these depths.

An implication of the three-dimensional velocity model for the San Francisco peninsula is that at 3-km depth, possibly extending to 7-km depth, are velocity boundaries which are correlatable to the downward vertical projection of the Pilarcitos Fault (fig. 12). Such a correlation suggests that the Pilarcitos Fault may be a high-angle feature. High-angle velocity changes are also evident across the San Andreas Fault and are strongest in the shallowest part of the upper crust (1-3-km depth), where an apparent high angle boundary exists between the Franciscan Permanente terrane southwest of the fault and highly sheared Franciscan rocks to the northeast (fig. 12).

We conducted a higher-resolution two-dimensional traveltime inversion for the velocity of the Permanente terrane (bounded along its southwest side by the Pilarcitos Fault), using traveltimes recorded on instruments (SGRs) along a closely spaced (50-m station spacing, 2-3-km shot spacing) southwest-northeast-directed recording spread (fig. 3). The spread was oriented at an angle of $\sim 90^{\circ}$ to the strikes of the Pilarcitos and San Andreas Faults. Because of the short station spacing and overlapping coverage, we were able to reduce the velocity-model cell size to 100 -m squares (in contrast to the $1-\mathrm{km}$ cubes in the three-dimensional velocity models). Models derived from the two-dimensional higherresolution seismic refraction data are most consistent with the Pilarcitos Fault as marking a vertical boundary in the uppermost 0.5 to $1.0 \mathrm{~km}$ of crust between relatively low velocity rocks of the Permanente terrane to the northeast $(\sim 4.5 \mathrm{~km} / \mathrm{s})$ and adjacent rocks of the Salinia terrane to the southwest (fig. $12 D)$. The higher-resolution results tend to verify the indications from horizontal slices out of the three-dimensional velocity model that the Pilarcitos Fault is a steeply dipping boundary. We thus interpret the Pilarcitos Fault as primarily a strike-slip fault rather than a thrust fault. Before $\sim 3 \mathrm{Ma}$, the Pilarcitos Fault probably accommodated most of the plateboundary strain; a change in relative Pacific-North American Plate motions at 3.9-3.4 Ma stimulated the formation of the Peninsular segment of the San Andreas Fault, and the Pilarcitos Fault was abandoned as the primary plate-boundary fault (Parsons and Zoback, 1997).

\section{5-97: Deep Configuration of the San Andreas and Hayward Faults from Crustal Reflections}

After a few faint reflections were observed in the original BASIX data in 1991, the presence of deep crustal reflectors was firmly established by land and marine experiments in 1995 and 1997. BASIX-2 in April 1995 showed high-amplitude reflections between 6- and 10-s two-way traveltime. In June 1995, land-based explosive sources were added that generated high-amplitude reflections similar in appearance but at 11- to 13-s two-way traveltime. The disparity in arrival time with source-receiver position and strong reflection dip, 


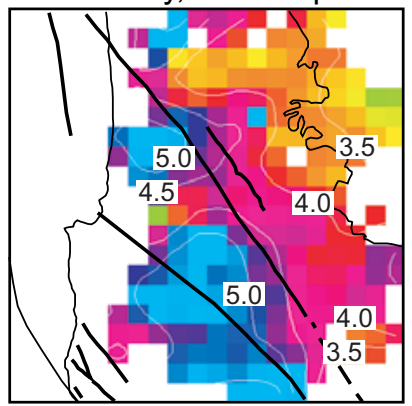

Velocity, 5-km depth

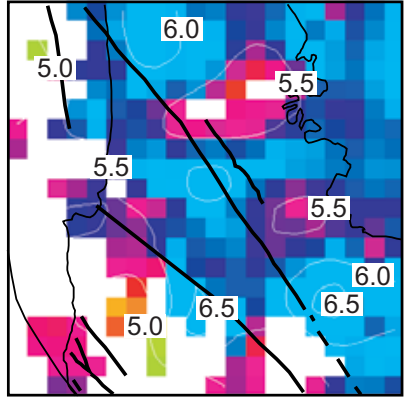

Velocity, 9-km depth

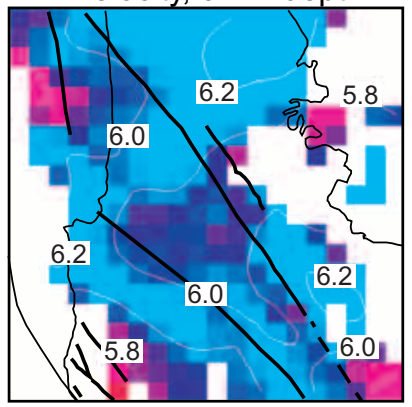

Velocity, 3-km depth

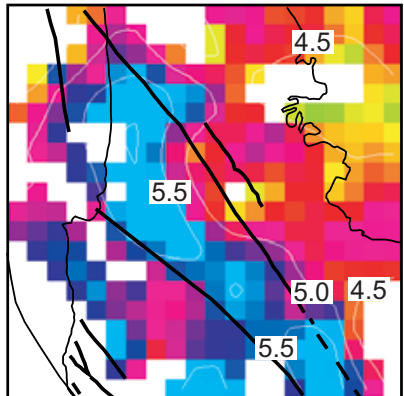

Velocity, 7-km depth

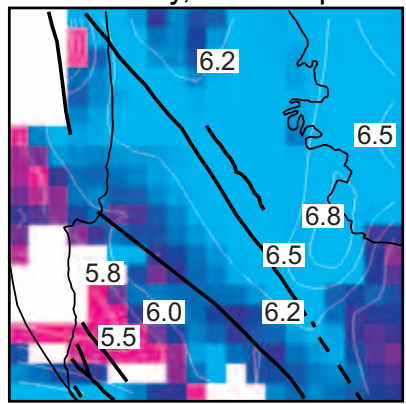

Velocity, 11-km depth

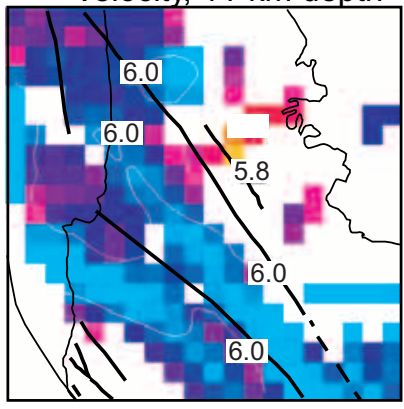

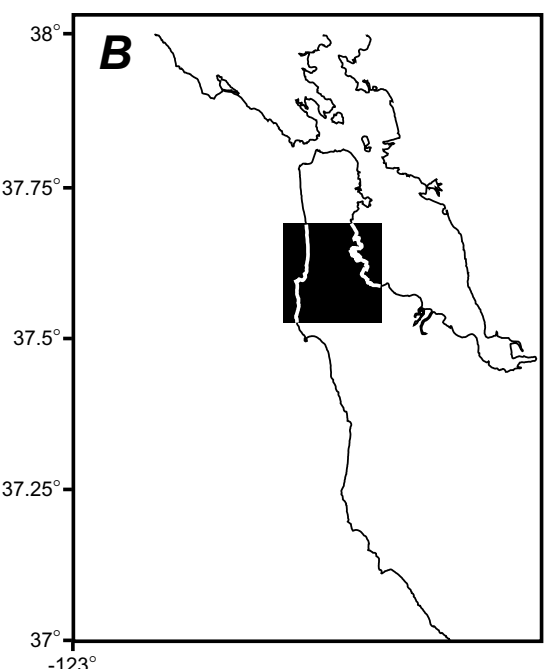

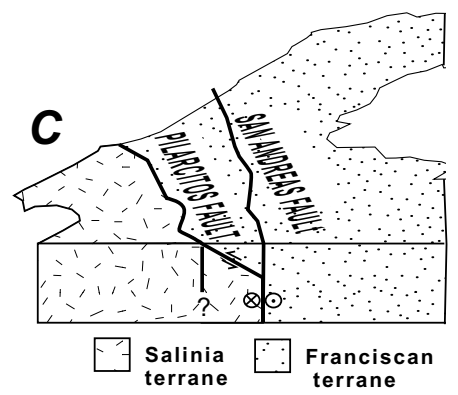

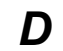

DISTANCE, IN KILOMETERS

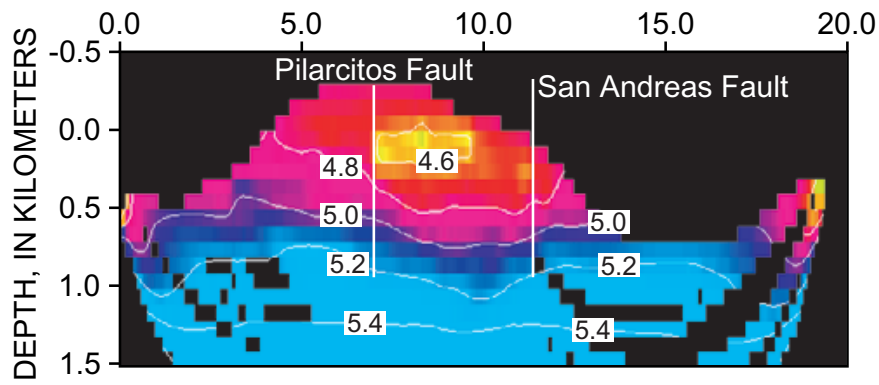

Figure 12.-San Francisco peninsula. $A$, Horizontal slices from the three-dimensional velocity model from 1- to 11$\mathrm{km}$ depth. Each slice represents a $20-$ by $20-\mathrm{km}$ area. Color scale for velocity differs from slice to slice to highlight velocity variations. Velocity contours in kilometers per second. Black lines, downward vertical projections of surface traces of the Pilarcitos and San Andreas Faults and coastlines. B, Sketch map of the San Francisco Bay region, showing boundaries of horizontal slices shown in figure 12A. C, Simplified geology of the San Francisco peninsula, showing possible structural models for relation between the Pilarcitos and San Andreas Faults. In most of central California, the San Andreas Fault separates the Salinia and Franciscan terranes, whereas on the San Francisco peninsula the Pilarcitos Fault marks the terrane boundary. The Pilarcitos Fault may be either an east-dipping thrust fault that has pushed Franciscan rocks up over Salinian rocks, or a vertical strike-slip fault that accommodated significant right-lateral slip before formation of the San Andreas Fault on the San Francisco peninsula at 3 Ma. $D$, High-resolution velocity cross section (inverted from explosive sources) across the San Andreas and Pilarcitos Faults, showing high-angle velocity contrasts associated with the two faults. 
or moveout (the change in reflection traveltime as a function of source-receiver offset), inspired a third marine experiment (BASIX-3) in 1997. Collectively, these seismic-reflection data enabled us to model the deep structure related to the Hayward and San Andreas Faults.

\section{Crustal Characteristics from Vertical-Incidence Reflection Data}

Large-airgun and chemical sources deployed in and around San Francisco Bay returned reflection energy throughout the crust (for example, Brocher and others, 1994; Parsons, 1998; Parsons and Hart, 1999), enabling some discussion on background reflectivity. The land-receiver spread crossed the Salinia terrane southwest of the Pilarcitos Fault and the Franciscan Complex between the Pilarcitos and San Andreas Faults on the San Francisco peninsula, and the marine receivers were all located within the Franciscan Complex (figs. 3, 12). These bedrock units show no coherent reflections down to about 5- to 6-s two-way traveltime ( $14-15-\mathrm{km}$ depth) over the entire source bandwidth (2-40 Hz; fig. 13).

Below about 5- to 6-s two-way traveltime, the land data best show an onset of discontinuous midcrustal and lowercrustal reflectivity (individual crustal-reflection segments generally less than $1 \mathrm{~km}$ long) that extends to the inferred Moho ( 8-9-s two-way traveltime, 24-28-km depth). This depth to the Moho agrees reasonably well with models from wide-angle seismic data (Catchings and Kohler, 1996; Holbrook and others, 1996) that found Moho depths of 22 to 26 $\mathrm{km}$ beneath the Golden Gate and near San Francisco Bay. The seismic-reflection data do not show a discrete Moho reflection but rather a progressive decrease of reflectivity that can be traced most clearly on the amplitude-decay curve (fig. 13). The background midcrustal reflections are far less evident in the marine data because they tend to be suppressed by more nearly continuous, higher-amplitude dipping reflections.

The onset of midcrustal and lower-crustal reflectivity at 5- to 6-s two-way traveltime corresponds to a step in crustal velocity $(6.4-7.3 \mathrm{~km} / \mathrm{s})$ at $\sim 20-\mathrm{km}$ depth, as modeled by Holbrook and others (1996). Because of wide observation in the San Francisco Bay region of an onset of reflectivity and associated change in crustal velocity at $\sim 20 \mathrm{~km}$ depth, and the choppiness and discontinuity of the reflections, we interpret the lower-crustal reflectivity beneath the San Francisco peninsula as resulting from an increase in shear fabric, possibly due to a rheologic change at $\sim 20-\mathrm{km}$ depth (for example, Holbrook and others, 1996). Lower-crustal reflectivity, which is generally observed in terranes that have been transported long distances along strike-slip faults, such as beneath the central California margin and in Alaska, has been attributed to lower-crustal shearing during translation (Beaudoin, 1994).

\section{High-Amplitude Dipping Reflectors}

The most distinctive feature of vertical-incidence seismic records from the San Francisco Bay region (fig. 14) is late- arriving (6-13-s two-way traveltime) reflections with high amplitude, strong continuity, large moveout, and variations in traveltime and moveout with source-receiver position (figs. 13-16). If these events had been reflected from a single, flat horizon, very little change in traveltime or moveout would be expected. Reflections from a flat surface have predictable dip and obey the normal moveout equation

$$
t=\frac{x_{2}^{2}-x_{1}^{2}}{2 V^{2} t_{0}},
$$

where $t$ is the time, $x_{1}$ and $x_{2}$ are the reciprocal source and receiver positions, $V$ is the seismic velocity, and $t_{0}$ is the zero-offset reflection time. Significant departure from normal moveout implies a reflection from a dipping interface; variation in moveout with source-receiver orientation can indicate the strike and dip of the reflector. Most of the highamplitude reflections observed at vertical incidence must be distinguished from those regionally observed at wide sourcereceiver aperture from a near-horizontal reflector interpreted as the top of mafic lower crust by Brocher and others (1994) and Holbrook and others (1996).

\section{High-Amplitude Dipping Reflections Recorded on Land}

Following Moho traveltimes ( $\sim 9$-s two-way traveltime), a band of continuous ( $\max 5 \mathrm{~km}$ long), high-amplitude reflections appears at $\sim 11$ - to 13 -s two-way traveltime on a land transect across the San Francisco peninsula (figs. 3, 13). The relative amplitude of these reflections is surprisingly high (5 dB above background; fig. 13). For reference, the relative amplitudes reported for the Death Valley, Socorro, and Surrency brightspots range from 8.5 to $10 \mathrm{~dB}$; the Death Valley and Socorro brightspots were interpreted as magma bodies (Brown and others, 1987). A consistent directivity is evident in the events at 11- to 13-s two-way traveltime; they all dip southwest and are reflected from a horizon that must be located northeast of all the shots and the recording spread (fig. 3). These events cannot be explained by $P$-wave Moho reflections because the long traveltimes at crustal velocities would imply at least a 40-km-thick crust beneath San Francisco Bay, inconsistent with interpretations of wide-angle seismic data (Page and Brocher, 1993; Catchings and Kohler, 1996; Holbrook and others, 1996), regional elevations, or the Bouguer gravity anomaly. Such origins for these events as crustal $S$-wave or upper-mantle $P$-wave reflections were ruled out by Parsons (1998).

\section{Marine High-Amplitude Dipping Reflections}

High-amplitude dipping reflections were observed from many consecutive airgun blasts at 6- to 9-s two-way traveltime throughout San Francisco Bay (figs. 15, 16). These events are nearly identical to the reflections at 11- to 13-s two-way traveltime recorded on the San Francisco peninsula, except that most of the events at 6 to $9 \mathrm{~s}$ have earlier traveltimes. The reflections were recorded during all three 
marine experiments in San Francisco Bay (BASIX-1 in 1991, BASIX-2 in 1995, and BASIX-3 in 1997), although in 1991 poor signal-to-noise conditions made interpretation difficult.

Strong reflections were observed in the pilot BASIX-2 in April 1995 when bottom cables were tested. Only three cable deployments were carried out in 1995 (fig. 14); all were oriented northwest-southeast, parallel to the dredged shipping channel in San Francisco Bay (see Hart and others, this volume, for detailed discussion). This orientation also proved to be nearly parallel to the strike of the dipping interfaces that produced strong reflections. As a result, most of the highamplitude reflectors appeared to be relatively horizontal, although small excursions by the source or receivers from strike-parallel orientations caused unusually large reflectionmoveout perturbations. These observations, tied to the similar, but much delayed, high-amplitude reflections recorded on land in June 1995, led us to question whether the events might be reflected from out-of-plane sources. We thus con- ducted BASIX-3 in 1997 to gather more data from different source-receiver orientations in order to measure the potential dip on the reflectors.

During BASIX-3 in 1997, we deployed bottom cables in a crossing pattern in the same area where high-amplitude reflections were recorded in 1995 (fig. 14), and made four more deployments oriented mostly southwest-northeast to augment the northwest-southeast-oriented cables deployed in 1995. Strong reflections were again observed after $\sim 6$-s two-way traveltime, but traveltime and moveout varied more widely than in the 1995 data.

\section{Combined Traveltime Observations: Why the Reflections Cannot Come from a Horizontal Detachment Fault}

Comparing the results from the 1995 land and marine experiments with the 1997 data, we find a consistent pattern of increased reflection moveout for source-receiver geom-

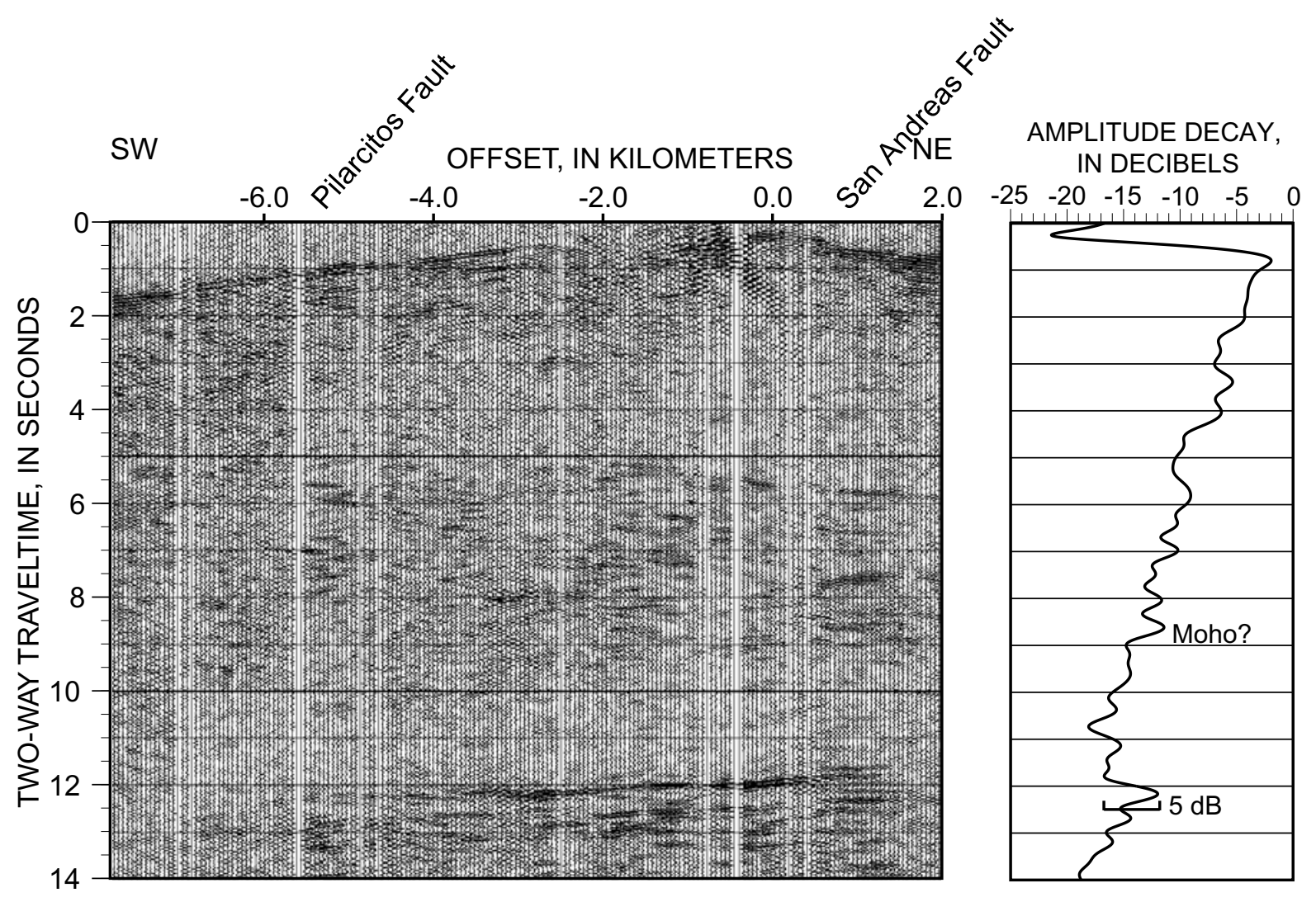

Figure 13.- Representative shot gather from an explosive source recorded by 183 Seismic Group Recorders. Shot was located at the San Andreas Fault on the San Francisco peninsula (see fig. 3 for location). Section shows a relatively transparent upper crust (no coherent reflections) in both the Salinia and Franciscan terranes. An onset of discontinuous midcrustal and lower-crustal reflectivity occurs at about 5- to 6-s two-way traveltime. No obvious changes in reflectivity are apparent across the San Andreas and Pilarcitos Faults on any shot gather. The Moho does not generate distinct reflections and is identified by a decrease in reflectivity at $\sim 9 \mathrm{~s}$ two-way travel-time (visible on amplitude-decay curve). Beneath the Moho, shot gathers show southwest-dipping, high-amplitude reflections ( $5 \mathrm{~dB}$ above background) at $~ 11$ - to 13-s two-way traveltime. Amplitude-decay curve was calculated from 30 traces of gather stacked after normal-moveout and spherical-divergence corrections. 

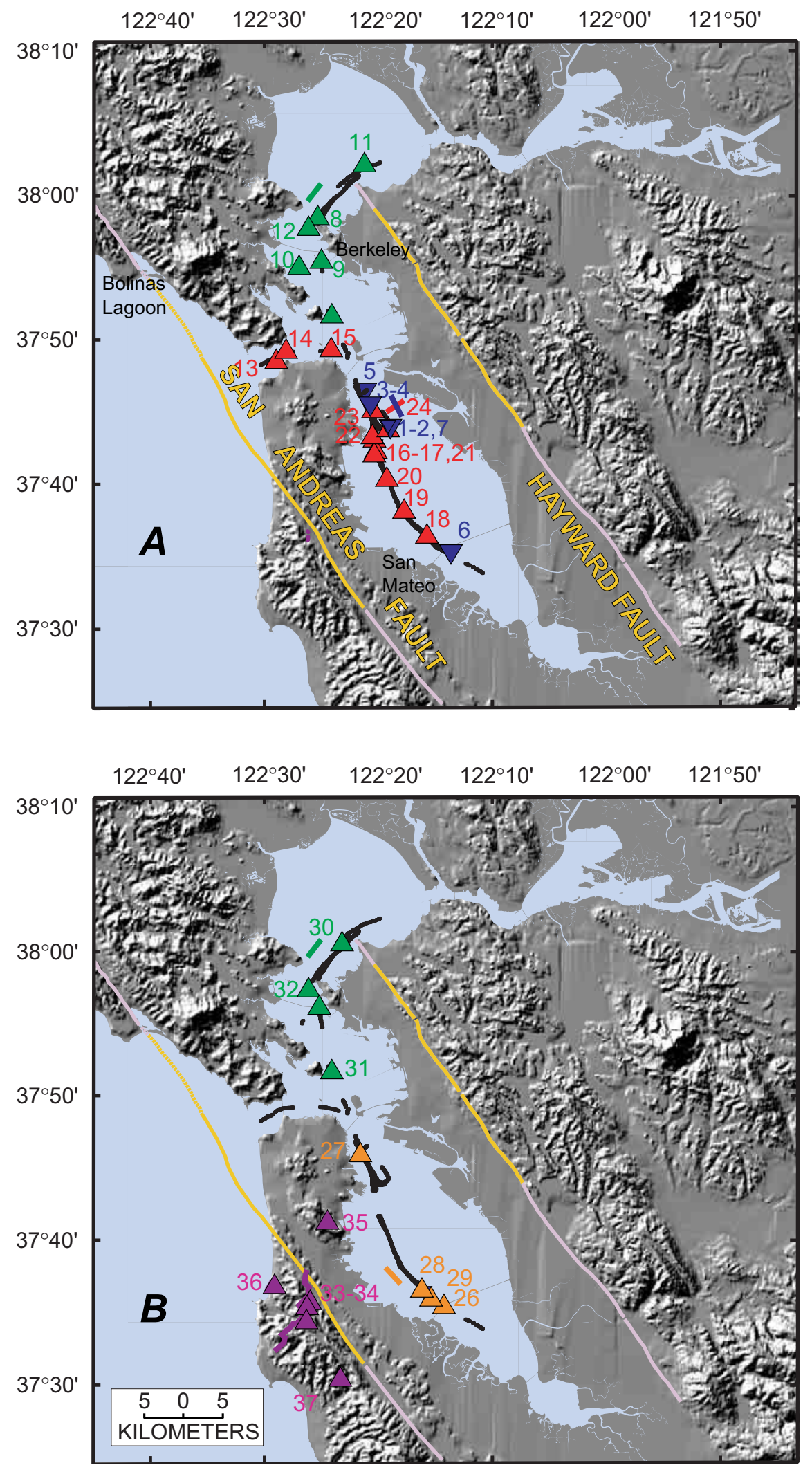

Figure 14.- San Francisco Bay region, showing locations of modeled arrivals from the San Andreas reflector $(A)$ and Hayward reflector $(B)$. Numbers correlate to gathers shown in figures 15 and 16 . Colored triangles, source positions as recorded by bottom cables, represented by lines of same color. 

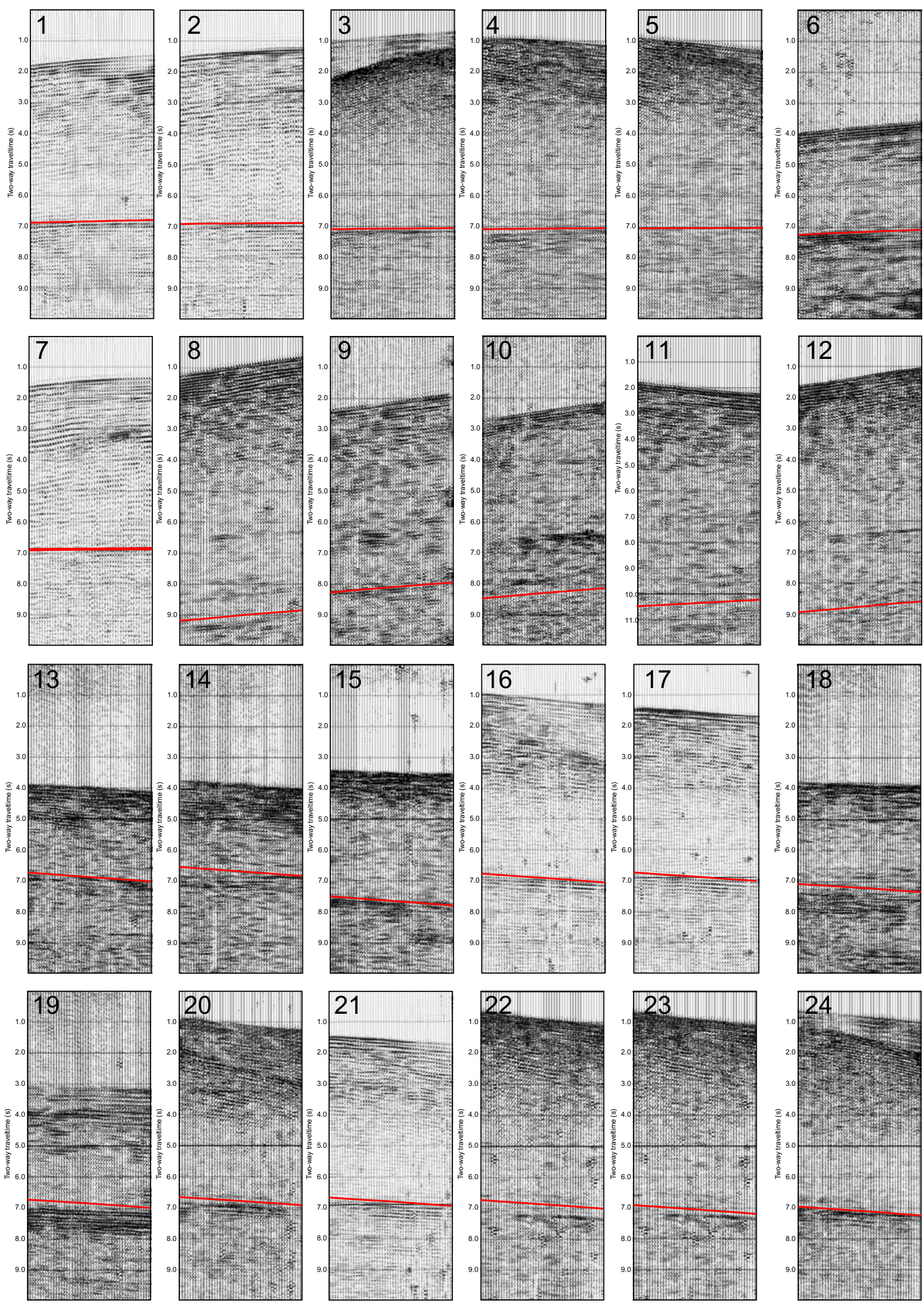

Figure 15. - High-amplitude reflections observed from different points throughout San Francisco Bay (fig. 14) and modeled traveltimes from San Andreas reflector (red lines). All gathers show $2.4 \mathrm{~km}$ of data. Offsets are mapped in figure 14. 
etries oriented southwest-northeast relative to a northwestsoutheast orientation. In addition, northeast-dipping events have progressively later traveltimes for source positions located farther eastward. Similarly, we observe a pattern of later traveltimes for southwest-dipping reflections with increasingly westerly source positions. These observations indicate that the regionally observed high-amplitude reflections at near-vertical incidence must be returning from at least two dipping interfaces deep in the crust or upper mantle which strike approximately northwest-southeast.

We recorded airgun sources on a crossing array of bottom cables in San Francisco Bay where high-amplitude reflections were known to occur. We observe a wide variation in reflection moveout as a function of bottom-cable azimuth. The expected normal moveout across a $2.4-\mathrm{km}$-long recording cable from a horizontal reflector at 7-s two-way traveltime
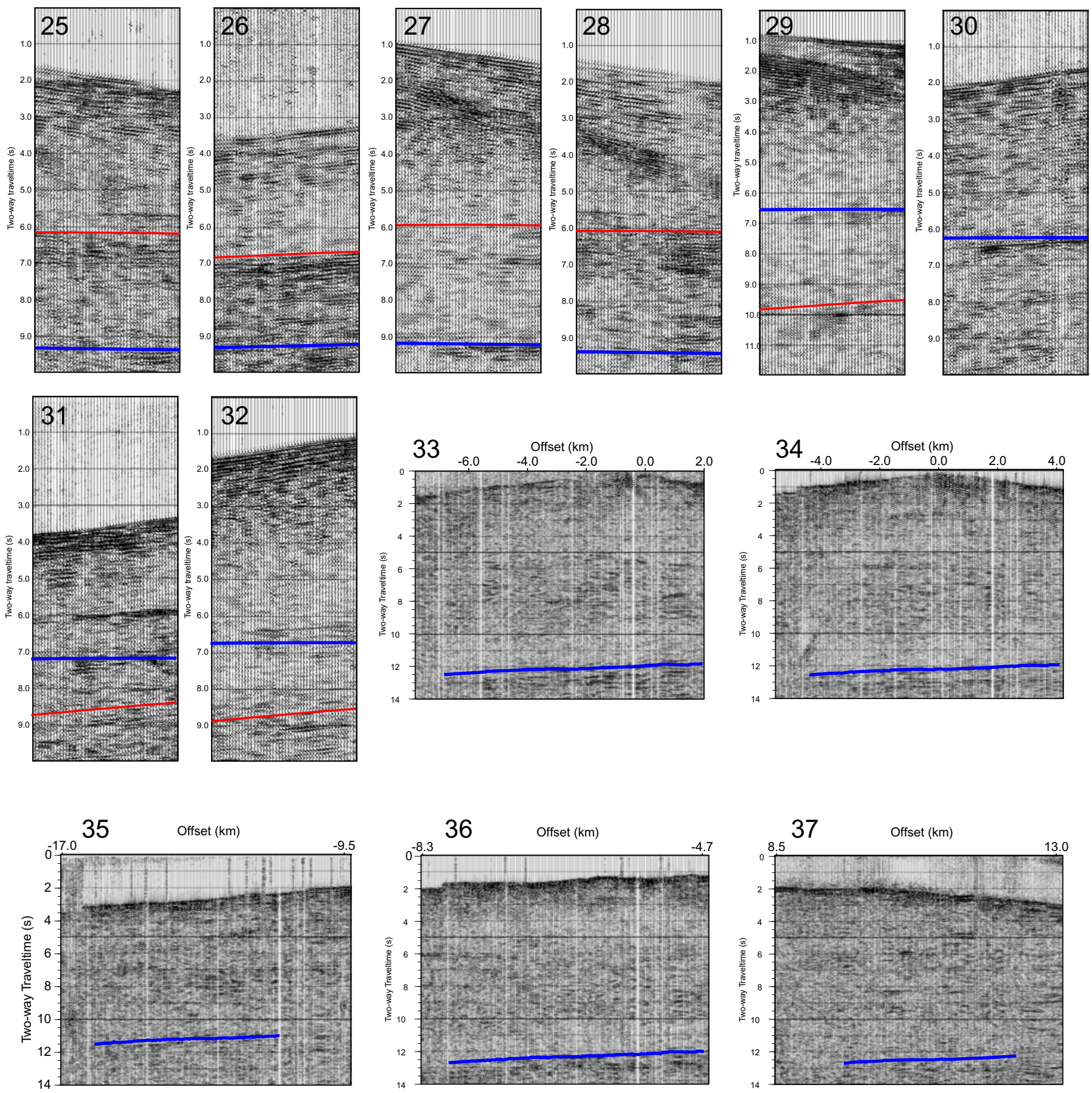

Figure 16.-High-amplitude reflections observed from different points throughout San Francisco Bay and peninsula (fig. 14), and modeled traveltimes from San Andreas (red lines) and Hayward (blue lines) reflectors. 
for a shot positioned $2.5 \mathrm{~km}$ away from the cable is about 40 ms. Much larger moveout values (hundreds of milliseconds) imply a dipping reflector. Reflections recorded parallel to the San Andreas Fault are nearly horizontal at $\sim 7$-s two-way traveltime (fig. 17A), whereas reflections recorded orthogonal to the fault dip down to the northeast (more than 200-ms difference in moveout over a $2.4-\mathrm{km}$ distance relative to the reflections recorded parallel to the fault; fig. 17B). If the reflector were horizontal, moveout would be independent of azimuth; thus, the reflector must dip down to the northeast. We note a consistent pattern of azimuthal dependence of moveout throughout San Francisco Bay (fig. 17C).

A dipping reflector causes offset dependence on reflection traveltime; if the source position is moved farther downdip from a fixed receiver, then the reflection traveltime is expected to be later. For example, in figure 18, the traveltime of the same reflection event progressively increases with shot distance from the San Andreas Fault. Such a relation can be explained only by a reflector with a steep downward dip to the northeast, somewhere in the vicinity of the San Andreas Fault. We observe a dependence of reflection traveltime (southwest-dipping events) on distance from the San Andreas Fault throughout the bay (fig. 18). We observe a second group of reflections with northeastward dip that have progressively later traveltimes with increasing source distance from the Hayward Fault; these events range in traveltime from $\sim 6 \mathrm{~s}$ in San Pablo Bay to nearly 13 s recorded on the San Francisco peninsula (fig. 18).

These observations demonstrate that a model with near-horizontal reflectors beneath San Francisco Bay is inappropriate for the high-amplitude reflections. Therefore, a twodimensional modeling approach that projects seismic raypaths into one vertical plane is also inappropriate. The combined geometry of the 1995 and 1997 land and marine seismicreflection experiments is complex, and poorly suited for projection into one plane, even if the subsurface geology were simpler. Thus, any analysis of reflection traveltimes in the San Francisco Bay region must be treated as a three-dimensional problem.

\section{Three-Dimensional Traveltime Modeling of High- Amplitude Reflections}

We use three-dimensional finite-difference traveltime calculations (Hole and Zelt, 1995) to model the surfaces responsible for high-amplitude reflections recorded in San Francisco Bay (Parsons and Hart, 1999). We apply a three-dimensional velocity model for the region, constructed from earthquake sources (Parsons and Zoback, 1997; Hole and others, 2000) in combination with an extrapolation of a two-dimensional lower-crustal velocity model (Holbrook and others, 1996). The reflector that best satisfies all the northeast-dipping reflection traveltimes dips $60^{\circ}$ beginning at $12-\mathrm{km}$ depth and parallels the strike of the San Andreas Fault in the study area (fig. 19). The modeled reflector dip begins beneath the downward vertical projection from the surface trace of the San Andreas Fault (fig. 19). The uniqueness of this model is tested by a wide variety of shot-receiver offsets and reflection angles (figs. 17-19).

All the reflection traveltimes were fitted to within a 240ms root-mean-square static shift (measured at the center of each reflection). The reflection-moveout variation was fitted to within an 80-ms root-mean-square error (measured from end to end); the spread in moveout versus azimuth in figure 17 is the result of a two-dimensional projection of varying shot-receiver geometry and velocity variations. These errors are less than the uncertainties inherent in the three-dimensional velocity model that we apply $(370 \mathrm{~ms}$; Parsons and Zoback, 1997). The fits to the reflections shown in figures 15 through 18, and the depth points shown in figure 19 were made by using the three-dimensional model. The collective moveout observations constrain a range in dip from $55^{\circ}$ to $62^{\circ}$, with the best fit at $60^{\circ}$.

Repeated reflection observations at different offset ranges provide the overlapping depth coverage that limits possible solutions. The sources identified in figure 14 in San Francisco Bay represent groups of airgun shots ranging from at least 5 to 20 sequential reflection observations. Thus, although 37 modeled source points are marked in figure 14 (dots), actually hundreds of repeated observations were made. The airgun spacing was $\sim 100 \mathrm{~m}$, generating only slight variations in reflection time and moveout between adjacent shots; however, the repeated sequential reflection observations give us confidence in their validity. The distribution in source-receiver locations produces reflection depth points on the $60^{\circ}$-NE.-dipping structure along the strike of much of the San Andreas Fault, from the north at Bolinas Lagoon to the south at the city of San Mateo, a distance of $50 \mathrm{~km}$ (fig. 14). The depth coverage on the dipping structure ranges from 14 to $22 \mathrm{~km}$ (fig. 19B). This dipping horizon passes beneath a right step in the San Andreas Fault where the M=7.8 1906 San Francisco earthquake is thought to have initiated offshore of San Francisco (Zoback and others, 1999). We model this right step as a slight bend in the fault at depth (fig. 16).

We similarly model a separate group of southwest-dipping reflections from beneath San Francisco Bay (fig. 14). Among the 37 groups of airgun and explosive sources shown in figures 14 through 16,13 produced reflections from a $70^{\circ}$ SW.-dipping structure between 22- and 24-km depth paralleling the Hayward Fault east of San Francisco Bay (figs. 14, 19). We observe this dipping structure from north of the city of Berkeley to south of the city of Hayward, an along-strike distance of $34 \mathrm{~km}$ (fig. 14). The combined land and marine depth coverage ranges from 18 to $24 \mathrm{~km}$. The Hayward Fault predates the Peninsular segment of the San Andreas Fault, has more cumulative slip (50-70 versus 19-23 km; Cummings, 1968; McLaughlin and others, 1996), and appears to dip more steeply beginning deeper in the crust.

Virtually all of the coherent high-amplitude reflections recorded beneath San Francisco Bay at near-vertical incidence have thus been fitted to dipping structures associated with either the San Andreas or Hayward Fault. No continuous high-amplitude horizontal reflections were observed from the Moho or the top of the lower crust, although weaker, discon- 
tinuous events were observed on some gathers that might be from lower-angle horizons beneath the bay at $15-$ to $25-\mathrm{km}$ depth.

\section{Integration, Implications, and Conclusions}

The impetus for conducting seismic experiments in the San Francisco Bay region was to test several tectonic models that postulated the existence of lower-angle, linking faults in the midcrust to lower crust. To explain the observed heat flow, crustal structure, surface compressional features, and offshore magnetic anomalies, various workers have proposed a low-angle mechanical link in the lower crust or midcrust that extends between the San Andreas and Hayward Faults or across both (for example, Furlong and others, 1989; Furlong, 1993; Page and Brocher, 1993; Brocher and others, 1994; Jones and others, 1994; Bohannon and Parsons, 1995). The depth to which high-angle strike-slip faults penetrate is important in resolving the possible interaction between faults beneath seismogenic depths (Furlong and others, 1989) and how much strain localizes in fault zones (for example, Sanders, 1990).

Our interpretation of the collective results from seismic studies in the San Francisco Bay region is that no low-angle detachment fault is required between the major strike-slip faults to balance seismogenic strain. Together, the results from active- and passive-source seismic studies in the San Francisco Bay region show shallow and deep crust that is dominated by slip along high-angle to vertical strike-slip faults. Evidence from turning rays and refractions, as well as direct reflections, indicates that the strike-slip faults pierce the entire crust. Also, geodetic and earthquake measurements indicate that lower-crustal slip occurs on the San Andreas Fault (for example, King and others, 1987; Sanders, 1990). Crustal-velocity models across the San Andreas Fault near the Mendocino triple junction (Henstock and others, 1997) and in San Francisco Bay near the Golden Gate (Holbrook and others, 1996) show evidence for upper-mantle offset or lowercrustal velocity anomalies associated with near-vertical strikeslip faults. If the major strike-slip faults of the San Francisco Bay region do penetrate the whole crust, then the implication is that broadly distributed viscoelastic strain in the lower crust or strain occurring on low-angle structures is minimized.

Thus, the primary link between the faults may be stress transfer through the elastic crust (for example, Stein and Lisowski, 1983; Reasenberg and Simpson, 1992).

An integration of seismic-reflection and seismicity data at the Kirby Hills fault zone provide evidence for high-angle $\left(\sim 80^{\circ} \mathrm{dip}\right.$ ) faulting that extends from the surface downward
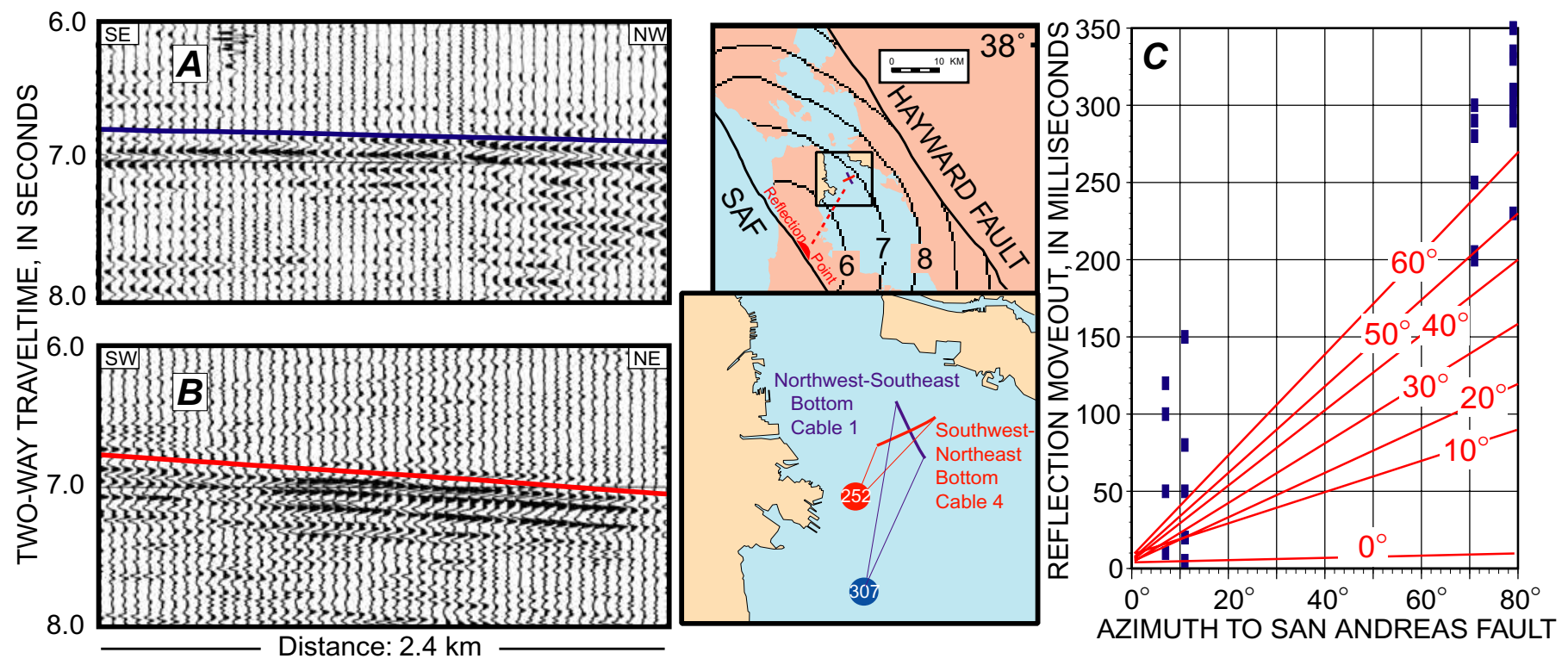

Figure 17.-Example reflections from two crossing bottom-cable profiles oriented parallel $(A)$ and orthogonal $(B)$ to strike of the San Andreas (SAF) and Hayward Faults. If these events reflected from a horizontal or low-angle impedance contrast, azimuth of recording cables would be unimportant, and both events would appear nearly flat. However, a strong dependence on receiver azimuth is noted: more than 200 ms greater moveout is observed on cable orthogonal to the San Andreas Fault than on that parallel to it, indicating that reflector dips down to northeast. Both arrivals are closely fitted by a $60^{\circ}$-NE.-dipping reflector that parallels the San Andreas Fault and begins at 12-km depth. Maps show reflected traveltime contours from three-dimensional modeling (Hole and Zelt, 1995) of events; a two-dimensional cross-sectional view is shown in figure 19. C, Reflection moveout versus recording-cable azimuth with respect to the San Andreas Fault for all 33 modeled reflection gathers. Events with greatest moveout are observed on orthogonal cables. Expected moveout from various dips is plotted on observations. Spread in moveout observations results from this two-dimensional projection of a three-dimensional geometry that includes varying source-receiver offsets and local velocity changes. Root-mean-square misfit of three-dimensional moveout, $80 \mathrm{~ms}$. 
to approximately the base of the crust. Because first-motion studies of earthquakes along the Kirby Hills Fault indicate predominantly right-lateral strike-slip motion, we interpret this fault to be the easternmost strand of the San Andreas Fault system. As such, this structure is presently offsetting the Cretaceous-Tertiary Coast Range-Great Valley tectonic wedge. The presence of whole-crustal dextral strike-slip faulting along the Coast Range-Great Valley boundary suggests that at this latitude, tectonic wedging is not currently active. Instead, any tectonic wedge that may have been constructed in the past is now being sliced and dismembered along the near-vertical crust-penetrating fault system at the east edge of the Coast Ranges.

The San Andreas and Hayward Faults are also modeled as cutting through the whole crust, at moderate to steep dip $\left(60^{\circ}-70^{\circ}\right)$. If the interpreted lower-crustal dips of the San Andreas and Hayward Faults persist beneath the crust, these two faults would intersect at $\sim 45-\mathrm{km}$ depth, $20 \mathrm{~km}$ into the upper mantle (fig. 19). Below that depth, a single fault might accommodate all the relative Pacific-North American Plate motion. Our observations of fault-plane reflections are limited to crustal depths because the constraints of marine recording in San Francisco Bay prohibit the long source-receiver offsets required to observe deeper, dipping reflections. We can thus only speculate about the sub-Moho geometry of the faults (fig. 19). The dip of the faults might change after crossing the rheologic boundary at the Moho; the initiation of fault dip appears to be related to layer boundaries (seismic-velocity steps), identified by wide-angle seismic methods, that also represent rheologic boundaries (Holbrook and others, 1996). Thus, a lower-angle fault might still be present in the upper mantle (fig. 19), although we observe no reflections from any near-horizontal boundaries at later traveltimes that could be observed at near offsets. Interestingly, all the faults identified in the lower crust of the San Francisco Bay region have some apparent dip, ranging from $\sim 60^{\circ}$ on the San Andreas Fault to $\sim 80^{\circ}$ on the Kirby Hills Fault.

The relatively high amplitude ( $\sim 5 \mathrm{~dB}$ above background) of reflections from deep, dipping surfaces signifies strong impedance contrasts in the lower crust beneath the surface traces of the Hayward and San Andreas Faults. Thus, rightlateral movement on these faults may have occurred through the whole crust and offset significantly different rock types. Alternatively, the presence of fluids in the fault zones or localized shearing and accompanying metamorphism within the fault zones may have generated an impedance contrast (for example, Fountain and others, 1984; Wang and others, 1989; Kern and Wenk, 1990; Siegesmund and others, 1991).
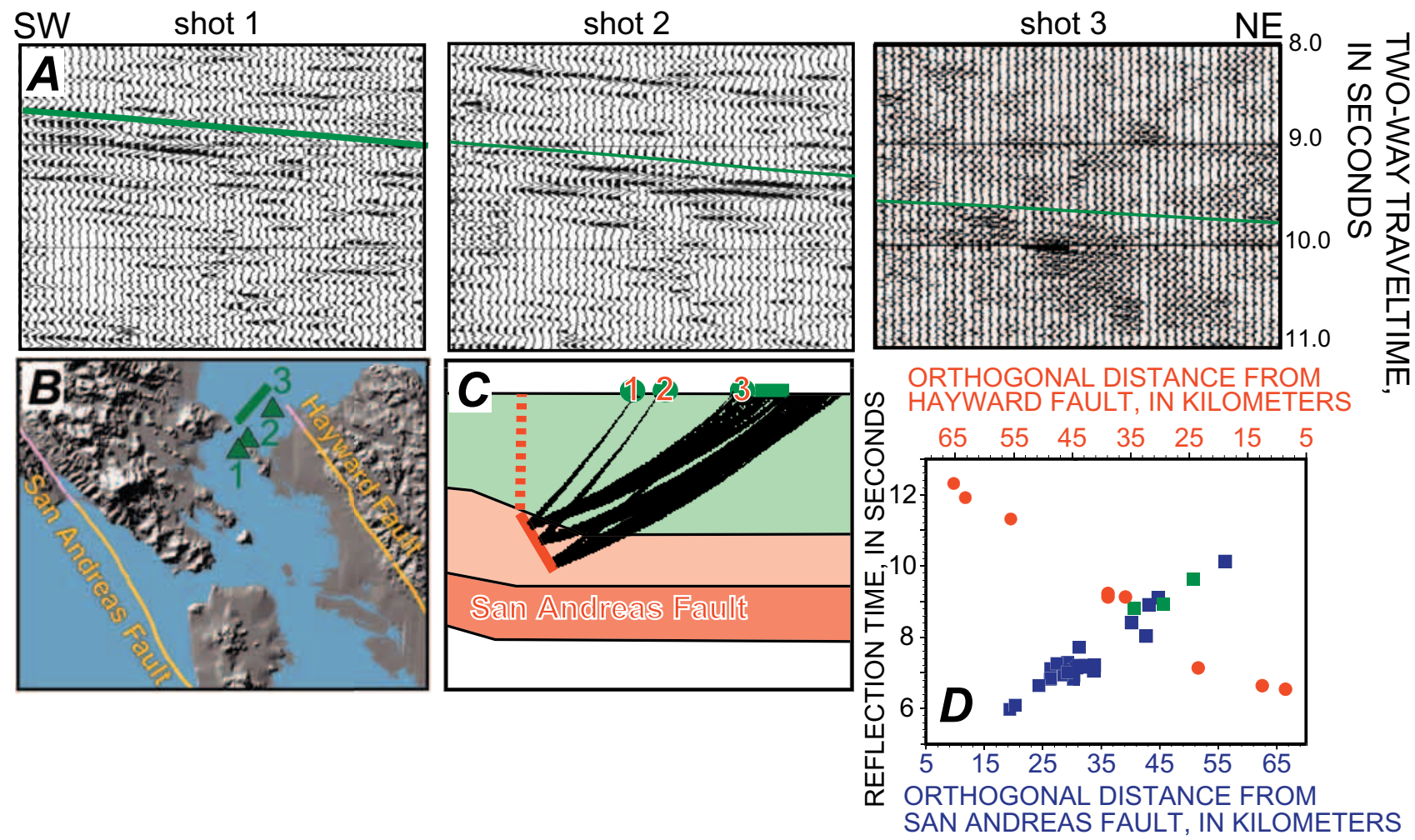

Figure 18.- Three shot gathers $(A)$ recorded in northern San Francisco Bay $(B)$, each showing same reflection event from the San Andreas Fault. Traveltime is progressively later with increasing shot distance northeast of fault, a consequence of a dipping reflector $(C)$. Calculated three-dimensional reflection traveltimes from a $60^{\circ}$ modeled reflector are superimposed on data plots. $D$, Reflection times to center of all modeled reflections as a function of their distance from the San Andreas (blue squares) or Hayward (red dots) Fault. Those source-receiver pairs located farthest from faults have reflections with latest arrivals. Three green squares represent data examples shown in figure $18 \mathrm{~A}$. 
The typical width in time of the high-amplitude reflections and coda is $\sim 1 \mathrm{~s}$. Given the uncertainties of potential near-surface reverberations and along-path scattering, we cannot comment on the width or possible multilayering of the reflectors, although the high reflection amplitudes suggest a possible fluid-saturated zone (for example, Brown and others, 1987).

We note that the results collected here do not dispute the previous observation of a regional high-velocity layer at long source-receiver offsets (Brocher and others, 1994; Holbrook and others, 1996). Wide-angle reflections can be returned from a velocity gradient that is transparent at near-vertical incidence. Our results do show that the higher resolution, near-vertical-incidence reflections do not correspond to the top of the high-velocity, mafic composition, lower-crustal layer, as previously interpreted.

\section{Acknowledgments}

We thank Richard Allen, Peter Barnes, Bob Bohannon, Tom Burdette, Philip Burrows, Sam Clarke, Diana Collins,
Ed Criley, Lynn Dietz, Moritz Fliedner, Anne Gibbs, Niki Godfrey, Mike Hamer, Jason Kelley, Will Kohler, Björn Lund, Richard Marsden, Andy Michael, Janice Murphy, Jean Olson, Stephanie Ross, David Rutledge, Holly Ryan, and George Thompson for their help in gathering the onland seismic-reflection data. The Golden Gate National Recreation Area, the Crystal Springs Water District, and the San Francisco Public Utilities Commission kindly permitted access to restricted lands. Seismic recording instruments and support were provided by the Incorporated Research Institutions for Seismology and Program for Array Seismic Studies of the Continental Lithosphere; Marcos Alvarez, Simon Klemperer, Bill Koperwhats, Steve Michnick, and Anthony Wei, Tom Burdette, John Coakley, Jason Kelley, Gonzalo Mendoza, Jean Olsen, and David Rutledge were indispensable during the acquisition and reduction of local network data. Tom Brocher, Rufus Catchings, and Steve Holbrook provided traveltime picks from their San Francisco Bay region controlled-source seismic experiments. Jon Childs, Dave Hogg, Walt Olson, Kevin O’Toole, Hal Williams, and Bill Robinson provided innovative solutions to difficult marine operational
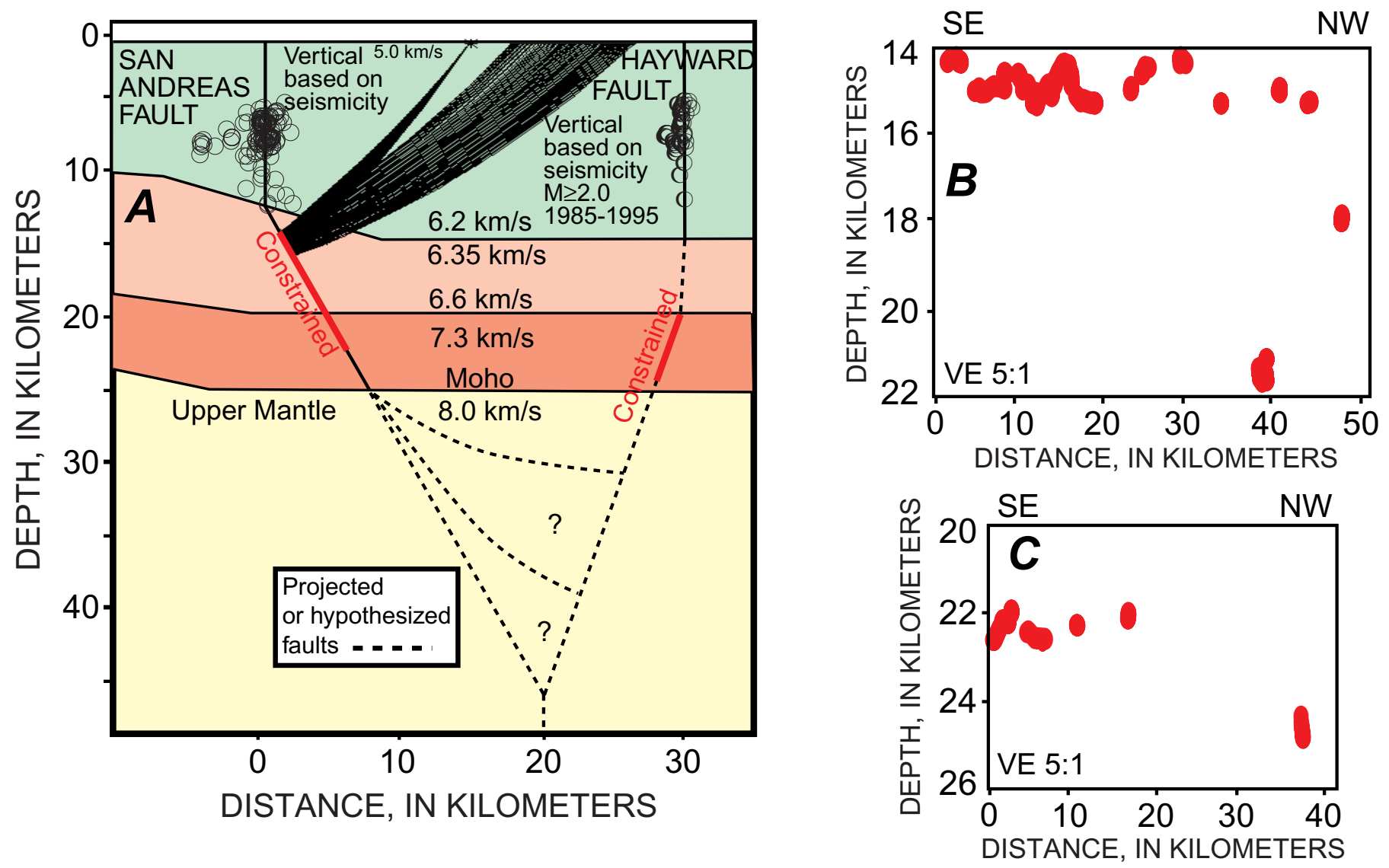

Figure 19.- Reflection modeling of the San Andreas and Hayward Faults. $A$, Cross-sectional view. Earthquake hypocenters show that faults are near vertical in uppermost $\sim 12 \mathrm{~km}$ of crust. Red fault planes, depth extent that reflections from them are modeled; dashed lines, projected and conjectural relation between the two faults in upper mantle. $B$, Subsurface reflection-depth-point coverage on the San Andreas Fault, projected onto two-dimensional plane associated with segments identified in figure 1. C, Subsurface reflection-depth-point coverage on the Hayward Fault. Points represent only 37 modeled gathers; complete data coverage is more continuous. Three-dimensional model planes have a constant dip but bend where vertical parts of faults bend. 
situations. Discussions with Kevin Furlong, Bob Jachens, Art Lachenbruch, Ben Page, and George Thompson helped to guide our thinking. Guy Cochrane, Alan Cooper, and Eric Geist reviewed the manuscript, which was edited by George Havach.

\section{References Cited}

Addicott, W.0., 1969, Late Pliocene mollusks from San Francisco Peninsula, California, and their paleogeographic significance: California Academy of Sciences Proceedings, ser. 4, v. 37, no. 3, p. 57-93.

Bakun, W.H., 1999, Seismic activity of the San Francisco Bay region: Seismological Society of America Bulletin, v. 89, no. 3, p. 764-784.

Beaudoin, B.C., 1994, Lower-crustal deformation during terrane dispersion along strike-slip faults: Tectonophysics, v. 232, no. 1-4, p. 257-266.

Blake, M.C., Jr., 1984, Franciscan geology of northern California: Society of Economic Paleontologists and Mineralogists, Pacific Section Field Trip Guidebook, v. 43, 254 p.

Bohannon, R.G., and Parsons, Tom, 1995, Tectonic implications of post-30 Ma Pacific and North American relative plate motions: Geological Society of America Bulletin, v. 107, no. 8, p. 937-959.

Brabb, E.E., and Pampeyan, E.H., compilers, 1983, Geologic map of San Mateo County, California: U.S. Geological Survey Miscellaneous Investigations Series Map I-1257-A, scale 1:62,500.

Brocher, T. M., McCarthy, Jill, Hart, P.E., Holbrook, W.S., Furlong, K.P., McEvilly, T.V., Hole, J.A., and Klemperer, S.L., 1994, Seismic evidence for a lower-crustal detachment beneath San Francisco Bay, California: Science, v. 265, no. 5177, p. 1436-1439.

Brocher, T.M., and Moses, M.J., 1993, Onshore-offshore wide-angle seismic recordings of the San Francisco Bay area seismic imaging experiment (BASIX); the five-day recorder data, U.S. Geological Survey Open-File Report 93-276, 89 p.

Brocher, T.M., and Pope, D.C., 1994, Onshore-offshore wide-angle seismic recordings of the San Francisco Bay Area seismic imaging experiment (BASIX); data from the Northern California Seismic Network: U.S. Geological Survey Open-File Report 94-156, $123 \mathrm{p}$.

Brown, L.D., Wille, C.E., Zheng, Li, de Voogd, Beatrice, Mayer, J.R., Hearn, T.M., Sanford, W.E., Caruso, C.W., Zhu, T.F., Nelson, D.K., Potter, C.J., Hauser, E.C., Klemperer, S.L., Kaufman, Sidney, and Oliver J.E., 1987, COCORP; new perspectives on the deep crust: Royal Astronomical Society Geophysical Journal, v. 89 , no. 1, p. 47-54.

Bürgmann, Roland, 1997, Active detachment faulting in the San Francisco Bay area?: Geology, v. 25, no. 12, p. 1135-1138.

Catchings, R.D., and Kohler, W.M., 1996, Reflected seismic waves and their effect on strong shaking during the 1989 Loma Prieta, California, earthquake: Seismological Society of America Bulletin, v. 86, no. 5, p. 1401-1416.

Cummings, J.C., 1968, The Santa Clara Formation and possible postPliocene slip on the San Andreas fault in central California, in Dickinson, W.R., and Grantz, Art, eds., Proceedings of the conference on geologic problems of the San Andreas fault system: Stanford, Calif., Stanford University Publications in Geological Sciences, v. 11, p. 191-207.

DeMets, Charles, Gordon, R.G., Argus, D.F., and Stein, Seth, 1990, Cur- rent plate motions: Geophysical Journal International, v. 101, no. 2, p. 425-478.

Dewey, J.W., Hill, D.P., Ellsworth, W.L., and Engdahl, E.R., 1989, Earthquakes, faults, and the seismotectonic framework of the contiguous United States, in Pakiser, L.C., and Mooney, W.D., eds., Geophysical framework of the continental United States: Geological Society of America Memoir 172, p. 541-576.

Fountain, D.M., Hurich, C.A., and Smithson, S.B., 1984, Seismic reflectivity of mylonite zones in the crust: Geology, v. 12, no. 4, p. 195-198.

Furlong, K.P. 1993, Thermal-rheologic evolution of the upper mantle and the development of the San Andreas fault system: Tectonophysics, v. 223, no. 1-2, p. 149-164.

Furlong, K.P., Hugo, W.D., and Zandt, George, 1989, Geometry and evolution of the San Andreas fault zone in northern California: Journal of Geophysical Research, v. 94, no. B3, p. 3100-3110.

Hall, N.T., 1984, Holocene history of the San Andreas fault between Crystal Strings Reservoir and San Andreas Dam, San Mateo County, California: of the Seismological Society of America Bulletin, v. 74, no. 1, p. 281-299.

Hall, N.T., and Wright, R.H., 1993, Paleoseismic investigations of the San Andreas Fault on the San Francisco Peninsula, California: final technical report to U.S. Geological Survey, National Earthquake Hazards Reduction Program, $15 \mathrm{p}$.

Hall, N.T., Wright, R.H., Clahan, K.B., 1996, Paleoseismic investigations of the San Andreas fault on the San Francisco Peninsula, California: Reston, Va., U.S. Geological Survey, National Earthquake Hazards Reduction Program Final Technical Report 14-08-0001-G2081, 45 p.

Henstock, T.J., Levander, A.R., and Hole, J.A., 1997, Deformation in the lower crust of the San Andreas fault system in northern California: Science, v. 278, no. 5338, p. 650-653.

Hill, D.P., Eaton, J.P., and Jones, L.M., 1990, Seismicity, 1980-86, chap. 5 of Wallace, R.E., ed., The San Andreas fault system, California: U.S. Geological Survey Professional Paper 1515, p. 115-151.

Holbrook, W.S., Brocher, T.M., ten Brink, U.S., and Hole, J.A., 1996, Crustal structure of a transform plate boundary, San Francisco Bay and the central California continental margin: Journal of Geophysical Research, v. 101, no. B10, p. 22311-22334.

Hole, J.A., 1992, Nonlinear high-resolution three-dimensional seismic travel time tomography: Journal of Geophysical Research, $v$. 97 , no. B5, p. 6553-6562.

Hole, J.A., Klemperer, S.L., Brocher, T.M., Parsons, Tom, Benz, H.M., and Furlong, K.P., 2000, Three-dimensional seismic velocity structure of the San Francisco Bay area: Journal of Geophysical Research, v. 105, no. B6, p. 13859-13874.

Hole, J.A., and Zelt, B.C., 1995, 3-D finite-difference reflection traveltimes: Geophysical Journal International, v. 121, no. 2, p. 427-434.

Jones, D.L., Graymer, R.W., Wang, Chi, McEvilly, T.V., and Lomax, Anthony, 1994, Neogene transpressive evolution of the California Coast Ranges: Tectonics, v. 13, no. 3, p. 561-574.

Kelson, K.I., Lettis, W.R., and Lisowski, Michael, 1992, Distribution of geologic slip and creep along faults in the San Francisco Bay region, in Galehouse, J.S., ed., Programs and abstracts of the second conference on earthquake hazards in the eastern San Francisco Bay area: California Division of Mines and Geology Special Publication 113, p. 31-38.

Kern, Hartmut, and Wenk, H.-R., 1990, Fabric-related velocity anisotropy and shear wave splitting in rocks from the Santa Rosa mylonite zone, California: Journal of Geophysical Research, v. 
95, no. B7, p. 11213-11223.

King, N.E., Segall, Paul, and Prescott, W.H., 1987, Geodetic measurements near Parkfield California, 1959-1984: Journal of Geophysical Research, v. 92, no. B3, p. 2747-2766.

Kohler, W.M., and Catchings, R.D., 1994, Data report for the 1993 seismic refraction experiment in the San Francisco Bay area, California: U.S. Geological Survey Open-File Report 94-241, 71 p.

Krug, E.H., Cherven, V.B., Hatten, C.W., and Roth, J.C., 1992, Subsurface structure in the Montezuma Hills, southwestern Sacramento Basin, in Cherven, V.B., and Edmondson, W.F., eds., Structural geology of the Sacramento Basin: American Association of Petroleum Geologists, Pacific Section Miscellaneous Publication 41, p. 41-60.

Lisowski, Michael, Savage, J.C., and Prescott, W.H., 1991, The velocity field along the San Andreas fault in central and southern California: Journal of Geophysical Research, v. 96, no. B5, p. 8369-8389.

Marlow, M.S., Jachens, R.C., Hart, P.E., Carlson, P.R., Anima, R.J., and Childs, J.R., 1999, Development of San Leandro Synform and neotectonics of the San Francisco Bay Block, California: Marine and Petroleum Geology, v. 16, no. 5, p. 431-442.

McCarthy, Jill, and Hart, P.E., 1993, Data report for the 1991 Bay area seismic imaging experiment (BASIX): U.S. Geological Survey Open-File Report 93-301, 26 p.

McKevett, N.H., 1992, The Kirby Hills fault zone, in Cherven, V.B., and Edmondson, W.F., eds., Structural geology of the Sacramento Basin: American Association of Petroleum Geologists, Pacific Section Miscellaneous Publication 41, p. 61-78.

McLaughlin, R.J., Sliter, W.V., Sorg, D.H., Russell, P.C., and SarnaWojcicki, A.M., 1996, Large-scale right-slip displacement on the East San Francisco Bay region fault system, California; implications for location of late Miocene to Pliocene Pacific plate boundary: Tectonics, v. 15, no. 1, p. 1-18.

Murphy, J.M., Catchings, R.D., Kohler, W.M., Fuis, G.S., and EberhartPhillips, D.M., 1992, Data report for 1991 active-source seismic profiles in the San Francisco Bay area, California: U.S. Geological Survey Open-File Report 92-570, 45 p.

Olson, J.A., and Lindh, A.G., 1985, Seismicity of the San Andreas Fault from Cienega Winery to the Golden Gate, in Shearer, C.F., ed., Minutes of the National Earthquake Prediction Evaluation Council, July 26-27, 1985, Menlo Park, California: U.S. Geological Survey Open-File Report 85-754, p. 316-324.

Olson, J.A., and Zoback, M.L., 1992, Seismic deformation patterns on the San Francisco peninsula [abs.]: Eos (American Geophysical Union Transactions), v. 73, no. 43, supp., p. 401.

Page, B.M., 1992, Tectonic setting of the San Francisco Bay Region, in Galehouse, J.S., ed., Programs and abstracts of the second conference on earthquake hazards in the eastern San Francisco Bay area: California Division of Mines and Geology Special Publication 113, p. 1-7.

Page, B.M., and Brocher, T.M., 1993, Thrusting of the central California margin over the edge of the Pacific plate during the transform regime: Geology, v. 21, no. 7, p. 635-638.

Parsons, Tom, 1998, Seismic reflection evidence that the Hayward fault extends into the lower crust of the San Francisco Bay area: Seismological Society of America Bulletin, v. 88, no. 5, p. 1212-1223.

Parsons, Tom, and Hart, P.E., 1999, Dipping San Andreas and Hayward faults revealed beneath San Francisco Bay, California:
Geology, v. 27, no. 9, p. 839-842.

Parsons, Tom, and Zoback, M.L., 1997, Three dimensional upper crustal velocity structure beneath San Francisco Peninsula, California: Journal of Geophysical Research, v. 102, no. B3, p. 5473-5490.

Reasenberg, P.A., and Simpson, R.W., 1992, Response of regional seismicity to the static stress change produced by the Loma Prieta earthquake: Science, v. 255, no. 5052, p. 1687-1690.

Ross, D.C., 1978, The Salinian Block; Mesozoic granite orphan in the California Coast Ranges, in Howell, D.G., and McDougall, K.A., eds., Mesozoic paleogeography of the Western United States (Pacific Coast Paleogeography Symposium 2): Los Angeles, Society of Economic Paleontologists and Mineralogists, Pacific Section, p. 509-522.

Sanders, C.0., 1990, Earthquake depths and the relation to strain accumulation and stress near strike-slip faults in southern California: Journal of Geophysical Research, v. 95, no. B4, p. 4751-4762.

Siegesmund, Sigfried, Fritzsche, Michael, and Braun, Günther, 1991, Reflectivity caused by texture-induced anisotropy in mylonites, in Meissner, R.O., Brown, L.D., Dürbaum, H.-J., Franke, Wolfgang, Fuchs, Karl, and Seifert, Friedrich, eds., Continental lithosphere; deep seismic reflections (Geodynamics Series, v. 22): Washington D.C., American Geophysical Union, p. 291-298.

Stanley, W.D., Benz, H.M., Walters, M.A., Villaseñor, Antonio, and Rodriguez, B.D., 1998, Tectonic controls on magmatism in The Geysers-Clear Lake region; evidence from new geophysical models: Geological Society of America Bulletin, v. 110, no. 9, p. 1193-1207.

Stein, R.S., and Lisowski, Michael, 1983, The 1979 Homestead Valley earthquake sequence, California; control of aftershocks and postseismic deformation: Journal of Geophysical Research, v. 88 , no. B8, p. 6477-6490.

Taylor, C.L., Cummings, J.C., and Ridley, A.P., 1980, Discontinuous en echelon faulting and ground warping, Portola Valley, California, in Streitz, Robert, and Sherburne, R.W., eds., Studies of the San Andreas fault zone in northern California: California Division of Mines and Geology Special Report 140, p. 59-70.

Thatcher, Wayne, 1975, Strain accumulation and release mechanism of the 1906 San Francisco earthquake: Journal of Geophysical Research, v. 80, no. 35, p. 4862-4872.

Thurber, C.H., 1993, Local earthquake tomography; velocities and $V_{p}$ $V_{s}$-theory, in lyer, H.M., and Hirahara, Kazuro, eds., Seismic tomography; theory and practice: London, Chapman and Hall, p. 663-683.

Vidale, J.E., 1990, Finite-difference calculation of traveltimes in three dimensions: Geophysics, v. 55, no. 5, p. 521-526.

Wakabayashi, John, and Moores, E.M., 1988, Evidence for collision of the Salinian block with the Franciscan subduction zone, California: Journal of Geology, v. 96, no. 2, p. 245-253.

Wang, Chi, Okaya, D.A., Ruppert, Charles, Davis, G.A., Guo, Tieshuan, Zhong, Zengqui, and Wenk, H.-R., 1989, Seismic reflectivity of the Whipple Mountain shear zone in southern California: Journal of Geophysical Research, v. 94, no. B3, p. 2989-3005.

Zoback, M.L., Jachens, R.C., and Olson, J.A., 1999, Abrupt alongstrike change in tectonic style; San Andreas fault zone, San Francisco Peninsula: Journal of Geophysical Research, v. 104, no. B5, p. 10719-10742. 